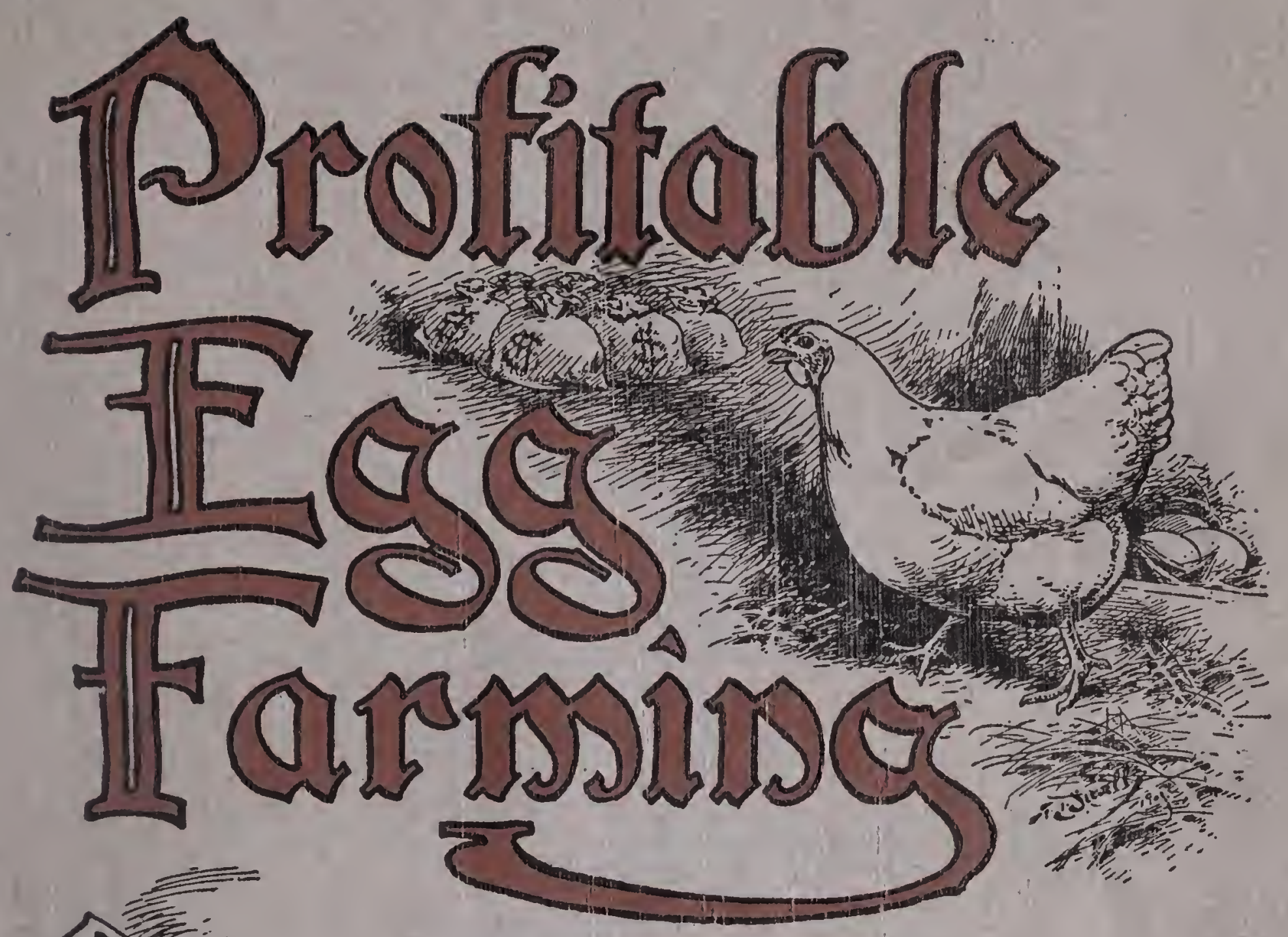

\title{
(8)
}

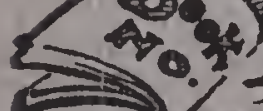

年-

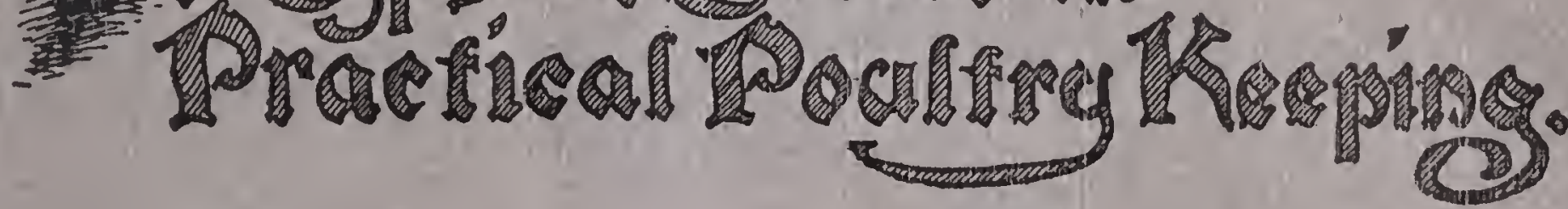



Copyright, July, 1903.

By

CYPHERS INCUBATOR COMPANY,

BUFFALO, N. Y.

Chicago, Ill., Biston, Mass., New York City.

All Rights Reserved. 


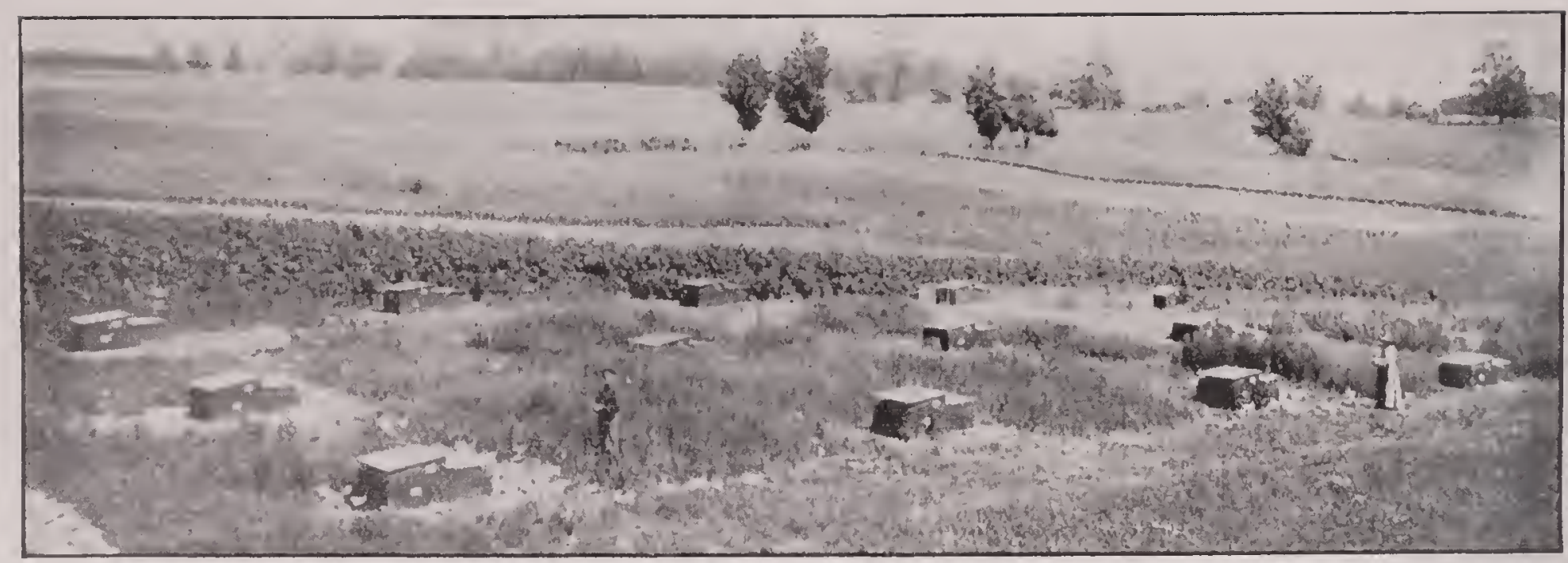

Baby Chicks in Brooders, Fairview Farm.

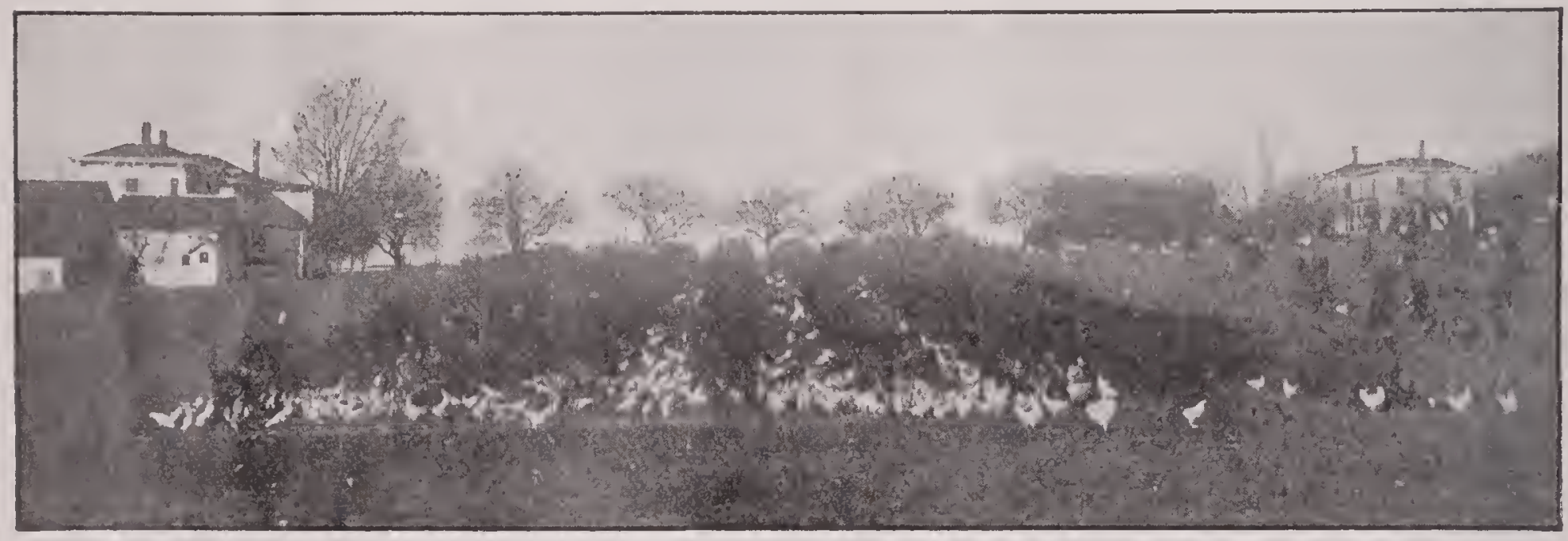

Chickens in the Blackberry Patch, Fairview Farm

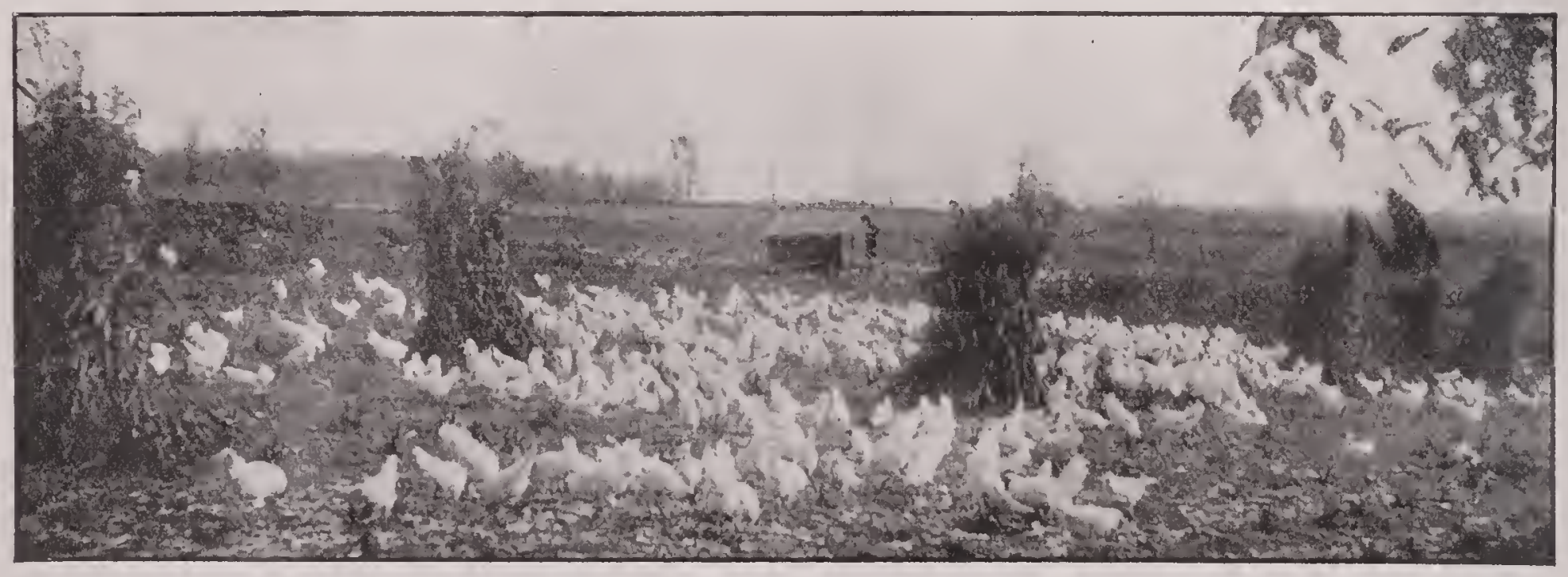

Pullets in the Cornfield, Fairview Farm.

Growing the Future Layers.

H. J. Blanchard's Fairview Farm, Groton, N. Y. 


\section{Profitable Egg Farming.}

A Practical Book; Telling What To Do and How To Do it to make a Success of this Profitable Branch of the Poultry Business; Describes many of the Large and Successful Egg Farms and the Methods Employed on them, with many Valuable Pointers on Breeding for Eggs and Feeding for Eggs.

FULLY ILLUSTRATED.

PRICE FIFTY CENTS.

PUBLISHED BY

CYPHERS INCUBATOR COMPANY.

BUFFALO, N. Y.

1903.

Book No. 4 Cyphers Series on Practical Poultry Keeping. 


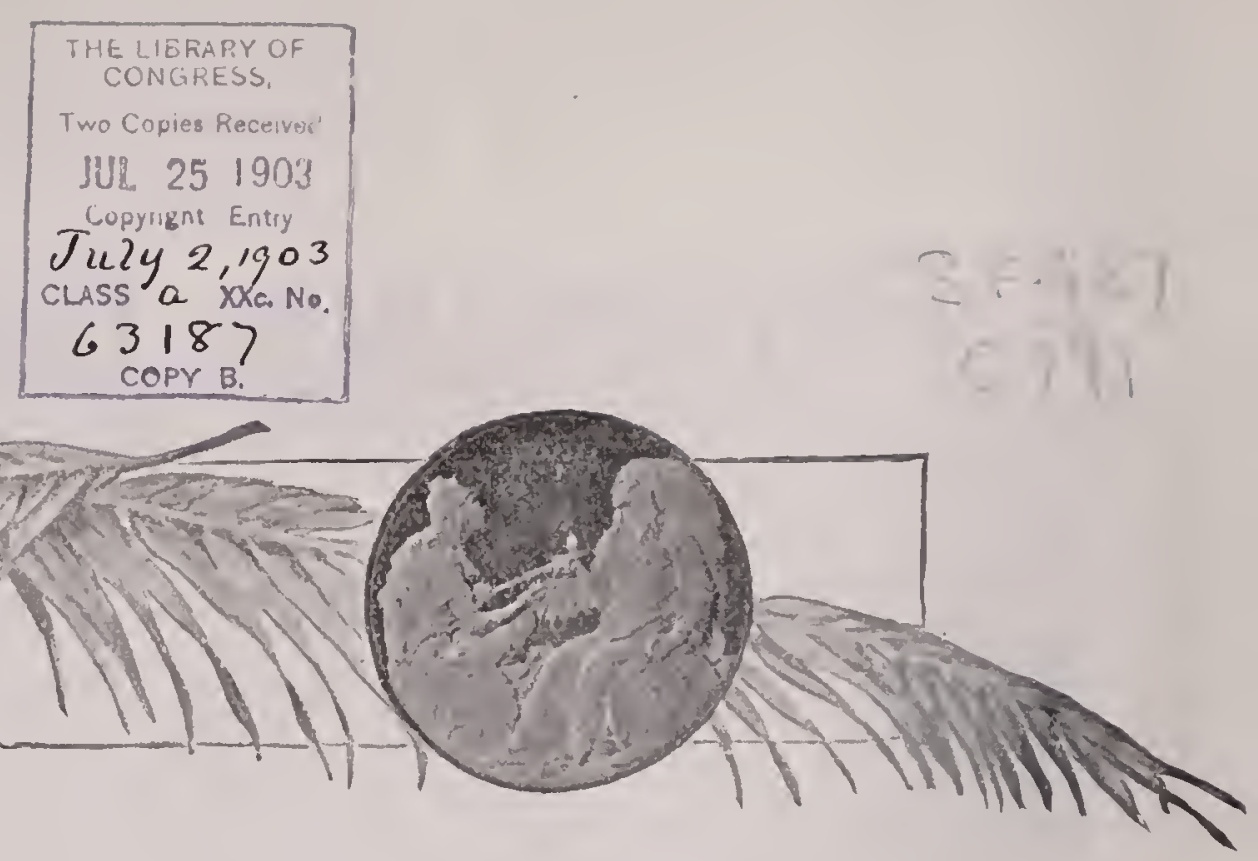

\section{PUBLISHER'S NOTE.}

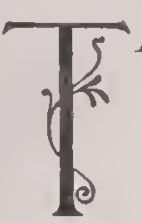

HIS is Book No. 4, of the Cyphers Series on "Practical Poultry Keeping," and treats of "Profitable Egg Farming." It tells how to make a success of this branch of the poultry business, and describes some of the large plants and the methods employed on them. It contains many valuable pointers on breeding for eggs and feeding for eggs.

Book No. 1 of the series is "Profitable Poultry Keeping in All Branches," and treats in a general manner of what is being done, how to start, practical breeds, egg farms, market poultry, combination farms, standard-bred poultry and the use of incubators.

Book No. 2, is "Profitable Care and Management." It covers the whole field of work with poultry from the egg to eggs. It tells the reader what to do and how to do it.

Book No. 3, on "Profitable Poultry Houses and Appliances," gives plans and specifications for poultry houses in sufficient variety to meet the needs of all, and tells in detail about many necessary and useful poultry plant appliances.

Book No. 5, "Profitable Market Poultry," tells all about growing, killing, dressing and selling market poultry, including squab-broilers, broilers, roasters, capons, green ducks, turkeys and geese.

We have endeavored to make these books thoroughly practical and suitable alike for the beginner and the veteran in the poultry business. They are thoroughly up-to-date and contain the best and most reliable information that is obtainable on the subjects treated. 


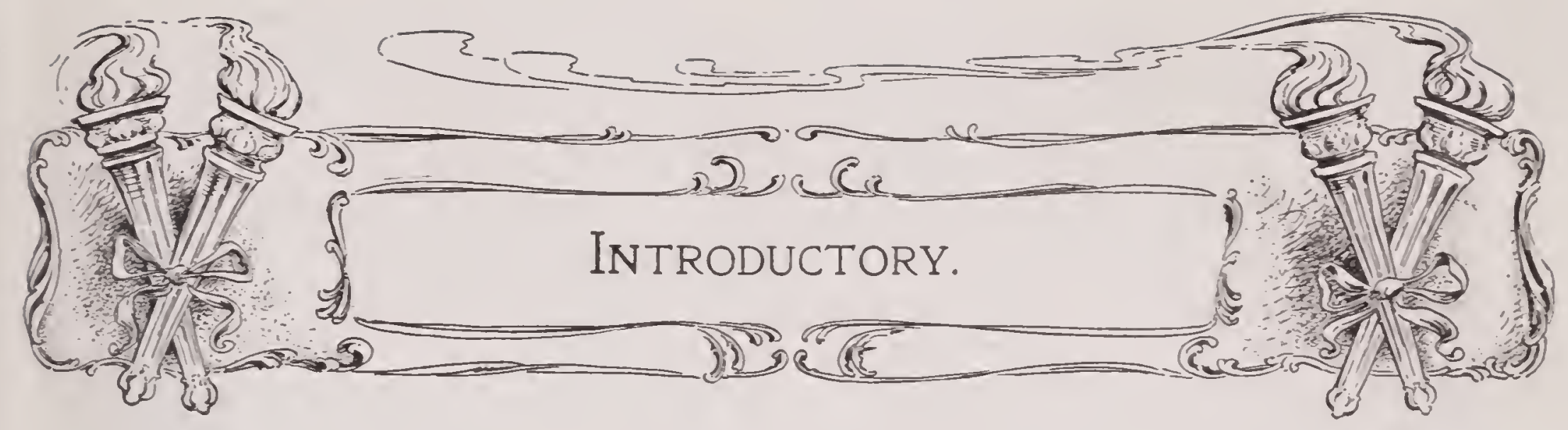

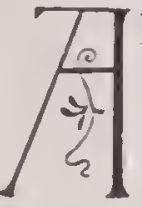

11 profit from poultry starts from the egg. hence the pruduction of eggs is the very foundation of a profitable poultry business. It Thether a man markets the eggs himself or produces egg: for the general market. w whether he turns the eggs into chickens and markets the chickens it is obvious that eggs are the foundation of all the profit he derives from his poultry work.

In this bouk it is our purpase to tell some of the methods of profitable poultry work. the special purpose being the eggs-for-market side of the busines: : and the rarious phases of breeding for eggs. feeding for eggs, the best methods to emplor for the best profit from egg production. the care. handling and marketing of the product. etc. will be considered. It is obvious at the nutset, horrerer, that in such a bonk as this re cannot go into the discussion of all phases of this important question. nor need we concern ourselves with such lesser questions as eggs in literature. eggs in mythology. or superstitions about' eggs. etc.. etc., howerer interesting they may be.

The great bulk of the eggs produced are either utilized in the hatching of chickens or consumed as human food and in the very numerous ways of preparing human fond. and we write this with full recognition of the great quantities of eggs that are consumed in manufactures. the arts. etc. ; great as is the use of eggs for many other purposes probably more than nine-tenths of all eggs produced the world over are consumed as human food.

\section{The Uses of Eggs.}

Eggs form an economical and nourishing food and are a staple article of diet with nearly every family in the land. The housewife could almost as well do without her kitchen range and cook- ing utensils as do withnut eges. There is no other branch of the poultry business which holds out such promise or assures so good a profit in return for a little common sense work as the production of fresle egos. There are few places where egos canmot be profitably produced: if not solil to the local market they can be readily shipperl to the large markets. eren at a considerable distance from the point of production: there is no other farm product that can be so easily packed and shipped to market. The chief requisite in uilding up a trade in iresh eggs is to establish a reputation for handling only the best: the consumers will do the rest. In some market: brown eggs are preferred above the white ones. while in others the white ones are the more salable. But in nearly all markets it will be found best to grarle the eggs. packing only those of one color and quality in a case. as better prices are often obtained by $s$ droing. When eggs are received by the rholesaler they are inspected and candled before being sent out to consumers. This testing or candling is done by passing the egg before a strong electric light. which is placed behind an egg testing derice in which are two holes before which the operator rapidly passes the eggs determining their quality and relative freshnes by their appearance as they are passed before the light. Only perfect eggs are sold. Thnse which have been cracked or which have very dirty shells are canned and frozen. Such canned eggs: are sold to the large baking establishments at a price considerably lower than that paid for fresh eggs. Some of these frozen eggs are also sold to the tenement house family trade. It has been found that these frozen eggs camnt be successfully used in making custards unless they are previously passed through a fine sieve.

Eren the spoiled and rotten eggs find a market. Millions of tainted eggs are used each 
rear in dressing the leather for gloves and in book-binding. They are also used extensively in the preparation of shoe blacking. mucilage and other manufactures; besides these uses many millions are also used for clarifying wine, and in calico print works. and in the preparation of photographer's paper, and by dre manufacturel's.

In the time of low prices when the supply of egg: exceeds the demand at a good figure. the eges are stored in considerable quantitics in cold storage houses, to be held against the season of seareity when they bring better prices. These cold storage roons are kept at a temperature of from $3: 3$ to 34 degrees. and eggs will keep in reasonably good condition in such rooms for sis or eight months. Eggs from bircls which have not been lumning with the male are best for storage purposes as ther are not fertilized, and "April" eggs are quoted at higher prices than those stored in summer.

The introduction to Farmers' Bulletin No. 12S. published by the I. S. Department of Agrriculture on "Eggs and Their Tses as Food," says: "Perhaps no article of diet of animal origin is more commonly eaten in all countries or served in a greater variety of mays than eggs. Hens' eggs are most common, although the eggs of clucks. geese, and guinea forls are used to a greater or less extent. More rarely turkers' eggs are eaten, but they are generally of greater value for hatching." $* * * * * * * * *$

"Eggs are especially rich in protein (the nitrogenous ingredient of food). This material is required by man to build and repair the tissues of the body. Some energy is also furnished by protein, but fats and carbohrdrates supply the greater part of the total amount needed. Combining egges with flour and sugar (carbohydrates) and butter, cream, etc. (fat). is perhaps an unconscious effort to prepare a food which shall more nearly meet the requirements of the body than either ingredient alone. When eggss, meat. fish, cheese, or other similar foods rich in protein are eaten, such other foods as bread, butter, potatoes. etc., are usually served at the same time, the object being. even if the fact is not realized, to combine the different classes of nutrients into a suitable diet. The wisdom of such combination, as well as of other generally accepted food habits, was proved long ago by practical experience. The reason has been more slowly learned."

\section{The Place of Eggs in the Diet.}

"Eggs are used in nearly every household in some one form or another, in varying anounts. From the results of the numerous dietary studies made under the auspices of this Department and by the agricultural experiment stations, it has been calculated that on an average eggs furnish 3 per cent. of the total food, 5.9 per cent. of the total protein. and 4.3 per cent. of the total fat used per man per day. Cheese was found to furnish 0.4 per cent. of the total food. 1.6 per cent. of the total protein, and 1.6 per cent. of the total fat, while the milk and cream together furnish 19.9 per cent. of the total food, 10.5 per cent. of the total protein, and $10 . \overline{7}$ per cent. of the total fat. Milk and cream togetler also furnish some carbohydrates, while eggs and cheese furnish no appreciable amount of this group of nutrients. Considering some of the common meats, beef and real together were found to furnish 10.3 per cent. of the total food, 24.6 per cent. of the total protein, and 19.5 per cent. of the total fat. The corresponding values for mutton and lamb together were 1.t. 3.3 and 3.8 per cent.

"It will be seen that, judged by arailable statistics, eggs compared farorably with the more common animal foods, as regards both the total food material and the total protein and fat furnished by them in the arerage daily dietary. In other words, investigations show that the high food value of eggs is appreciated and that they constitute one of the rery important articles of diet in the American household.

"Many families of moderate means make a practice of buying fresh meat for but one meal a day-i. e., dinner, using for brealifast either bacon, dried beef, codfish, or left-orer meats. etc., and for lunch or supper, bread and butter and the cold meat and other foods remaining from the other two meals, with perhaps the addition of cake and fresh or preserred fruit. It is the thrifty housekeeper, who uses all her material as economically as possible in some such way, who is likely to fall into the error of exchuding eggs at higher prices almost entirely from her food supply. If her economy was directed principally to restricting the use of eggs in the making of rich dessert dishes, cake, and pastry, one might not only refrain from criticising but welcome the circumstances which necessitated the making of simple and 


\section{INTRODUCTORY.}

therefore more wholesome desserts. But usually the housekeeper conomizes by the more obvious method of omitting to serre them as a meat substitute.

"The statement so frequently made by housekeepers that eggs at 25 cents a dozen are cheaper than meat is true in one sense. Jot of course. with reference to the total amount of nutrient: obtained for the money expended. but because a smaller amount of money is needed to furnish the meal. That is to say, whereas at least $1 \frac{1}{4}$ prunds of beefsteak, costing 25 cents, at 20 cents per pound, would be necessary to serve five adults; in many families five eggs. costing 10 cents, at 25 cents per dozen, would serve the same number and probably satisfy them equally well. If the appetites of the family are such as to demand two eggs per person, doubling the cost, it is still 20 per cent. less than the steak. Many persons eat more than two eggs at a meal. but the arerage number per persin it is believed does not generally exceed two in most families. A hotel chef is authority for the statement that at least onchalf the orders he receives are for one egg. Frequently when umelets, suufflés. creamed eggs, and other similar dishes, are served in place of fried, poached. or boiled eggs or meat. less than one egg per person is used.

"These statements must not be understond as adrocating a free use of eggs at any price, but merely as pointing out that even at the higher prices the occasional use of eggs in place of meat need not be regarded as a luxury."

\section{Description and Composition of Eggs.}

"Size. The eggs of different kinds of domestic poultry vary in size as well as appearance, and there is also a considerable range in the size of eggs of different breeds; thus, hens' eggs range from the small ones laid by bantams to the large ones laid by such breeds as Light Brahmas. (on an arerage, a hen's egg is 2.27 inches in length and 1.72 inches in dianeter or width at the broakest point, and weighs about 2 ounces. or $S$ eggs to the pound ( $1 \frac{1}{2}$ pounds per dozen). Cienerally speaking, the cggs of pullets are smaller than those of old hens. those of ducks somewhat larger than hens' eggs, white those of turkers and geese are considerably larger. Guinea eggs, on an average, measure $1 \frac{7}{8}$ by $1 \frac{1}{2}$ inches, are rather pointed at one end. and weigh about $1 . t$ ounces each, or 17 ounces to the dozen. Cioose eggs weigh about 5.5 to
6.7 ounces each, or about 5 pounds to the dozen - that is, more than three times as much as hens' eggs. The eggs of wild birds are said to be smaller than those of the sanc species when domesticated. Wild ducks' eggs are said to be on an arerage. 1.97 to 2.17 inches in diameter, domestic chucks' egogs 2.36 to 2.56 inches.

"Composition.-The shells of hens' egors constitute about 11 per cent., the yolk 32 per cent. and the white $5 \bar{t}$ per cent.. of the total weight of the egg. According to tests made at the New York Experiment station, whiteshelled egge have a somewhat hearier shell than brown-shelled eggs."

\section{Increase of Eggs.}

The last L.S. Census Report sars:

The increase in total $\mathrm{egg}$ prochuction is a fair inclex to the growth of the poultry and egg industry in the several states churing the past decade. In the North Atlantic division the increase in eggs was 37.5 per cent., Rhode Island leading with a gain of 59.2 per cent. In the South Atlantic division the increase was 59.1 per cent., West Tirginia showing a gain of 73.8 per cent. The production of egg: in the North Central division exceeded the product returned in 1890 by 54.5 per cent. Jinnesota with a gain of 112.3 per cent.. and North Dakota with 109.t per cent., showing the greatest progress. The South Central division gained SO.S per cent. Oklahoma returned but $9 \$ 9.625$ dozens in 1890. when the territury was just opened to settlement, and the figures for the present census, 13.724,900 dozens. showed a gain of 1,286.9 per cent. Tennessee and Kientucky both showed decreases in number of fowls, but increases of 37.3 per cent. and 43.1 per cent. respectively in egg production, proving conchusively that the industry prospered there, as already explained.

The Western dirision, with its almost unparalleled advance in all lines of agricultural industry, gained 112.3 per cent. in egg production. Idaho and Montana made the greatest progress, the gain for the former being 290.3 per cent. and for the latter. 260.0 per cent.

The total value of poultry raised on farms and ranges in the Lnited States in 1899 was \$136.\$91.ST; ; the average value per farm of poultry raised was $\$ 26 . \$ 6$.

The five states of the highest rank in the value of poultry products in 1899 were Illinois, $\$ 11,307.599 ;$ Missouri $\$ 9,525.252$; Iowa, 
$\$ 9.491 . \$ 19$; Ohio $\$ \$, \$ 47,009$; and Indiana $\$ 8,-$ 172.993 .

The production of eggs in 1899 was 1.293,$\$ 19,186$ dozens, an average of 5.5 dozens per chicken. (This does not inchude eggs of turkers. geese and ducks). The value of these eggs was $\$ 144,286,158$. Iowa was the banner state in egg production, it reported $99,621,920$ dozens ; Ohio ranked second, with $91,766,630$ dozens; Illinois third, with 86.402 .670 dozens; Missouri fourth with S5.203.290 dozens; and Kansas fifth, with $73.190,590$ dozens. In value of eggs produced Ohio ranks first, with $\$ 10.2 \$ 0,769$; Iowa second. with $\$ 10.016 .707$; and Illinois which was first in value of poultry raised was fourth in value of eggs prochuced, reporting \$5.942,401: being outranked by Pennstrania with \$9.050.725, and followed closely by New York with $\$ \$ .630 .062$.

\section{Storage and Uses.}

Only perfect eggs are stored. those cracked in transit and the small and dirty-shelled ones being canned and frozen. Such eggs are sold to large baking establishments at prices below those of fresh eggs. thus taking the bakers out, to a large extent, from the winter clemand, and having a moderating effect upon prices. In 1900 orer 1,000 dozen eggs were frozen in Kansas City alone. Eggs found to be tainted are used in dressing leather for glores and bookbinding, an inclustry largely carried on in foreign tenement districts of large cities. A disinfectant is also made of the tainted eggs, and they are extensively used in the preparation of a shoe-blacking. The shells are used to make fertilizers.

Besides the culinary use of eggs, millions are used each year by wine clarifiers, calico print works, dye manufacturers, and in the preparation of photographers' dry plates. A considerable trade in dessicated eggs has sprung up in recent years. By a process of evaporation all or most of the white or rolk, as the case may be, is dried out. Eggs thus treated are used to some extent in the family tracke, but more by bakers, and are of special service in provisioning camping parties and expeditions.

When placed on the market the dried eggs are usually ground. Sometimes salt, sugar or both are used as preservatives. If the process of manufacture is such that the resulting product is palatable and keeps well, the value of evaporated eggs for many purposes is evident.
THE EGG.

From Wright's New Book of Poultry.

Every animal, of whatsoever kind, is developed from the egg form, or as phrsiologists express it, "omne animal ex oro." But the mode of that development differs, in one detail especially. In mammalia the egg is retained throughout within the body of the mother, which is its sufficient protection, and the derclopment is uninterrupted. In oviparous animals, such as birds, the egr is enclosed in a hard protecting shell. and. at a certain stage of development, extruted from the body of the mother; in this case development is arrested at that point, and may, may not, be resumed and completed.

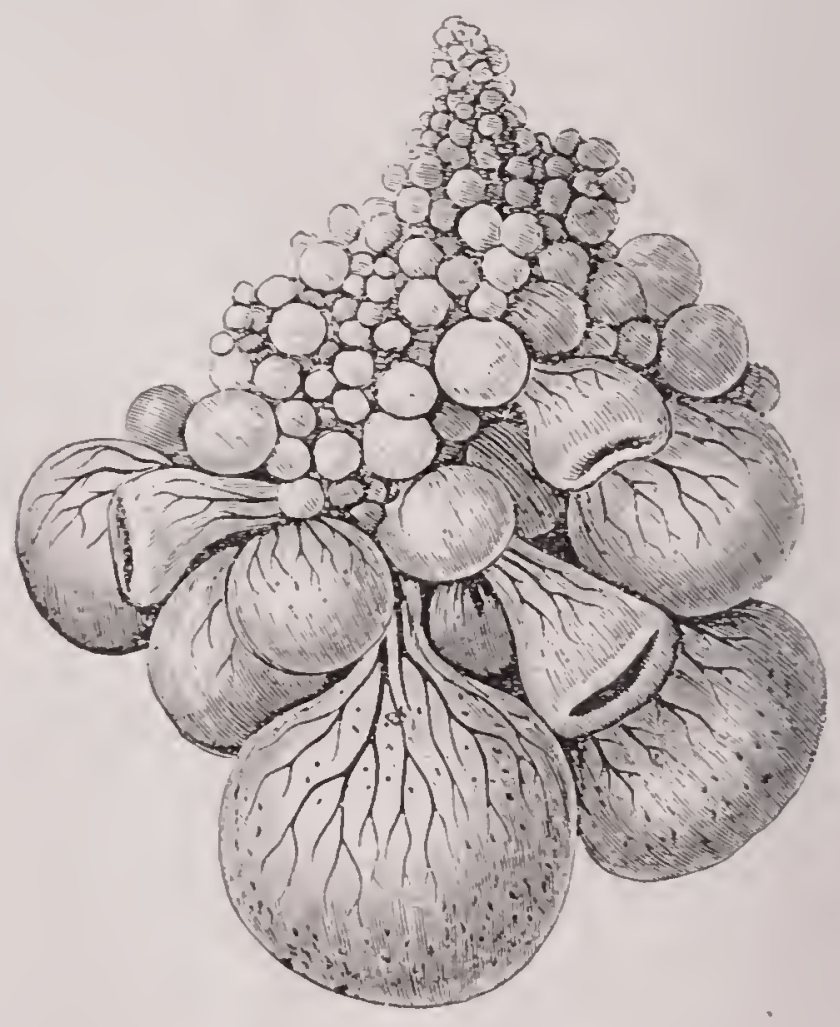

Fig. I. - Ovary of Laying Hen.

The orary of a hen churing or near her laving season presents an appearance much like that of a cluster of fruit, and is accurately shown by the illustration. There are, strictly, two such organs in every bird; but one remains merely rudimentary and undereloped, the fertile one being almost always that on the left of the spine, to which it is attached by means of the peritoneal membrane. By the orary the essential part of the egg. which consists of the germ, and also the rolk, is formed, each yolk being contained within a thin and transparent orisac, connected by a narrow stem or pedicle with the ovary. These rudimentary eggs are of different sizes, according to the different degree of development, and during the period of laying they are constantly coming to maturity in due succession. 


\section{INTRODUCTORY.}

As the rolk becomes fully matured, the enclosing membrane or ovisac becomes gradually thimer, especially round its greatest diameter or equator, which then exhibits a pale zone or belt called the stigma. Finally. whether or not fecundation takes place, the sac ruptures at the stigma, and the liberated rolk and germ, surrounded by a rery thin and delicate membrane, is received by the fumel-shaped opening of the oriduct or egg-passiage. whose office it is to convey it to the outer world, and on its way to clothe it with other structures needful for its development and preservation. This organ, with its various convolutions a little modified for convenience of represcontation, is shown in the illustration. and in an ordinary hen is nearly two feet in length. It will easily be seen how two yolks may become detached and enter the oriduct at nearly the same time; in which case they are likely to be developed in the same white and shell, causing the "double-yolked egg" so well-known to every poultry lieeper.

Thus received into the oviduct. the rolk becomes enveloped in a

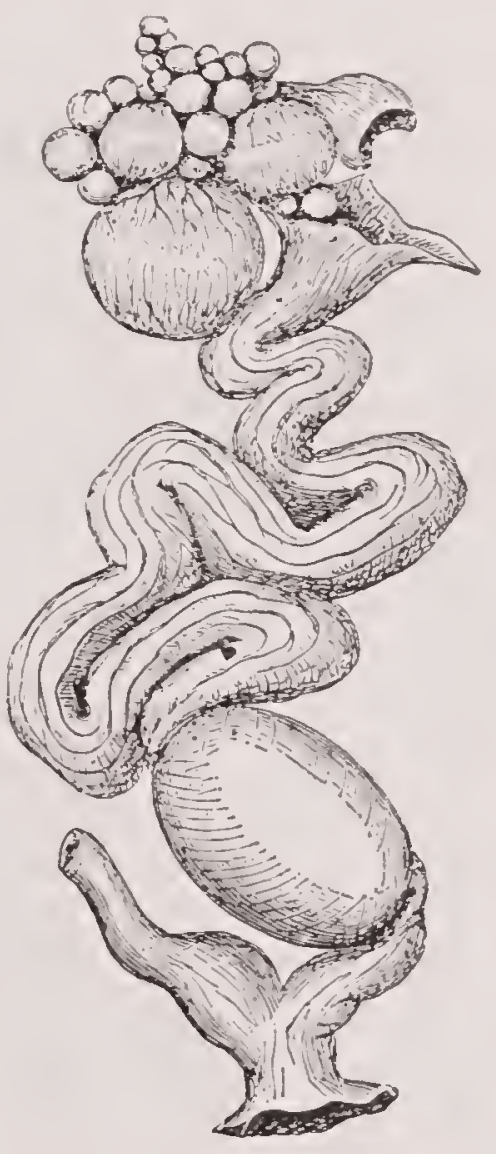

Fig. 2.-Ovary and Oviduct. glairy fluid called the white, or by chentist. albumen. This is secreted by the mucous membrane of the oviduct, and added layer by laver as the egg passes on. The uses of the white or albumen are manifold. It is eninently nutritious, forming indeed the chief nourishment of the chick during its growth in the shell; as it becomes absorbed by the little animal, and forming as it does by far the greater part of the egg when laid, it gives the fastgrowing little body the needed increase of room; it is a very bad conductor of heat, and hence guards the hatching egg against the fatal chills which would otherwise occur when the hen left the nest; and finally it preserves the delicate yolk and vital germ from concussion or other violent injury.

At a still further point of the oviduct the egg becomes invested with the skin or parchmentlike covering which is found inside the shell. In reality this skin consists of two layers, which can easily be separated, and at the large end of the ego they do separate entirely. forming the air-chamber. At first this chamber is small, but as the egg gets stale, it beeomes larger and larger, so that even in egres stored, it fills at length, a large portion of the space within the shell, the ego itself drying up in proportion. In eggs on the point of hatching it usually occupies about one-fifth of the space. It has been proved by experiments that the perforation of this air chamber, even by a neelle point, is an effectual prevention of successful hatching.

In the last portion of the oriduct, the egg becomes coated with that calcareous deposit which forms the shell, after which it passes in to the cloaca and is ready for expulsion. In some breeds, coloring matter is added over the solid ingredient, producing the deep-colored eggs of the Cochin, and in other birds the splashed and spotted patterns so well-known. In forls which lay colored eggs similar splashes of ten oecur, and we have had Brahma hens which laid eggs with a white ground. corered thickly over by chocolate-colored spots. We have had others, again, lay eggs covered apparently with a coat of white-wash, which on being rubbed off with a rough cloth, revealed the usual buff-brown tint beneath. All these things obriousty depend on some peculiar condition of the secreting organs, as does the shape of the egg of each bird when finally laid.

Occasional departures from the ordinary type of egg will now he understood. If the latter portion of the oriduct be in an unhealthy condition, or if the yolks be matured by the orary, faster than shells can be formed by that organ, "soft" or unshelled eggs will be produced. If, on the contrary, the oriduct and its glands be active, while the supply of yolks is temporarily exhausted, the diminutive eggs, which consist of only white and shell, and which not infrequently terminate the laying of a long batch, may be expected to occur. Disease extending to the midelle portion of the passage may result in eggs without even the membraneous skin, and if the entire canal be in an unhealthy condition, yolks alone may probably be dropped without any addition whatever, even of whites. This last 
occurrence therefore denotes a serious state of affairs, and should be met at once by depletic medicines, or it will probably be followed by the loss of the bird.

Let us now consider the egg itself, which is a much more complicated organism than many people are aware of. There is much even in the shell to excite our interest. It is composed chiefly of prismatic particles. so arranged as to leave pores or interspaces between them. As laid, the shell is of enormous strength. so that it will resist great pressure between the palms of the hands applied to the opposite ends; though it is not correct that. as we hare seen stated, "the strongest man camnot break it" in this way. Still. for it thickness and texture, its strength is phenomenal. As hatching proceeds. howerer, the carbonic acid and dioxide formed by the breathing of the chick, dissolved

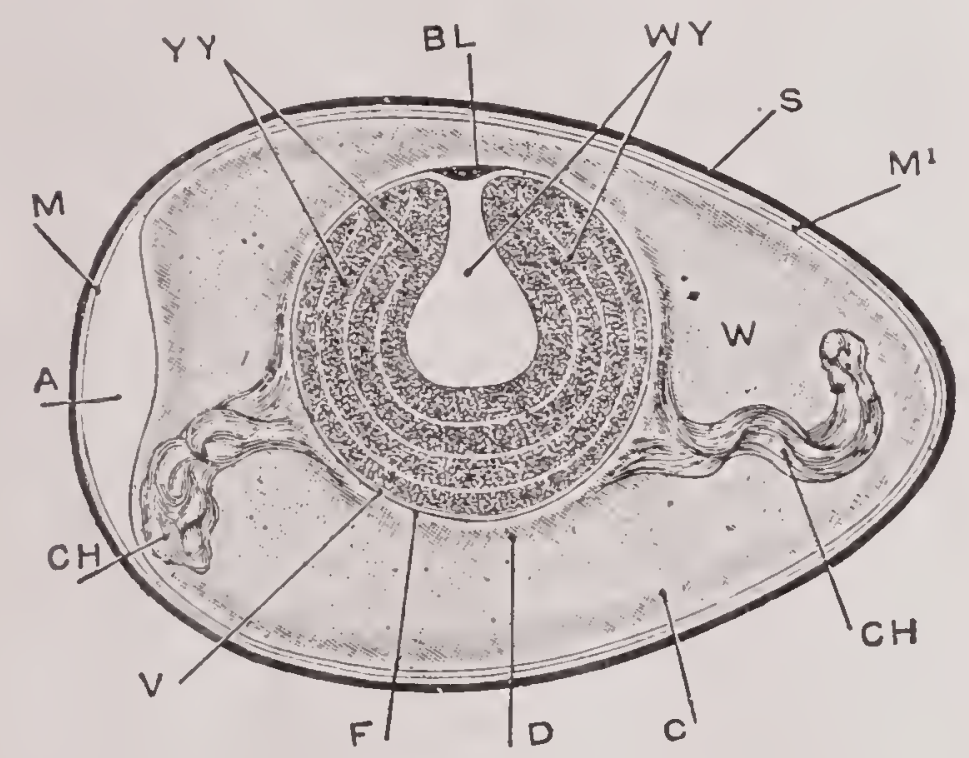

Fig. 3.-Diagram of an Egg.

in fluid, grachually dissolve a portion of the material, and thus the prismatic bodies are slowIy softened and disintegrated. The shell thus becomes far softer and more brittle as hatching approaches; and so great is the difference, that if the edge of a fracture made across a fresh egg-shell, and another of one hatched or hatching, be examined under a microscope, it will be instantly seen that the two are in a quite different molecular condition. Were it not for this beautiful provision of nature. the chick could never break the shell.

The outer and inner shell membranes II and II, separating at the air chamber $A$, need no further explanation. Proceeding inwards. we come next to the white or albumen W. This is composed of a denser, and a more fluid kind, arranged in layers, which can be peeled off in a hard-boiled egrg, like the layers of an onion. A layer of the more fluid kind is always next the shell, and another thin one, F, next the yolk, but enveloped by another layer, $\mathrm{D}$, of the dense kind. If an egg be broken into a basin, there will further be observed attached to two opposite sides of the rolk, two slightly opaque and rather twisted thick cords $\mathrm{C} \mathrm{H}$. of still denser albumen, termed the chalaza. They are not attached to the shell, but to opposite sides of the dense laver of albumen, D, which envelopes the inner fluid layer and the yolk. They are attached at opposite sides, rather below the center, thus they act as balancing weights, keeping the sicle of the rolk which carries the germ always uppermost, and very nearly in floating equilibrium. If the egg be tumed round, therefore, the rolk itself does not turn with it, but retains its position with the germ on the upper side.

It will be seen how elaborately and beautifully the rolk, bearing upon its upper surface the tender germ, is protected within the egg. Itself rather lighter at the upper part, it is further balanced by the chalazce. so as to float germ uppermost in the albumen. It is usually very slightly lighter than the albumen, but scarcely perceptibly so; thus it floats near the upper side of the shell, but ahways separated from it by a layer of albumen of more or less thickness, and oscillating gently away from the shell on the least motion. In a few cases it probably floats more strongly up against the shell, and these are generally the cases in which adherence takes place, or the rolk is ruptured during hatching; but an exquisitely delicate floating balance is the rule. Nevertheless, it will be readily understood why it is inadrisable to leave an egg lying on the same side for any length of time. The shell being porous, and permitting of evaporation, such a course keeps the germ close to the portion of albumen which is slowly drying up, and may cause a tendency to adhesion.

Turning now to the yolk, this is contained in a very delicate vitelline membrane, $\mathrm{V}$. It is composed of both white and yellow cells, and if an egg be boiled hard, and cut across, it can be seen that there is a flask-shaped nucleus or center of white yolk, $\mathrm{W} \mathrm{Y}$, round which are several concentric layers of yellow yolk. I I'. Under the microscope additional thin layers of white yolk cells can be distinguished amongst the yellow layers. On the top of the white yolk rests the blastoderm (germ skin), a small disc about oneeighth of an inch across, shown at B L. The difference between a fertilized and an unfertilized egg is solely to be found in this small disc. 


\section{CHAPTER I.}

\section{THE NATURAL HABITS OF THE HEN AND WHAT DOMESTICATION HAS DONE. THE EARLY HISTORY OF DOMESTIC FOWLS. THEIR ORIGIN AND GRADUAL DEVELOPMENT. SOME OF THE RESULTS ALREADY ATTAINED. THE PROBABILITIES \\ OF THE FUTURE.}

F is quite generally believed by naturalists that our common donestic hens are descended from the wild jungleforls of Asia, which are scientifically named Gallus Bantiva. There are four recognized species of Gutlus found there, very possibly of one common origin far back in the unrecorded past. but now having little in common except their wildness, and because of their being sterile, or producing only barren hybrids when mated, a common origin is doubtful; if of common origin they have raried so widely as to now be distinct species, and, tested by the standard of fertility when mated, the other species are unrelated to G. bankiva. This wild jungle fowl of Northern India. bears a quite close resrmblance to the Black Breasted Red Game fowl as we know it, the chief difference being that the Cames carry the tail more erect; in the bankira the tail is carried drooping. Of the history of these birds the Encyclopedia Britannica says:

" "It inhabits Northern India and greatly resembles in plumage, the Black Breasted Red Game, and this is especially the case with examples from the Malay countries, between which and examples from India some differences are noticeable, - the latter have a plumage less red, and ear lappets almost invariably white, while in the former the ear lappets are crimson, like the comb and wattles, and the legs yellowish in color. If the Malay birds be considered distinct, it is to them that the name G. bankiva properly applies. This species is said to be found in lofty forests and in dense thickets. as well as in ordinary bamboo-jungles, and when cultivated land is near its haunts it may be seen in the fields after the crops are cut, in straggling parties of 10 to 20 . The crorr of the cock is described as being just like that of the Bantam. but never prolonged, as in some clomestic birds. The hen breeds from January to July. according to the locality, and lays from $S$ to 13 creamy-white eggs, occasionally scraping together a few leaves or a little dried grass by way of a nest.

"Several circumstances seen to render it likely that fowls were first domesticated in Burmah or the countries adjacent thereto, and it is the tradition of the Chinese that they receired their poultry from the West, about 1,400 B. C. By the Institutes of Manu, the date of which is variously assigned from 1200 to $\$ 00 \mathrm{~B}$. C.. the tame fowl is forbidden, though the wild is allowed to be eaten. showing that its domestication was already accomplished when they were written. The bird is not mentioned in the Old Testament. nor by Homer, nor is it figured on ancient Egyptian monuments. Pindar mentions it, and Aristophanes calls it the Persian Bird, thus indicating it to have been introduced in to Greece through Persia, and it is figured on the Babylonian cylinders between the 6 th and 7 th centuries, B. C.

"Game fowls differ les, from the wild bankiva than any other variety; they are, howerer, considerably larger, and carry the tail more erect than the wild birds. In some parts of India, sportsmen find it not easy to distinguish between the wild and domesticated birds."

Discussing the origin and history of domestic fowls, Darwin, in his "Animals and Plants under Domestication," sars:

"History" of the Forl--Rutimeyer found no remains of the fowl in the ancient Swiss lakedwellings; but, according to Jeitteles, such have certainly since been found associated with extinct animals and prehistoric remains. 


\section{PROFITABLE EGG FARMING.}

It is, therefore, a strange fact that the fow is not mentioned in the Old Testament, nor figured on the ancient Egrptian monuments. It is not referred to by Homer or Hesiod, (about 900 B. C.); but is mentioned by Theognis and Aristophanes, between 400 and 500 B. C. It is figured on some of the Babylonian cylinders between the sixth and seventh centuries B. C., of which MIr. Layard sent me an impression, and on the Harpy Tomb in Lycia, about 600 B. C., so that the fowl apparently reached Europe in a domesticated condition somewhere about the sixth century B. C. It had travelled still farther westward by the time of the Christian era, for it was found in Britain by Julius Caesar. In India it must have been domesticated when the Institutes of Manu were written, that is, according to Sir IV. Jones, 1200 B. C., but,, according to the later authority of $\mathrm{Mr}$. H. Wilson, only 800 B. C., for the domestic fowl is forbidden, whilst the wild is permitted to be eaten. If, as before remarked, we may trust the old Chinese Encrelopedia, the fowl must have been clomesticated several centuries earlier, as it is said to have been introduced from the West into China 1400 B. C.

"Sufficient materials do not exist for tracing the history of the separate breeds. About the commencement of the Christian era, Columella mentions a five-toed fighting breed, and some provincial breeds; but we know nothing about them. He also allucles to dwarf fowls; but these cannot have been the same with our Bantams, which, as Mr. Crawfurd has shown, were imported from Japan, into Bantam in Java. A charf fowl, probably the true Bantan, is referred to in an old Japanese Encyclopechia, as I am informed by Mr. Birch. In the Chinese Encrclopedia, published in 1596, but compiled from various sources, some of high antiquity, seven breeds are mentioned, inchuding what we should now call Jumpers or Creepers, and likewise fowls with black feathers, bones and flesh. In 1600, Aldrovandi describes seven or eight breeds of fowls, and this is the most ancient record from which the age of European breeds can be inferred.'

Mr. Darwin tells us that "Sufficient materials do not exist for tracing the history of the separate breeds" of fowls, and it is equally true that sufficient materials do not exist for tracing the growth (or evolution) of the clomestic fowls of today as a whole, but from what materials we have and by what we can surmise from the practically analogous history and traditions of the human race, we can piece together a probable history. We in America have received the so-called "Mediterranean," (the non-sitting), varieties from the countries bordering upon the Mediterranean sea, the so-called "Asiatics" from China and Bantams from Japan. It is interesting to recall the numberless invasions of the tribes and peoples of eastern (Asiatic) origin into the countries borckering upon the Mediterranean sea, and to remember that while those invading peoples frequently conquered the countries they invaded, they were in turn absorbed into the peoples of the countries which they had conquered, the conquerors and the conquered being ultimately merged into one family; a most familiar example of such merging of races, that of the English people, is recognized by the late Laureate in the well-known lines of his welcome to the princess who has now become the queen of England:

\section{"Saxon and Norman and Dane are we, All of us Danes in our welcome to thee, Alexandra."}

It is easy to imagine the movements of innumerable tribes and peoples who thus became inhabitants of the countries bordering upon the Mediterranean sea, and to picture them as taking their flocks and herds with them on their migrations, and probably in this manner the domesticated descendants of Gallus bankiva were introduced into Europe. That the process of domestication and entire change of liabit in the species was a long one there can be no question; it woukl certainly require many thousands of generations to effect so complete a revolution in habits and instincts as we see in the non-incubating varieties. The old proverb tells us that "Self preservation is the first law of nature," and we can easily believe that next to self-preservation the perpetuation of the species is the strongest instinct. It is true that with domestic fowls the propagating of their kind is a dual act, comprising, first, the laying of the eggs, and, second, the incubating of them; and in the Mediterranean varieties we have the incubating instinct practically become clormant through long-continued clisuse. It must have required a long, long period of time to have effected so momentous a revolution in so potent an instinct. The have, in Egypt, the familiar instance of the incubating of eggs being done artificially, but no other example has come to 
us, nor does recorded history mention other peoples practicing the art so far as we have knowledge. It would be possible for the incubating instinct to become clormant in the fowls of that country and through a correspondingly greater development of the egg-producing instinct the fowls be more highly valued and consequently imported into adjoining countries.

It would be possible also, that "natural selection" would have gradually effected the permanent abandonment of the brooding instinct; the birds being preferred which were most prolific layers and least persistently broody, such preference (and conserquent "selection") were found among the ruins of the buried city of Pompeii and are now preserved in the National Museum at Naples; one of these represents. a cock, life size, which differs little if at all in shape, color, etc., from the Brown Leghorn cock of today, the other is likewise of a Brown Leghorn cock but shows some sprinkling of white among the sadclle feathers. The correspondent to whom we are indebted for this information, writing of the common Italian fowls, says: "The Nediterranean races are of course the universal ones, and here almost exclusively are the Brown Leghorns, saucy, self-reliant, quick to assert themselves and great foragers.

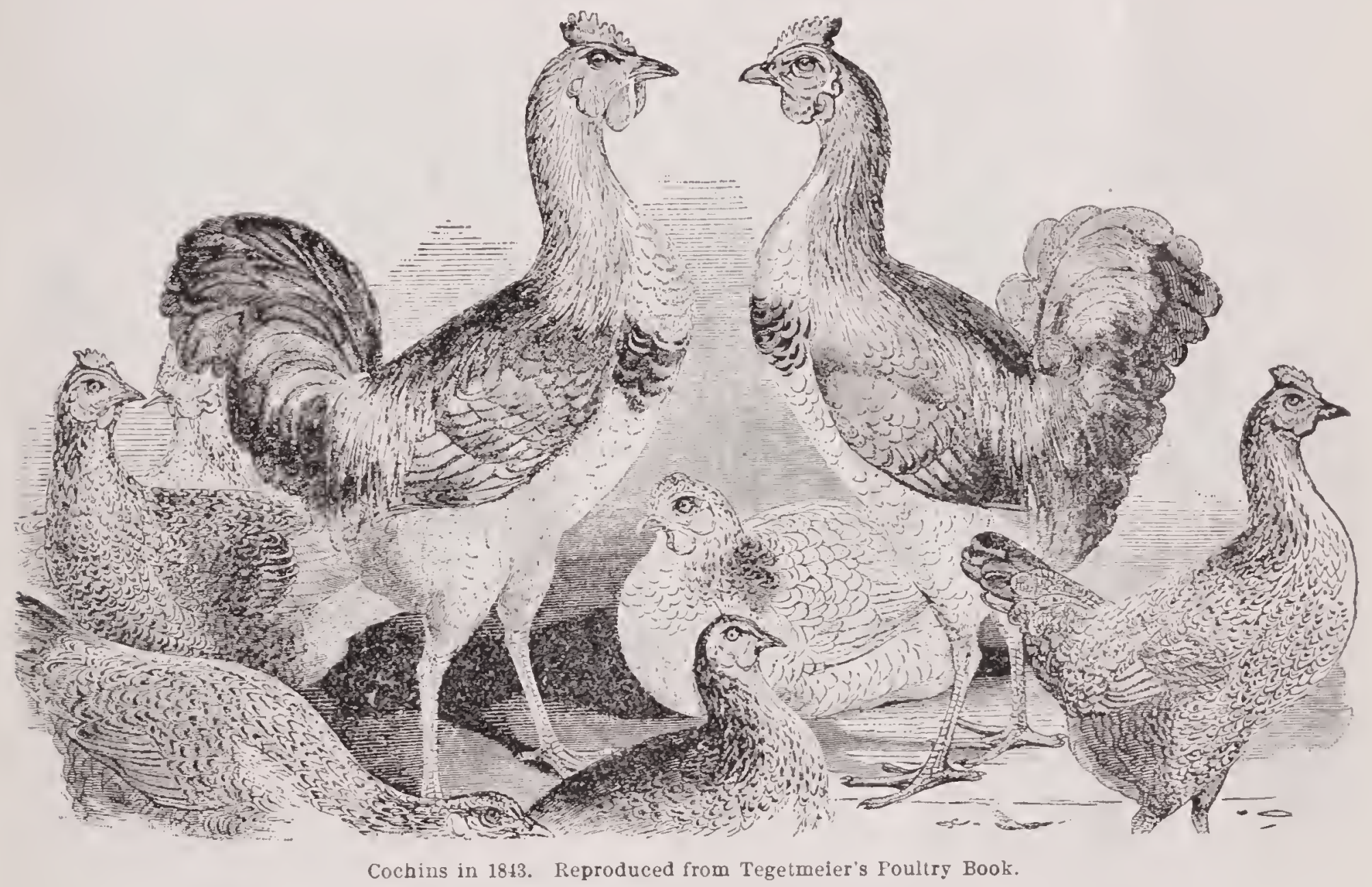

would gradually, although very slowly, weaken and finally destroy that instinct. In the countries where artificial incubation was not practiced, however, fowls of incubating disposition would have to be kept to hatch the necessary chickens; and we find that very condition in Italy today, where can be seen, among the innumerable flocks of the common Italian fowls (which we in America know as Leghorns), here and there a flock of more or less mongrel Asiatics and other incubating varieties.

That the common Italian fowls have changed little, if any, in the past two thousand years, we have good evidence in two fine mosaics which
There is no attempt whatever made to maintain any special variety of color or marking, although one sees often enough trpical cocks and hens resembling very closely the Brown Leghorn as it exists in the United States today, yet since they are not selected for breeding with any definite object the evils of inbreeding manifest themselves in frequent white feathers.

"Nevertheless the race of the Brown Leghorn must be one of remarkable vigor and of great age. Nowhere have I seen anything like the modem pea-comb or rose-comb, always the large, well developed single comb,-and only rarely a white or black variety. The rose. 
combs and Black and White Leghorns are of course either the results of admixture with, or sports of the ancient type of the race,-and that type seems to be the brown Leghorn."

It would be still more correct to say the type is that of the progenitors of the race, for the black-red colors of the Brown Leghorn male rery closely resemble the black-red colors of the male Gallus bankiva, and the persistence of these color-markings in the common fowls of Italy is an illustration of the persistence of race characteristics, as well as of reversion towards the original ancestral type. This result is precisely what would be expected from centuries tioned and extremely broody "Asiatics."

If we suppose that quantity and quality of meat were preferred to a great egg product we would expect just such a derelopment of the meat producing qualities as those Asiatic fowls possess. Some of us can remember the great vellow Shanghais and Grey Chittagongs of fifty or sixty vears ago; so tall that, while standing on the floor beside it, they could eat corm off the top of a barrel that was standing on end; cock birds of the descendants of those varieties have reached serenteen or eighteen pounds weight.

It is quite unnecessary for us to enter into the much discussed question of whether the Chitta-

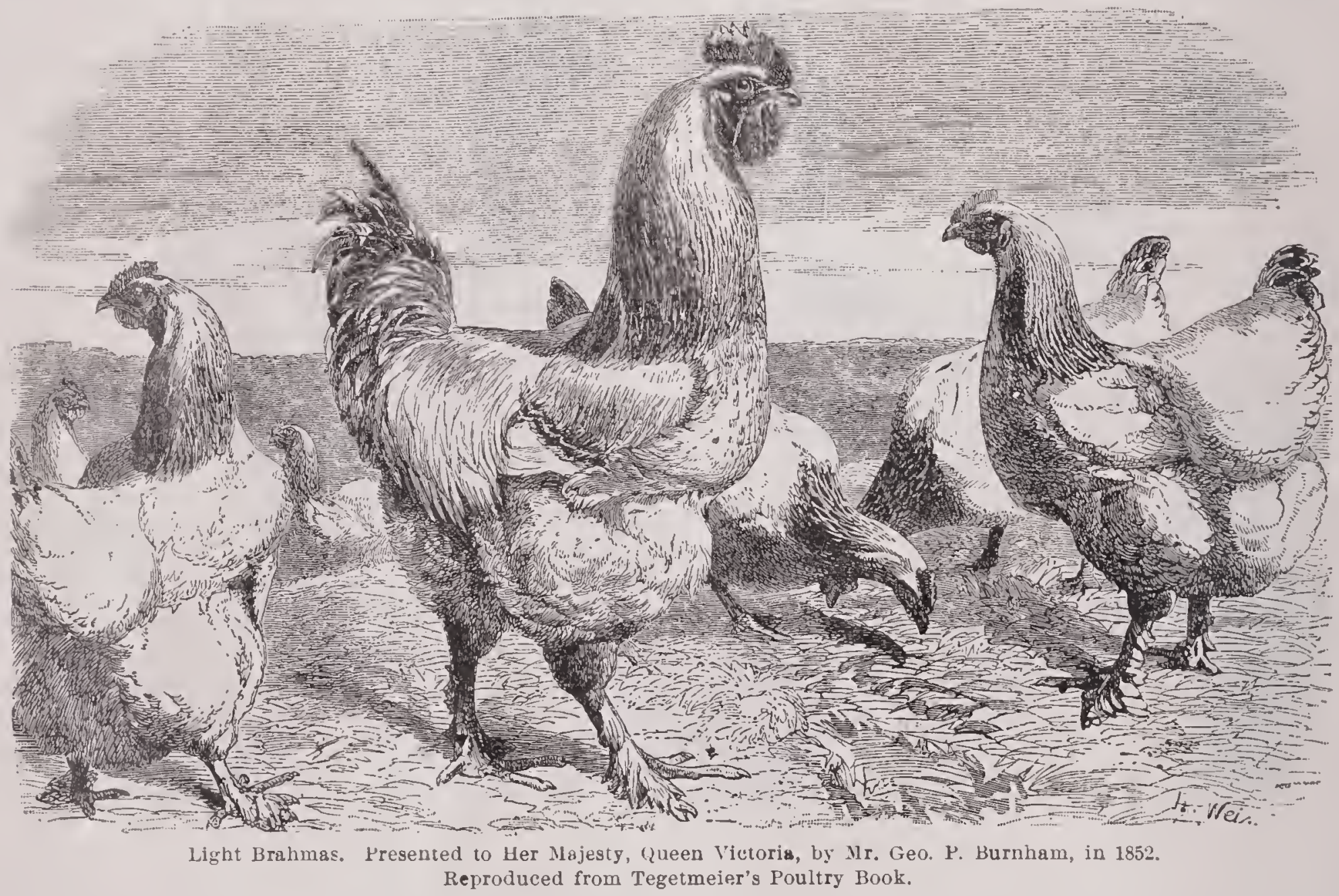

of promiscuous interbreeding, just the result that we find in the common Italian fowls described above and from which our finely bred Leghorns have been developed.

Mr. Darwin tells us the domesticated fow is said to have been introduced from the west into China about 1400 B. C., and we see in the descendants of those fowls a development in a decidedly different direction from that taken by the domesticated fowk in Europe and North Africa. Instead of the small, non-sitting, intensely nerrous and active "Mediterraneans" we find the large, clumsy, placid-disposi- gongs were of Chinese or Indian origin, it is sufficient for our purpose to know that both the Chittagongs and Shanghais were of the same great Asiatic race, and that our Cochins and Brahmas have been developed from them. We in America received the ancestors of our Cochins and Brahmas from Asia, the ancestors of our Leghorns from Italy, and from Spain and the countries which were for centuries dominated by Spain the other "Mediterranean" varieties; and from the mixing of these races has been evolved our popular American varieties, the Plymouth Rocks and Wyandottes. 


\section{NATLRAL HABITS OF THE HEN}

\section{What Domestication Has Done.}

We have seen that our common domestic hen probably originated in the wild jungle-fow of Asia, and that currents of conquest and commercial enterprise carried them east into China and west into North Africa and Europe; in the one case the influence of selection has developed the meat producing qualities and in the other the tendency to increase the production of eggs his been carefully developed and the instinct of incubation rendered dormant; these remarkable results having been attained by the persistent and long continued selection of the nost prolific lavers in the onc care and those of greatest size in the other. From the wild jungle-fowl, producing a clutch of " $\mathrm{S}$ to 13 creamy white eggs" in a season, to the highly" organized egg-machines that produce 150 to 200 eggs each in a rear is a long journer, one that has required several thousand rears to accomplish. - and the end is not yet. Te have every reason to believe that we are continuing to progress. and that continued careful breeding to a definite purpose will give us still more gratifying results, with reasonable assurance of even greater permanency of results.

Te have quite analogous conditions in the domestic cow, which, in the wild state, vielded milk for three or four months for the sustenance of its calf and ran dry the balance of the rear, but has by careful breeding to one purpose, been developed to give an almost uninterrupted milk flow, and in individual cases has reached the phenomenal yield of upwards of 10,000 pounds of milk in a year, when the average for the whole United States is but about 3.400 pounds. The "Biggle Cow Book" says: "Creat is the dairy cow! Hail to her! But if she gives less than 5.000 pounds of milk per" year, or 200 pounds of butter, away with her! She is not profitable." A grade cow, "Topsey," (out of a Shorthorn cow by a Holstein bull) made a yearly a verage for five years of 10.037 pounds of mill. which made 456 pounds of butter. the arerage cost of the butter being $\$ .6$ cents per pound. As there are only about half a million head of thoroughbred cattle and some ten to twelve million "grades" (out of a total of nearly" seventy millions) in the (nited states, it can be surmised that comparatively few came up to eren Judge Biggle's modest standard of profitable production.

It is exactly similar with our hens. The statistics of the last census show an arerage egg production for the whole United States of 5.5 dozens per fowl, the state of Maine being credited with an average of 8.5 dozens and Louisiana ranking lowest with but 3.3 dozens per fowand yet we have individual hen records of 200 to 251 egrs within a year of reaching laying maturity. In the tables of estimater average egr production the Asiatic varieties are credited with 120 to 150 eggs each; the Amcrican varieties with 175 to 200 egge each and the Nediterrancan varieties with 180 to 200 eggs each. It is only within a few years that we have had trap-nest records of indiridual birds, and the best previous authentic records of birds in flocks (the total egre product being divided equally among all the birds), gare 194 eggs each from 600 White Leghoms on Mr. Wrecioff's farm, 17s eggs each from 280 White Wrandottes and Barred P. Rock: on Mr. Norton's farm. 198 eggs each from 135 Barred P. Rocks on Mr. Parks' farm, 196 egos each from ten Buff Wrandottes on Dr. Samborn's farm and 210 eggs each from 11 White Wrandottes on Mr. Woods' farm. By the use of trap nests the exact record of each bird in the flock is obtained, and Mr. Silberstein developed egg production in his Light Brahmas to an extent that one bird laid 232 eggs within a year of laying maturity and Mr. John II. Boswell. Jr., got 242 eggs in a year from a White Wrandotte pullet.

The best work of which we have knowledge, in this field, has been done at the Ilaine Agricultural Experiment Station, where they have been breeding from known great larers for the past five rear's. They have found in their flocks thirty hens that laid between 200 and 251 eggs each in a rear, twenty-six of these hens being now in their breeding pens, and constituting the foundation stock upon which their breeding operations are based. "All the breeding strock we are now carrying are tested hens that have laid over 180 eggs in a year; pullets whose mothers laid orer 200 egrgs in one year and whose father's mother's laid over 200 eggs in a year: and pullets sired by cockelels whose mothers and grandmothers laid orer 200 eggs in one year." For those who have thought a hen that laid freely in hel first year was of little value as a layer thereafter it will be a comfort to know that some of the great layers there at the Maine Experiment Station are doing great second and third year laying also. The report says: "No 286, in her first year, commencing Nov. 1, 1899, laid 191 eggrs, with 157 during the 


\section{PROFITABLE EGG FARMING.}

second, and 138 in her third year." "No. 4 laid 201 eggs the first year, 140 the second and 130 the third." These two hens laid 486 and 471 eggs respectively in three years.

Speaking of the advantages of incubators and the beneficial effects from their use the U.S. Census Report says: "The continued use of the incubator tends to make the hen forget in a measure, her maternal instincts. It is said that in Egrpt, where artificial incubation has been employed for centuries, the hens exhibit very little tendency to bacome 'broudy,' and much of the time formerly spent in being 'broody' is available for egg laying. This fact assumes gigantic importance when it is remembered that it has been chiscovered that there are 600 embryo eggs in the ovary of a hen. It has been further ascertained that two-thirds of this number can be secured in the first two years of a hen's life, provided suitable measures are employed. If the tendency to become 'broody' can be suppressed, and more time can be giren to egg laying, incubation being left to the artificial incubator, and if, in addition, egg-producing food be feck, the problem of getting the greatest number of the eggs from the hen in the first two years of her life will be very near solution."

Assuming for the moment that the census writer is correct in his statement of there being 600 embryo eggs in the ovary of a hen, the problem of getting the greatest proportion of that number the first two yoars of her life is easily solved if wo but breed from birds that have the egg-laying habit fixed; the success of the Maine Experiment Station people is good proof of that. Does our census friend, however "know" that there are 600 eggs in the ovary of a hen? Wc believe that the number is not so fixed as he implies, and that an increase in the numbar can be developed by breeding from birds of a fixed egg-producing habit. Faculties are developed by long-continued and persistent use. With the wild Gallus bankiva there woukd hardly be occasion for a store of 600 embryo eggs when she produced but 8 to 13 in a season; there certainly was no probability of her living through fifty seasons, hence by no possibility could she ever use half, or a fourth, even, of 600 embryo eggs; and nature is not so wasteful of her provision for the reproduction of species. Rather would we believe that in the wild state the female Gallus bankiva was provided with perhaps 100 embryo eggs, and that the increase in the domesticated hen to a possible 600 has come through long development of the egg-producing faculty; and in that belief (and it is plausible) we find encouragement to look forward to a still further enlargenent of the supply of embryo eggs in future great laying stock. There are countless analogies in nature of such development through long continued and persistent use of a faculty or function, and with the prolific laying habit heveloped and transmitted through many generations we confidently predict a still further increase of capacity for eggproduction.

Similarly with the market qualities of our stock; by selecting the breeding birds with a view to improving the quantity and quality of breast meat, by choosing birds with long, deep keels and short legs and thighs, that most important quality will become gradually more highly developed; bringing about an increased quantity of the highest quality of meat, which will result in increased appreciation of and demand for that product.

\section{The Probabilities of the Future.}

Far too many poultry witers, as well as poultry raisers, take no thought of the probable future growth or development of the poultry business; we are all prone to live fully up to the motto, "Sufficient unto the day is the evil thereof." Those of us who can look back fifty years, can see tremendous changes, and if we study the situation aright, those changes of the past are certainly suggestive of what future development may be. Up to this time the practical end of poultry raising has been very little studied; the bulk of poultry writing, the influence of the poultry shows, etc., have almost all been along what is callect the "fancy" branch of the business. Some little thought for the practical there is, some little preaching of better quality, both of poultry meat and eggs. and there is some slight interest in the better conditions of collecting and shipping to farorable markets. Taking the country as a whole. however, there is very, very little thought of this, and very, very little attention paid to the bettering of quality, and the improving of market conditions.

That improvement in quality is one phase of future development, seems highly probable, and it will tend to an increased appreciation of both poultry meat and eggs, if this improvement in quality and also in market conditions is brought about. One of the effects of improvement in 


\section{NATURAL HABITS OF THE HEN.}

quality will be an increased public appreciation of both poultry meat and eggs, and an increased consumption by the public, and this wholly outside of certain natural causes which are steadily influencing an increased public consumption of these products. These natural causes are a rapid and steady increase in population, and a steady decrease in supply of other meat products, and there are excellent reasons for believing these conditions will continue. With the population of the United States doubling every forty years, and the beef, pork and mutton supplies steadily decreasing through natural causes, it is reasonable to argue that there will be a constantly increasing demand for eggs and poultry meat as a substitute; and with the rapid multiplication of population, and especially the evident disposition of the people to center in cities and towns, thus increasing the consuming class far more rapidly than the increase of producers, that increase in demand should be likewise rapid. One very decided influence in this direction will be an improvement in quality, and this is quite as applicable to eggs as to dressed poultry. Thousands and thousands of cases of eggs now reach the large consuming markets in very poor shape for use, largely because of the great lapse of time between the production of the eggs by the hens and their ruaching the tables of the consumers. A bettering of conditions hele would be a comparatively simple and easy nuatter; it requires more regular and systematic collecting of the oggs on the farms, and a regular collecting from the farms by the dealer's who ship them to market; and the time is not far distant when we shall see regular eggcollecting routes, comparable to the cream-collecting routes now established in great dairy sections of the country. Indeed, there is 110 reason whatever why the two lines of work should not be combined, and the cream collector likewise collect the eggs from the farms daily, and bring them to the cool-room of the creamery, where ther can be lighted, packed and shipped promptly and regularly to the most desirable market.

Our friends in Europe are already far in advance of us in this particular, and in Denmark alone, there are 24,000 farms enrolled in a "Danish Egg Association," the eggs of the members being collected either daily or three times a week. In this association the eggs of each farm are marked with a letter and number, so that the origin of every egg brought into the depots is known.

These eggs are lighted to test their freshness, and then packed and shipped to market; if a bad egg is found in any farmer's lot, he is fined for the first offense, and if a second offense of sencling in bad eggs is discorered within a year, he is expelled from the association, and has to fall back on the ordinary market chances for disposing of his product. As there is a substantial increase in price received through being a member of this "Danish Egg Association," obriousty the nembers are jealous of their reputations, and are careful not to send in any questionable eggs.

An important movement in England has been the forming of a National Poultry Organization Society. The head offices are in Hanover Square, London, and the society was founded (we quote from the prospectus) "with the object of affording British Poultry keepers the same advantages of information and organization as are enjoyed in foreign countries, thus enabling them to compete on equal terms with their rivals abroad. Its chief aims are: (a) the organization and derelopment of the Poultry Industry as a most important branch of British Agriculture: (b) the improvement in the quality, and the increase in the quantity of eggs, poultry, etc., producerl in the Lnited Kingdom: (c) the maintenance of regularity and uniformity of supply: (d) the provision of facilities for rapid transit: and (e) the bringing of producers and retailers in closer touch, in order that the best arailable market may be obtained at a minimum cost.

"The society is not a trading concern, but seeks to further the above objects by promoting the formation of (a) Branches and (b) collecting Depots in the rural districts.

"Branches encleavor by the mutual co-operation of all interested in the poultry industry, in their districts, to improve the class and increase the number of fowls kept, to secure the adoption of improved methods of management, to disseminate among the members such information and render such aid as they may require, and to co-operate with the Technical Education Committees of the County Councils in ensuring the success of lectures and classes in poultry keeping."

Upwards of thirty branches or collecting depots have been established. These branches and collecting depots, "undertake the rapid 


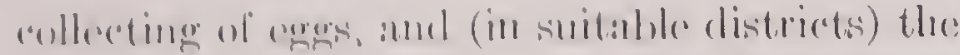

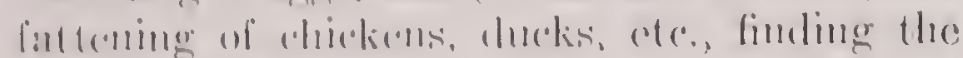

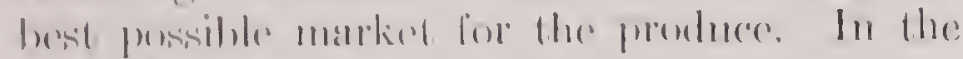

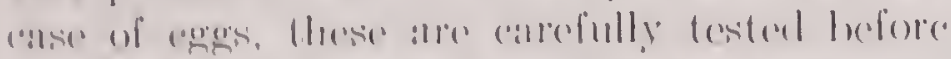

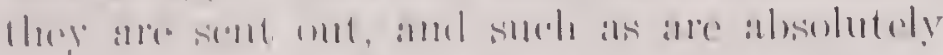

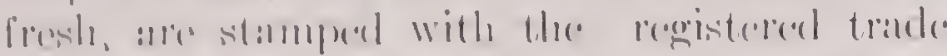

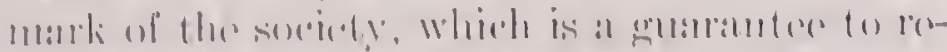

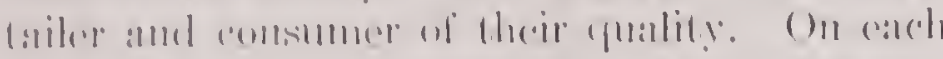

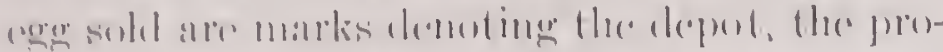

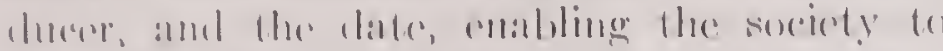

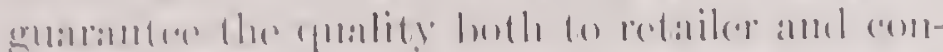

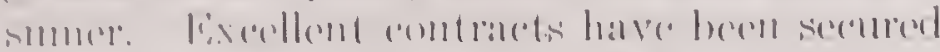

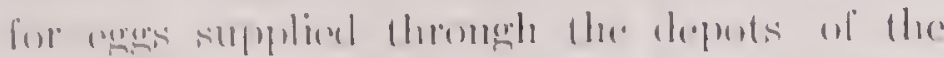

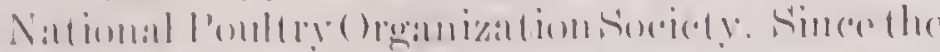
(1)

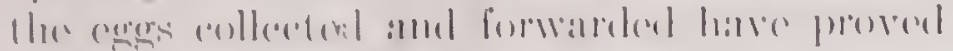
most silfisfardery. and the elomamel lore these

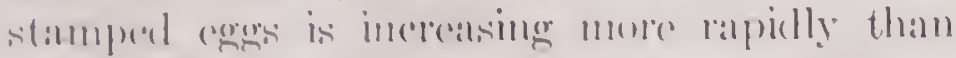

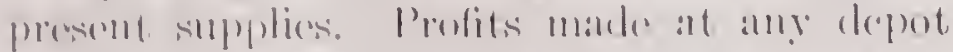

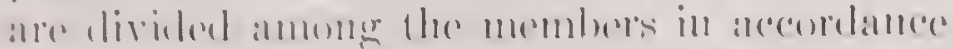

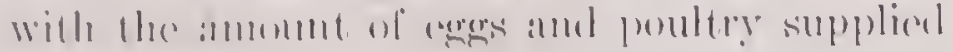

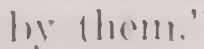

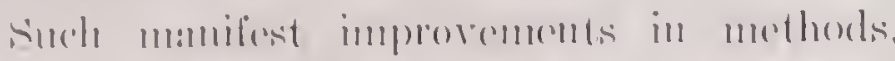

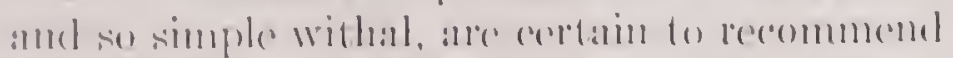

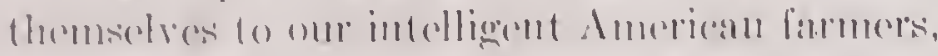

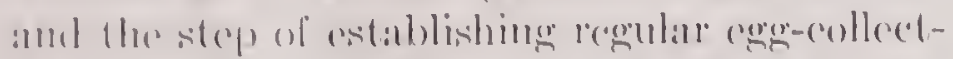

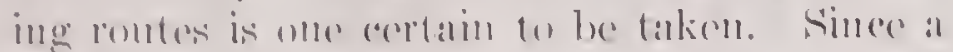

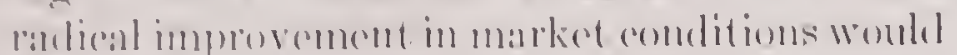
follum the astal)lishment of soleh entlectimer

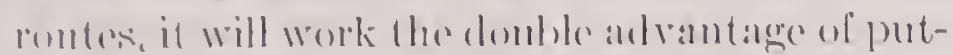

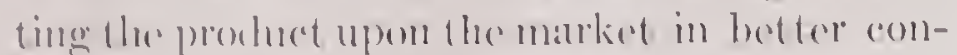

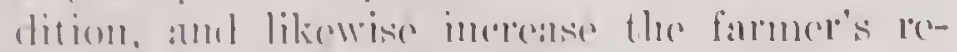
turns for his probluet.

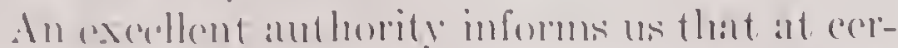

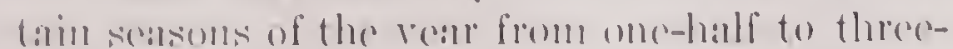

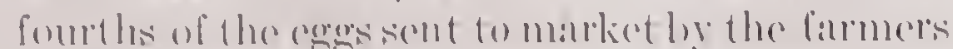

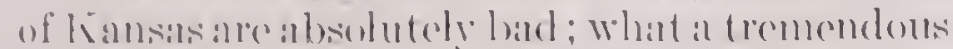
wasto! Tho remonly for this state of affatrs is simply resulate amel systematic collereling of the

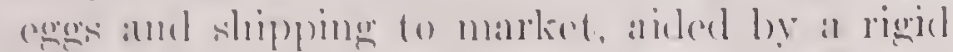

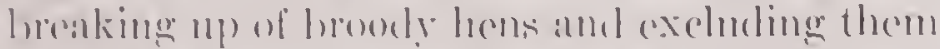

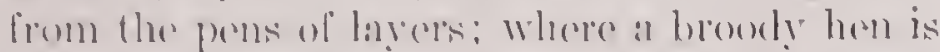

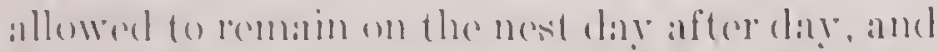

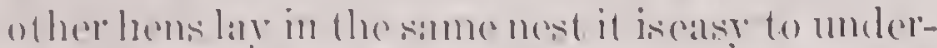

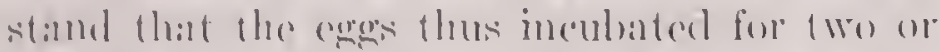

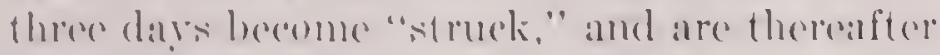
uscoless for human ford. Anothere siter in the right diroetion would ho tho killing off of all use

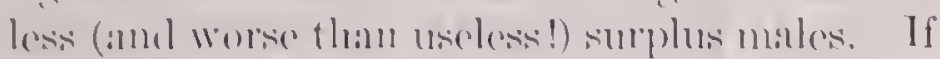

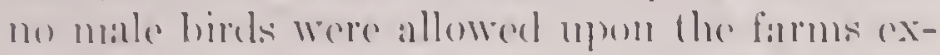

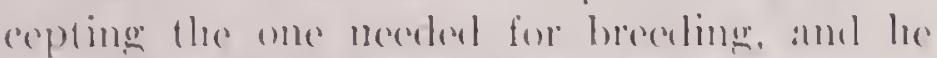
rigidly comfined to the brealing pen with the

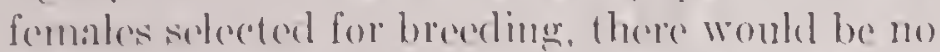

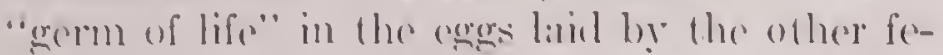

malcs, and no dangere of their egers becoming "strucele" by the gembstarting to develop), We fimbly boliove that this ovit is much more farreaching than is above indicated. It is known that the encrm of life in all owere will begin to develop in a stemly temperature of 80 to 90 de-

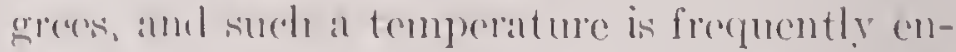

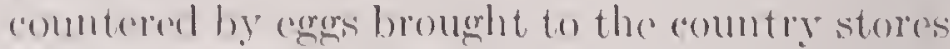
(1) Le trakel (amel quite likely lodel a wock or was hedero hoing sent forwarel to maket), and

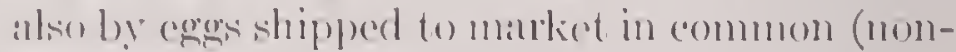
relrigurafor) froight rats; and if such a loald of reges was side tracked for a day or two in midsummmer, tho hot sum hlaxing upou it all day womkl heat it sufliciontly to stall every fortile (rege on the maty to hatchimg.

In "Inculation and its Natural Jaws," Mr. (yphors silys:-"J)uring the deseent of the egreg alomg the oriduet of the fowt. where it is expresel to a tompreature of 110 degreses or more, tho hbastoderm mulergors important dhanges. llhon the reger is laid and hecomes colel, the changes all hut entirely coase, and the blastoderme rematins inactive; meler the influcence of the higher temperature of natural or artificial incubation, the vital activities of the germe alo bromele back into play, and the arresterl changes go on again. In Warm Weather changes of the same kind as those (alused by actual incubation may take place, to a cortain extent, in the intrrval botwrenlaying and incubation," "There is the idea chaty stated, and the obvious prevention of the commeneing of life-development in the egers is the prevention of the germ of life getting into the regra the romoly is simple, lill uff the worthless (and more than worthless!) male birds, and allow mone on the fams excepting those neceled for breeding.

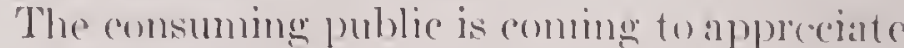
the fact that unfortilized reges aro hotter and kere better, and are payme a permimm of two or three (and reven five) rents a dozen for such ogese; when the farmers themselves come to melerstand that thoir hems will lay more ocros when not afflicted with the attentions of a male hind. there will be decidedly fewer of these permicious croatumesloft to tase and ammoy them.

Further improvement will most reetainly be made along the line of the development of the egegroducing instincts of the fowls, and what an immense improvement ean be made here! What a cain it woukl bo if all the fowls of the Luited States rould bo hrought up to even the nodest right and a half dozen coges each, of the 
fowls of the State of Maine! The arerage product of the hens of the whole United States was (by the figures of the last census), 5.5 dozen eggs each, the total egg product being 1,293,\$19,1S6 dozens; bringing the average product up to the S.5 dozens of the hens of Maine would add 700.794. 255 dozens to that total, and add $\$ 7,437,-$ 765 to the income from eges alone. How can such an improvement be brought about? By first, converting the farmer's to keeping pure bred stock, and, second, by breeding only from known great layers. By intelligently following this simple method the Maine Experiment Station has dereloped the laying qualities of its stock to a production of as high as 251 eggs in a year from one bird, and all the breeding stock in their rards are hens that have laid 180 eggs each in a year. pullets. whose mother's have laid orer 200 egos in a rear, and pullets sired by cockerels. whose mothers and grandmothers laid over 200 eggs each in a rear.

The time is not far distant when large eggfarms will be establisher, upon a commercial basis. deroted to the production of unfertilized eggs, (or "virgin eggs"), for supplying special private trade in the great citics. On such farms every bird consigned to the breeding pens will be a known great layer, and of proved greatlaving ancestry, along lines similar to those laid down in that report of the Maine Experiment Station. What a power for increasing the eggproducing habit there is in such an ancestry!
"All the breeding stock are hens that have laid 180 eggs each a year. pullets whose mothers have laid orer 200 eggrs each in one year; and pullets sired by cockerels whose mothers and grandmothers laid orer 200 eggs each in one year." Certainly the accumulated momentum of such egg-producing ancestry would be of tremendous value as compared with the hap-hazard methods of breeding. as conducted in the past. When we have developed generation after generation of great lavers. and have the egg-producing habit fixed by breeding from birds whose fathers, grandfathers and great grandfathers, whose mothers, grandmothers and great grandmothers were all of great laying stock, we shall have taken a most substantial step toward more profitable poultry. The better-shaped market bird, the chicken with longer. deeper and fuller breast, will be developed likewise. and a uniting of the two strains in one is probable, with very great adrantage to the pockets of the poultry grower and the market poultry dealer.

This, then, is what we believe will be the development of the future; a decidedly greater egg-product. a much better quality of eggs reaching the tables of consumers in known gond condition. a better quality of chresed poultry reaching the markets in prime condition, and an increasing appreciation of cags and poultry as articles of food. The great consuming public will do its part if we will but do ours, and a mighty uplifting of this great industry will result.

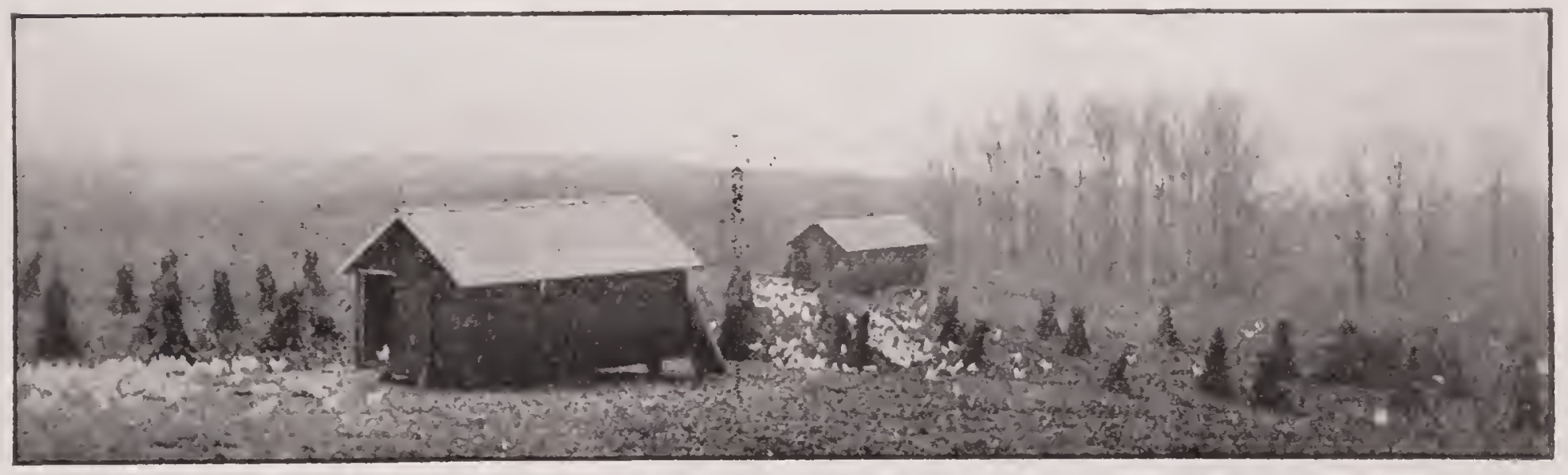

Colony Houses for the Growing Pullets, Fairview Furm. 


\section{CHAPTER II.}

\section{THOROUGHBRED, OR BRED TO A PURPOSE. THE LEADING PRACTICAL BREEDS.}

部"

hat is a thoroughbred? Webster's International Dictionary gives this definition: "Bred from the best blood through a long line; pure bloocked," and the Century Dictionary gives the definition: "Of pure or ummixed blood, stock or race; bred from a sire and dan of the purest or best blood." A well-known judge and authority on breeding thoroughbred fowls states that they are thoroughbreds which have been bred to type a sufficient length of time, so that a majority of the progeny is true to type; or, in other words, when mated they reproduce their kind.

In the introduction to Darwin's "Animals and Plants Under Domestication," we find:

"Although man does not cause variability, and cannot even prevent it, he can select, preserve and accumulate the variations given to him by the hand of nature almost in any way which he chooses; and thus he can certainly produce a great result. Selection may be followed either methodically and intentionally, or unconsciously and unintentionally. Man may select and preserve each successive variation, with the distinct intention of improving and altering a breed, in accordance with a preconceived iclea; and by thus adcling up variations, often so slight as to be imperceptible by an uneclucated eye, he has affected wonderful changes and improvements. It can, also, be clearly shown that man, without any intention or thought of improving the breed, by preserving in each successive generation the individuals which he prizes most, and by destroying the worthless individuals, slowly, though surely, induces great changes. As the will of man comes into play, we can understand how it is that domesticated breeds show adaptation to his wants and pleasures. We can further understand how it is that domestic races of animals and cultivated races of plants of ten exhibit an abnormal character, as compared with natural species; for they have been modified not for their own benefit, but for that of man." How rich in suggestion is that sentence,- "By preserving in each successive generation the individuals which he prizes most, a breeder slowly but surely effects great changes." Preserving those individuals which we prize most is one form of "selection," even if wholly unconscious selection.

From the article "Breeding," in the Encyclopechia Britannica, we quote:- "Since a breed is a domestic variety, it implies the existence of a group of individuals marked off from their congeners by the possession of certain characters which are transmitted to their offspring. It is this transmission of peculiarities which is the essential characteristic of a breed; for any collection of domesticated organisms could be divided into groups of individuals, distinguished by certain points, but such groups would not necessarily form breeds. It is evident, then, that the law of heredity which asserts that like begets like' must hold good, or the existence of breeds will be an impossibility." * * * * "Whatever views we may entertain, respecting the origin of our domestic animals and plants, there can be no doubt as to the matter of fact that breeders have alwars proceeded on one principle,--select the best indiriduals in each generation and pair them."

Speaking upon this point, Wright's "New Book of Poultry" says:- "Every desired quality which has become characteristic of a lace or strain of animals, is the result of repeated and continuous selection year after year of breeding stock which possesses that particular quality in more or less perfection. This is equally true, whether we consider some purely 'fancy' point, such as the pencilling of a Hamburgh pullet, or some useful quality such as the laying of over 160 eggs in a year; or the profuse milk yield of a highly bred Jersey cow."

From this it is perfectly evident that birds which have been persistently bred for egg or meat production, may as rightly be called "thoroughbred," (if they have been bred to the type a sufficient length of time to have acquired the 


\section{THOROUGHBRED, OR BRED TO A PURPOSE.}

power of transmitting those characteristies to their offspring), as though they have been bred solely for the points which win ribbons in the show room. "It is the transmission of peculiarities which is the essential characteristic of a breed," and the peculiaritics transmitted mav just as well be the great laving or great meat producing qualities. The essential point is that we "select" the birds possessing the desired characteristics, and then we accomplish our purpose of cleveloping and perfecting the power of transmission of those peculiar characteristics.

To make the best success in his individual rork the poultriman must study the situation, learn the requirements of his especial field or market. and choose a breed or variety which will best meet those requirements. He should consider whether he is to build up an egg-farm pure and simple, or combine eggs and meat or eggs and fruit production, and choose accordingly; after he has made his choice he can, by "selecting" the individuals best adapted to his purpose, greatly improve and develop the preferred characteristics. The gratifying success in dereloping the egg-producing faculties of the stock at the Iaine Experiment Station, is rich with pronise, and indicates what may be done by continued work in that field, and work being clone at the Ontario Agricultural College Experimental Station, in the direction of dereloping an improved market poultry type of bird, is equally promising in that field; certain it is that persistent effort in these two ficlds will be richIy rewarded.

This is an age of specialists, and the man succeeds best who chooses some one line of work and devotes all the energy with which he is endowed to the development of that chosen line. If ego-production is his specialty he should choose a variety known to be prolific layers; if market poultry is his specialty he rill need to choose a variety best adapted to the special line of trade he caters to, and if he desires to combine both egg and meat production, he can choose a variety combining both the tro qualities to a very considerable degree. After he has chosen he can better his profits by selecting the best birds and breeding from them, as the Maine Experiment Station people are doing in breeding from "hens that have laid 180 eggs each in a rear, pullets whose mothers have laid over 200 eggs in one year, and whose fathers' mothers laid over 200 eggs in a rear; and pullets sired by cockerels whose inothers and grand- mother's laid over 200 eggs each in a year" -or in following the similar line of work with the best type of market poultry bird, generation after greneration, as is being clone at the Ontario $\mathrm{Ex}$ periment Station. Persistent rork along these lines, carefully and intelligently followed for generations, will intensify and develop the peculiar characteristics selected, and increase the profits from the practical poultryman's work.

A point in this connection that is worth noting is that there is a rapidly growing demand for breeding stock and eggs of birds of known excellence in practical quality, and at prices which compare farorably with the prices paid for stock bred solely for show-points; there is good proof of this in the willingness of buyers to pay two and three dollars per sitting for eggs from known great lavers. We recently received a letter from a breeder who advertises stock and eggs for sale, asking where a good male bird of assured great laying ancestry could be bought, and stating that he would gladly pay thirty dollars for such a bird. When we recall that great prices are paicl for heifers from great milk-producing dams and bulls of great milk-producing ancestry, we can well believe that there will soon come a time when cockerels and pullets of great laying ancestry will be as eagerly sought for and will fetch as good prices as do the winnels of the blue ribbous at our poultry shows.

\section{The Leading Practical Varieties.}

No one variety of fowl is perfect; while all varicties have practical qualities of more or less merit, some have more than others, and the wise choice is to select the one that possesses most adrantages, coupled with ferest disadvantages. We say "select the one" adrisedly, because the commonest mistake made by the beginner in poultry work is to take up two or thrce (or half a dozen) varicties, with the mistaken idea that he will learn by experience which one is the best for him and then keep only that one. The ordinary life of a man is none too long a time in which to fully master and develop to its best all that there is in one rariety of fowls, and the man who takes up several has not time to carefully study their various good points; he gets at best but a superficial knowledge of them, and will find himself at the end of a few years, in the unfortunate position of the man who is "A Jack of all trades but master of none!" Besides all of that ground has been gone over again and again, the qualities of all varieties have been fully 
tested and discussed publicly for years, hence all that is necessary is to intelligently survey the field, decide what special merits one wants in a variety, and concentrate all one's energies and ability upon the further development of those merits; he will then find that one lifetime is all too short for him to accomplish his fullest ambition.

We give in this and the following pages, illustrations and brief descriptions of the most popular egg-farm breeds, and the best combined egg and meat producers, the exigencies of space limiting our selection to those that the experience of practical poultrymen approves as the best. We will consider the White Leghoms and Black Nimoreas as the great ego producers,

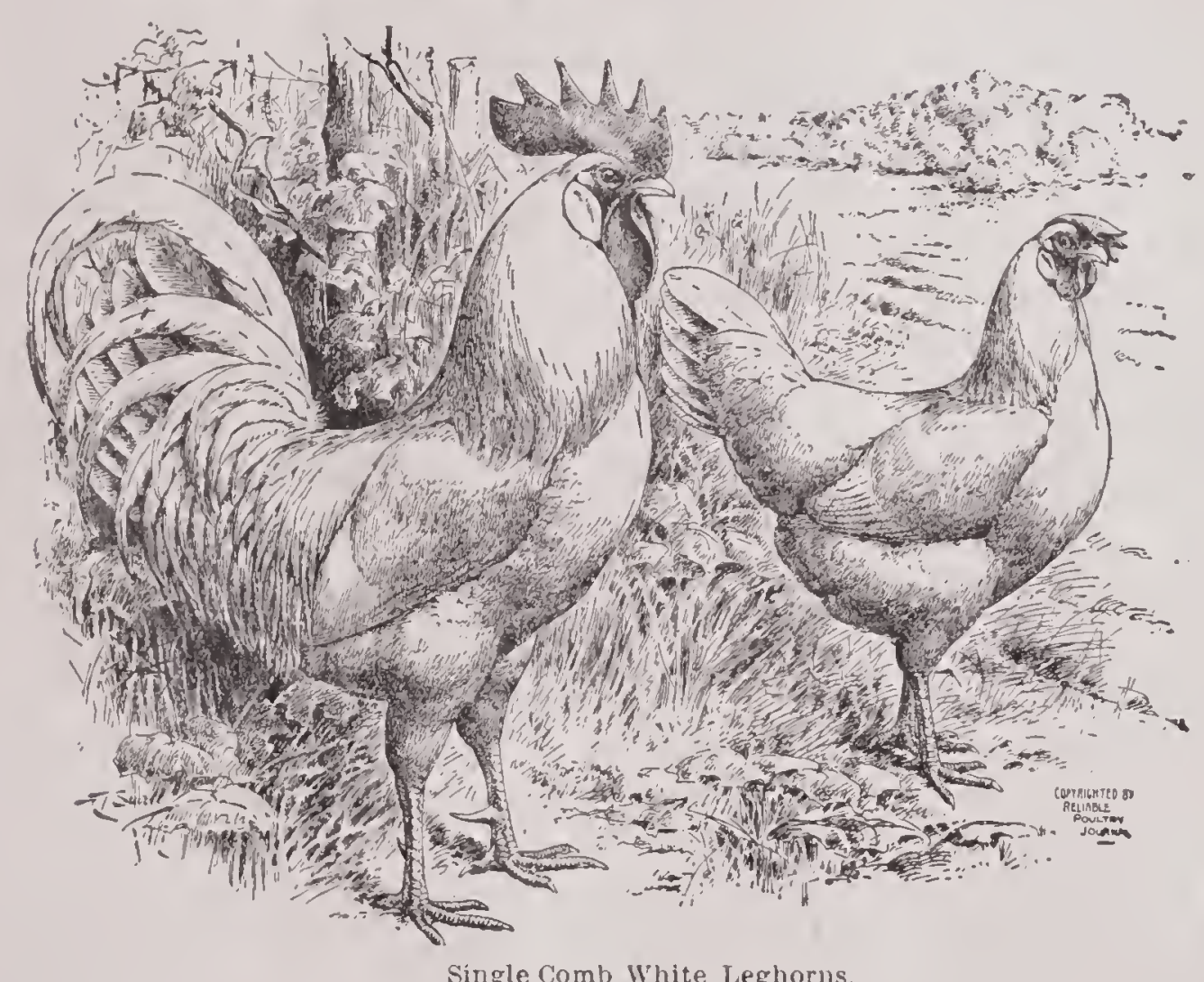

and the Barred. White and Buff Plymouth Rocks White and Buff Wyandottes, and Rhode Island Reds as the best combined eggs and meat varieties; with a brief mention of Orpingtons and Light Brahmas.

\section{Single Comb White Leghorns, the Most Popular Egg-Farm Breed.}

The White Loghorn is the popular egg-farm breed, especially on the large and highly successful egg-farms of New York State and New Jersey. They are prolific layers of good-sized, white eggs, non-sitters, mature early, and are especially hardy. They are of an active, nervous temperament and naturally great foragers, but do well in semi-confinement. excepting that it is somewhat difficult to confine them in yards; some Leghorn breeders find it necessary to cover over the tops of the yards with old fishnetting, to keep the male birds where they belong.

When bred with a special view to good size they are fair meat producers and in some parts of the country, particularly in Southern New Jersey, they are extensively bred for the production of squab-broiler's broilers and small softroasters. As however, the cockerels begin to grow "hard" very early, they must be fatted and marketed by the time they dress five to six pounds to the pair, and we need to keep in mind that while they can be thus made into profitable market poultry, they are first and alwars an egg-breed, and their market poultry value is of ninilor consideration

The White Leghorms are particularly attractive fowls, their clear white plunage. bright red combs and wattles. white earlobes, clear eyes, smooth, yellow lears, lomg. full tails, sprightly, active manner, and graceful carriage make them favorites with lovers of beautiful fowls.

The Leghorns are nonsitters, hence do not trouble or annoy their owner's by frequently becoming broody. This is of very great advantage to the egg-farmer, whose object is to profuce guaranteed fresh eggs, as there is no danger that a broody hen will snuggle down upon the eggs and start development of the germ of life before the eggs are collected. The greatest advantage, however, is that egg-production is not interrupted by attacks of broodiness, and the Leghorn hen attends strictly to business without the owner haring to be continually fussing with broody hens. Although naturally timid and very active, Leghorns can,with good care and judgment, be easily managed, and there is no need of their becoming "wild" birds.

The egg-farmer keeping Leghorns, finds incubators and brooders a necessity for hat ching and raising the stock, and this has a good effect on the disposition of the birds, for their naturally timid, nerrous temperament is softened and 
subdued by the familiarity with the caretaker which comes of the artificial raising.

The various families of Leghorns are the common fowls of Italy, and owe the name by which they are popularly known in America and England solely to the fact that they were brought to this country from the port of Leghorn, in Italy. They were bought up in the markets of that city by the captains of America n ships, homeward bound, to furnish eggs and an occasional roast or boiled fow for the cabin table on the voyage; to the simple fact that some of these common fowls bought in Leghorn were not used on the rovage and were sold when the ship reached New York, they are indebted for their introduction into this country and the name given them. Having won the reputation of being great layers, it is small wonder that shipmasters were instructed to bring orer more "Leghorns" and direct importations began, but that they were very much mixed is proved by the fact that the same matings threw both rose and single-combed birds, and the fowls were of various colors.brown, white. black. buff and cuckoo. To American breeder's belongs the credit of separating them into distinct families, and by selection and careful breeding bringing forth the distinct varieties now so well and favorably known. In the little pamphlet "The Leghorn," by F. H. Ayers, the Brown, (then called "Red"), Leghorns are reported as being wonderful layers, and Mr. L. K. Felch is quoted as anying of them: "These fowls as egg-producers were truly marvelous. I have known of a hen, of the original importation, laying one hundred and fifty-nine eggs in succession, and have the assertion of a friend that one laid two hundred and seventy-five eggs in a year; but the largest number of which I know personally, and which I deem very extraordinary, was two hundred and fifty. An arerage has been in my experience from one hundred and seventy-five eggs to two hundred in a year. With good care two hundred eggs may not be despaired of."

With such a reputation as great egg producers, it is not at all strange that the Leghorns

became the approved egg-farm breed, and as the White Leghorns were the simplest and easiest to breed, it became the most popular variety.

\section{The Black Minorcas.}

STANDARD WEIGHTS.

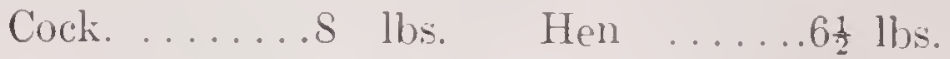 \\ Cockerel. ... 6. $6 \frac{1}{2} \mathrm{lbs}$. Pullet .... $5 \frac{1}{2} \mathrm{lbs}$.}

The Black Minor'as are less well-known than they should be, in fact, as an egg-farm breed the writer does not recall ever having found them used on a large scale. This is somewhat surprising in view of the fact that they are credited with being equally prolific layers with the Leghorns, and that they lay a large white egg; this would secm to especially qualify them for use on egg farms which are catering to a particularly select family-trade. a trade which is willing to pay a considerable premium for an especially nice article.

There is little loubt that the Black Ninorca of torlay is, practically. the "Spanish" of forty or fifty years ago, - the time before the several sub-varieties of Spanish were developed. In the White-Faced Black Spanish, which retains the fanily name, the special derelopment of the eccentric and abnormally large white face has practically annihilated the useful qualities of this famous variety. and it is not impossible that this fact has in a way been a handicap to the Black Minorcas. The latter, however, secm to have preserved the natural practical qualities of the race and retain the prolific laying habit, along with the natural strength and vigor, 
active, nervous temperament and good size for which the family is well-known.

Speaking of their naturally good qualities, Brown's "Pleasureable Poultry Keeping" says: "The Ninorea has, during the past fifteen years, won a very prominent position, and taking the number and weight of eggs, it is probably the most prolific fowl we have. It lays large, white-shelled eggs, and hens of this variety in their first year often arerage 170 and 180 eggs."

In addition to the number and size of Black Ninorca eggs they are to be credited with beginning to lay at a very early age, and continue to be profitable layers for a longer period of time than almost any other bird of which we have knowledge. They are excellent foragers, strong and active, always on the alert for any natural advantages that come within their reach, and having little tendency to lay on fat, the food they consume gives profitable returns in the form of eggs.

The white skin, somewhat marred by the black pin feathers and black legs, is a handicap from the market poultry standpoint, but the flesh is of an excellent flavor, deliciously tender in the younger birds, and with such a considerably larger amount of flesh than is found in the Leghorn it is, as we stated, a matter of a surprise that the Black Minorca is not more generally utilized as an egg-farm breed.

\section{The Plymouth Rocks.}

\section{(Barred, White and Buff.)}

STANDARD WEIGHTS:

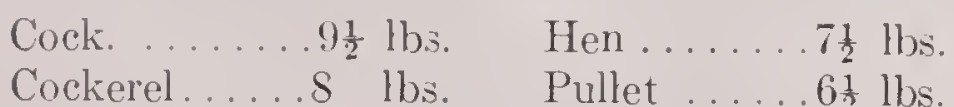

The Plymouth Rocks are pre-eminently an allpurpose breed. They are not only great layers of good sized brown eggs, but they take high rank as meat producers also. For egg-farm purposes it would be difficult to name a breed combining great laying ability with meat producing qualities in so high a degree, and they are a most satisfying bird in every sense of the word. The Plymouth Rock is a "made" breed, and originated in a cross of an American Dominique cock on black Java hens. The "Cuckoo" marking of the original Plymouth Rock was received from the Dominique male, and the size, station, single comb, etc., from the dam. It is practically certain that the blood of other breeds has now and then been introduced into the Plymouth Rocks, which has given them size, type, greater uniformity of plumage and the desirable yellow beak and legs. Their remarkable hardiness is one of their strongest claims to popular faror; being an American breed, accustomed for many generations to the extremely changeable and trying New England climate, and being thoroughly acclimated, they would be placed among the very first for hardiness and vitality. Writing of them nearly twenty rears ago, the American Poultry I'ard said: "The perennial popularity of the Plymouth Rock is something wonderful to those who do not know its real merits, but to those who do, to those who know that it is hardy, healthy, vigorous, prolific, excellent for the table and thoroughly adapted to the requirements of an American market and an American climate, there is nothing wonderful at all."

\section{The Barred Plymouth Rocks.}

The Barred Plymouth Rocks, the original of the several varieties of Rocks, are the most popular and most widely bred rariety of fowls in the world today. They enjoy the distinction of being the first breed of domestic fowls produced in America, and their eminently practical qualities have won for them and their sterling merits have held a place in the very front rank of popular favor; they are noted for being bred by a greater number of persons and in greater numbers than any other one variety of fowls.

"The Barred Plymouth Rocks commend themselves to the lovers of useful breeds. Of all our domestic fowls, this breed stands the highest for general purposes. They almost vie with the Asiatics in size, the Leghorns in egg production, the Dorkings in quality of flesh, and the Dominiques in hardiness and adaptation to climatic changes. They combine more useful qualities than any other breed known to us, and fill the void between the size and weight of the Asiatics and the European fowls."

Mr. E. B. Thompson, of Amenia, N. Y., a wellknown Plymouth Rock expert, writes of the Barred variety: "The Plymouth Rock is a product of American skill and breeding, and there is no other variety we can put on the markets of the world with so much pride, and none other is received at our shows by foreign fanciers with so much favor. They have taken their place at the front without need of booming, and today stand acknowledged without an equal, as the 
best general-purpose fow $\mathrm{l}$. They are rapid growers and make plump, juicy broilers at from eight to twelve weeks old. They have no successful rival among the pure breeds as a market fowl. Ther are great favorites with farmers and market merr, who breed this variety more extensively than all other pure breeds combined. The popularity of the Plymouth Rock as a fanciers' fowl has nerer been reached by any other breed. Its popularity is based on its practical utility worth, and as a practical-fancy fowl, the Barred Plymouth Rock has come to stay. They are excellent all the rear round layers. and will lay as many egges as any breed that incubates and rears its young. In some of the smaller breeds we may get better layer's but less size. The larger breeds give us no more eggs, if as many, and are later maturing and lack the sprightliness and elasticity of movement so much admired in the Ply-

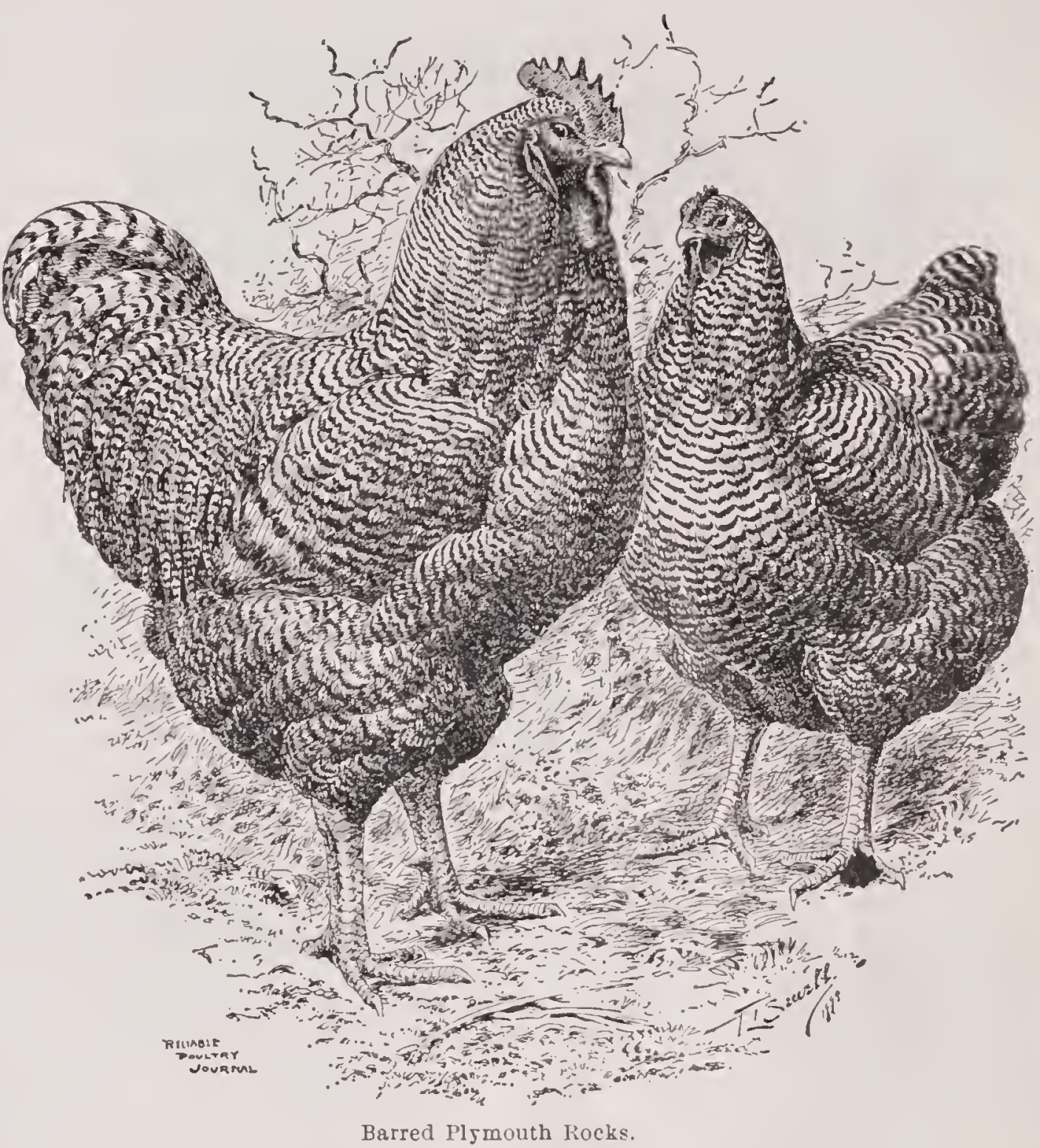
mouth Rock. The Barred Plymouth Rock class at our American shows is nearly alwaỵs the largest, and the birds usually command a higher price than any other American breed, which proves their sterling nerit.

"New breeds have come and gone, but the Barred Plymouth Rock with its good qualities remains invincible. They are practical fowls, well suited to the wants and conditions of those who desire eggs, meat and feathers combined in one breed."

The general verdict of Plymouth Rock breeders can be encompassed in the words of a noted fancier and judge. "The Plymouth Rock is. beyond all question, the best general-purpose forl of all the breeds before the public. They have been before the public many years, have borne the competition of other fowls, have been subjected to every test that fowls could be subjected to,and have come out of all these trials still as much praised and as much liked, both by the fancier and general public, as when they were first known. Two things are demanded of the

perfect fowl-a large amount of good meat when on the table, and a large laying capacity. It is safe to say that no other breed combines these two qualities as well as the Plymouth Rock. There may be hens that will lay more eggs, though we doubt it. Taken weight for weight, we have never seen the fowl that could equal the Plymouth Rocks, and certainly no fowl surpasses them for table use. They are a beautiful breed, combining with their large size, beauty of carriage to a degree not common with fowls: The only fault that can be found with them is the tendency to breed back to show some of the characteristies of the breeds from which they are derived; but those showing only the best points should be kept for breeding purposes. For the farm no fowl is equal to the Plymouth Rock."

\section{The White Plymouth Rocks.}

The White Plymouth Rocks originated as sports from the Barred. It is no uncommon thing for parti-colored fowls to throw now and then a 


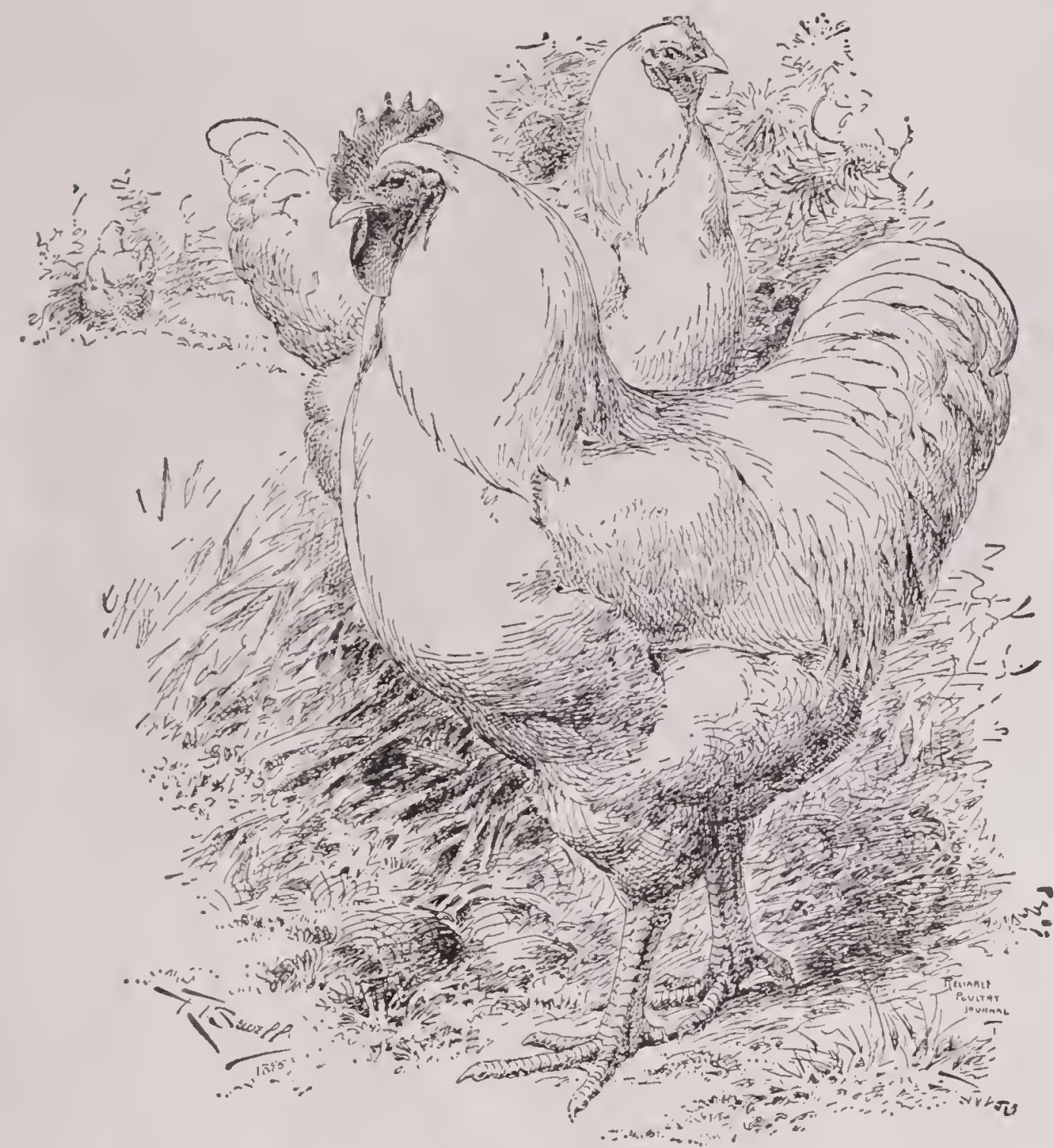

White Plymouth Rocks.

white chick, and to Mr. O. F. Frost, of Maine, is given the credit of first "mating" a male and female of these white sports, and by careful selection of the whitest of their offspring for breeding the pure white color became fixed and they now breed true. "Like their excellent progenitors, the White Rocks are plump, compact, full breasted and bodied forls, hardy and rigorous, great layers and excellent flesh formers, handsome in looks and carriage, showing well on the lawn or in the exhibition coop. The name itself will be a passport to popular faror. for whoever has heard of the noted Barred Plrmouth Rocks will take it for granted that their offspring must be a 'chip of the old block,' and they will be found worthy of a place in the front ranks, where beauty and utility go hand in hand."

It is the combining of beautr and utility that most strongly recommends a breed or variety to popular faror, and in the White Rocks the two qualities are combined to a remarkable degree. On the beauty side their fine, stately carriage, clear white color, bright red combs and wattles, with rich yellow beak and legs, make them of most attractive appearance; while on the utility side their great laying ability combined with good size of body and fine quality of flesh, make them equal to the best. In view of this strong combination of undoubted merits, it is not at all strange they are a very popular variety.

\section{The Buff Plymouth Rocks.}

The Buff Plymouth Rocks, like the senior variety, the Barred, is a macle variety and it is not improbable that there are some strains of the variety that are of entirely different origin from others. The earlier strains of Buff Rocks were undoubtedly made by mating Single Comb - Rhode Island Reds with White Rocks, and breeding back and forth within those matings until the desired size, color and shape became (comparatively) fixed. In spite of the fact that the origin of Buff Rocks is so well known we have recently seen it stated that there was no Rhode Island Red blood in them, that they originated in a cross of Buff Leghorn male on Buff Cochin females, and the tendency to feathcred legs bred out of them; it is probable that some strains of Buff Rocks were thus originated, but the Rhode Island Red paternity is well known, and the great laying ability combined with vigor inherited from the Reds, has made a variety that makes a strong claim to popular favor, based upon both the utility and beauty qualities. Dr. O. P. Bennett, in the Reliable Poultry Journal, sars: "As egr producers I found them superior to the larger breeds, and with proper care ther will equal the smaller and non-sitting breeds-they lay their eggs in the winter when eggs are most raluable, and they keep at it, too. Buff Plymouth Rocks are cxtremely hardy, are good foragers, and in size many of them equal Asiatics. They grow rapidly, mature early and are ready for market at any time, retaining their plumpness during their growth. When dressed they present a very neat appearance, having a nice yellow skin, legs and 
meat, and there are no unsightly dark pinfeathers to mar the carcasss; their meat is rich, tender and toothsome."

\section{The White and Buff \\ Wyandottes. \\ Standard Weights.}

Cock, $S \frac{1}{2} l b s$

Cockerel, $7 \frac{1}{2} 11 \mathrm{ss}$

Hen, $6 \frac{1}{2} 11 \mathrm{ss}$ Pullet, $5 \frac{1}{2} \mathrm{lbs}$.

The Wyandottes are like Plymouth Rocks in that they are a made breed and are American made, and they compete with Plymouth Rocks for first place in popularity, as all all-purpose fowl. As egg producers they are quite the equal of the Plymouth Rocks, and lay the brown egg much desired in most of the great markets. They are a pound lighter in weights, which is a handicap when size only is considered; but when we remember that the difference in size is largely in frame (which is waste), and that the particularly plump, full-breasted carcass of the Wyandotte is heavy in the quality of meat most desired, it will be seen that the advantage is with the Wrandottes. The fact, too, that the plumpness of body is attained very early in life is decidedly in their favor, particularly as a broiler chick and soft roaster, since they avoid the undesirable length of leg and thinness of flesh which makes some of the larger varieties so undesirable during chicken size.

The Silver Laced Wrandottes were the originals of the several families of the.name. and the Silver Wyandottes were the result of several crosses; which accounts for the unusual excellences of the breed, since they combine the good qualities of several different varieties. The original stock was derived from a cross of Silver Spangled Hamburg and Buff Cochin, and they were at first called "Sebright Cochins." As woukd naturally be expected, both single and rose combs, and likewise feathered and clean legged birds were the result of early matings. Later, a cross of Silver Spangled Hamburg and Brahma appeared, and a uniting of the two different strains produced a superior type of fowl,

which was admitted to the standard under the name of Wyandott in 1893.

The making of a Buff-Laced variety of Wyandotte, which was given the name of Golden $1 \mathrm{Yy}$ anclotte to distinguish it from the first variety, which was called Silyer Laced, was followed by the breeding of white sports which appeared from the Silvers; these ponduced the variety called White Wyandottes. The difficulty of breeding a laced feather, with a black edge and clear white or clear buff center. was a handicap to the silver and ciolden varieties. and as the White variety possessed all the economic nerits of their predecessols, and added to their remarkable attractiveness the quality of breeding true to type. they soon distanced their older sisters in popular favor, and have becone close rivals of the Barred Rocks for first place in popularity as an all-purpose breed.

Writing about them in his book on the Mryandottes, published in 1891, Mr. Joseph Wallace says:

"As egg producers and table fowl, the W'Thites are equal to the Laced. They have the same plump bodies, constitutional vigor, physical beauty, commanding carriage, standard points, and the only difference is the color. They can be used at an early age for broilers and roasters. The adult males will weigh from seven to eight pounds, and the females from six to seven pounds. These weights, in a comparatively 


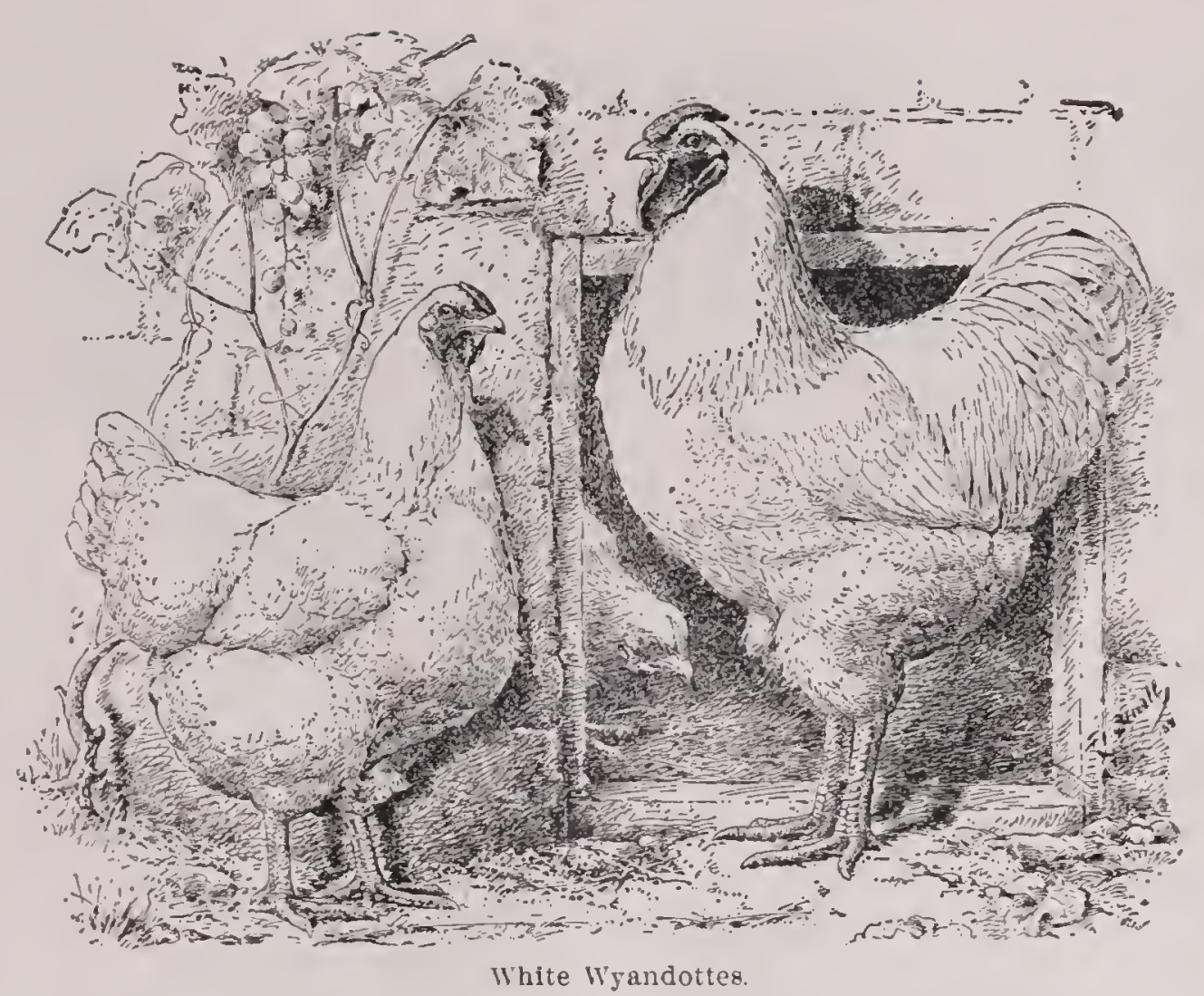

color of the meat and skin is of that attractive vellow so much in demand in our markets. It has the combination of attractive shape and color, and the white plumage remores all chance of prejuclice so often advanced against dark pin feathers, thus giving it three very important advantages for sale as market poultry."

Mr. Arthur G. Duston of Marlboro, Mass., a man of extensive personal experience in the production of broilers, sars: "The White Wranclottes stand heary feed and forcing better than any other variety; will produce a two-pound broiler in eight weeks, and they will stand on their

short and clean-limbed fowl, indicate a solid, compact flesh-former, with little offal.

"Although utility is the leading merit and strongest recommendation to all interested in poultry keeping, the Whites are also a clean cut and comely variety. This is associated with their usefulness; and no breeder speaks of one without coupling it with the other, as by common consent ther are pronounced a handsome variety of fowl. In the showroom or on the green lawn they are pretty and attractive. White breeds having bəen comparatively rare until the past clecade, the color is always pleasing to the beholder, whether he breeds fowls or not; and the only reason that can be given now for the sudden change of mind in breeding and booming the white varieties is that they have become popular among the people by reason of fanciers' catering to the tastes of the masses. The rich, red comb, like a full blown rose growing on the head, red face, ear-lobes and pendant wattles, contrasting with a white plumage and yellow legs, is both pleasing and attractive."

From Bulletin No. 31 of the U.S. Department of Agriculture, written by T. F. McGrew, we quote the following paragraph on their utility qualities:

"The White Wrandotte is without question the model for market poultry. The compact form and full, plump breast give the desired broiler as well as the most perfect roaster. The legs where Plymouth Rocks would be rolling on their sides with the same food. $B y$ continuing the regular food we have made five and five-eighths pound roasters at fifteen weeks." There could hardly be a stronger argument in farol of the White Wyandottes for broilers and roasters than this. Such results can only be produced by knowing how, and by a common sense application of the knowledge; but what one man has done another may do.

We again quote Mr. Duston: "Their good qualities are many. Deep, short bodies, stout legs, a close comb that withstands the extreme cold weather better than a single comb will; a hardy bird that matures in five and six months; rellow legs and skin; lars a brown egg; a splendid family fowl. On the lawn their white plumage and red combs make a picture with the green grass for a background, and a fancier will find in them full use for all the experience he possesses to breed them to standard requirements. I have sold hundreds to dress eight ounces and ther were as 'round as a butter ball,' this being one of their most important merits, that when properly ferl they are always ready for market. As pullets the White Wrandottes mature a full month earlier than the Plymouth Rocks, thus giving eggs for early hatching."

The Wyandottes are easily confined by a fourfoot wire fence and do well in confinement. On range they are particularly good foragers, and on the farm if given their freedom will pick up 
a large part of their living. They make excellent sitters and mothers. Being very hardy anc exceptional layers of strongly fertilized eggs they are readily adaptable to hatching and raising by artificial means. There is nothing prettier or that will appeal more promptly to the heart of a poultryman than an incubator full of sturdy; downy white chicks

Mrs. J. 1). Barnes of Wenham, Mass., sars: "There is no breed like the White Wrandotte for eggs, for broilers anch roasters, and for exhibition. We raise nearly all of ours in brooders, as they grow faster. do better and look better than when we use hens."

\section{The Buff Wyandotte.}

Coming into the field at a later day, but possessing remarkable elements of popularity, the Buff IVyandottes are pushing to the front as an all-purpose variety; they are proving themselves great larer's, are plump, full-breasted broilers and soft roasters; they are equal to the best. and their attractive golden-buff phumage, with bright yellow skin and legs, marks them as destined to reach the first rank in popular faror.

The Buff Wyandottes, like their Silver ancestors, had two or three different origins, and it is certain that Rhode Island Red blood was used in the making of them, just as in making the Buff Plymouth Rocks. In the U. S. Bulletin on the Wyandottes, Mr. McGrew speaks of the Buffs as being formed from a WrandotteBuff Cochin cross, others being from a Rhode Island Red-Wyandotte cross and others from still different crosses, and says:

"The Buff Wyandotte is nearer related to the Asiatic family than any of the older Wyandotte varieties, as the latter were crossed again upon the Cochin to gain the desired color. The original Fall River strain (so-called) came as the result of an unguided cross of Silver-Laced Wyandottes and Rhode Island Reds. The Rhode Island Red, a cross-bred farm fowl, in union with the Wyandottes, which were placed among the Reds to advance their value as market poultry gave a product that was molked into the proper form and color for the Buff Wyandottes. The Rhode Island Red was largely descended from the early Asiatics, and thus gave renewed strength to these later blood lines, and adding to, rather than detracting from, the tendency toward Asiatic form. This strain was badky handicapped with black in tail and wings, an inheritance from both ancestors. The union of these two strains gave strength and character and better color.

"As an all-purpose fowl, or the combination egg and dressed-poultry producer, the White and Buff Wyandottes would be very hard to outclass."

\section{The Rhode Island Reds.}

The Rhode Island Red, as its name indicates, originated in Rhode Island and is red in color. Unlike some of the other breeds we have been considering, it was not so much "made" as the result of rather promiscuous crossing, and it is of decidedly mixed ancestry. The story is interesting. $\mathrm{Nr}$. Wm. Tripp of Little Compton, R. I., and Mr. John Nacomber of the adjoining town of Westport, Mass. both drove teams to New Bedford as marketmen, selling dressed poultry and eggs. Desiring something better than the common fowls of that region, they began crossing different strains to get better layers and also better looking poultry for the market. Mr. Tripp is said to have bred his 


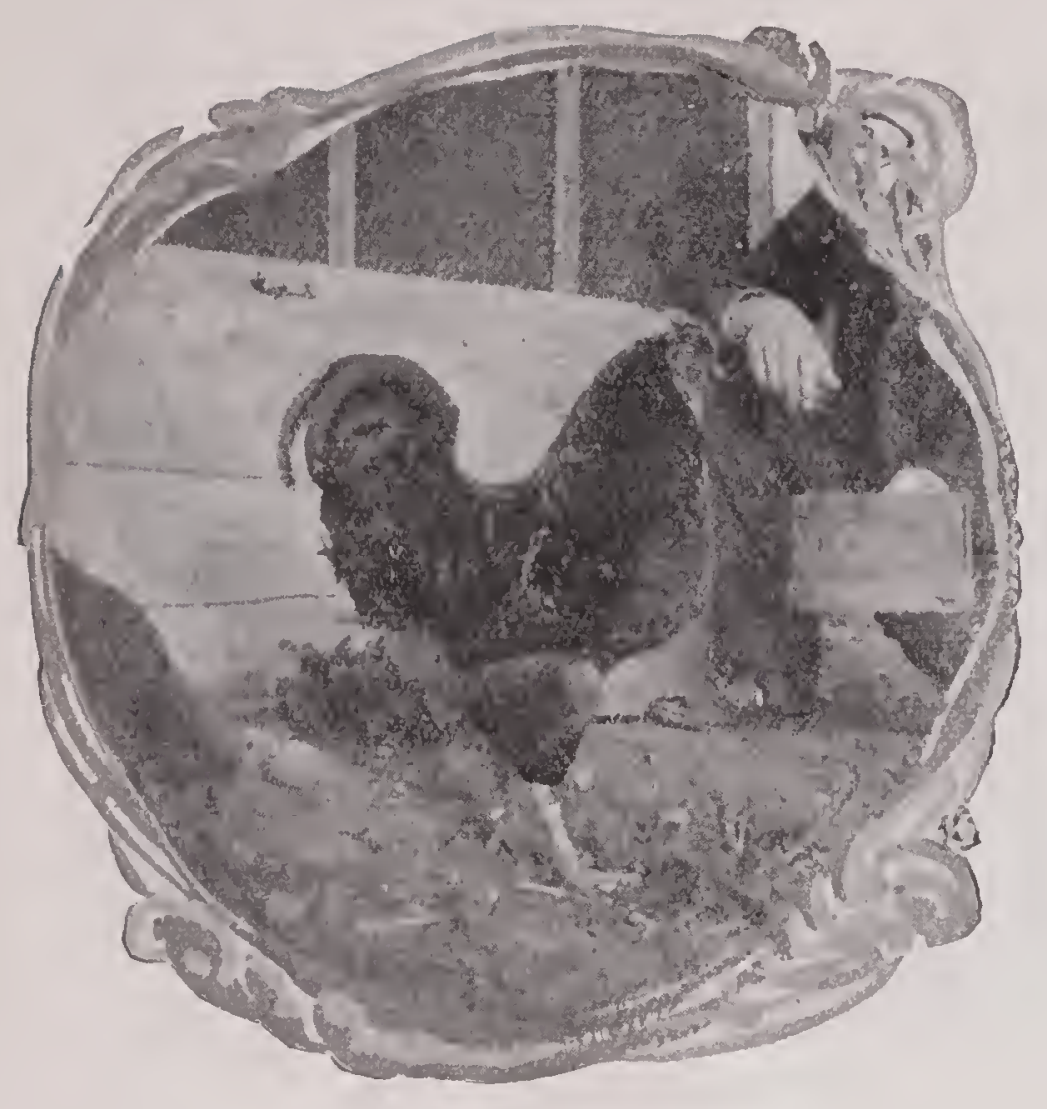

Rhode Island Red Cock,

Bred By P. R. Park, Reacling, Mass.

birls from a Malay-Brahma cross, while Mr. Nacomber got his from putting a Chittagong cock with pullets he had raised from what was called the Cochin-China. The result of a uniting of these two varieties proved so satisfactory that they kept on improving them by selecting the best laying pullets and cockerchs and in that way improved their laying qualities and got birds that would dress off with the best appearance for market forms. As would naturally be expected with so much Asiatic blood in them most of the birds had feathered legs and feet, but by continuous picking out both pullets and cockerels that were clean legged, and also those that had the brightest yellow legs, the objectionable characteristics were gradually eliminated. A visit to the Tiverton, Little Compton and Westport farms on which the Reds are so extensively raised, shows them as breeding all sorts and conditions of legs and combs. and Mr. Isaac Wilbur of Little Compton, who usually wintered four thousand of them. once told us that he commonly got clean legged and feathered legged, also single-comb and pea-comb birds, from every hatch.

A Dr. Aldrich of Fall River became interested in this popular farm-fowl, bought a few pullets and cockerels and exhibited them at New Tork in 1892, and won prizes on them there in the miscellaneous class as "Rhode Island Reds."
With the reputation of being most prolific layers of good brown eggs and of being plump bodied and fine meated it is not strange that they have proven very popular as all-purpose forls. Writing of them in the Reliable Poultry Journal of November, 1901, Mr. Theo. Hewes say"s:

"In our candid opinion there is a great future for the Rhode Island Reds. The fowl itself is attractive. It has a deep keel-bone, plenty of meat in front. good hams and stands woll up on its legs. The females are remarkably good layers and keep at it almost constantly both winter and summer. Ther make good mothers and. orring to the amount of crossing that has been done to bring them as near perfection as they are, they have all the rign of several breeds in one. in fact it is so great that a large per cent. of the egge hatch and ninety per cent. of the chicks hatched should live. This is not exaggerated in the least, especially when proper care is given in the management after the chicks are hatched. The vigor of the roung chicks is something remarkable and their growth to maturity is rapid and they are laring eggs before other breeds begin to think about it. Still, they are heary cnough for table fowls and in some cases are heavier even than the Wyandottes or Plymouth Rocks."

\section{The Orpingtons, Black and Buff.}

An English variety named Orpingtons, because originated at Orpington House-Farm, is giving evidence of great practical qualities and has decided merit as a combination eggs and meat breed. There are several varieties of Orpingtons, the Blacks and Buffs being most popular; and of the Blacks and Buffs there are both rose and single-combed rarieties.

The Black Orpingtons were the first originated. and were made with the intention of creating an all-purpose fowl,- that is, a fowl that would combine the qualities of great laying ability with superior meat production. In making the Black Orpingtons, Black Minorea cocks that had red ear-lobes were mated with some black Plymouth Rock pullets. which were sports from American Barred Rocks, and with the choicest pullets of that cross was mated a good Langshan male of the old, short-legged type,-the tendency to feathered shanks coming in with the Langshans was bred out by selection and careful breeding. The result was birds that were unusual late-autumn and winter layers 
of brown-shelled eggs, and also fine bodied, long-deep breasted, white-skimmed birds.

The Buff Orpingtons were similarly made by crossing Golden Spangled Ha m bur cocks on Dorking hens, and mating a Buff Cochin cock with the pullets of the first cross.

The Orpingtons have all the strength and rigor of erossbreds, and as egg producers. especially in autumn and winter, when eggs bring the highest prices, they are remarkable; they lay also the brown, or brown-tinted eggs which are much preferred and command a premium in the market. In size they rank about with the Plymouth

Rocks: but are naturally somewhat shorterlegred, and of a more chunky-bodied builı, with the round. full breast which indicates strength and rigor and gives an abundance of bereast meat. One disadrantage which ther have for Americans is the white skin and legs, and so long as the consumers prefer rellow skinned and yellow meated fowls, it is the part of wisdom of the producers to cater to that preference. There would be little difficulty in orercoming this handicap with the Buff Orpingtons, since a pure buff variety naturally firvors the rellow skin, hence breeding and feeding for yellow skin would soon give them that desired quality. It might ba objected that when the boeeder had accomplished this purpose his birds would no longer ba Orpingtons, since it is imperative that they have white flesh and leg.s.

\section{Light Brahmas.}

\section{STAXDARD WEIGHTS.}

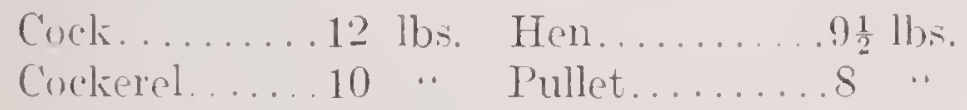

At first thought it seems strange to list the Light Brahmas among the leading practical breeds, since they are the largest fowls in the world and usually classed first on the list of market-poultry breeds. Notwithstanding which fact there is good reason for considering them among profitable egg and market poultry producers combined. Bred for practical

qualities they are excellent layers, and as they produce very large sizod eggs, of superior darkbrown color. which command a substantial premium where fancy eggs are appreciated, it is obrious that they deserve attention simply as egg producers. In some sections, notably in southeastern Massachusetts there are considerab'e poultry farms stocked wholly with Light Brahmas; probably not such Light Brahmas as the enthusiastic show-point breeders rould admire, but possessing practical qualities of very great merit. We once had a stock of "early laring" Light Brahmas, somewhat b low the standard weights in size, rather finer boned and chunkier bodied but pretty good Light Brahmas for all that, that could be grown to laring maturity before they were six months old, and were most prolific lavers of eggs of the highest quality in size and color. Mr. Silb rstein, a well-known breeder of Light Brahmas three or four years ago and the inventor of the Eureka Trap Nest, had great having Light Brahmas. individual pullets of which made records of 191, 197, 210, and 233 eggs each, within a rear of laying maturity, and with such great laring stock to breed from undoubtedly those records could ba improved upon, and the prolific laring habit so fixed that 200 eggs each within a year would not be difficult to attain.

Considering, then, the rery high quality eggs of Light Brahmas and their superior merit as 


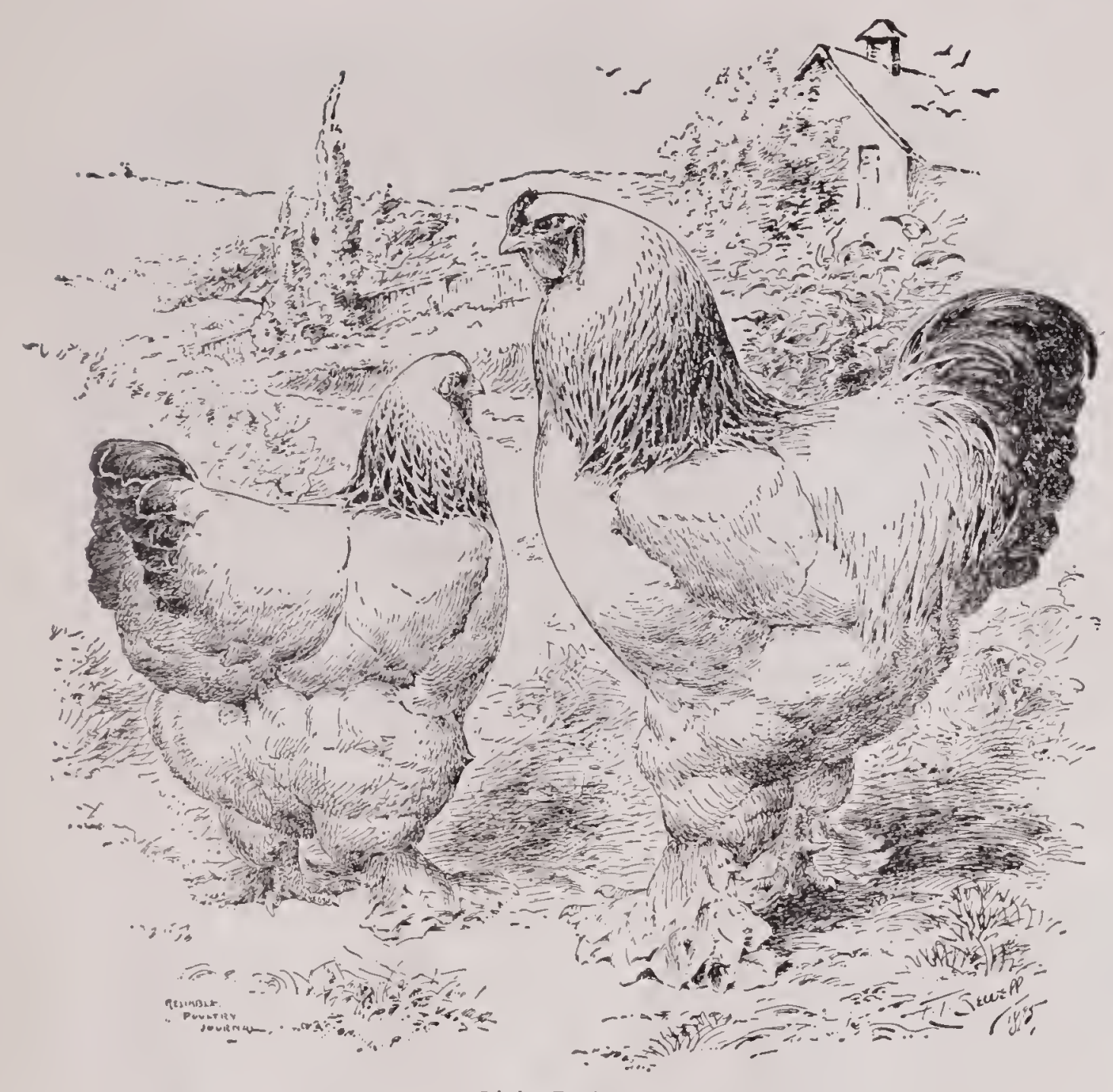

Light Brahmas.

meat producers, it will bo conceded that they have excellent qualities which fairly entitle them to be considered as profitable all-purpose fowls. A well-known poultry editor writing of this breed, says:

"The Light Brahma is one of the oldest and bast known breeds. They are the largest variety of fowl, a very hardy meat producing breed, and good layers, of large brown eggs. Their beautiful plumage, a happy combination of black and white, small pea combs, red faces and earlobes, and heavily booted, yellow legs, together with their prourl, stately carriage make them a very attractive fowl. Although considered chiefly a meat breed they are, when properly handled, excellent layers, and being fine winter layers they produce the most of their eggs in the scason when eggs command the highest prices.

"The Brahmas make good sitters and mothers but are somewhat more clumsy then the lighter weight sitters. Their extreme hardiness makes them particularly easy to raise by artificial means. They are exceedingly tame and gentle and are easily confined by a low fence. For a large breed they mature early, the pullets being ready to lay when from seren to nine months old. This variety is especially popular with growers of winter roasters and is also widely used for growing broilers and frying chickens, both straight bred and used as the foundation or unclercross. As large roasters the full grown fowls are unsurpassed by any pure breed. The growers of winter roasters in eastern Massachusetts use light Brahmas ahnost $\mathrm{ex}$ chusively. Their rentle disposition and the ease with which they may be confined, with their ability to do better in linnited quarters than almost any other varicty make them cspecially valnable.

"This breed will prove exceedingly raluable for those whose space is limited and who desire to try profitable poultry keeping on a city lot. or village acre. As a cifybrecter once said, "The Brahmas are an idcal fow where lack of ground-roon would forbid the keeping of other varictics. They do well, with good care, in a space that would seem scarcely 'turning about room' for other fowls, and they will lay quite as many eggs as the other meat producing varieties. Then when one wants a fowl or roaster for the family dinner, it is only necossary to kill one bird to get right or ten pounds of dressed poultry, which is a decided advantage to the man who keeps a small flock.",

'The Light Brahma is deservedly popular. the most popular variety of the Asiatic class, and is a formidable rival of the leading American general purpose varieties. The following statement by Mr. I. K. Felch will be endorsed by all who know and love this grand fowl: "The breeder who took the Light Brahmas in his keeping fifty years ago, acknowledging their worth then, is today their staunch friend, and he tells you with the same enthusiasm that they are the best fowl on earth when they are allowed to appear in the shape and color that is their birthright." 


\title{
Chapter III.
}

\section{PEDIGREE BREEDING FOR EGG PRODUCTION. BUILDING UP AND MAINTAINING}

\author{
AN EGG LAYING STRAIN. PROFITABLE USE OF TRAP NESTS.
}

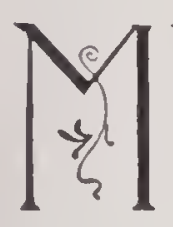

uch attention is being given to improving the laying quality of our forrls, and as the production of eggs in liberal quantity, and especially at the time of highest prices, greatly increases the profits, it is obvious that the choice of a suitable breed or variety for the special purpose is most important; and not only that the right choice be made, but that the stock be improved in laying quality by breeding from the most prolific layers of the chosen variety. A dairy farmer selects from the most noted dairy breeds for his herd, and similarly the egg farmer should select from the best laving varieties of fowls for his egg producers.-failure to do this handicaps a man from the start.

There is a great variety of fowls now being bred, and this variety offers a poultry farmer a wide field for selection; he should remember, however, that of these numerous varieties not all are adapted to his purpose. One breed may give excellent satisfaction with one poultry keeper while another mar find the same breed quite unsatisfactory, possibly because he does not keep them under the conditions which enables them to thrive best; under such conditions the very best of egg producers might not prove to be satisfactory lavers.

After he has made his selection the wideawake, up-to-date poultryman will ever be on the lookout to improve his fowls for his purpose. He should not be content with simply choosing what he thinks is the best rariety; selection of the best specimens of the variety should be continued year after rear, and the forrls be continually improved for the special purpose for which they are kept.

As practiced by most farmers the selecting of eggs for hatching is decidedly faulty, and often leads to steady deterioration of the flock. This is due to the fact that the eggs are selected instead of the selection being of the forls that produce the eggs. If the object of keeping forls is egg production the choice should obviously be made according to the number of eggs laid, just as the dairyman values his cows for the number of pounds of butter fat they produce. It is acknowledged that it is difficult, and in many cases impossible, to ascertain the number of eggs laid by individual fowls; and this difficulty has bren the chief cause of so little attention being paid to selecting the best layers to breed from. Because of this difficulty it has been the common practice to select for hatching the well formed and desirable colored eggs gathered from the flock from day to day, and very likely the eggs selected have been laid by birds which have laid hardly any (and possibly not at all) through the fall and winter, in fact the birds which have been the most indolent layers in the fall and winter are likely to be the most fruitful layers at hatching time, hence their eggs are all the more likely to be the ones selected for setting; consequently eggs so collected at random are quite likely to consist largely of those laid by the poorest laying hens of the flock. It is quite unnecessary to discuss this subject at length to show that this kind of selection of eggs for hatching tends toward deterioration of laying quality,- - mdoubtedly many persons follow this practice without fully realizing its evil tendency.

A much better plan would ba to select a few of the bast hens, and preferably year-old hens, and place them in a pen by themselves, so that their eggrs only may be used for hatching. It is possible for an expert poultryman to estimate the laving ability of the birds he selects for breeding by their early feathering and steady growth as chicks, their early maturity and early laving as pullets and their activity and evidence of strength and vigor of constitution; it is well known that the best layers are strong, active, vigorous fowls, they are known to have strong constitutions. 
If breeders are to select for vigor they cannot do better perhaps than to make the choice during the pullet period and verify the choice at the subsequent molting period. Strong. vigorous forls pass through the molting period rery much more quickly than do those with weak constitutions. The robust, vigorous hens that lay a large number of eggs throughout the year. will pass through the molting period rery quickly and will hardly stop laying. while those haring weak constitutious will be a long time in producing the new coat of feathers and will not lay for many weeks. The experienced poultryman therefore finds this period in the life of the fowl a most excellent one in which to make his selection. The fact that the birds with strong constitutions are the most profitable for egg production, suggests the explanation of why the fowls of poultrymen who make a specialty of egg production are of larger arerage size and are more vigorous and active than the fowls of those who breed chiefly for exhibition purposes; almost without exception the arerage size of fowls of flocks especially noted for egg laying, is considerably larger than the average size of fowls of the show-bird stock of that breed.

A good sized body and a deep, broad breast are indicative of a strong constitution, hence they are the requisites of a good laring hen. If one is compelled to make his selection for egy production solely from the general conformation and appearance of the birds he should select those that hare deep-long bodies. Those having a short underline and that are circular in outline should be discarded. The feeding capacity of the hen is important, for those that are able to digest and assimilate large quantities of food are strong, rigorous, and consequently can produce eggs in great abundance.

\section{Trap Nest Selection the Best.}

The man who would do the very bast in selecting his breeding stock should have recourse to the trap nest device to accurately determine the number of eggs each individual pullet or hen produces; then he can select with certainty and use for breeding only the eggs of birds known to be great layers. While observation will aid in selecting the prolific layers, it is not infallible because not infrequently a most active and to all appearances an egg-type bird will be proved to be a poor layer when put to the test of the trap nest; with the help of this most raluable device we know positively which birds are the good layers and which are not, then we can $b$ = certain that we breed from the best layer's. Not only does the trap nest tell us which birds are the best layer's, but it tells us infallibly which birds lay the largest and best egas and which lay the small, inferior and defective eggs.-There are rery, very many adrantages in the trap nest.

An objection that has been made to it is that it takes time,-and so does everything in the world that is worth while! Those who recommend that we select out breeding birds by the aid of observation of their labits, etc., forget that observation also requires time; our experience is that it takes quite as much extra time as attending to the trap nests,-and there is this further disadrantage, it is not accurate. The trap nest requires decidedly less time than inexperienced poultrymen think; we have to go into (or through) the pens four or five times a day, to do the regular feeding and watering and collecting of the eggs; it takes but a minute or two at time of each risit to liberate any bird that has laid and wants to get out of the nest, the egg is marked with her legband number and put in the collecting box. True, this takes one or two minutes of time, but experience proves that it takes no more time than should be given to observing the birds; one point worth mentioning is that "observation" can be (and probably will be) slighted, with the result that we fail to accomplish the much desired result of breeding from the linown great layers; with the trap-nest record of what each hen has accomplished we know with absolute certainty what we are doing, there is no "guess work" about it.

In this chapter we give sone testimonials from users of the trap nests, and have thought it wise to incorporate an extract from a report of the Rlode Island Agricultural Experiment Station, which contains some criticisms of trap nests. We should keep in mind, however, that the Rhode Island Experiment Station people had twenty different kinds of trap nests, and they seem to have been rather more interested in finding the cbjectionable points of those different kinds of trap nests than in determining the general merits of the trap nest idea.

The Maine Agricultural Experiment Station has done the most satisfactory work with trap nests, and the results attained prove conclusirely the decided adrantages of breeding from 


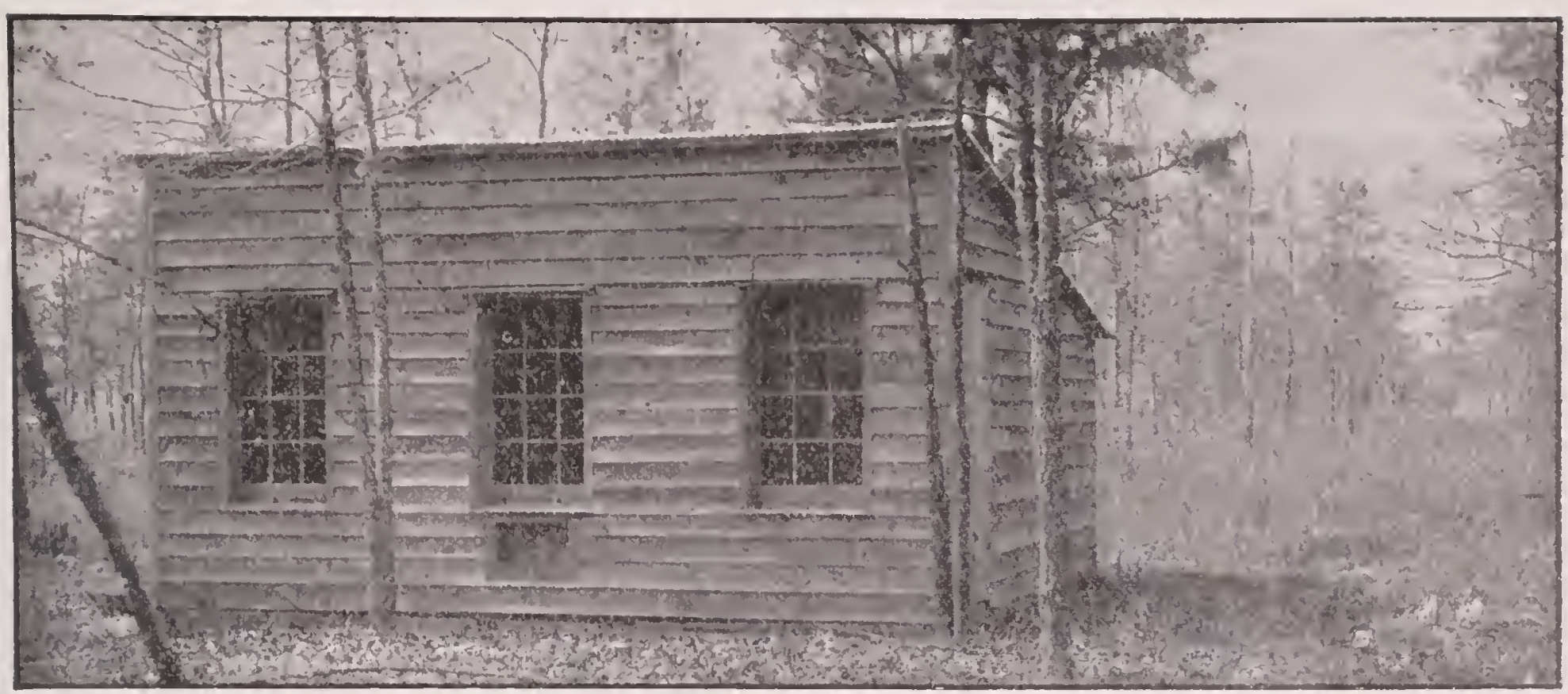

Colony Houses in the Woods, Lakewood Farm.

known great layers. A recent bulletin of that station says:-

"In 1898 trap nests were derised and placed in all of the breeding pens. This was done so that the producing capacities of hens could ba known, and selections for brecding could be made upon merit alone.

"It is known that the laws of inheritance and transmission are as true with birck as with cattle, sheep and horses, and when we consider the wonderful adrance in egrg production that the hen has made during her clomestication, there is ample reason for assuming that a higher average production than the present can be secured by breeding only to those birds that are themselves large producers. It has been found in our practice with the trap nest. that with the most careful selection we could make when estimating the capacities for agg yielding, by the types and forms of birds, that we were still including in our breeding pens hens that were small workers."

Of the results of that trap nest work the bulletin says:-

"Of the four that laid over 200 eggs during the first 12 months after commencing, No. 4 laid 201 eggs the first year. 140 the second and 130 the third year, and she is now on her fourth year's work. No. 14 laid 208 cggs the first year, 141 the second year and 28 the third year. She molted in July, 1900, and met with an accident in August which came very near ending her existence, but her great vitality enabled her to rally and she shed her feathers again, completely, and grew a second suit that scason. She did not begin laying again until the following Narch when she laid 28 eggs by the close of May. At molting time in June she died. She was an upheaded, strong hen, and the first one to give us over 200 eggs in one year. No. 101 laid 201 large brown eggs the first ycar; 30 the sccond year and 63 the third year. She is now on her fourth rear's work. No. 266 was a late hatched pullet and did not commence laring until February 12, 1899. In a year forward from that date she laid 206 cggs. In the first year, commencing Norember 1, 1899, she laid 191 eggs. with 157 during the second, and 138 in her third year. When three and a half years old she died suckdenly, haring laicl 119 eggs during the last 160 days she lired.

"With many poultry keepers and farmers the idea is prevalent that if a hen lay but few eggs the first year she is likely to do better the sceond year than though she laid well during the first year. The data so far secured does not show that hens that laich 120 eggs or less the first year yicld satisfactorily the second year. Those that rielded in the vicinity of a hundred or less the first rear yielded very light the second rear. On the other hand many of those that vielded from 130 to 200 or orer during the first rear laid quite well the second year." * * *

"During the three years in which we have becn selecting breeding stock by use of the trap nests we have found 30 hens that laid between 200 and 251 eggs each in a year. Twenty-six of them are now in our breeding pens and con- 
stitute-until other additions are made-the "foundation stock" upon which our breeding operations are based. Males for our use have been raised from them during the last two years. The number of the foundation stock. now secured, makes practicable the avoidance of inbreeding, and this is to be strictly guarded against, as it is doubtful if the inbred hen has sufficient constitution to enable her to stand the demands of heary egg production.

"All of the other breeding stock we are now carrying are tested hells that have laid over 180 eggs in a year; pullets whose mothers laid over 200 eggs in one year and whose father's' mothers laid over 200 eggs in a year; and pullets sired by cockerels whose mothers and grandmothers laid over 200 eggs in one year."

Such results, attained in the comparatively brief time of five years, are eloquent of what can be done by continued intelligent mork along this line. That breeding from hens that "have laid over 180 eggs in one year"; pullets whose mothers laid over 200 eggs in one year and whose fathers' mother's laid over 200 eggs in one year; and pullets sired by cockerels whose mothers and grandmothers laid over 200 eggs in one year"-is tremendously suggestive! What an accumulated momentum of prolific laying, as $\pi$ ell as absolute certainty as to the record of mothers and grandmothers; that absolute certainty as to laying record we can attain to only by the intelligent use of trap nests.

\section{WHAT MR. EDGAR WARREN SAYS. A Nest Box for. Individual Records.}

Within the past fer years the poultry business has been almost revolutionized by the introduction of a nest box for individual records. It is a fact well known to all breeders of animals, that desirable traits may be transmitted, and by careful matings a strain may be permanently established. Among cows some breeds are noted for the production of butter, other's for milk and others for beef. Among hens there are some breeds that excel as egg producers, and in all breeds there are strains that lay better than others. It is obvious that if we are to build up a great egg-producing strain we must breed from great layer's.

How may these great layers be picked out? There are two ways. One is by the testing pen; the other, by a trap nest box. The former makes the pen the unit, the latter the individual bird. The former is the way I myself proceed.
My laying pens are made up of birds that have been thoroughly tested in solitary confinement, as described in a preceding section. If every bird in the pen is a layer, and the arerage of the pen in egg production is satisfactory, I do not hesitate to breed from that pen. This is a great labor saving method. The birds do not require the constant attention that is demanded where individual records are kept. Each bird is tested at the beginning of the season, and marked with a leg-band if she meets the test. Otherwise she is put in the pen for culls or dispatched.

$$
\text { "200 Eggs a Year per Hex." }
$$

\section{BETTER LAYERS AND MORE OF THEM. Breeding Systematically for Increased Egg Production is the Only Method of Develop- ing a Strain of Prolific Layers- Trap Nests a Necessary Means to This End.}

BI C. BRICAULT, M. D. Y., ANDOTER, MIASS.

It is an acknowledged fact that the surest and most profitable source of income for the majority of poultrymen is the sale of eggs to the daily market. How to obtain the largest possible egg rield from our stock becomes, then, a most important question to those of us who are interested in this, the most profitable branch of the business.

$\mathrm{By}$ properly feeding our hens, we can obtain results which a less careful poultryman will not, but no matter how well we understand this difficult part of the work, and no matter how careful we are in making use of our knowledge in this direction, it will be observed that in every flock of pullets raised, fed and cared for in the same manner and under the same conditions, that several will lay almost double the number of eggs that others will in the same pen. With but few exceptions, these large egg producers were born with this raluable trait, and it is by breeding from these heary layers that we can increase the arerage egg vield of our flock. Breeding systematically and persistently from our heaviest layers will develop a strain of layers which will pay us generously for our work. No other method will give is as good results.

\section{Trap Nests Necessary.}

In order to follow this system of breeding it will be found of absolute necessity to ascertain 
the number of eggs each hen lays. Fortunately we have at our disposition the automatic nest which will help us to accomplish this accurately. This valuable addition to the practical poultryman's needs has been severely criticised by some, but its adrantages cannot be orerlooked and no real progress can be made without ituse. By placing these trap nests in the pen: it will be an easy matter to distinguish the best layers from the poorest. The members of the flock that do not lay enough eggs to pay a profit should be disposed of to the butcher.

Iou can overcome the greatest drawback to trap nests by putting in the pens half as many nests as there are layeirs and placing them on a platform trenty inches above the floor. $B y$ this arrangement the work is reduced to a minimum and the hens have the adrantage of using the whole floor space. By this plan you can gather the eggs with more ease and at a saving of fifty per cent. in time. as compared with nests that are under the drop boards. With this number of nests in the pens there will be no need of risiting them of tener than four times a day.

If you use trap nests like the Ideal, which is easy of operation and well rentilated, you need not worry should your hens be confined in them a short time. It will not harm them a particle; neither will it induce them to become broody any sooner. Certain ones who condemn the use of trap nests because they wouk have us beliere it is cruelty to so confine a hen, do not hesitate to keep fowls for days at a time in a show room. which really is the kind of confinement that is detrimental to their health.

\section{Keeping the Records.}

When your pens are equipped as advised above, the next thing to do is to place a leg band around one leg of each hen. These leg bands can be stamped with a number, letter, or both, then you are ready to begin record keeping. As you go the rounds of the nest., you release the hens confined in them. note their numbers on the leg bands, and mark each egg. or enter it at once on record sheets kept for the purpose. You may find some customers who object to having anything written on the eggs they buy; many grocers and merchants object to this.

The only remedy is to enter the numbers on the egg record sheet, or on a small slate carried around by the attendant. and, later, enter them on the egg record sheets. If the eggs are wanted

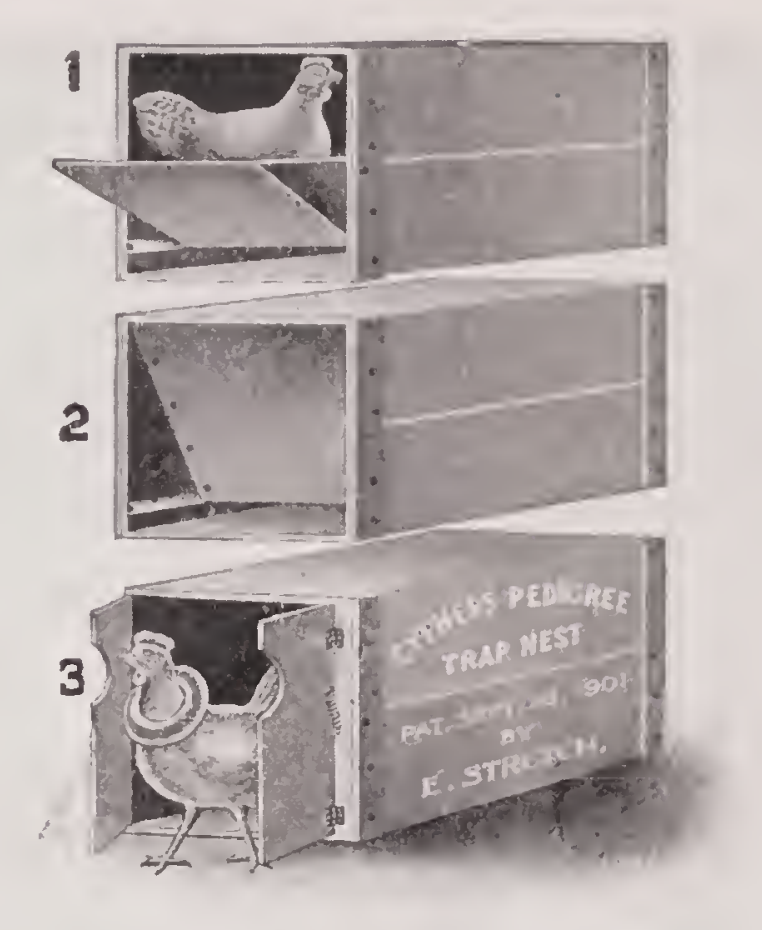

Cyphers Pedigree Trap Nest.

for hatching. it will then become necessary to mark each egg.

There is no need of complicated record keeping. The record sheets on which are written the number of each hen, and the dates on which she lays, checked off, and a small book are all that are required. Every page of this book is ruled off in three sections. and in each of these is entered the number of one hen. her record, her dam's record, and her sire's dam's record; also the number of each chick hatched from her eggs. When a chick dies, the letter D is written across its number. When we are ready to begin hatching each hen's eggs are incubated separately under a hen or placed in a compartment of a pedigree tray in the incubator. When the chicks are hatched, each one is marked by placing around one of its legs a small leg band. As they grow older these bands are changed for larger ones.

\section{Mating for Egg Production.}

One of the most important points in mating your pen for egg production, is the selection of the male birds. for we lean to the belief that it is through her sons that a great layer transmits her qualities. Lse none but well developed, vigorous sons of your very best larer. Another equally important thing in selecting your breeders, is rigor. Choose only the most vigorous hens and cockerels. Vigor is the outward sign of a strong constitution, and a good larer must be strong and vigorous to enable her to digest and assimilate the food necessary to lay a large number of eggs. By 


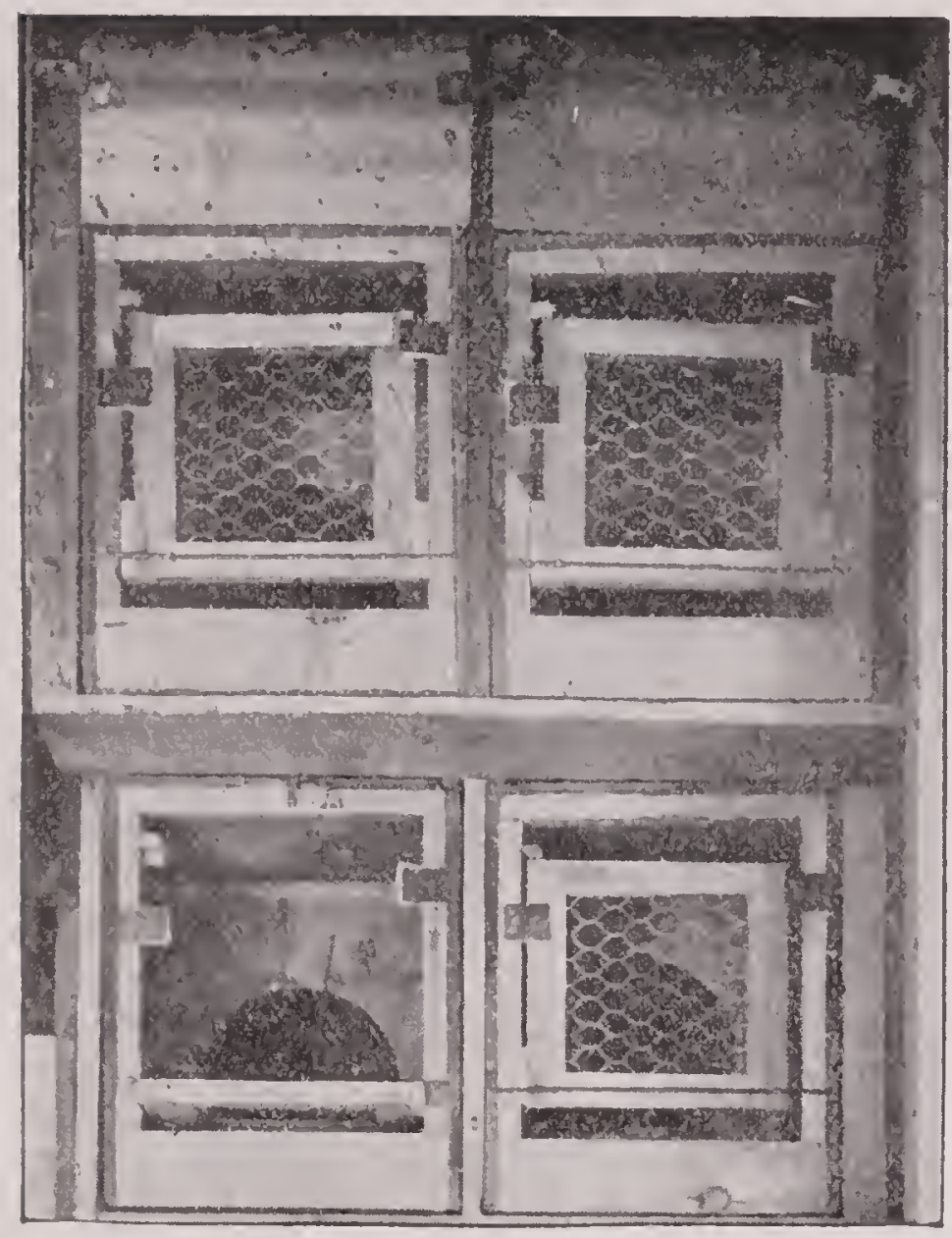

The Maine Experiment Station Nest Boxes in Position.

thus selecting each rear the most rigorous descendants of your best layers, you will intensify both these qualitis in rour strain and produce layers that will lay more eggs than their ancestor's did.

When you have arrived at this period of your breeding operations, that is, when, by a few ycars of this systematic breeding you have fixed rigor and a good egg record in your strain, you can profitably practice some inbreeding. By inbreeding you can improre your egr yield quicker than by selection. But be rely careful to select only the most rigorous and healthiest individuals from your few best layers.

Tre will suppose you have just such a hen with a large egg record. Iou can mate her to her most rigorous and best developed son, and in this same pen you may also put the hens which have given you the largest number of eggs. The following year you can mate one of these inbred cockerels to the pullets bred by the first cockerel, but out of the other hens-they will be half sisters. Of course, you will always pick out your highest record hens to mate to these choice breeders.

You will bo pleased with ega records of the pullets bred from this last mating. The major- ity will be excellent layers, and will be the very bast of breeders. If you have been careful to select only rigorous birds and the best layers in your matings, you will notice very soon a great improvement in the average egg vield. You can then use these inbred cockerels on unrelated hens, but only on the grood layers, and then follow up as before.

Great productiveness in our hens is a trait which can be easily fixed by breeding. The principles governing our breeding are the same as those which apply to all other classes of animal breeding; it is only the application that differs. With the fancier it is feathers, with us it is eggs; both can be developed to perfection by the same principles of breeding. There is nothing to prevent you, if you so desire, from improving both the egg yield and exhibition points of your strain, but the progress will be much slower. The results, however, will be more pleasing in the end. To us this question of breeding layers is a most fascinating one, and it is one which offers more real adrantages to the interested poultryman than rould be believed at first. Breeding from our best layers systematically is, to our way of thinking, the only sure way of increasing the profits. - Rctiable Poultry Journal.

\section{A Nest Box for Keeping Individual Egg Records.}

[Reprinted from the 13th Annual Report of the Maine Agricul[ural Experiment station.]

Desiring to conduct experiments in breeding hens we found it necessary, first, to be able to determine the eges produced by each individual. Several appliances and patented derices were examined, but all secmed open to the objection that while they might indicate to an extent the producer of the egg, the lack of certainty would be so great as to render them of little value for our purpose. We constructed a nest that proved so satisfactory that we placed fifty-two of them in the breeding-house, where they have been in use sereral months. They cnable us to know the eggs produced by each bird with certainty. The boxes are placed four in a bank, and slide in and out like drawers, and can be carried away for cleaning if necessary. If desired they could ba put on the floor or shelf by simply having a cover to each box.

Our breeding pens are ten by sixteen feet in size, and there are twenty hens and a cockerel in each one. Four nests in each pen have accommodated the birds by the attendant going through the pens once an hour during that part 
of the day when the birds were busiest. Earlier and later in the diy his visits have not been so frequent. More nests in the pen would reduce the frequency of his visits. To remove a hen the nest is pulled part way out, and as it has no cover she is readily lifted up and the number on her leg band noted on the record sheet that hangs at hand. After having been taken off a few times they do not object to being handled, the most of them remaining quiet, apparently expecting to be picked up.

The nest box is very simple. inexpensive, easy to attend and certain in its action. It is a box-like structure, without front end or cover. It is $2 S$ inches long, 13 inches wide and 13 inches deep-inside measurements. A division board with a circular opening $7 \frac{1}{2}$ inches in diameter is placed across the box 12 inches from the back end and 15 inches from the front end. The back section is the nest proper. Instead of a close door at the entrance, a light frame of inch by inch and a half stuff is covered with wire netting of one inch mesh. The door is ten and one-half inches wide and ten inches high, and does not fill the entire entrance, a space of two and a half inches being left at the bottom and one and a half inches at the top, with a good margin at each side to avoid friction. If it filled the entire space it would be clumsy in its action. It is hinged at the top and opens up into the box. The hinges are placed on the front of the door rather than at the center or back, the better to secure complete closing action.

The trip consists of one piece of stiff wire about three-sixteenths of an inch in diameter and eighteen and one-half inches long, bent as shown in the drawing. A piece of board six inches wide and just long enough to reach across the box inside, is nailed flatwise in front of the partition and one inch below the top of the box, a space of one-fourth of an inch being left bətwreen the edge of the board and the partition. The purpose of this board is only to support the trip wire in place. The six-inch section of the trip wire is placed across the board, the long part of the wire is slipped through the quarter inch slot, and passed down close to and in front of the center of the seven and a half inch circular

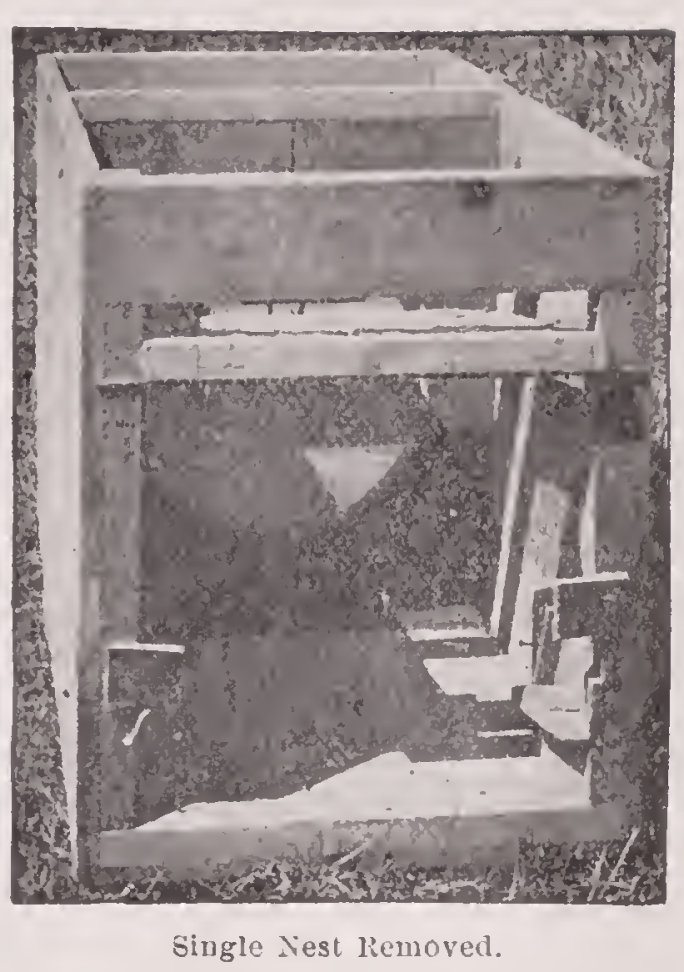

opening. Small wire staples are driven nearly down over the six-inch section of the trip wire into the board, so as to hold it in place and yet let it roll sidewise easily.

When the door is set, the half-inch section of the wire marked $A$ comes under a hard wood peg, or a tack with a large round head, which is driven into the lower edge of the door frame. The hen passes in through the circular opening and in doing so presses the wire to one side, and the trip slips from its connection with the door. The door promptly swings down and fastens itself in place by its lower edge striking the light end of a wooden latch or lever, pressing it down and slipping over it, the lever immediately coming back into place and locking the door. The lateh is five inches long, one inch wide and a half inch thick, and is fastened loosely one inch from its center to the side of the box, so that the outer end is just inside of the door when it is closed. The latch acts quickly enough to catch the door before it rebounds. It was feared that the noise arising from the closing of the door might startle the hens, so instead of wooden stops, pieces of old rubber balting were nailed at the outside entrances for the door to strike against.

The double box with nest in the rear end is necessary, as when a bird has laid and desires to leare the nest, she steps to the front and remains there until released. With one section only she would be very likely to crush her egg by standing upon it.

One experiment which has been undertaken, and which requires a long period of time in 
preparation, is the attempt to establish families of hens that shall excel as egg producers. To do this reliance upon the laws of inheritance and transmission must be coupled with selection. Selection will depend upon the actual production of the birds taken for foundation stock. From offspring of the foundation stock will ba selected-by use of the nest boxesthe greatest rielder's of desirable egrgs.

The male birds will ba bred from dams of known capacity and quality. Only by use of nest boxes and leg bands can we expect to control the work. Two hundred and sixty females, from three distinct breeds, are undergoing test for the foundation stock. One year's time will be required in the selection. From among them it is hoped may be found a few birds that are suited for the founding of the families. The breeds employed are Barred Plymouth Rock, White Wyandotte and LightWeight Light Brahma.

\section{TRAP NESTS.}

\section{An Experiment to Test the Practicability and Comparative Effíciency of Various Con- trivances for Ascertaining the Egg- Laying Records of Fowls.}

The trap nest has been used to a limited extent for at least thirty vears. but it is only within the last three years that it has come into general notice through the claims of several inventors of devices to determine the number of eggs laid by individual hens.

Some of the objects have been to save the eggs of individuals from special mating pens, to select the best layers, to detect the nonlaying fowls and those that lay but few eggs, and to ascertain the characteristics of the egge from certain fowls.

The trap nest is certainly valuable, especially in line breeding, to the fancier having a limited number of choice fowls from which he wishes to establish a pedigree strain. It is also of use to the experimenter in breeding when he wants to determine the results of certain crosses or matings.

It is a favorite device with a man who has a desire to build up a strain of phenomenal layers, even if by so doing he weakens the stock. Others are using the nests to substantiate their claims for the wonderful egg-producing qualities of their hens by advertising their actual laying records.
Trap nests may ba divided into two classes, single and double compartment nests. The latter named may work well, but their use is rarely advisable. They are hard to clean, and, bing bulky, take up valuable space. The claim for the double compartment nest is that it allows the hen to leave the nesting space after laying, thus preventing her breaking or soiling the egg by trying to get out. The hen should not, however, ba confined in so small a space for so long a time that she worries, or her laying may be impaired. She should be released as soon after laying as possible, which is as easily done from a single as from a double compartment nest. The single compartment nests are generally preferable. They are simpler, more easily cleaned, and require no more room than an ordinary nest.

A trap nest should ordinarily be no larger than a common nest, and easily cleaned. It should be simple in construction, and so well made that it will not get out of order. It should hold but one hen at a time, and after she is in should prevent her exit or the entrance of others until the first hen is released and the trap set again. It should also be attractive to the hens, or they will lay outside rather than enter the nest. It should be adaptable to all classes and sizes of fowls. Not a single nest met all of the requirements as above stated, though a few have proved to be far superior to others. The openings in some have been so large that two hens have been known to enter at one time. Others failed to hold the hen or admitted other hens because not provided with a latch to the door, or when so provided it failed to work. Defective operation of other's was due to their flimsy construction, and to the fact that the nesting material often interfered with their mechanism. This interference from the nesting material was so great in some instances that it was necessary to readjust the nest nearly every day.

With a few exceptions the devices were more adaptable to the American and Asiatic than to the Mediterranean breeds, as the former are more quiet and easier to handle than the latter. A few interesting facts were brought out by the use of the trap nests regarding the peculiarities of certain hens, among them that a number laid two eggs a day at times. The average, however, was never more than one egg a day, as, after laying twice in one day, the hen would very likely miss the next day or the 


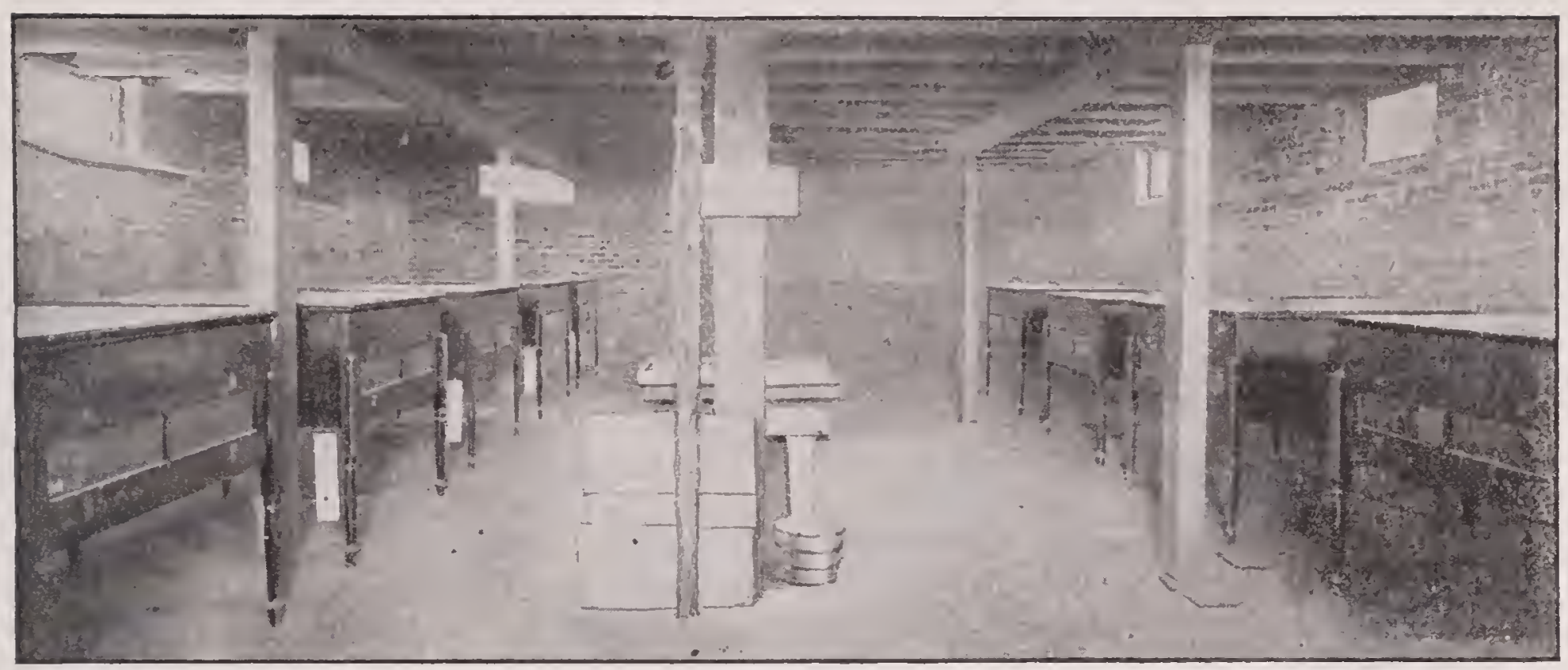

The Incubator Cellar, Lakewood Farm.

day following. Sometimes the male bird developed the trick of catching himself in the nest, for no apparent reason but his own enjoyment.

Although it is possible by the use of trap nests to determine the number of eggs laid by the individual hens, the impracticability of their use on a large scale is evident since the expense of attending them overbalances, in a business sense, the results obtained. In all the tests here reported it was found necessary to look at the nests during the busy laying season at least five times per day, and if a hen had laid each time it took considerable more than "one minute a day" claimed by more than one of the inventors, to release the hen and credit the egg to her account.

In looking after twenty pens of about five hens each it took on the average of fifteen minutes each time, or one and one-fourth hours per day. A person keeping about five hundred fowls would therefore use about six hours a day determining how many eggs each hen was laying. This time could often be used to better advantage in giving the hens better care and in looking after other details.

We fail to see how any of the devices could prevent egg-eating, as was claimed for some of them. In all the nests the hen had access to the egg after it was laid, and in one or two instances a hen was known to eat the egg.

To sum up, let us say, except in the cases mentioned in the beginning of this report, we fail to see that trap nests are of the practical value that the several inventors claim for them, to say nothing of the prices asked for their ideas or the finished article. What will please one is likely to prove unsatisfactory to another. The poultryman wishing to use trap nests will do well to consult with persons already using them, and construct his own to suit his purpose; for any one with ingenuity can construct a trap nest as good and better than many we have seen.-Annual Report, Rhode Island Agricultural Experiment Station, 1901.

\section{Lay Two Hundred Eggs.}

Can we produce hens that will lay two hundred eggs per annum? Without a doubt. How? By scientific breeding, as for a good butter cow or a great milker; as for a good trotting or high jumping horse. Experiments have been made to increase the number of rows of corn on the cob with success. The same method is applicable to poultry breeding. We will start with a hen that lays one hundred and twenty eggs. Some of her chicks will lay one hundred and fifty per year. From these we will pick out layers, and so on until two hundred or better are the result. At the same time it is just as essential to breed our males from prolific layers as it is the females. In fact it is more so. If we look after the breeding of the females only, we will introduce on the male side blood which is lacking in proficiency, and thus check every attempt in progress. It is just as essential that the male should be from a hen which laid one hundred and seventy-five eggs and from a male that was bred from a hen that laid one hundred and fifty eggs as it is that the hen was from one that laid one hun- 


\section{PROFITABLE EGG FARMING.}

dred and seventy-five eggs and whose mother laid one hundred and fifty eggs.

$$
\text { - Poultry Herald. }
$$

\section{Larger Production.}

The man who most steadily increases the producing power of his flocks is he who selects his eggs from a very few of his best layers. The sharper the selection, the more rapid and certain the increase. It is an approach to systematic, consecutive breeding, and no other policy is to be endorsed. Even now is not too late to gather up a few sittings and grow some fine layers. Larger production is what every egg man is crying for, and it is possible by simply selecting the breeders and using eggs from only the best. If you are satisfied with one hundred eggs per head, there is nothing more to be said; but if you want one hundred and fifty, then select with sole reference to egg producing power and breed for a larger business.

$$
\text { -Maine Farmer. }
$$

\section{PEDIGREE BREEDING FOR EGG PRO- DUCTION.}

The Greatest Egg Producer is the Fowl that has been Bred for the Sole Purpose of Producing Eggs.

From a lecture read at the annual meeting of the Ontario Poultry Association, at London, Ontario, January, 1898.

The greatest egg producer is the bird that has been bred for the sole purpose of producing eggs. This bird will not necessarily be a Leghorn or a Minorca, although these breeds deservedly have the reputation, of being the greatest egg producers living - that is, as a class. Without. doubt there is a greater proportion of eggs laid by these two breeds than by any other two breeds that can be named; yet there are many individual birds of other breeds that may equal or even surpass them. If such should be the case, it will be found that these individual birds have been bred with one object in view, namely; egrg production. Just as the fancier raises birds for exhibition, so may the farmer breed birds for laying purposes. Undoubtedly the proper course to pursue would be to choose your prospective layers from a class already noted for their laying proclivities, but do not imagine you have the best layers on earth simply because the breed selected has that reputation. Every descendent of Hambletonian does not trot within 2.30, but nobody denies that many a trotter with no breeding has come well within that mark, and has, in addition, been the foundation of a line of fast ones. Similarly with regard to hens. Many Minoreas and many Leghorns have proved unsatisfactory lavers, while many a Brahma and many a Plymouth Rock has abundantly helped to fill the egg basket.

As I have said, if you are commencing, select your birds from the classes bearing reputations as layers, but do not ba discouraged because it is not convenient to do this. Commence right now with the stock in hand and note the best lavers among your birds. Commence line-breeding with as great regard to mating as you would if breeding for show purposes. Mark the pullet that is the first to lay, mark the most persistent layer; mark the hen that molts quickly and gets down to business before the hard winter scts in, and when you have done marking, the spring will be here and you may commence mating. Better to breed from two or three well-known layers than to take chances and make up a pen containing a dozen indifferent ones. As the cock does not lay you can not judge whether he is likely to produce good layers; but you can choose the largest and most vigorous bird of the flock to mate with your selected females. After that it is easy. Never allow anybody to induce you to change the blood of your flock by the introduction of a male bird of another strain, unless you are satisfied he comes from a strain which equals your own as layers. Remember the sire controls one-half the blood of the produce, and if you desire to introduce new blood or new stamina into your flock, do so by means of the best laying female you can procure. Even then I would not use her sons as sires, but would dispose of them and mate her daughters back to the old male bird; the produce from this mating would have in their veins three-quarters of the blood of your own strain, with sufficient new blood to maintain the vigor of the flock. Do not over-look the necessity for observation each year, so as to intelligently mate your birds the next season, continually choosing the best lavers and limiting your breeding pen to these. The result will be that no matter what breed you start with, you will eventually own layers far ahead of any that have been indiscriminately bred. The same advice applies to production of large eggs. I have had Ninoreas which have laid large eggs, and Ninorcas which have laid small eggs; Brahmas, layers of large eggs, and Brahmas, layers of small. During recent years 
in breeding Buff Plymouth Rocks I have found that some hens lay small eggs, others large; and as I have carried out the system of pedigree breeding, I have noticed the fact that layers of large eggs transmit this attribute to their progeny, and layers of small eggs have produced birds which have also laid small eggr. It rests altogether with the particular strain of birds, ana not with the breed, as to which will give the best return, either in size or number of eggos laid.

Thoroughbreds have time and again demonstrated their ability to hold the lead in egg production, and all that is necessary for the bəginner in egg farming is to inquire of a reliable breeder whether or not his strain of birds possess that qualification. Then go ahead and do your own breeding.

There is a material difference between 150 eggs a year, which is a fair average, and 289, which is I balieve the record of a pen of fowls which have $b$ sen entered for competition in an egg-producing contest. It show's what can b3 done by padigree breeding and judicious feeding, and constitutes the difference between profit and loss.

If you keep many varieties you cannot give the necessary time to each one. Since I limited myself to breeding Buff Plymouth Rocks, I have won more prizes and obtained more satisfaction than I did on all the others combined. In addition to which there is the pleasure of noting results of experiments in mating from year to year.

There has bəen so much information given as to raising, housing and feeding, that anybody who reads should have no difficulty in these respects, if the directions are faithfully followed. Each breeder may have different methods, but analyzed they will be found to agree in the main. One feeds cut green bone every day, another every second day, but the amounts fed also differ, and the result is much the same. One feeds soft food for breakfast, another for dinner ; even this is regulated by the habits of the poultryman. The man who feeds early in the morning may, with good results, feed grain as a breakfast, while the one who feeds late will do batter by giving the soft food first. The hens become habituated to certain methods, and will do fairly well under any, so long as they are not radical. Still, the man who gets up early and feeds his fowls regularly, will get the bast returns, and he deserves them.
Give little soft food, a small but regular supply of meat, or ground green bone, and a rariety of grain, not forgetting the green food in winter, and the principal requirements for egg production have bzen performed. The next important requisite is work. Feed the grain in litter, covel it well and make the hens work to find it. Do not be governed by false kindness, and throw down the food in heaps, but cover every grain.

Be careful as to scaring the birds. Strange dogs, cats or even your next door neighbor going among the hens when in confinement, will effect the layers detrimentally. A change of pens, removing a hen from one pen to another, will cause a cessation of laying for a time. Change the position of your nests, and it has the same effect. Introduce a strange male bird, and you will notice the reduced numbrr of eggs. Any change, every change, should ba guarded against.

Give plenty of room and plenty of sunshine to the workers, and never reduce the scratching space to less than six or eight square feet per hen. Eren this amount is small, and when confined to such a space it is necessary to limit the numbrr of fowls in a pen to ten or a dozen. The most important requirement has not been mentioned, that is the water. Watch the hen come off the nest after laying and see her make for tha water, and you will understand the necessity for pure water and lots of it.

In the winter, if your house is dry, the fowls will keep themselves warm during the day if you feed little and often, and make them work. At night care must ba exercised to see that they have a warm corner for a roosting place.

1. Hatch your chicks as early as possible, but certainly not later than May, and if properly cared for you will have winter layers, and receive all the way from 25 to 40 cents a dozen for your eggs. If you allow the hen to have her own sweet will,she will probably incubate in June, July and August and rou will have lots of worry, lots of squabs, and any amount of expense feeding, during winter, chicks that bring you no return.

$$
- \text { R. H. Essex. }
$$

\section{Breeding for Eggs.}

I receive many letters asking adrice as to feeding in order to increase egg production. It is impossible for one even to give suggestions, in my opinion, without a detailed knowledge as to breed and surrounding conditions; but after all through food we can induce the fowl to lay only the limit of her capacity. 


\section{PROFITABLE EGG FIR.MING.}

A fowl does not manufacture eggs; if she did not have them supplied to her by nature she could not produce them herself. Nature is more gencrous with some fowls than with others, and if we would increase egg production we must find such fowls and breed from those to which nature has been the kindest; so we can but do our best with the fowls in hand, to feed them for health, and our success or want of success will be demonstrated by their laying and holding their weight.

Who would expect to breed large sized fowls from small-sized parent stock? Just so in increasing ege production. If we would attain and hold increased ege production, it is as important to breed it in the blood, and fix it there, as it is to attain any of the other numerous aims of modern breeder's.

It is almost needless to say that healthy, vigorous parent stock must be our foundation; and our aim must be to keep the parent stock healthy and vigorous through proper feeding and care; and the best food with the best care will be in vain if that ever present enemy of poultry breeders is not constantly kept at bay-lice.

The warning to fight lice has been repeated again and again by our poultry writers, and yet I venture to say most breeders smile complacently to themselves and think "No lice here."

Only recently one of the editors of Farm-Poultry paid me a visit at Hartnest, and asked "How are you fixed with lice?" My laconic reply, born of self assurance, was, "Ain't fixed at all. We breed Brahmas, not lice." "Well, let's see," said the editor, and I asked him to select a sprcimen that looked the lousiest if one such could be found. He made a sclection, scrutinized the head, throat, back, breast and fluffno lice; then he looked under the vent and found two or three; then "I thought it about time my hens needed dusting again."

"Let's try some more," said the editor, with about the same result. "Now, let's see your old hens." We looked at them, but this time, under the vent first, and there $I$ found them swarming -actually swarming. I was anazed, and when I looked at the leg bands of such as were the worst, I fancied I had an explanation of their recent small egg record.

Now, I had been told and had read time and again, to quarantine all new birds. The head of that pen was a bird I purchased a month or two ago, and after giving him a good dusting was satisfied that all was well; but cloubtless in dust- ing we did not get through the thick, fluffy feathers under the rent, consequently the lice which were close to or under his skin escaped us, and so they spread from him to all the hens in that pen. In another pen where we found lice were one or two hens that I purchased about the same time. My hens were practically clear of lice all over the body, except under the vent, and there they more than made up for their absence elsewhere. Had I taken the ordinary precautions so often repeated, I probably would have been a hundred eggs better off now.

To the breeder whose sole aim is increased egg production, the path is comparatively easy. It is important that he know cxactly what each of his breeders do. In order to aroid loss of time he should begin by breeding from all of his birds, making such provision for identifying the progeny of each breeder as his convenience may dictate. That some mode of identification be carefully and regularly followed is of vital importance.

At the end of the season he should select from his birds such as have excelled in the work in the nest, and to begin "fixing the laying habit" by selecting the best son of such breeder's and mating him back to his dam. Nate the pullets to a son of his heariest layer, being careful to aroid the mating of brother and sister.

It must be remombered that the daughters of these heary layers will not all inherit their clam's prolificacy, unless one is fortunate enough at the start to have at the head of his pen the son of a heary layer; and the drone blood will have to be bred out before uniformity can be depended upon.

Again, the varying individuality of fowls(until a strain is established)-necessarily produces in each flock some which are prone to take on fat, and other's which are prone to "go light," neither of which shoukd be bred from, or neither of which should have their progeny perpetuated.

It is not alway's possible to recognize either of these peculiarities before the hatching season is well under way, consequently I have advised as above, that the eggs from all breeders be set, and only those chiclis retained for the next season whose dams have shown the desirable traits.

As stated, a single object is casicr to attain than several aims. For instance, if early maturity and prolific laving is required, we must very naturally have an eye to both; if the brecder (in the system of identifying chicks 
which he adopts), includes also a mode of identification whereby he can not only tell the parent stock, but also the clate of hatch of each chick, early maturity can be had as easily as prolific laying; combining the two makes it of course a little slower of accomplishment.

It does not always follow that because a pullet matures slowly, she will not make a prolific laver; but most of us have no use for a slow maturing bird.

If in addition to early maturity and prolific laying, a breeder alio desires large size in eggs, two methods present themselves, either of which may be adopted. One may either abstain from setting eggs that are under a certain size which he may fix in his mind. or he may take the progeny of a hen laving the largest number of heary eggs, and mate them to the progeny of the heaviest layer. Discarding the eggs that come under the limit is of course the quickest way of obtaining all large eggs, but one is apt to lose in this way the use of some of his heaviest lavers.

I clon't mean by this that the heariest layers lay the smallest eggs. My experience has shown that size of eggs has no bearing whatever upon prolific laying. No. 61 for instance lays an $\mathrm{egg}$ that arerages very close to two and a quarter ounces.

If one desires in addition to heary laying, early maturity and large size of eggs, to breed to a certain color of egg, he again adds to the time it will require to accomplish his four-fold aim.

We occasionally read that prolific laying and the breeding of show specimens cannot be combined. I am quite confident that those who make this assertion have not made the proper effort.

In preparing birds for the show room, one of the requirements would be that they be checked from laying eggs, so that they may appear in their best dress. The only harm here done is that the individual record of that bird is slightly reduced. If she is a prolific laver and mated to the son of a prolific layer, her daughters will not suffer from this reduction.

My experience has been that just as soon as the birds are permitted to lay, in fact the second or third day of the show, they start in and keep everlastingly at it; even the journey home does not stop them.

True, I have not yet evolverl a flock of world beaters, either in the show room or in the nest; I did manage to get third at the late New Fork show, with June hatched pullets, two of them daughters of $\mathrm{my}$ second heaviest layer. Perhaps, this is but a straw but it shows the "way the wind blows." It shows that utility and beauty can be combined if we go about it right.

Where one's aim in breeding is a single purpose, I repeat it is comparatively easy of attainment; far easier than where the object includes a multiple of aims.

\section{A. J. Silnerstein in Farm Poultry.}

\section{A Study of Profits.}

We present herewith some tables of egg yield and profits of different flocks under different conditions, the purpose being to get a basis for comparison of profits. We have long preached that the creamy profits are from the eggs layed in Norember. December and January, and that the sure method of getting those November, December and January eggs was to keep early hatched pullets, kept steadily growing until they reached laying maturity, and then kept laying by good care" and good food We believe that such early hatched pullets, got to laying by October and kept laying, will produce from one hundred and seventy-five to two hundred eggs apiece within a year of reaching laying maturity, and that the best profit is got by selling them off to market after about one year of laying,- - that is, just before the next generation of early laying pullets are brought into the houses to succeed to the work. We have also preached and fully believe that, generally speaking, the keeping of the old hens is far less profitable. We believe in the great majority of cases it gives almost no profit at all, and the record of the old hens in the table illustrates this point. For convenience, and to facilitate comparison, we have figured the cost of food and the selling price of the eggs the same in all the tables--the cost of food at $\$ 1.25$ per head per year, that being about what it costs us to feed a fowl a year, and feed her well.

Table No. 1 is a report of the laying achievement of thirteen White Plymouth Rock hens. Table No. 2, that of eleven White Wyandotte pullets, and these two columns show an average of 215 and 210 plus eggs per fowl within a year, and prove conclusively that fowls bred for eggs can be made to produce 200 eggs per year or better. Whether fowls liept in larger numbers would do that however, is uncertain. Table No. 3, of 280 White Wyandotte and Barred Plymouth Rock pullets and hens, shows an average of 178 eggs within a year; and table 


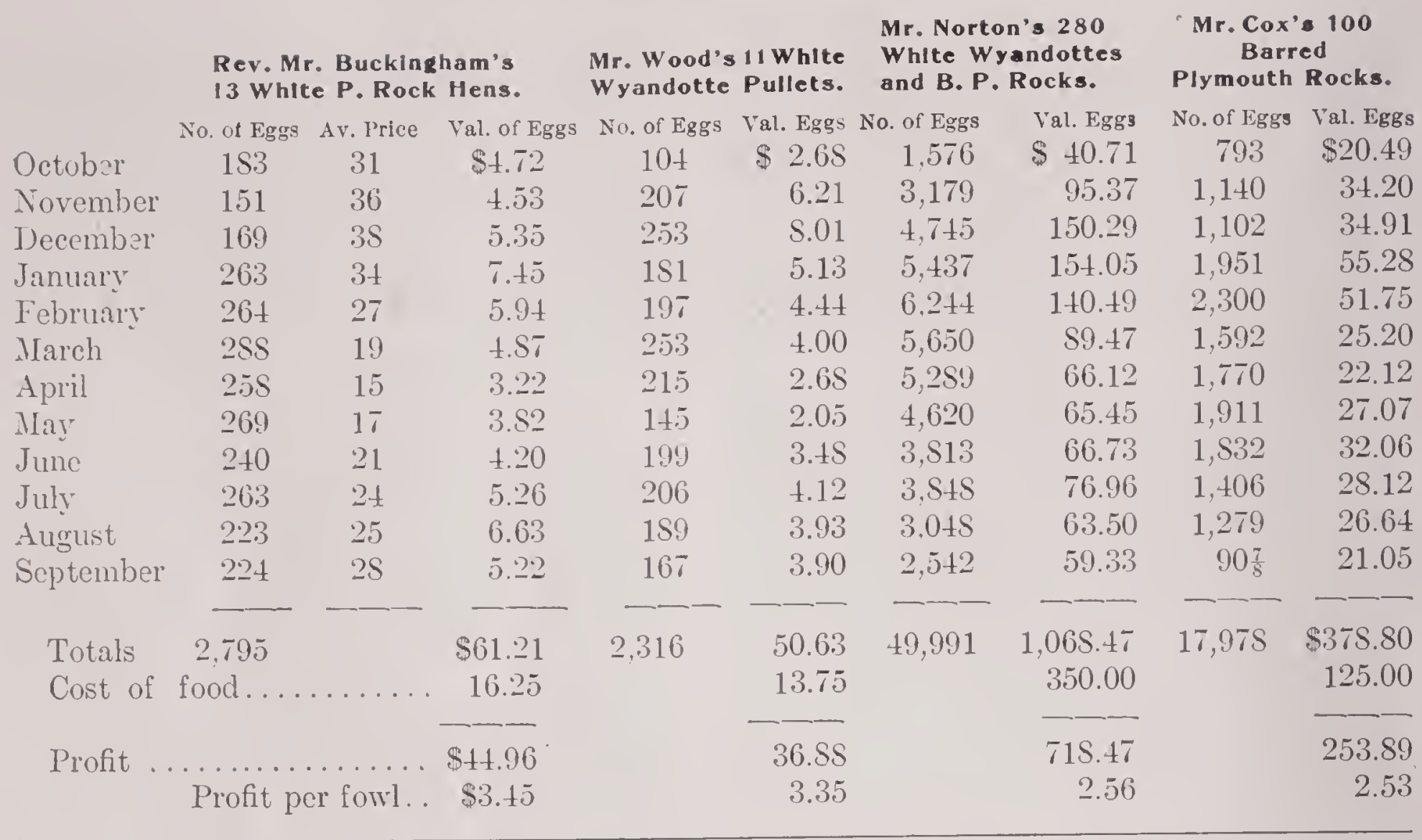

\begin{tabular}{|c|c|c|c|c|}
\hline \multicolumn{3}{|c|}{$\begin{array}{l}\text { Utah Ex. Station } 8 \text { Late } \\
\text { Hatched Leghorn Pullets }\end{array}$} & \multicolumn{2}{|c|}{$\begin{array}{l}\text { Utah Ex. Station } \\
8 \text { Old Leghorn } \\
\text { Hens }\end{array}$} \\
\hline & No. of Eggs & Val. Eggs & No. of $\mathrm{Eggs}_{\mathrm{g}}$ & Val. Eggs \\
\hline Novembər & 0 & $\$ 0.00$ & 0 & $\$ 0.00$ \\
\hline Decembər & 3 & .10 & 0 & .06 \\
\hline January & 56 & $1.5 \mathrm{~S}$ & 11 & .31 \\
\hline February & 63 & 1.42 & 25 & .56 \\
\hline March & 130 & 2.06 & 59 & .94 \\
\hline April & 151 & $1 . S S$ & $12 S$ & 1.60 \\
\hline May & 153 & 2.16 & 132 & 1.5 \\
\hline June & 138 & 2.41 & $9 t$ & 1.64 \\
\hline July & 135 & 2.70 & 6.5 & 1.30 \\
\hline August & 144 & 3.00 & 60 & 1.25 \\
\hline Scptember & 112 & 2.61 & 68 & 1.58 \\
\hline October & 68 & 1.75 & 4 & .10 \\
\hline Totals & 1,153 & $\$ 21.67$ & $64 \mathrm{~S}$ & $\$ 11.21$ \\
\hline \multicolumn{2}{|c|}{ Cost of food } & 10.00 & & 10.00 \\
\hline \multicolumn{2}{|l|}{ Profit } & $\$ 11.67$ & & 1.21 \\
\hline \multicolumn{2}{|c|}{ Profit per fowl } & $\$ 1.45$ & & $\$ 0.15$ \\
\hline
\end{tabular}

No. 4, of 100 Barred Plymouth Rock hens, shors an average of 179 (almost 1S0) eggs in a year. The best record for large numbers of hens of which we know, is that in which Mr. Wyclioff shows an average of 196 eggs apiece from 600 head of White Leghorns.

Anyone who carefully considers the question of profit will concede that fowls that lay 175 to 200 eggs apiece in a year, pay a good profit to their owncrs, as a study of these tables will easily show, and if he compares the first four tables with the last two, he will easily understand why it is that the November, December and January eggs pay the richest profit. It is, of course, because of the highest prices of those months; and it is equally manifest, if one studies the matter closely, that those high prices are due to the scarcity of fresh eggs in those months; and that scarcity is due to the faet that the great bulk of the poultry kept on our farms is either old hens or late hatched pullets. The point of December and January. profits will be better understood if we compare the egg yield and profits of those months with those of April and May, of course with the same flock of 125 fowls, 12 of them one-year-old hens, and 113 pullets.

$\begin{array}{lccr} & \text { No. of eggs } & \text { Sold for } & \text { Profit } \\ \text { December, } & 1,626 & \$ 51.49 & \$ 37.43 \\ \text { January, } & 2,065 & 51.70 & 37.64 \\ \text { April, } & 2,232 & 27.50 & 13.84 \\ \text { May, } & 2,332 & 30.12 & 16.06\end{array}$

Here we see that either the December or January egg yield paid more profit than April and Nay together. Everybody's hens are laying in April and May, and prices are the lowest of the year; only the "bred for eggs and fech for eggs" birds are laying in November, December and January, and the prices of those months pay the "creamy" profits. 
Table No. 5, showing the performance of old Leghorn hens, gives us clear proof of the unprofitableness of keeping old hens. They lay fairly well when they get down to work, but there is so much "dead horse" to pay for in the idle months of November, December and January, that it is practically all they can do to pay off their old debt and come out even. With the late hatched pullets it is somewhat different, because they are such persistent layers after they get to laying, and as the summer prices pay a very fair profit, they come out at the end of the vear with a fair balance in their faror. The late hatched pullets, howerer, are at a great disadvantage in more ways than one. Not only have they got to be fed well into the winter, before they begin to lay, and their best egg yield comes at the time of lowest prices, but their eggs are generally small in size, hence of little use for hatching; or, if they are used for hatching, they transmit the late maturing and late laying habit to their offspring, begetting another generation of late laying pullets, and "the sins of the parents are visited upon the children even unto the third and fourth generation::

The study of the history of the birds which have made these several records, is extremely interesting. The Rer. Mr. Buckingham sars he selected his thirteen $I T$. P. Rock year-old hens from a flock of about two hundred, and paid a premium for the privilege of going into the flock and selecting. That he had the ability to pick out good layers that spendid egg record attests. and we can but regret that the enforced remoral of that gentleman, due to the system of clerical rotation obtaining in his church, obliged him to give up the flock which he had so excellently begun; it would have been very interesting to have had a continuance of that experiment.

Mr. Woods' pullets were raised from eggs bought of Dr. Sanborn, and were fed for growth as chickens, and fed for laying after they were mature. It is worthy of note that a friend of Mr. Woods shared with him in the purchase of several sittings of eggs, and that the pullets raised by the friend from precisely simildr eggs to Mr. Woods', were fully two months later in maturing, and then laid much less well. This certainly gives us a valuable object lesson of the decided advantage of good care and good food.

Mr. Norton's story is équally interesting. He keeps from 275 to 300 head of fowls; got, in 1895, 29,726 eggs; 39,551 in 1896, and 49,991 in the twelve months October, '96, to Sept., '97, inclusive. There was an increase of substantially 10,000 eggs each year, entirely due to more house room, better care and careful selection of breeding stock-in other words, by following commonsense methods. With practically the same number of birds, he increased in three years from 29,000 to 49,000 egg., which is eloquent of what good care and good feeding, (or, if one prefers the term, common sense methods intelligently applied), will accomplish. Mr. Cox's story is almost similar. He tells us how he increased his egg yield from about ninety a year to an average of 179 a year, breeding from known layers and taking good care of them. He says in a letter, that "Tis a long story, not straight up either, but down and back a couple of times," and in the tabulated statement which he gave us (from which this table is made) he says, "We got above results by giving our hens the same thoughtful care and attention we give our cows, pigs, horses, farm and garden crops. The very same principles applied to our wheat fields, gave us a yield of 23 bushels

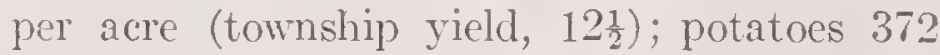
bu. per acre, (township yield, less than 100) and so on. Any thoughtful, intelligent farmer, with the aid of a good poultry paper and a few good poultry books, can do as well or better with his hens, for, I am ashamed to say, in the hurry and rush of the busy season on our farm, our hens are the first thing neglected."

There is a splendid object lesson in that story and a like splendid one in the tables which we present herewith for our readers to study. The keeping of old hens and late hatched pullets, while it pays a profit, pays not at all like the keeping of early hatched pullets, kept growing, or of carefully selected year-old hens got through the molt early, and got back to laying before cold weather, then kept laying. We want the very best profit on our farm, and get very little consolation in the half-loaf when the whole loaf is just as easily obtainable. It only requires that the plan shall be carefully thought out and then systematically followed; or, as Mr. Cox graphically puts it, that the same intelligent care be given to the hens that is given to the other farm industries or business interests. Poultry will pay and pay well if the owner wills it; and that our readers may make it pay and pay well, is our purpose.

Farm Poultry. 


\section{Mr. Wood's 210 Eggs Per Hen.}

We have had a number of inquiries in regard to the details of that egg yield of tro hundred and ten eggs per hen within one year, which Mr. F. E. Woods got last year-and we drove up there the other day to see his stock, and asked permission to look over his egg record. From twenty-six White Wyandotte eggs which Mr. Woods bought there were eleven pullets raised, and it was those eleven pullets which made this excellent record. The chickens were hatched the 23d of April, and the first egg was laid Sept. 22nd, - one day before the pullets were five months old. During the remaining days of September they laid eight eggs. In the twelve months beginning October 1st, their egg yield was as follows:

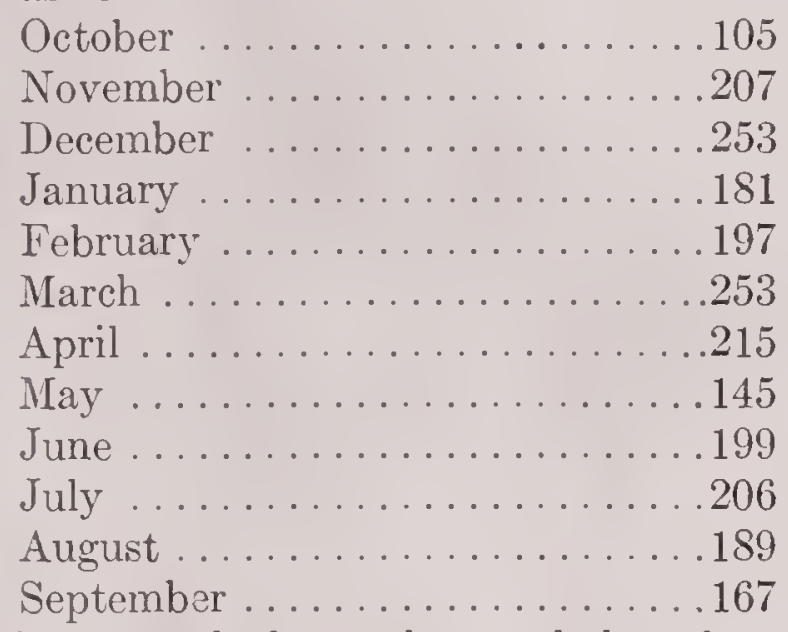

making a total of two thousand three hundred and seventeen, which is two hundred and ten and seven-elevenths eggs for each of the eleven birds.

The daily record is exceedingly interesting to look over. There are quite a number of tens in it; eights and nines are very numerous through November, December, February, March and April, and on Christmas day, they laid eleven eggs, scoring one apiece, on account of the day, no doubt. There is one day's record of twelve eggs, but Mr. Woods says that he is practically certain that one or two of these eggs were laid before that day, as eight eggs were found in the regular nests, and four more in one corner, where one or two of them had probably been overlooked, so he does not claim that any one of his birds laid two eggs in one day. Three or four of the pullets were allowed to sit the last of April or first of May, which would account for the smaller number of eggs in May and Mr. Woods is confident the small egg yield in January is due to his having fed whole corn once a day for a couple of weeks or so.

Farm Poultry.

\section{Eggs in Fall and Winter.}

Br EDGAR WARREN.

Some weeks ago I risited a man who is one of the most successful egg farmers that I know anything about. He is employed ten hours or more each day in a store, and yet he manages to clear up several hundred dollars a year from his hens. He does not get fancy prices for eggs or stock, but ships to Boston and gets the prices current there.

This man is very systematic and methodical and can tell just how many eggs he gets in any given year and, to a fraction of a cent, what it costs to produce them. His financial year runs from November 1 to November 1. Last year (1902) he kept four hundred and seventy-five hens, and they laid 70,399 eggs, which he sold for $\$ 1,429$. The year before (1901) he kept four hundred and serenty-five hens and they laid 69,506 eggs, which he sold for $\$ 1,104$.

You will observe that he got but 893 more eggs last year than he did the year before, and yet his eggs brought him $\$ 325$ more. How do I account for that? It is very simple. His hens laid more eggs in the fall and early winter last year than they did the year before.

Late Fall and Early Winter Profits.

I mention this case because it is so suggestive. Unless a man can get high prices for eggs for setting in the spring, the time for him to make his profits is in early winter and late fall. A dozen of eggs at Thanksgiving are worth two dozen St. Patrick's Day or the Fourth of July. There never has been a year within my recollection when eggs have not been high in fall and early winter, and I do not believe there will be till the end of time. And yet there is no difficulty in getting eggs at this season if one goes about it in the right way.

\section{The "First Rule."}

Eggs in fall and early winter must come principally from pullets. A hen that has laid faithfully for nine or ten months is now in the midst of her molt or just recovering from it. Consequently we must not expect her to do much in the way of producing eggs. If she is of the American breed she will lay now and then, enough to pay for her keep, but nothing great. So, as I have said, we must depend upon pullets. But a pullet must be thoroughly mature before she settles down to lay an egg a day.

The first rule for fall and winter egg production, therefore, is this: Get out your pullets 


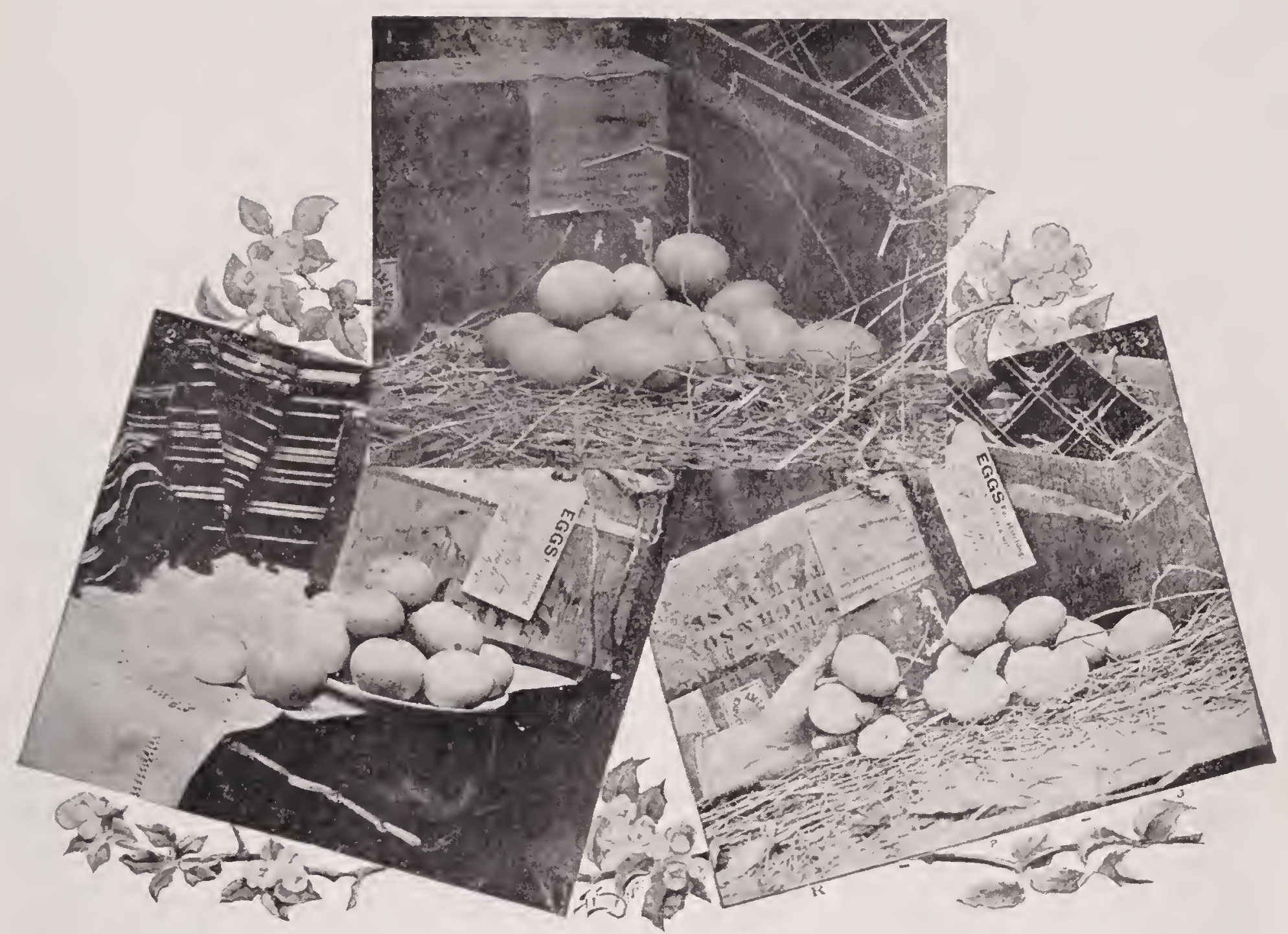

Light Brahma Eggs Weighing 2 lbs. to the Dozen, Laid by Yeal-Old Pullets that Weighed 8 and $101 / 2$ lbs. Each. In the Hand is Seen a Light Brahma Egg Contrested with the Egg of a Buff Plymouth Rock Pullet; the Small Egg Just Below was Laid by a Japanese Bantam.

early, and keep them growing from the day they break the shell to the day they go into their houses in the fall.

\section{From Free Range into Confinement.}

I have always advocated free range for growing stock, but I question whether I shall do so any longer. The man I have been telling you about has a method of handling his birds that seemed to me very peculiar at first, but which the more I think of it the more it commends itself to my judgment. He gives his laying hens free range (except in winter), while he keeps his chicks shut up in their yards.

Such a course is so antagonistic to the one commonly pursued that it does not seem to us at first glance as if it could possibly be right. And yet reflection shows us that it is based on a sound philosophy. After a hen begins to lay she acquires a certain momentum in egg production and is not easily checked. The change from confinement to free range, there- fore, does not interfere with the egg output; if anything, it increases it.

Then, too, a year-old hen in confinement has a tendency to become fat, and the range is almost necessary to keep her in good condition. She needs to be encouraged to take exercise. But with a chick it is different. The little restless thing is on the move from morning until night. Nuch of the food that is eaten goes to repair the waste of tissue that comes from so much exertion. If a chicken is left to itself it will run about the fields until the snow flies, wasting the days in useless exercise; but if the chick is kept in a yard where it cannot run about so much a large proportion of the food consumed goes to growth, and the chicken reaches maturity much sooner than it would otherwise.

The time is coming when it will not be thought necessary to allow chickens to range all over creation, but they will be brought up in small yards and kept coming from the start. I venture to say that a pullet brought up this way 
will lay at least a month carlier than one that is allowed free range.

\section{House Influences Egg Production.}

The house where the laring stock is kept has a great influence upon winter egg production. There is a man here in New Hampshire who keeps seven thousand laying hens, in houses that are open to the weather on one side--the southall the year round. While he is entitled to the credit of demonstrating the fact that fresh air is good for hens, ret it is safe to say that it is not a very heary job on his farm to gather the eggs during the winter months.

The house must be dry, warm, sunny and comfortable. Before the roung bircls are placed in it in the fall, it should be thoroughly renovated and whitewashed. If there is no scratching shed, litter must be placed in the house and the birds made to work for at least a part of what they eat. Birds in confinement need a moderate amount of exercise, although they need not be kept on the jump from morning until night. There should be a box in the house with compartments for grit, charcoal and orster shells, and there compartments should never be allowed to become empty. Eggs are 37.7 per cent. water. and so the water supply should be carefully looked after.

\section{Generous Feeding Absolutely Necessary.}

Gencrous feeding is absolutely necessary for egrgs in the fall and winter. and the food must not only be generous in amount, but must also contain all the ingredients that are necessary to repair the waste in the bird's system and produce the egg. A balanced ration is best. Bra a balanced ration I do not mean a ration mathematically and scientifically compounded, but I mean a ration from which no important element is absent.

\section{A Four Days' Bill of Fare.}

Instead of entering into the philosophy of feeding, which I have not time to do here, I can do no better than give a bill of fare for four dars which has been thoroughly tested and will do the business:

First Day: Potatoes boiled in the afternoon or evening and allowed to stand in the water in which they were boiled over night, eight quarts. In the morning pour off the surplus water from the potatoes, add the gluten, also add mixed green feed, two quarts, corn and oats ground and mixed (provender), two quarts. At noon throw whole wheat in litter, two ounces to each fowl.

Second Day: Waste bread, soaked over night, cight quarts; beef scraps, two quarts; corn and oats mixed (provender), two quarts. At noon two ounces wheat or cracked corn to each fowl.

Third Day: Clover, chopped fine and soaked over night, eight quarts. In the morning pour off the surplus water and add two quarts flour middlings, two quarts boiled beef and bone, two quarts corn meal and oats. Cracked corn for dinner, two ounces to each fowl.

Fourth Day: Whole oats, soaked orer night, eight quarts; gluten, soaked over night. four quarts. Add in the morning two quarts shorts, one quart beef and bone, two quarts corn and oats, ground and mixed. Noon, cracked corn or bickweat.

\section{The Mash and the Litter.}

All are not situated so that they can feed as I have described, but all can give their fowls a warm mash in the morning in which there are corn meal, oat meal, shorts or middlings, and a little meat in some form. Feed them all they will eat up clean in fifteen minutes, and at noon give them enough grain in their litter to keep them seratching until dark. Don't feed corn along. but vary by throwing in wheat, oats and occasionally some other grain.

\section{Green Food Every Day.}

Green food should be given to the birds every day, either in the mash or separately. Hang up a cabbage in the pen for them to pick at. Turnips, split in two and placed where they can get at them, will be eaten with a relish.

\section{Poultry Kecper.}

\section{When the Pullets Take to Laying.}

At this time of the year we anxiously look day by day for our first pullets' eggs. Some early hatched stock has been laving a week or two, but November is the month for pullets' eggs.

It is very important to place your pullets in coops as they are intended to renain during the fall and winter. It takes them a while to get accustomed to their surroundings, or, in other words, to fcel at home. Fowls are great creatures of habit, and once they establish certain habits they do not like to be disturbed. Moving layers, therefore, from coop to coop simply upsets their habits, and they begin all orer again to study the new situation, and during this time they usually stop laying. 
When pullets begin to lay they seem quite uncertain. Some will lay regularly every other day, and some only twice a week. Of coures the first eggs are generally too small for use, or at least for market use, but they increase graclually in size. It becomes quite a study to keep pullets laying regularly. A regular system of feeding has much to do with it. Br regular feeding is meant, not so much a regular hour as a regular quantity at each meal. One day a feast and the next a famine, will upset any flock of layers, and especially pullets. Forlis, as at rule, eat about so much at each meal, and it is a very easy matter to determine just the quantity required. Feeding a little short during the day induces exercise; and feeding all they will eat at night brings contentment and quiet roosting until morning. It is my opinion that the majority of breeders, even our best, feed too much, or feed injudiciously. Feeding layers to produce eggs is a very delicate matter-I do not mean to produce an ordinary number of eggs, but to produce the greatest possible number.

Birds bred exclusively for show purposes, and to produce prize winners, are usually poor lavers. This is not to be rondered at, if one knows how such stock is bred and raised. Early laying in such stock is discouraged. If the breeder is saving a string of pullets for his own show purposes, he prefers that they do not lay bafore going in to a shor, and to prerent this he continually moves them from coop to coop each time the laying tendency becomes manifest. A pullet being at her best as to shape and plumage bofore she lays her first eggs, it is the object of such breeders to keep her so.

I consider that green food of some sort fed every day in the year is really more important in a continuous egg yield than a choice of grains. Of course, in spring and summer, nature in the fields produces green food enough and in sufficient variety, but in the fall and during the winter, this green food ration should be kept up. Cabbages, mangel wurzels and steamed clorer, together with boiled beets, carrots and turnips, fill the bill almost as well.

The hardest task in maintaining a constant and continuous egg rield is to keep the laying stock in prime condition. This means such a condition of perfect health that the eggs will not only be laid regularly, but that they will be of uniform size, according to the breed laying them. Under such conditions. we should have large eggs from Minorcas, Leghorns, Plymouth
Rocks and Brahmas. When. such breeds lay small eggs, abnormally large eggs with perhaps double yolks or soft-shelled eggis, the stock is out of condition and usually orer-fat. The egges will thus be laid irregularly, and many times laying will stop entirely. Layers should be kept active, and activity is induced by short feeding. A hungry hen is usually a good layer. some breeds, such as Leghorns, Minorcas, Andalusians, etc., are by nature active, but still they can be overfed. Other breeds, such as Brahmas, Cochins and Leghorns, being naturally slow in their movements, are less active, and can be easily overfed. As a rule, lazy hens are poor layers, and must be induced to exercise. Hunger will compel activity more or less. some breeds are called good foragers. If hens are inclined to forage, and they can do this in a coop as well as in the fields, they must find something after a diligent search. Scattering grain, therefore, in very deep litter, will compel a great deal of exercise to find it. A hen that seeks and finds will be induced to seek again; but, if after great efforts in scratching, she finds nothing, she will become discouraged and wait for feed time, and then eat too much, and thus contract lazy habits.

A rery successful egg farmer once told me that in winter he always had something in his coops for his hens to pick at-scattered grain, a cabbage hanging up, and even bones with a little meat on them, always something to find in order that his flock should not contract lazy habits. In this he was humoring the natural instinct of the animal. A hen let run at large is almost alway's hunting, picking and scratching -first at a blade of grass, then a bug, then a worm, and next a seed. I think yarded hens lay more eggs than fowls let run. They cost more to keep. but the returns in eggs are usually larger. The fact is that rarded hens fed on food which is chosen because it will make eggs, convert this food into eggs, as it is intended they should, whereas if let run and fed the same way, they are apt to convert the food into flesh and muscle rather than eggs.

Feeding for a continuous egg yield requires good judgment, and a great deal of careful watching in order to keep the flock in prime condition. A good laying strain of any breed, when in prime condition, will lay eggs regularly like clock work, but it requires care and constant watching to keep the machinery in order. E. O. Roessle, in "Country Gentleman." 


\section{Chapter IV.}

PULLETS FOR LAYERS. YEAR-OLD HENS FOR BREEDERS. THE WINTER EGGS PAY THE BEST PROFIT.

原 HE onc object of all poultry keeping is profit, and as in practical egg farming it is the fall and winter eggs that pay the best profit, it is necessary that we study the conditions farorable to getting eggs in fall and winter if we would have that best profit. It is very generally concerled by observing poultrymen that the pullets are the early winter layers, hence it is obrious that we must look to the pullets for the eggs that pay that best profit. It is equally well understood. by experienced egg farmer's, that to be good fall and winter layers, these pullets must have been early hatched, and have been kept growing so that they come to full size and laying maturity before the cold weather of winter overtakes them; indeed, the writer has frequently expressed the opinion that the key note to the best profit from poultry can be laid down in these three short rules:

First: Hatch the chicks carly.

Second: Keep them growing so that the pullets shall come to laying maturity before eold weather.

Third: Keep them laying by good care and good food.

The full story of profitable egg farming is condensed in to those three short rules.

It is equally well understood that the chicks hatched from the eggs of pullets are generally slightly smaller, and are likely to be less hardy and vigorous than the chicks from the eggs of year-old hens, and the wisest poultryman hatches the chicks which are to be the future laring-breeding stock from the eggs of year-old hens. This principle of pullets for layers and year-old hens for breeders makes it easy to plan our method of procedure. To get the best allround results, three-fourths of our stock should be early hatched and well matured pullets, we will get the bulk of the early fall and winter eggs from them,- the eggs which pay the creamy profit: and by selecting for the future breeter's the best layers among those pullets and breeding from them when they are year-old hens, we will strengthen the laying habit and thus increase and derelop it. It is well known that not every pullet hatehed from eggs produced by a great layer will be a great laver, just as it is known that not every colt from record trotting ancestry will prove a great trotter; still we will get the best results if we breed from stock of known great-laying ancestry, because by breeding from that stock we will strengthen and develop the egg-producing quality.

In this chapter we give numerous articles which show, also a report of a poultry experiment conducted at the Utah Agricultural Experiment Station, the illustrations accompanying which clearly show, that it is to the pullets that we must look for profitable egg production. With a certainly better average size of the egg, and consequently better size of the chick hatched from the egg (even with a lesser egg yield), the year-old hens will be profitable to us if we consider them chiefly as breeding stock; they will not lay so many eggs at the time of the highest prices, but during the breeding season, when we want their eggs the most, they will be practically as good egg producer's as the pullets; the profit of keeping year-old hens is in the greater strength and vigor of the young chicks hatched from their eggs, and that greater strength and vigor is of itself a good profit for keeping them. We must have great strength and vigor in our laying stock if they are to be really great layers. This point is well brought out in Bulletin No. 79 of the Maine Agricultural Experiment Station which reports poultry experiments in the years 1900 and 1901 . In that report is given the egg records for two years of the many tested birds, and this statement is made:

"Every hen that has laid large numbers of eggs through the first two years, has shown 


\section{PULLETS FOR LAYERS.}

much vigor and constitution." This strong statement will be no surprise to an experienced poultryman, and is worth quoting here because we want to emphasize the fact of the neccssity of the greater strength and vigor, which we get in chicks hatched from the eggs of year-old breeding stock. This same bulletin of the Maine Experiment Station reports the results of breeding from known great layers, and by thus breeding it has developed the egg laying tendency of the stock. In their breeding pens are hens that have laid over 200 eggs each within the year, and the best layer of all laid $251 \mathrm{eggs}$ within a year of reaching laying maturity. One is reported which laid 201 eggs the first year, 140 the second and 130 the third year; making a total of $t \bar{r} 1 \mathrm{cggs}$ within the three years; another hen laid $191 \mathrm{eggs}$ the first year, 157 the second year and 138 the third year, making 486 eggs in the thrce years. The bulletin goes on to say. "During the three years in which we have been scketing breeding stock by use of trap nests we have found 30 hens that laid between 200 and 251 egge in a year. All of the other breeding stock we are now carrying are tested hers that have laid over 180 eggs in a year, pullets whose mothers laid orer 200 eggs in one rear and whose father's' mothers laid over 200 eggs in one year; and pullets sired by cockerels whose mothers and grandmothers laid over 200 eggs in one year." It is a plcasure to quote these statements, they so capitally illustrate the importance of breeding up the eggproducing habit; by following in the foot steps of the Iaine Expcriment Station people we will substantially improve the laying qualities of our stock.

A point frequently overlooked in connection with pullets for layers is, that if the hens are all kept over a second, third and fourth year they occupy the house room and are eating food of pullets which would pay double the profit. We do not claim that a pullet would lay twice as many eggs as a hen, the point we want to bring out is, that a greater proportion of the pullets' eggs are produced at the time when prices are highest and pay the best profit. Eggs are high in price at that time because the hens have not recovered from the molt and are taking a rest, and also because many of the pullets are late hatched and have not begun to lay. If we are so fortunate as to have carly hatched and well matured pullets laying at that time we are getting the "crean" of the profit from egg production.

Another point which we necd to keep in mind is, that if the hons are kept over we lose the amount which they would sell for, and if we have got good stock the anount the hens sell for materially increases the profit account.

A few weeks ago the writer was visiting Chicago and was told of an Illinois farmer who shipped some coops of Plymoutly Rock hens to a South Water Street commission dealer the wrek before, the hens met a 15 cent market and returned the farmer $\$ 1.07$ cach after freight and commission rere paid. Obriously if this Illinois farmer had kept orer those hens he would not have received that $\$ 1.07$ each.

Some writers claim that the cost of raising pullets to take the place of the year-old or twoyear-old hens must be considerable, but re have proved, year after year, that the cockerels hatched with the pullets can be sold at from four to fire months old for curough to pay for all the food eaten by both themsclves and the pullets, hence, considering the cockerels as simply a by-product, the pullets cost nothing for the food they have caten up to laying maturity. Some will be inclined to doubt this statement, but, as we stated before, we demonstrated it again and again, and can prove that the pullets at laying maturity cost absolutely nothing but the labor of caring for them; obviously then, all of the money received for the sale of the ycar or two-ycar-old hens is clear gain.

It is the old familiar story of the slow shilling and the nimble sixpence; the latter pays its owner many times more interest than the slow shilling. The pullets not only pay us the better profit in the increased number of eggs produced, but the failure to sell the old hens entails the expense of house room and food which could have been used by more profitable pullets, which would be so much better layers; and it also cuts us off from the income of the sale of the hens themselves.

With these several points of advantage clearly in mind we think our readers will understand the importance of the motto,- "Pullets for layers, and year-old hens for breeders."

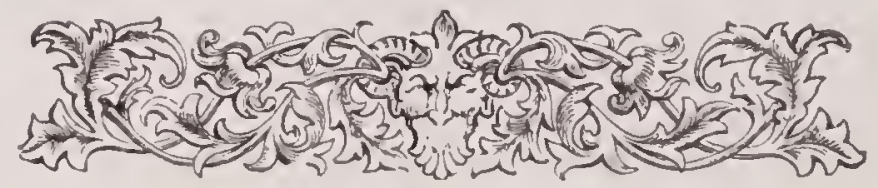




\section{Four Thousand Eggs in December.}

We didn't quite do it - the exact figures being 3,957-but we expected to pass the 4,000 mark, and up to Christmas day there was every indication that we would do so; but our young man went home for a week's vacation, and the eggs dropped off a little-one here, another there, possibly owing to slight difference in quantity of food, and we were 43 eggs short of our ambition.

The record is perfectly satisfactory as it is; we have no hard feelings toward the birds that gave us $\$ 130$ worth of eggs in thirty-one days, and we feel that not many of our readers can beat that record.

We have 90 year-old fowls, and 290 pullets, and their total egg-yield for each day was:

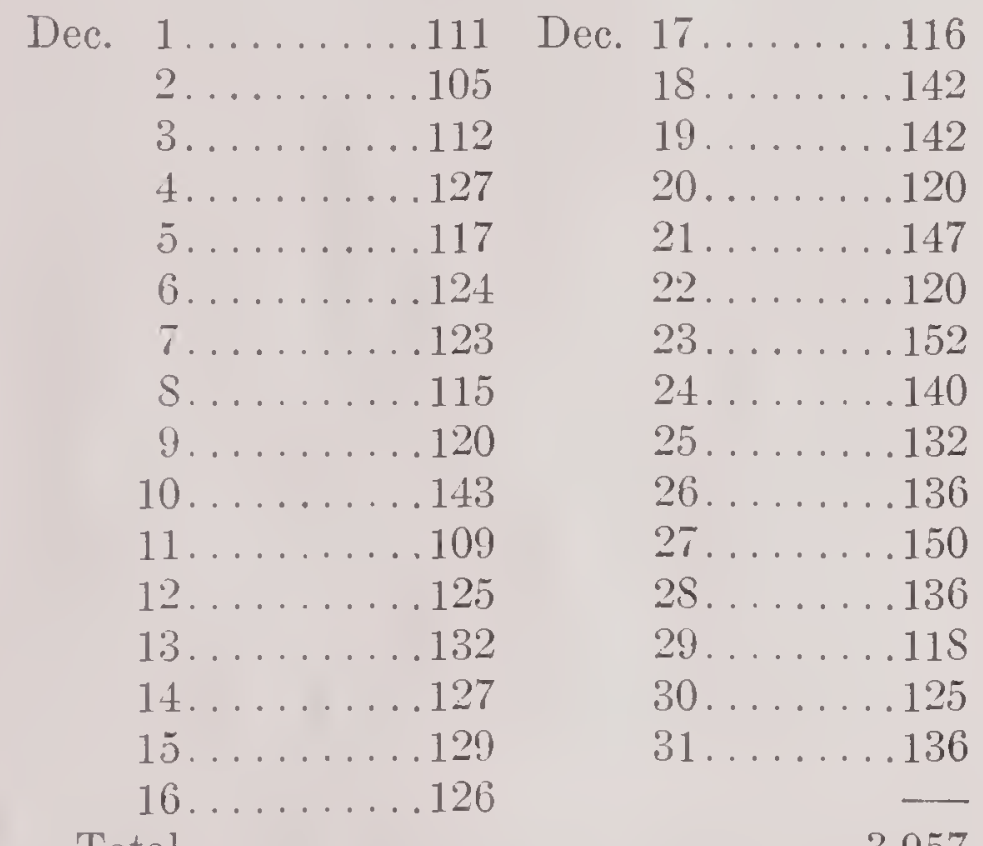

Total . . . . . . . . . . . . . . . 3,957

This is an average of almost ten and one-half eggs per hen for the month, and quite as much as can reasonably be expected. If one is getting $\frac{1}{3}\left(33 \frac{1}{3} \%\right)$ egg yield in December, he is doing all that he has a right to expect. Many of the old hens haven't fully recovered from the drain of the molt; and pullets do not (as a rule) produce an egg every other day in early winter. We have one pen of pullets that did. One pen of Leghorn-Lt. Brahma cross, laid an average of $15 \frac{1}{2}$ eggs apiece-exactly $50 \%$ egg-yield; and a pen of White Wyandotte pullets laid an average of $14 \frac{1}{2}$ eggs apiece, a very close second.

It is easily apparent that it is the pullets that produced this highly satisfactory egg-yield. The 290 pullets laid 3,373 eggs, an average of (practically) $11 \frac{2}{3}$ eggs apiece; while the 90 yearold hens laid but 554 eggs, (practically) $6 \frac{1}{2}$

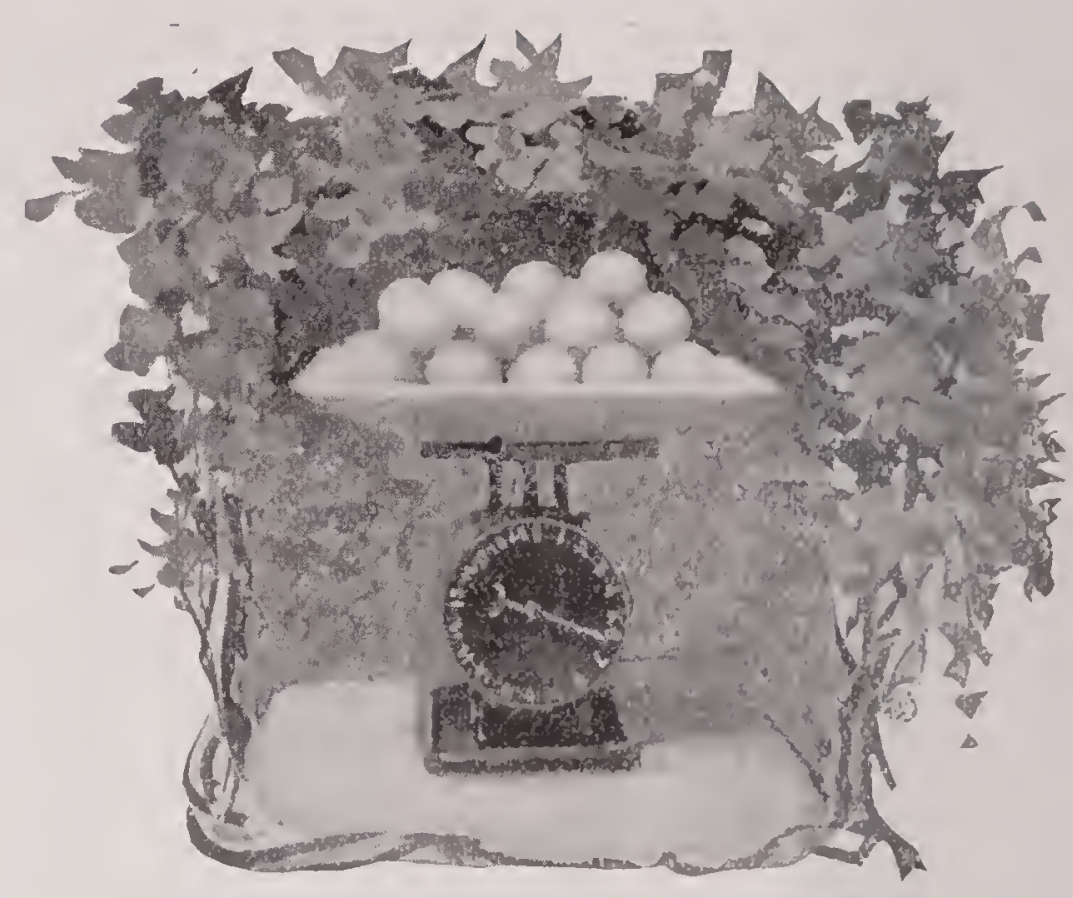

White Wyandotte Eggs Weighing Two Pounds to the Dozen. This is the kind of eggs that the housekeepers crave and will pay a Handsome Premium for. From the Poultry Farm of Barnes \& Woodbury, Wenham, Mass.

eggs apiece, a difference of about $90 \tau_{0}$ in faror of the pullets.

The price of eggs has been 40 cents a dozen for most of the month, and the market ralue of these eggs is $\$ 130$. It costs us about $\$ 1.35$ to feed a fowl a year, which is $11 \frac{1}{4}$ cents a month, making a cost of feeding these 380 forls for that month, $\$ 12.75$, leaving us a profit of $\$ \$ 7.25$ a pretty fair return for one month's work, and that the dull month of December. The profit, however, is really greater than that. Those fowls have got to be fed whether or not they are laying. A certain amount of food has got to be fed them to repair waste and furnish fuel for necessary warmth; those animal economies must be met first, and it is only when there is a surplus over and above these calls, that there are eggs produced. It is usually estimated that it costs $\$ 1$ a year to feed a fowl, which is $8 \frac{1}{3}$ cents a month, making $\$ 31.67$ for a month's food for 380 fowls, and that allows $\$ 11.0$ for the surplus-the meat meal, green food, etc., which induced the egg-yield.

There was no "happen so" about those eggs. They were planned for long ago. The pullets that laid them were hatched early, were fed for growth, so that a good many were laying in October, and since November they were fed for eggs, and they have been kept at work.

\section{Farm Poultry.}




\section{PULLETS VS. HENS AS PROFITABLE LAYERS.}

\section{The Pullets Excel Yearling Hens and Greatly Excel Three and Four-Year-Old Hens-Reliable Data from a Reliable Source.}

Age may bring reason to the hen, as it sometimes does in the case of a man; it may bring her experience and witl experience wisdom, as occasionally happens to her owner. But does age with its reason and experience with its wisclom, assist the hen in the production of egrgs? That is the question that appeals to the practical pouttryman.

Having in view the interests of this class of poultry keepers, experiments were inaugurated at the Utah Experiment Station to test the relative egg-producing capacity of hens at different ages. 'Two pens of three and four year' olds were placed in "competition" with two pens of pullets. The breed was Rose Comb Brown Leghorn in each case, and the strain was the same. There were four fowls in each pen. The pens were 5 feet by 7 feet, and attached to each was an outside yard $5 \times 40$ feet.

The following table gives the average results of the experiment for the first year, 1896-7:

\begin{tabular}{|c|c|c|c|c|c|c|c|c|c|c|}
\hline \multicolumn{7}{|c|}{$\begin{array}{l}\text { Weight of Food Consumed Per Fowl, in } \\
\text { Pounds and Cost of Same. }\end{array}$} & \multicolumn{4}{|c|}{$\begin{array}{l}\text { Number of } \\
\text { Eggs Produced } \\
\text { and Value. }\end{array}$} \\
\hline 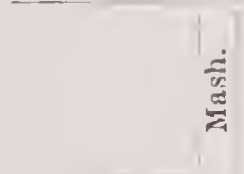 & 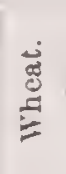 & $\begin{array}{l}\dot{D} \\
\stackrel{0}{3} \\
\dot{D}\end{array}$ & ¿̇ं & $\underbrace{\dot{0}}_{0} \frac{0}{2}$ & 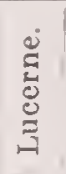 & 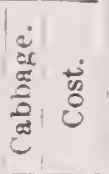 & 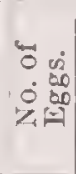 & 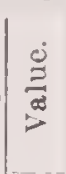 & 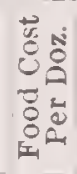 & 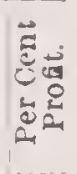 \\
\hline $\begin{array}{l}\text { Old Hens }(1) \ldots 10 \\
\text { old Hens }(2) . .10 \\
\text { Average........... } \\
\text { Pullets }(1) \ldots . .10 \\
\text { Pullets }(2) \ldots . .10 \\
\text { Average............ }\end{array}$ & $\begin{array}{l}221 / 8 \\
27 \\
\ldots \ldots \\
25 \\
27 \\
\cdots \cdots\end{array}$ & $\begin{array}{l}10 \\
101 / 2 \\
10 \% \\
101 / 2 \\
\cdots \cdots\end{array}$ & $\begin{array}{l}6 \\
61 / 2 \\
\cdots \cdots \\
6 \\
61 / 2 \\
\cdots \cdots\end{array}$ & \begin{tabular}{l|l}
11 & 1 \\
14 & 1 \\
$\ldots$ & $\cdots$ \\
14 & 1 \\
14 & 1 \\
$\cdots$ & $\cdots$
\end{tabular} & $\begin{array}{l}5 \\
41 / 2 \\
\cdots \ldots . \\
41 / 2 \\
41 / 2 \\
\cdots \cdots\end{array}$ & $\begin{array}{r}\quad \text { Cts } \\
3531 / 4 \\
462 \\
\ldots 57 \mathrm{r} / 2 \\
7611 / 4 \\
462 \\
\ldots 62\end{array}$ & $\begin{array}{r}64 \\
107 \\
85 \\
158 \\
182 \\
170\end{array}$ & $\begin{array}{r}\text { Cts } \\
56 \\
100 \\
78 \\
168 \\
188 \\
17 x\end{array}$ & $\begin{array}{l}\mathrm{Cts} . \\
9.9 \\
6.9 \\
8.4 \\
46 \\
41 \\
4.4\end{array}$ & $\begin{array}{r}5 \\
61 \\
33 \\
174 \\
203 \\
188\end{array}$ \\
\hline
\end{tabular}

It will be seen from the above that the two pens of old hens laid an average of 85 eggs per fowl during the year, while the two pens of pullets laid 170 , or exactly double the number laid by the former. The value of the eggs laid by the old hens was 78 cents per fowl, and by the latter $\$ 1.78$ per fowl. The cost of the food required to produce a dozen eggs was 8.4 cents for the old hens and 4.4 cents for the pullets.

The pullets of $1896-7$ were continued as onerear-old hens the second year, 1897-8, with addition of another fowl of like age, breed, and former treatment, to each pen, making five fowls in each during the second year. The results of their second rear's work are giren in the folkowing table.

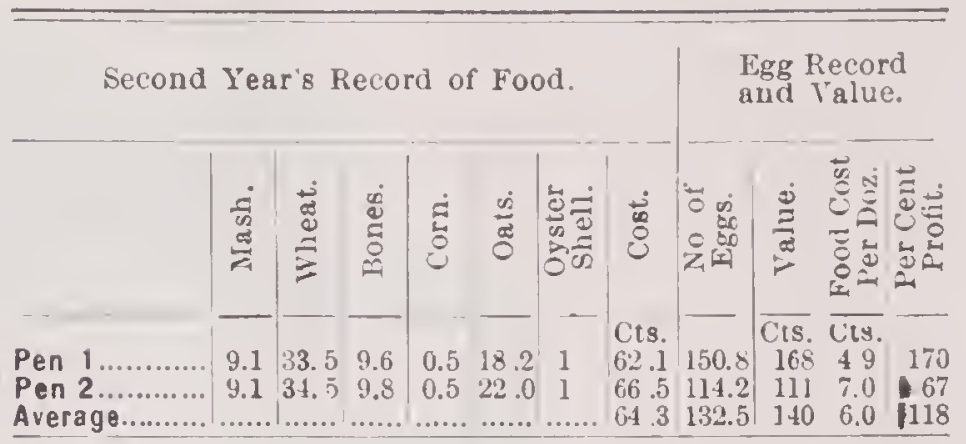

It is seen that pen 1 laid during the second year an average of 150.8 eggs per fowl, against 158 the first year. Pen 2 laid 114.2 the second year against 182 the first. They areraged the first year 170 per forl and 132.5 the second year. As pullets their eggs were worth an average of $\$ 1.78$ per fowl, and as one-year-old hens they averaged $\$ 1.40$, a difference of 38 cents in favor of the first year's laying. But the profit from the two is another question. Deducting the cost of food in each case we find that the profit was $\$ 1.16$ per fowl the first year and 76 cents the second year. That makes the per cent. profit on food the first year 188 and 118 the second.

These figures will afford some basis for discussion of the question, does it pay to keep hens two years? Figuring on food cost alone there is a ver'y satisfactory profit the second year as well as the first; so that it does pay when food cost alone is considered. But then there are other items of cost-labor, a yet unknown quantity, and interest on investment. The expense of keeping a pullet is no greater than that of a hen, and these figures show that the profit was some 50 per cent. greater for the pullet than the year-old hen. For ease of calculation suppose a man can care for a thousand hens. If they are pullets, according to these results, they will yield a profit on food of $\$ 1,160$ per year. If they are one-year-old hens the profit will be $\$ 760$. In the one case the man will have $\$ 1,160$ for his labor, interest on investment, etc., and $\$ 760$ in the other case; a difference of $\$ 400$ in favor of killing off the hens at the end of the first year. As he can care for only a limited number of hens it certainly would pay him to renew his flock every year, assuming that the cost of replacing the hen with a pullet can be paid with the money recerved from the sale of the hen. But the life of the great majority of the hens of the country is doubtless longer than 

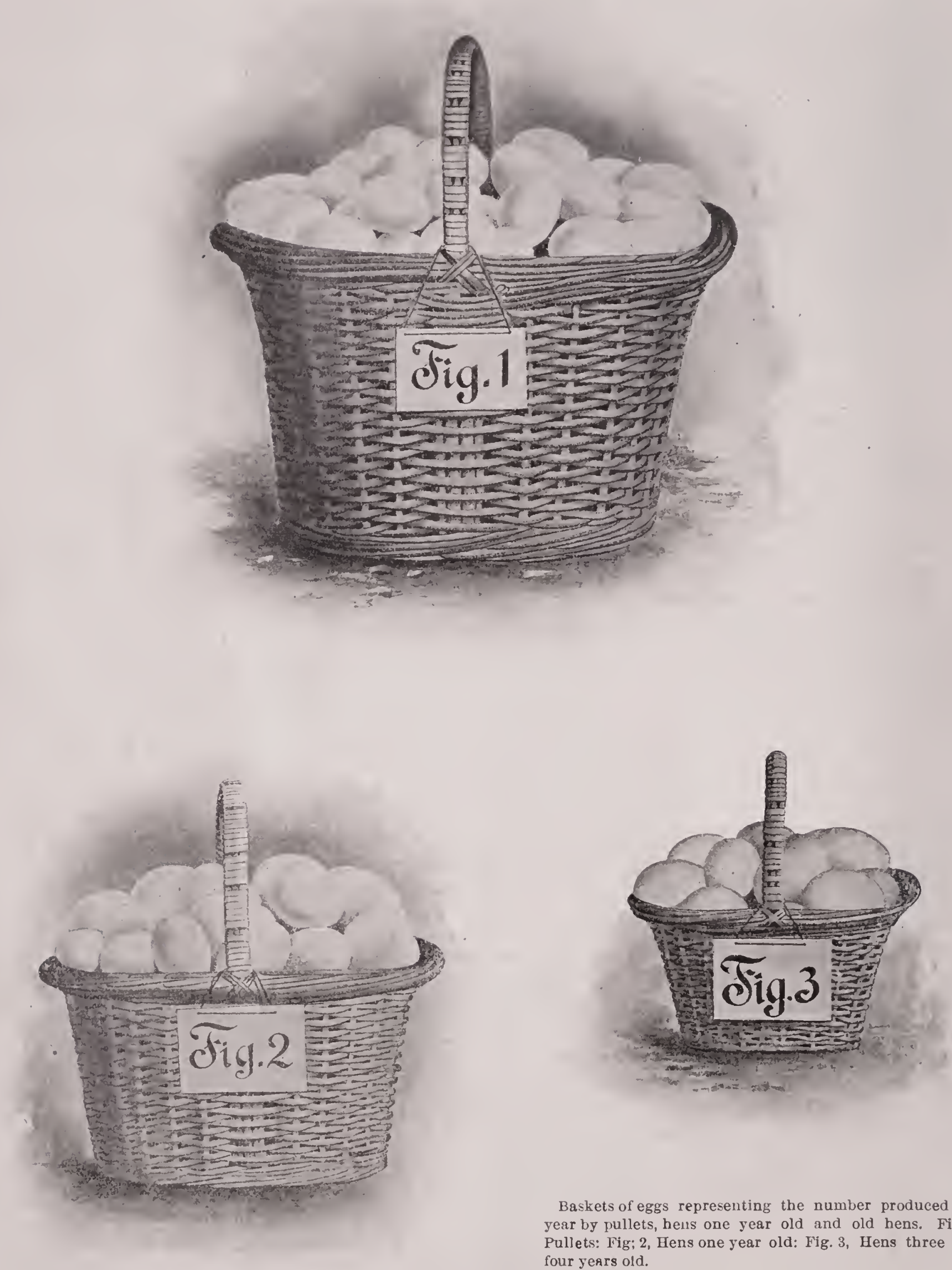

Baskets of eggs representing the number produced per year by pullets, heus one year old and old hens. Fig. 1. Pullets: Fig; 2, Hens one year old: Fig. 3, Hens three and four years old. 


\section{PULLETS FOR LAYERS.}

two years. If we refer again to table 1 , we sce that the average value of the eggs produced per fowl of old hens was 78 cents. Their food cost $57 \frac{1}{2}$ cents, leaving only 20 cents profit on food. With a thousand such hens there would be left only $\$ 200$ to pay for labor and interest on investment, as against $\$ 1,160$ in the case of pullets and $\$ 760$ for one-year-old hens.

In the above I have given the data obtained in a two year's experiment. The results may be modified in further experiments. They are being continued at the Station and the third year will be completed in November.

All pens were fed alike, except as to quantity. A mash composed of two parts bran and shorts and one part each of chopped corn and oats, was fed in the morning. About 10 o'clock a little grain was fed. Three times a week cut bones were fed. Cabbages were fed until about the first of March, after which, and until green grass could be secured, lucerne leares were fed dry. This was scattered in the pens. During the summer green grass was thrown into the pens. No stimulating food was fed, except a little cayenne pepper in the morning mash. Salt was also used in the mash. During the winter coal ashes $\pi$ ere kept before the fowls, also a little gravel. No oyster shells were fed until the middle of the summer.

Though it is not a part of my subject, it may be mentioned incidentally that this experiment involved a test of the value of exercise. The pens marked (1) received their grain food in a box; the others (2) were fed in a litter of straw on the floor, inducing exercise.

\section{Eggs in Winter.}

The poultryman, or the housewife, who fails to get eggs during the cold months of the year is not getting the best returns possible, and runs very close to making a bad showing of the year's work. It seems strange to meet the apparently indifferent feeling of many as regards winter production. Some will tell you that you cannot get many eggs in winter. Others say it does not pay for the extra work to produce the eggs during cold weather. You may be sure that these doubtful poultry keepers do not get many winter eggs, and probably have to buy of some neighbor who has good "luck."

In my experience with poultrymen I have known only one who failed to get winter eggs, who ever had the courage to expand his poultry plant, and he succeeded only because he was catering to a fancy egg demand at three dollars per sitting. I have noticed that quite a number who do not adrocate winter egg-production have only an ordinary egg yield in other months of the year, while those who do succeed in getting winter eggs have just as large a supply in spring and summer. Another side to winter egg yield is the pleasant results when eggs from these layers are set in spring, as they are most sure to be fertile.

Eggs can be had in winter. In Canada, in the Northwest, in New England, and in the South, wherever we turn our eyes, we see those who are getting good results in winter. If others are succeeding you can. Iou may be cliscouraged because no one in your town is getting winter eggs, and you fear you cannot. I think if you inquire at the store, rou will find that there is someone near you who is quietly bringing to market eggs every month of the year. Look up such a one, call and ask questions, and you will get plain answers. Ijo not be satisfied until you get out of your poultry all it is possible, both of profit and pleasure.

In order to begin to get eggs by November, it is necessary to have well matured birds. Brahmas and Cochins should be hatched in March, Wyandottes and Plymouth Rocks in April, Leghorns and Minorcas in May or June. Under the best conditions, birds may be hatched later than the months stated, but for all-round success, the time given will be found about right.

The early hatched birds should not have to fight for existence. Keep lice under control from the egg to the laring age. Feed for growth, many poultrymen fail just here. The fecding ration must contain all elements needed for building a living creature. It does not pay to take the chance of a bird finding for itself any special line of food. Buy only sound food. Do not use any grain that is musty or sour, because it is cheap. Less in quantity of better grain will give as good results, and you will not run the risk of sick birds from bad food. Feed wheat and barley rather than all corn. Do not depend on bugs to supply animal food, but fecd every day something in the way of ground meat or green bone. Fresh water is necessary to get the best results from good and proper care.

As chicks and roung pullets, the birds must have air and sunlight. Do not at any time allow the chicks to be crowded. Have wire front to coops, giving safety from enemics, while air is admitted freely. Give the growing birds 
all the run possible, cooping out on grass fields after having. If this is not possible, do the best you can, supplying green food and not raising too many birds. When the cockerels are half grown, remore them to some other yard, giving their room to the pullets.

The most important prerequisite to success is birds with the winter laying habit. By giving the right care, you can do much with any birds to increase the winter ege yield, but good solid success only comes when you have good working birds: to use. By selecting the best layers to breed from each year, rou can build up a prolific strain. Buying a male bird of known pedigree for winter laying, and mating him with the best hens you will hasten the time when you will be getting good results.

In the long run, it pays to start as soon as you can, with birds that have fixed in them the laying habit. If you have no such birds, be on the lookout for egg's or stock from prolific layers. No matter what birds you prefer or need for your special purpose, you will find that there is a wide difference in the laying on various poultry plants. It is not aways the ordinary bird that does the extraordinary laying. On the contrary, we find today many prolific layers that are high scorers. Fancy breeders are giving more attention than ever before to attaining utility as well as show points. Blood does tell in a hen, as well as in a horse or cow. Build up an egg strain, and in time you will get your rewaril.

Whatever the condition of the birds you may have to depend upon for your winter layers, much can be done to get the best results. Get the pullets into their winter quarters early. This enables them to settle down and become at home. 'Hare the house well whitewashed, and free from red mites. Clean up all floors and rindors. Dust every bird with some good insect powder, and repeat in two weeks. In caring for the birds, be quiet as possible, making no motion that they consider to mean danger to them. By all means keep the dog out of the house and yard.

The house should be water tight, with no cracks to let a current of cold air onto the birds. The open front scratching shed house has helped solve to a large extent the keeping of healthy stock, and the getting of eggs in the off season of the rear. The hens are so warmly clad that they will stand a low temperture. provided they receive proper food and are obliged to scratch for their grain. The trouble from the old time house was danger from extremes of temperature. The tight house woukd warm at midday to $\mathrm{SO}$ or 90 degrees and cool down to 10 or 20 degrees at night. Hens well fed and kept busy will pay little attention to freezing weather.

Scratching material must be furnished with free hand. This may be cheap hay, straw, leaves, or corn fodder. It will need little cutting as the birds will soon work it up fine enough if fed their grain in it. Clean water and sharp grit must always be within reach. To depend, even partially, on snow and gravel, is to take serious chances of failure.

Ficeding the mash in the morning give only what the birds will eat at once, keeping them in a condition to be willing to hunt in the litter for stray grain. At noon a light feed of grain or barley is scattered in the straw, and the hans scratch, sing and lay. The busy hen is the business hen.

The supper should be a full feed of wheat or corn. Too many farmers depend upon corn and corn meal for poultry food. Corn is the most unbalanced grain we have in use. If not sure how to feed it, err by using little of it.

When using the mash suggested above don't give green bone. If you wish to use cut bone, feed it twice a week, at noon, giving what the birds will eat quickly, having omitted from that morning's mash all animal food. Cut clover may be fed in the mash or by itself.

Be quick to notice anything wrong about the birds. Fnow your best layers and hatch from them each spring. Of their chicks mark those that mature early and prove prolific layers. In buying fresh blood see that you get birds or eggs from good layers. It is not necessary to use crosses to get good layers. In fact, the thoroughbreds have got ahead of the old barnyard fow or cross. In the cold North, I should prefer to take my chances of success with the mediumsized birds, such as Wyandottes or Plymouth Rocks. Whatever breed you keep, do not be satisfied until you have as good a winter egrg record as has been recorded for the variety.

There is a pleasure in getting eggs when they are high in price, not only for the cash they bring, but also for the satisfaction that comes from succeeding in what we try to accomplish. The foundation upon which to build the successful poultry plant is winter eggs.

Dr. N. W. SANBORA, In "Farm Poultru." 


\section{CHAPTER V.}

\section{PRACTICAL EGG FARMS. HOUSES AND YARDS; CONTINUOUS HOUSES WITH}

\section{YARDS; COLONY POULTRY HOUSES. MANY SUCCESSFUL POULTRY \\ PLANTS ILLUSTRATED AND DESCRIBED.}

$\int_{0}^{1}$

HERE are many practical egg farms in the Eastern States, and in this chapter we give several accounts of visits made to, and observations upon, several of those practical egg farms. with the purpose of contrasting methods and suggesting instructive comparisons.

A study of these various articles will reveal that the great majority of these poultry farmers house and yard their stock upon what we may define as the continuous-house plan. The consensus of opinion among observant poultrymen is to the effect that yarded fowls are greater egg producers than fowls giren free range,--the theory being that fowk kept on the semi-confinement plan, (that is, kept confined to houses and yards), do not waste food-energy in ranging widely. Experienced dairy farmers have learned that cows yielded a substantially more liberal milk-flow if fed at the stable by the soiling system, and given perhaps two or three hours of outdoor exercise daily to keep them in good health, than if permitted to range widely; and as the conditions of milch corrs and of fowls hept for egg production are decidedly analogous, it seems reasonable to think that forrls which are somewhat restricted as to exercise, will have more energy for egg production.

There forls are kept confined to houses and rards, scrupulous attention must be paid to cleanliness of floors, nests, roost-platforms, etc., exercise must be promoted in winter when the birds are shut in by inclement weather or snow on the ground, and plentiful supplies of animal and vegetable food must be provided; growing careless as to some of these essentials has frequently been the first step on the road to failure!

It is the opinion of many poultrymen that the disadrantages of the colony-house plan decidedy outreigh the theoretical adrantages, and we know of poultry farms where the semi- confinement plan has been adopted after giving the colony-house plan a full trial, it having been found that there ras a decidedly greater cost in caring for the fowls and smaller proportionate returns, also that in inclement weather, (the very time when most needed), regularity of feeding and watering was extremely difficult. In mild elimates these objections rould have less reight, and there are situations where the colony-plan would be most desirable, such as on a fruit farm where the services of the birds as insect exterminators and scarengers would be decided helpful. The unprotected condition of the birds at all times would need to be considered, as both tro and four legged enemies have to be guarded against; in the one locality where colony egg farms have been most successful, in the towns of Tiverton and Little Compton, R. I., and the adjoining torn of Westport, Nass, the conditions are exceptionally farorable; it being practically a peninsula extending out into the sea and with no railroad or other disturbing factor. Other things being farorable, protection could be provided by a strong woren- wire fence enclosing the tract and a brace of stout dogs turned loose in the enclosure at night.

If fowls are to be confined in houses and yards, it is economical of both labor and fencing material to build the houses upon the continuouspen plan, or on what might be called the semidetached house plan. In the one case the attendant is wholly under cover in going from pen to pen, and in the other there is some exposure in the short clistance betreen the houses; in the colony-house plan there is considerable exposure in traveling orer the farm, visiting the different houses to do the essential work of feeding and watering and collecting the eggs.

Where forls are kept confined in houses and yards their bodily wants must be carefully at- 


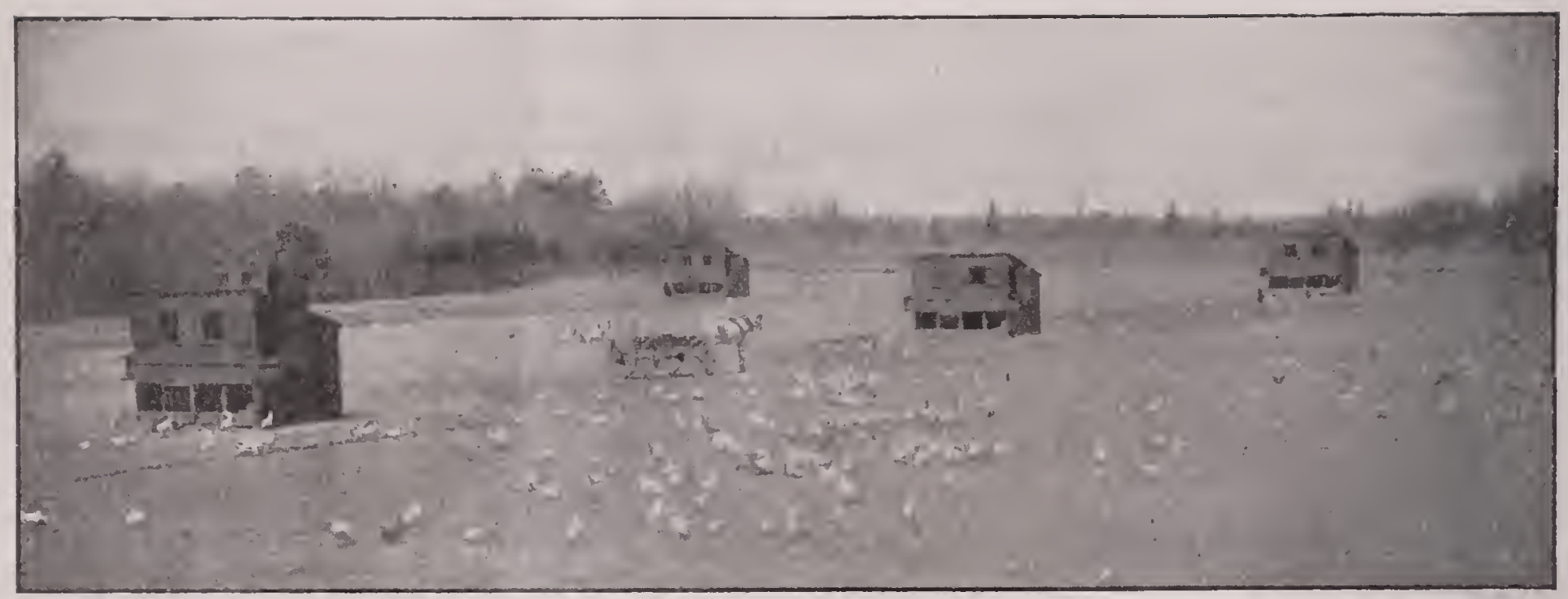

Colony Houses for Laying Stock, Lakewood Farm.

tended to,- and regular supplies of green food, animal food, etc., must be given. Where fowls are kept on the colony plan and allowed free range, they will supply themselves with green food; and, in summer time, when worms, insects, etc., are abundant, ther will supply themselves with considerable animal food. Most of the colony-house egg farms which we had the pleasure to visit, rere established before the method of "dry-feeding" had received much consideration. and the decided success of the dry-feeding method may cause us to revise our estimates somewhat. With fowls cared for by the dry-feeding method, with food and beef scraps constantly accessible. they do not roam far and give better all-round results than when they are fed twice daily by the attendant, and are given a mash food in the morning and hard grain at night. This thought is suggested by some correspondence which the writer has recently had with some gentlemen of a Missouri corporation, relative to the establishing of an egg farm in connection with a 3,000 acre fruit ranch in that State. Obriously the colonyhouse plan woukd be the only plan for such a combination business, and equally obviously the dry-feeding method would decidedly facilitate economy of operation, as well as give better returns.

Some of the adrantages of continuous-house egg farms are the housing and yarding of large numbers of birds in a comparatively small space-say 400 or 500 birds to the acre-and grouping the houses and yards about the farmbuildings, there is coupled with this method the disadvantages of decided increase in cost of construction,- the expense of building and main- taining fences, practically doubles the cost of construction. Opinions differ as to the economy of operating. The more constant attention required by fowls confined in houses and yards, with an average round of six visits per day to each pen, (three for the morning, noon and night feeding, two for watering and one for collecting the eggs), is fully balanced if not outweighed, by the greater time consumed in going around to fifty or one hundred houses set 150 to 200 feet apart, two or three times a day by man and horse.

It is important that a plan of operating be carefully considered, and the poultry plant constructed to facilitate the operating. Many poultry plants are just a "happen-so," having been built from time to time as the circumstances and inclinations of the owner farored, and not infrequently one is found that has become unwieldy, has become so top-heary it is impossible to carry it on advantageously. One does not need to have elaborate and expensive buildings, but the houses for the stock must be dry, free from draughts, and so situated that they can have the maximum of sunshine in the winter; and they should be so planned that the essential labor of caring for the flocks is favored as much as possible. The conditions that promote the best health of the birds must not be sacrificed to the "convenience" of the caretaker", lowerer, and those conditions are absolute dryness of the pens, sunshine and fresh air, fresh, clean water and an adequate supply of proper food. House plans and yard plans are fully treated of in Book No. 3 of this series of Practical Poultry Books. hence we do not need to consider house plans in this book: our interest is the basic principles of profitable egg farming. 


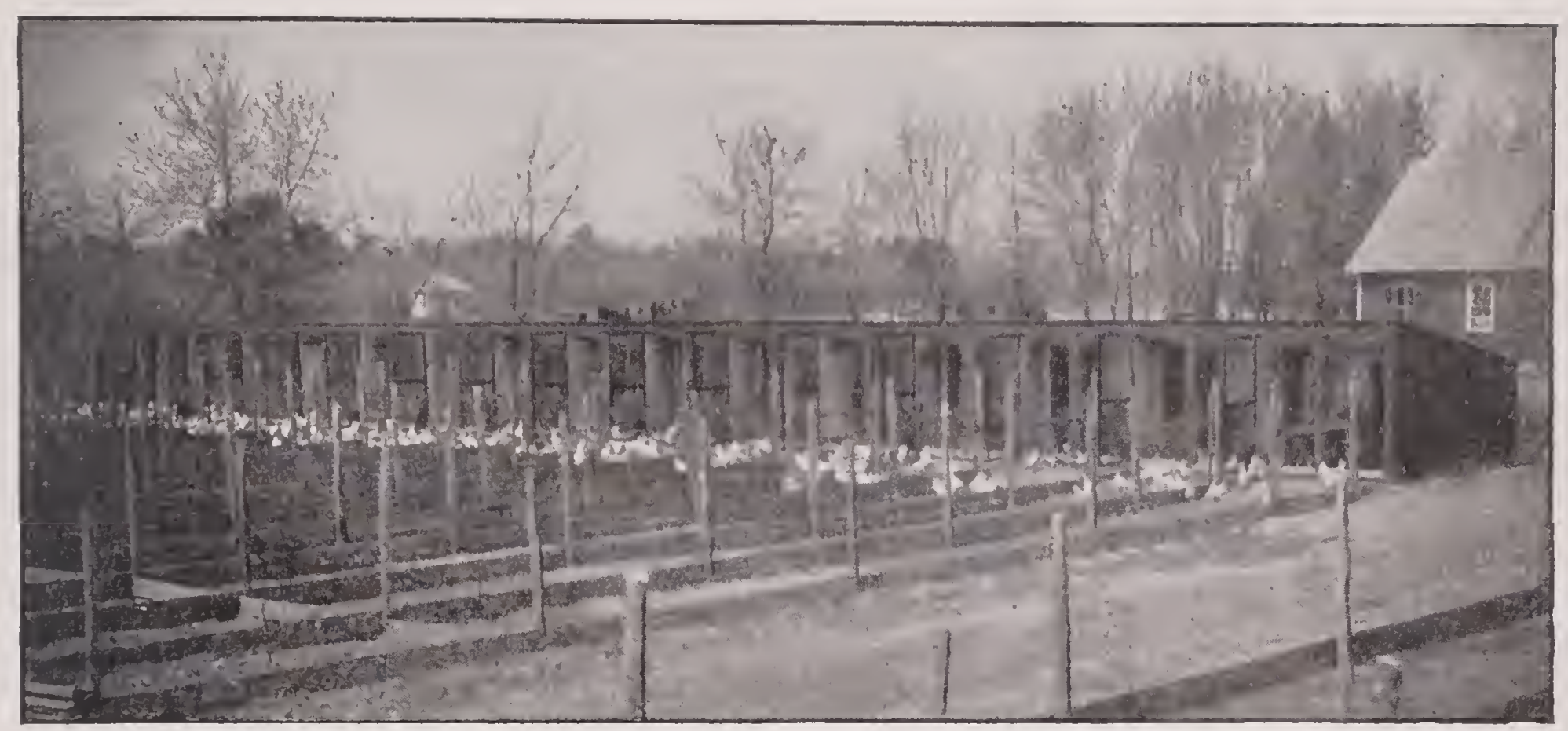

Breeding House and Yards, Lakewood Farm.

\section{A GREAT EGG FARM.}

\section{How Two Young Men are Building up a Profit- able Business. Strictly Fresh Eggs in Demand.}

It is very interesting to visit a large poultry plant soon after it has got under way, and, indeed, while it is still in process of construction, and such was my pleasure a few weeks ago when I visited Lakerrood Poultry Farm, Burrsville, N. J. Lakewood is widely celebrated for its mild winter climate, and its attractiveness as a winter resort is well known. Situated on the eastern-central shore of New Jersey, but a few miles back from the coast, Lakerood air is dry and warm for such a northern latitude, and that section of the State is much resorted to by people with delicate throats and a tendency to lung troubles. It was an affliction of this kind that brought Mr. A. S. Brown to Lakewood, and the region so strongly attracted him that he bought a farm of about 90 acres at Burrsville, situated on the State road, four or five miles from Lakerrood and about half way between that town and the ocean. Here the Lakewood Poultry Farm was established and a young friend, Mr. Ammidown, was taken into partnership.

The proprietors of Lakewood Poultry Farm are working partners, as is evidenced by the fact that Mr. Brown was pointed out to me at work down in the field, where I found him putting in the foundation of a new colony poultry house, and shortly afterwards we found Mr. Ammidown feeding the chickens in the long brooder house.

The introductions and greetings over, Mr. Brown began right where we were standing by telling us something of the methods of erecting poultry houses there on the south Jersey sandy land. The method is simply to set posts in the ground below the possible frost line, the tops being cut off a foot above the ground level, hemlock boards are nailed to the foundation posts and the ground filled in to the level of the sills by simply shoveling the sandy soil into the inclosed space; with land consisting almost wholly of sand, there is no trouble about the drainage, water sinks into it immediately, and it carries with it the wash from the droppings, so that with reasonable care the soil does not become poisoned by the accumulated droppings.

The farm consists of about ninety acres of land, one-half of which is still in the native woods; and most of the cleared land is set in fruit trees. At the time of our visit they were keeping about 2,500 head of laying fowls, White Wyandottes and Single Comb White Leghorns, and buildings being erected were planned to increase the capacity to about double the number, - it is the intention to carry about 5,000 head of laying stock each winter. The business began with supplying strictly fresh eggs to a select city trade, and has grown to include the furnishing of strictly fresh, unfertilized eggs to hospitals and other public institutions. The trade, originally in New York City, has been extended to the city of Newark, and 


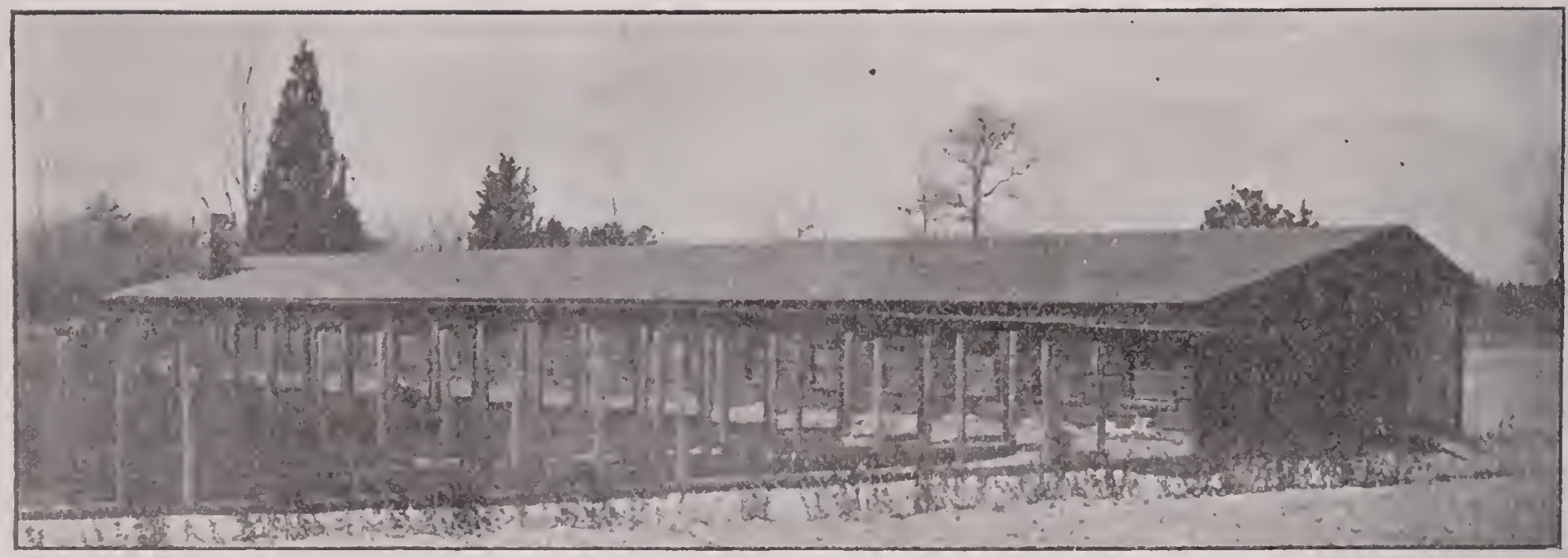

Brooder House and Yards, Lakewood Farm.

(alls from the numerous hotels in Lakerrood and other cities receire attencion as the supply of eggs permits. As Mr. Brown expresses it, there is no trouble whatever in finding a market, the only difficulty is to get eggs enough to supply the demand already in sight!

This farm embolies both the colony-house plan and the continuous-house plan. Across the road from the dwelling is a group of twelve colony houses, fet about 150 feet apart, in which

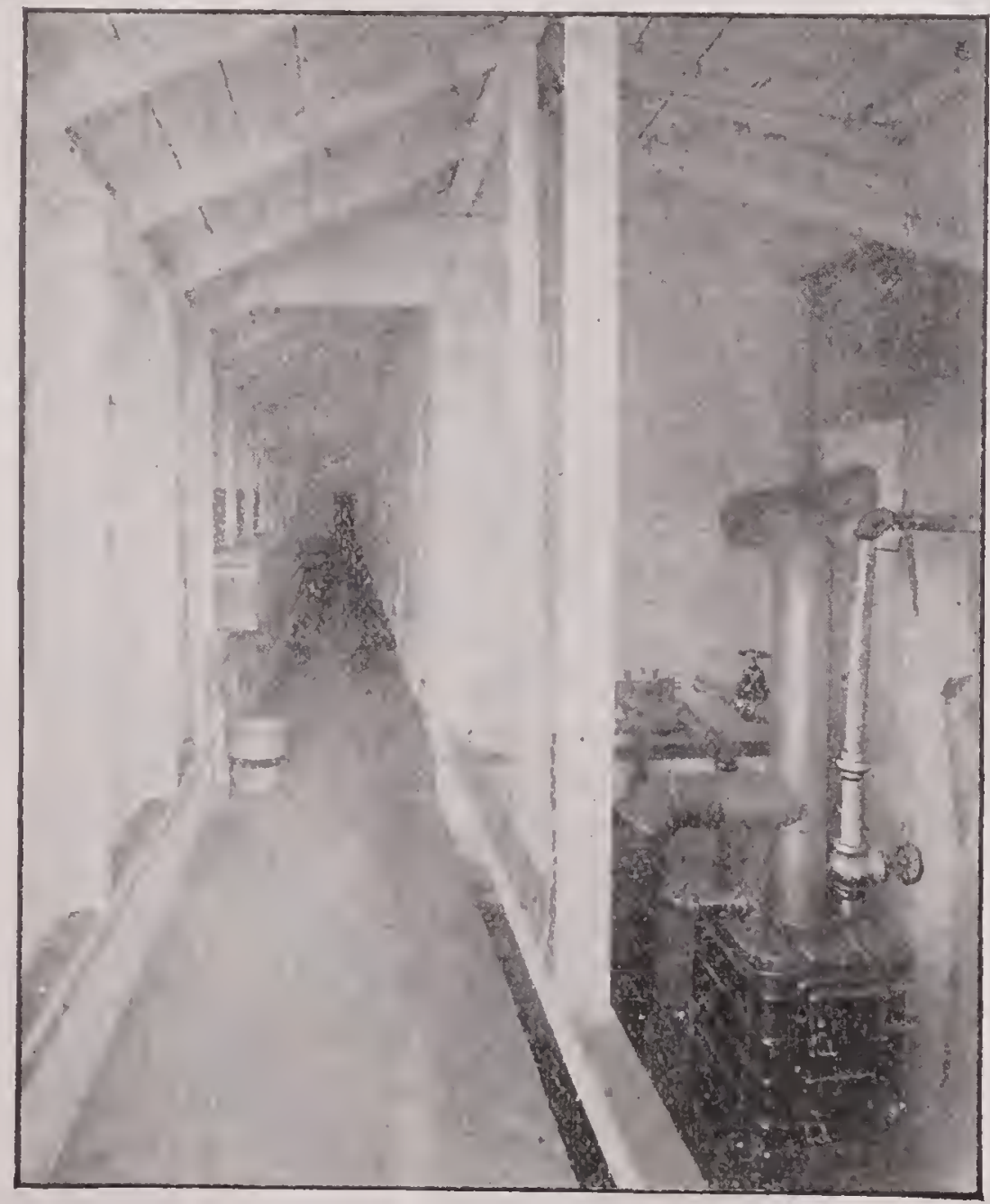

Broorler Heater with Electric Regulator, Lakewood Farm. were some 600 head of White Leghorns ranging at will over the adjoining territory; a 6 -foot woren wire fence encloses the whole tract and serves to confine the roaming birds, and also protects them against the depredations of fourfooted enemies. Those colony houses are different from most, in that they are set up from the ground about three feet, the space beneath being an open-front scratching shed. The ronsting apartment above is $S \times 12$ feet in size, has two half-sash window's in the front, and furnishes a comfortable home for fifty birds, with thescratching-shed basement and the liberty to range outside. An objection to the low, basement-scratching-shod would ba that the birds would lay some eggs. in there, and it would be rexatious to creep into such a low space to secure the eggs; Mr. Brown said that they had not found this a scrious objection, but as they had banks of nests in the open basement as well as in the roosting room above, almost all of the egrgs were gathered from the nests. Other colony houses are scattered through the roods east of the farm buildings, and these were used for carrying the surplus males and surplus stock generally through the winter, and in summer the birds selected for future breeders will be colonized in them while the yards of the regular breeding houses are being seeded down. Four long houses, each $128 \times 16$ fect, were occupied by laring-breeding stock, and others were being built at the time of ou risit. These long houses are 


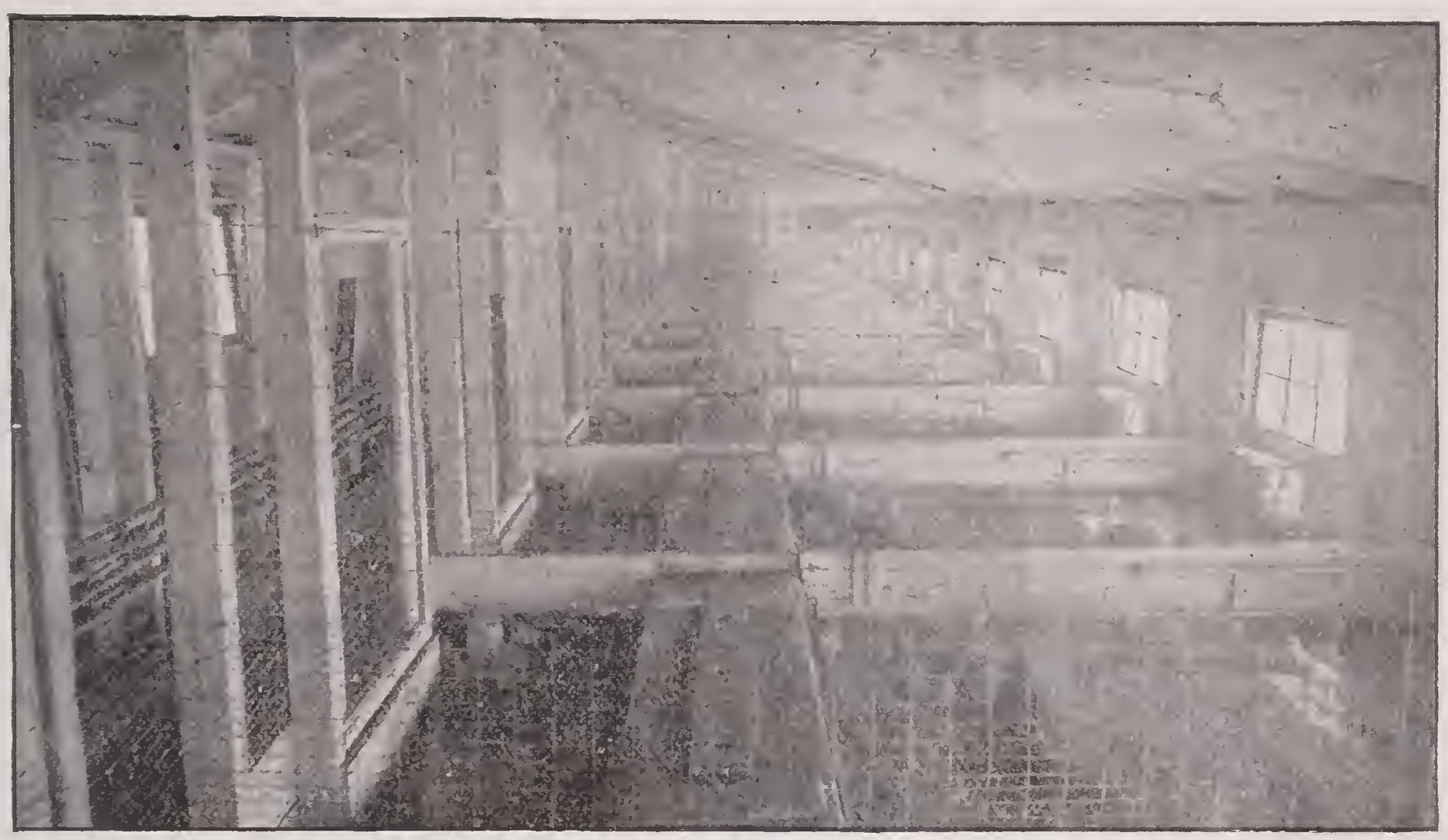

Interior of Brooder House, Lakewood Farm.

divided into pens $16 \times 16 \mathrm{ft}$., each pen haring a door opening into it at the back, the front being made up of three windows which slide. - the right and left hand sash sliding the one in front of and the other bahind the center one. making the pen trio-thirds open-front. An enclosed roosting apartment is made after the plan of the Maine Agricultural Experiment Station curtained-front louse. This roosting apartment is two and a half feet above the floor, and has a solid matched board floor 3 feet wide by 13 feet long. and a solid matched partition at the end next the door in rear of pen.-the solid matched board partition between the pens makes the other end. A curtain attached to a swinging frame is hinged to the roof, swinging out and up, and is hooked up out of the ray when not in use. It is only necessary to close this curtain in front of the roosting pen on the rery coldest nights of winter, - for ordinary weather the closing of the sliding-sash-front is sufficient.

The rards in front of these pens are 90 feet long by 16 feet wide and have a scratching pen 8 feet in depth by 16 feet of width of the yard. at the far end, and into the litter in these scratching pens, all the grain food is thrown when the birds can be fed out of doors. In addition to these long laring-houses there are three breed- ing houses 128 feet long, built upon the wellknown Crphers plan, of scratching pen in front of the laving-roosting pen, and the rards of these houses also have the scratching pen at the south end.

A commodious grain-cook house furnishes store room for foods and work room as well, and the basement is a light and well ventilated incubator cellar, occupied by nine 360-egg Cyphers incubators, which were ruming at their full capacity. On the other side of the farm buildings is a 110 feet long hot water pipe brooder house built on the Cyphers plan. with electric regulator, and the thousand or so baby chicks were enjoying a ration of Cyphers Chick Food as we looked them over. The houses all have sand floors, and when we asked Mr. Brown if they were bothered by rats, he laughingly said, "Xo, we drove them all away to the neighbors!" We reve surprised to learn that 'possums had bothered them some, but vigorous hunting cured that affliction. It is interesting to know that not one bird had died from disease there in the past rear. This spealis rolumes for the healthfulncss of the stock, or the healthfulness of the sandy soil there, or the correct methods employed; more probably, however, of a combination of the three. To lose not one bird by disease in a total of 2.500 carried through 


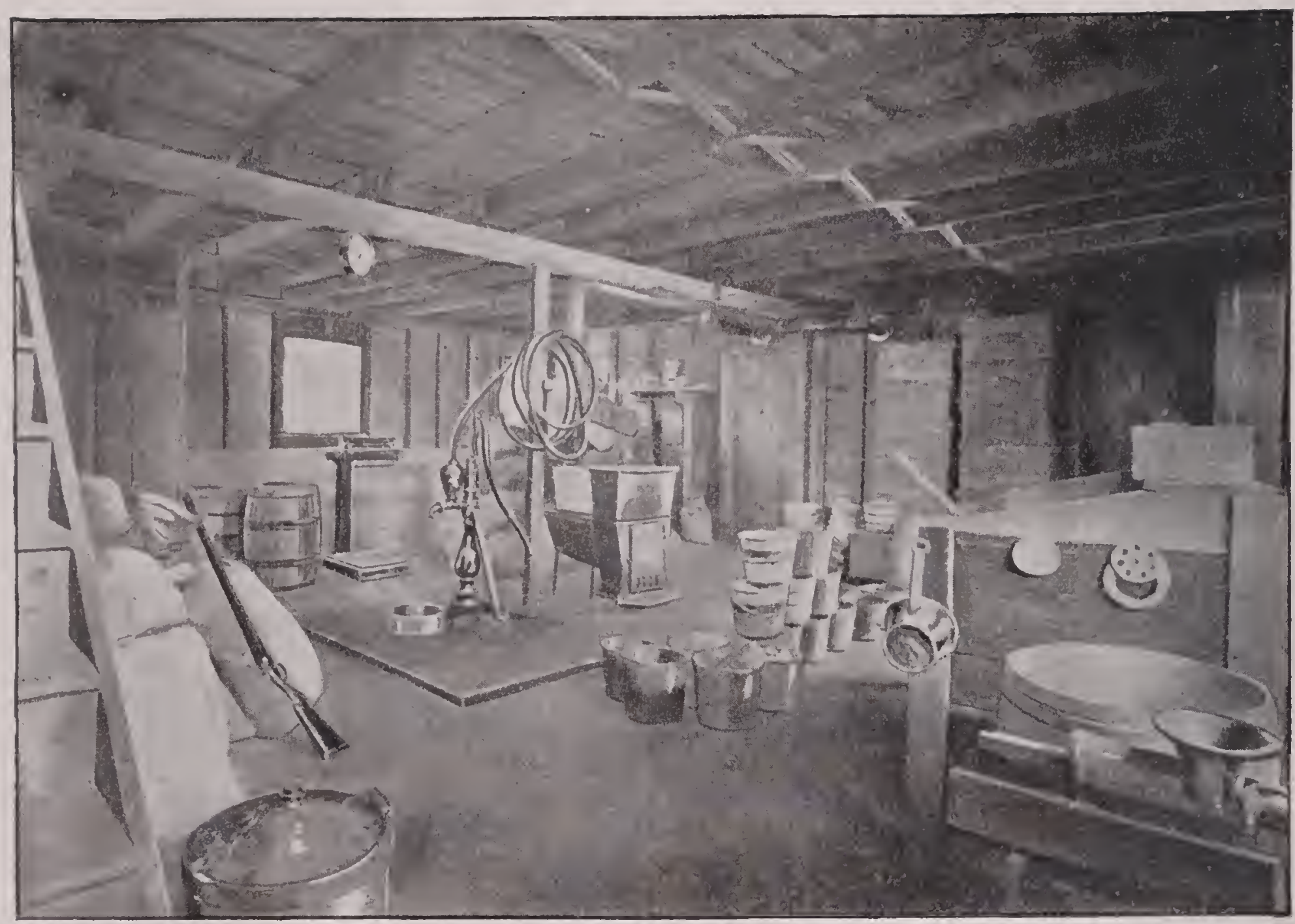

Feed and Cook House, Lakewood Farm.

the winter is certainly remarkable. The egres are shipped every day excepting Sunday, and the eggs of yesterday are being used by their customers today; from three to five cases being the daily shipment.

In addition to their fancy "strictly fresh" egrg trade they are raising summer broilers for the near-by sea-shore trade, and this line of work promises to be decidedly profitable. Here is a most promising poultry business already developed, and with the addition of the selling of eggs for hatching and breeding stock of their two popular varieties there is a brilliant future in store for Lakewood Poultry Farm.

\section{A NEW ENGLAND EGG FARM.}

Specializing Poultry Work; 1,500 Rhode Island Reds Bred for Business and Thoroughbred

\section{Excellence.}

This is an age of specializing and we are rapidly becoming a nation of specialists. Whether a man is in a profession, trade, or other field of endeavor he must choose some specialty and work that for all there is in it, if he would reap a harvest of golden shekels. This is particularly true of poultry work, and we find our most successful poultrymen of today are specialists. True we may, and often do, find them combining two or more branches of the work, but they are none the less specialists for all that. Life is too short for any one man to learn all there is to know about all branches of poultry keeping, and if he desires to make a success he must apply all his energies to mastering the particular branch or branches, which most appeal to him. If he docs this success is assured, and in no other field of labor are more satisfactory profits obtainable for intelligent work.

In looking over the field of opportunities in the various branches of poultry culture, one cannot help noting the importance of the production and marketing of strictly fresh, newlaid eggs and it seems strange.that this particular field is comparatively unworked in proportion to its importance. Egg farming is today perhaps one of the best specialties in practical poultry keeping, in which large profits and quick 


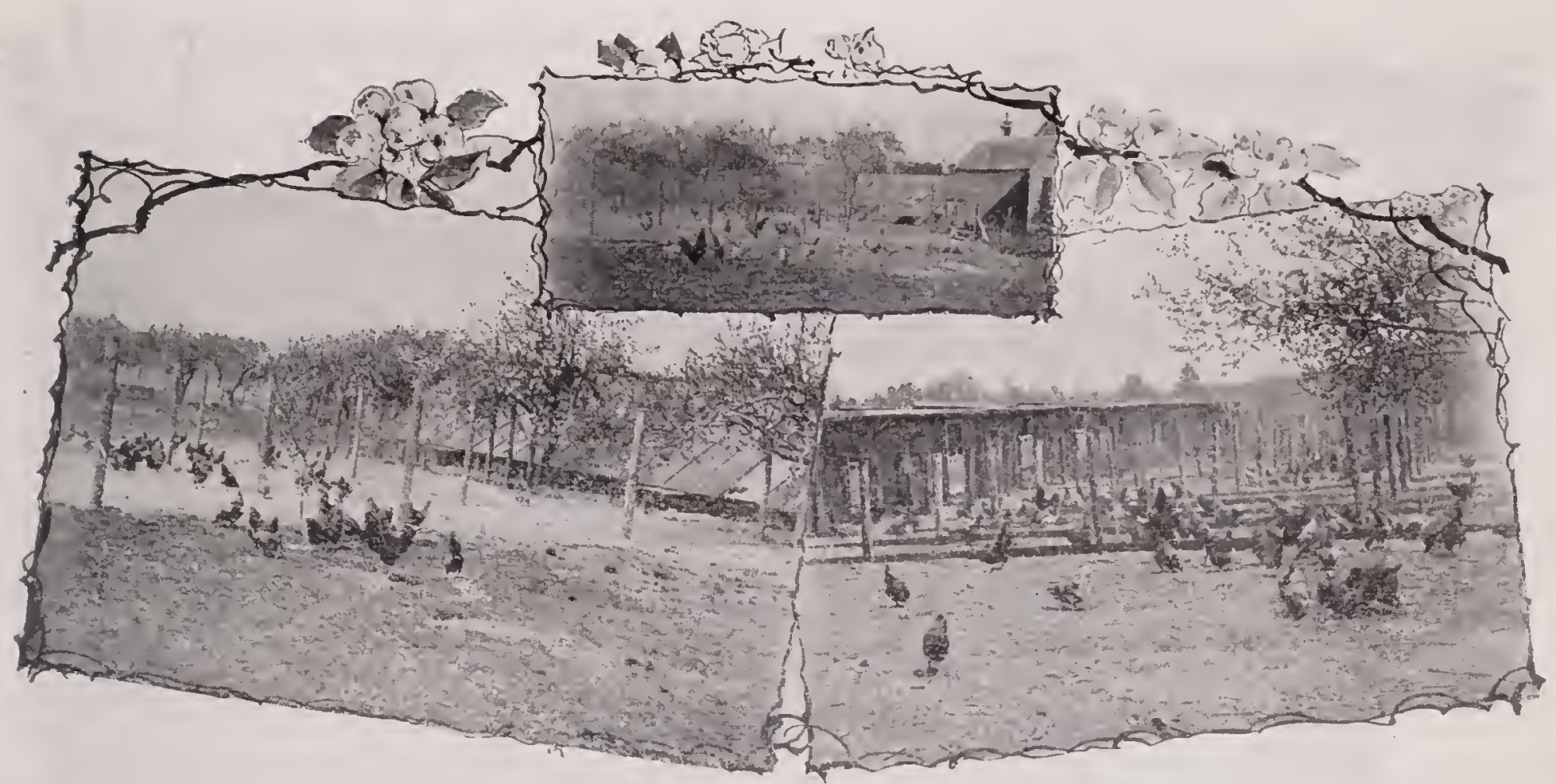

Breeding-Laying Houses, Harris Egg Furm, Mansfield, Mass.

returns are readily obtainable by those who are quick-ivitted enough to grasp the opportunity offered.

Strictly fresh eggs are always in demand and always salable at a fair price. So soon as the market discovers the reputable egg farm specialist, and he establishes his reputation for supplying goods that are strictly first quality, his chief concern thereafter will be to produce eggs in sufficient quantity to meet the demand and to avoid disappointing his customers. The first quality product, that is dependable and always as represented, will never go begging for a customer,-it practically sells itself.

If one wishes to make a study of poultry specialties let him make a trip within a radius of thirty miles of Boston, Mass., and visit the many poultry experts in that section of the country. Boston market is well known, the nation over, as the most fastidious market in the world, for poultry and eggs, and while all sorts and conditions of poultry products may be found on sale, its special family trade is almost super-critical and demands the ultra fancy product in both eggs and poultry meat. So great is the demand for fancy quality poultry products, that in spite of the large number of specialists catering to this market, one seldom, if ever, is able to find the very best poultry produce displayed in the market stalls; it is practically sold, (engaged by the consumer) before it reaches the hands of the dealer.
On a recent visit to New England the writer had a pleasant visit at the egg farm of $\mathrm{II}$. S. Harris at Mansfield, Mass. Here we found Rhode Island Reds in exclusive possession of the farm, with the exception of a few buildings and flies devoted to Homer pigeons, of which some fine specimens were seen. After an allround experience in poultry work, Mr. Harris is now devoting himself to egg farming and Rhode Island Reds as a specialty. At the time of our visit, there were about 1,500 layers and some 1,500 or nore small chicks, all Reds, on the farm. The buildings on the plant corer about 20,000 square feet of ground. In the illustrations we show some of the poultry buildings, the laying and breeding stock, and some of the promising youngsters. Most of Mr. Harris hatching is done in incubators and the chick: are raised in brooders. The chicks are fed exclusively on a dry-grain chick food.

We leave it to $\mathrm{Mr}$. Harris to tell in his own words his incubator experiences, quoting from a letter received from him in May, 1903:

"Plenty of straw for litter in winter and liberal grass range in summer, with a variety of wholesome food for hens, means a high percent fertility. Proper exercise and food are essential.

"To get the best results, eggs nust be from properly kept breeders; the incubator will do. the rest, provided it is built on the correct principle. So far, I much prefer the Cyphers Incubators, having hatched as high as 95 percent. 


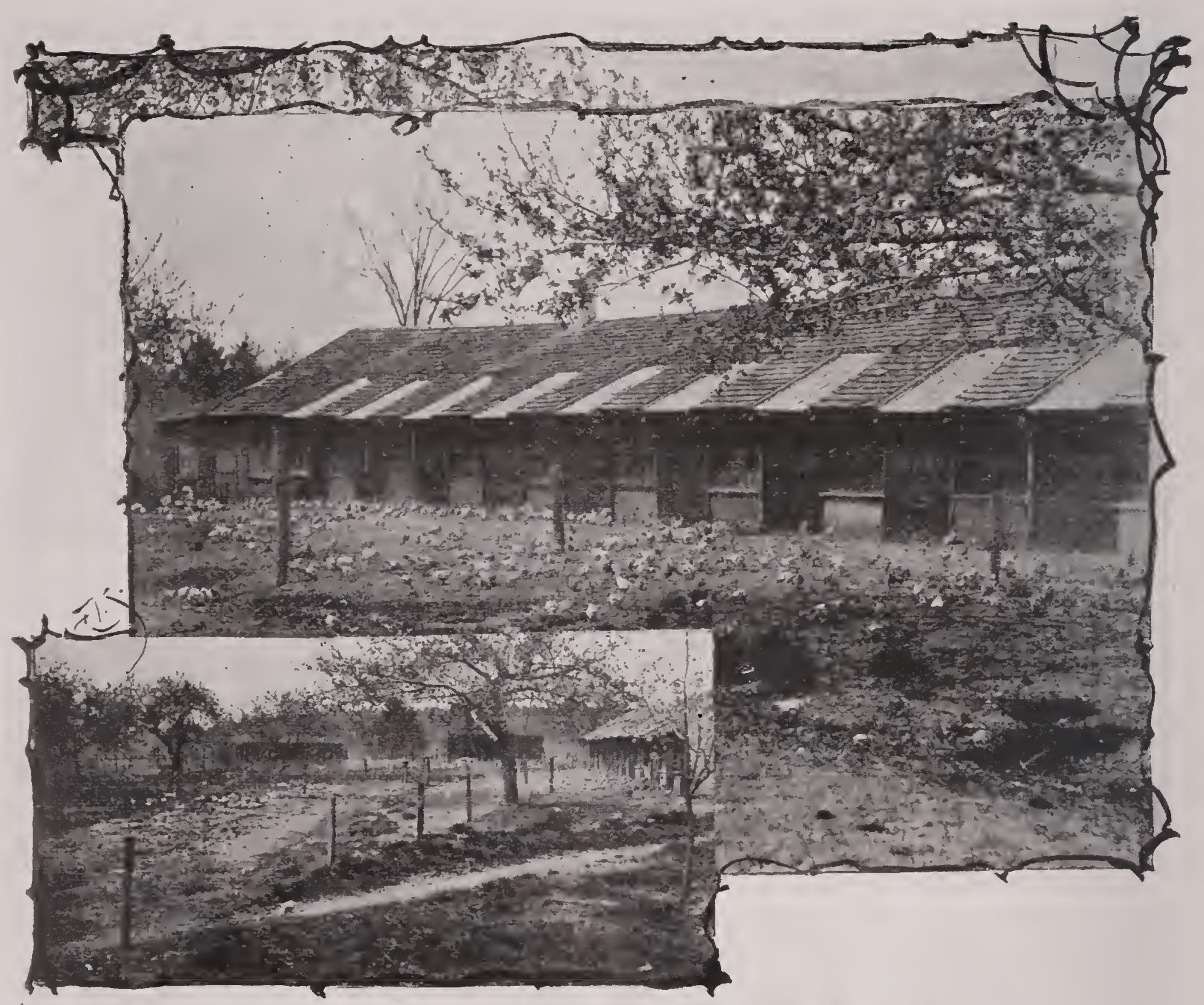

Breeding-Laying Houses, Harris Egg Farm, Mansfield, Mass.

The inside porous top which admits warmed air into the egg chamber at all times, requiring no moisture, is no doubt the correct principle. The system of turning the eggs is the simplest and best. The regulator is perfection.

"I have tried, side by side, the Cyphers with several different makes of incubators, with eggs from the same flock and other conditions being the same. The Cyphers always hatches the greater percentage with less variation in temperature, while other makes of incubators would addle a good many eggs.

"A metal inside top is, according to my experience, a bad defect. The side by side test with other machines has cost me about $\$+00.00$. I have disposed of all other makes and will replace with Cyphers' incubators. I like the Cyphers brooders too.
"I have always been highly successful in the show room. IIy Boston record for 1903 is the best of any one breeder of Rhode Island Reds. I cannot see any difference between a henhatched and a Cyphers hatched chicken in the show room, or out. As to feeding chickens, there seems to be no rule. The idea is to feed a balanced ration. I, having so much faith in the Crphers people, thought I would give their Chick Food and Beef Scrap a test, and ordered several hundred bags. The Chick Food is an honest food and their scraps the best I ever saw. I find this method the easiest and quickest way of feeding, with the best of results.

"I have ahways been suspicious of these socalled balanced-ration foods, as you cannot tell what the mixture is, while in the Cyphers Chick Food you can see the different grains, they being sweet and wholesome. 


\section{PRACTICAL EGG FARMS.}

"I advise following the directions just as they are given by the Cyphers Incubator Company. Chickens that are confined in small quarters must have plenty of cut straw to scratch in for exercise, or off their feet they will go. Green stuff in some form must be given every day, keep cracked charcoal before them as well as cracked oyster shells and plenty of water. Shade is very necessary."

Mr. Harris began raising chickens for market, producing fall and winter chickens. He has marketed as high as 5,000 fall chickens in a season, and ahways had the reputation of producing a thoroughly good article, which commancked top prices. As an instance of what he has clone, we cite the case of nimety-six chickens returning to him the sum of $\$ 200.32$ net, above the expense of picking, expressage and commissions. This was received in the latter part of the month of May, and was not extraordinarily high priceck, and is simply one instance of many which could be quoted.

He now makes a specialty of furnishing eggs for hatching as well as breeding stock, and shipping fresh eggs to special trade in Boston market. When asked how many eggs hens would average to lay in a year, he thought that 150 eggs per hen would be a fair average. Some hens would lay 200. They are kept in flocks of from twenty-five to thirty-five each, according to the size of the pens. While Mr. Harris believes that ten square feet of floor space is the proper amount for each hen, yet he seldom practices what he preaches in this respect, for almost always his fowls have less room.

His buildings nearly all have closed fronts, and are a variety of shapes, showing the growth of the owner's convictions with regard to utility. Several of the buildings have slanting fronts, but Mr. Harris very positively affirms that no more buildings with slanting sides will be built on his place. The latest type has a nearly flat roof, there being no more than two or three inches drop from the front to the rear. The roofs are covered with two-ply tar-paper and the sides with one or two-ply. These are washed with hot coal-tar and given a generous sprinkling of fine sand or gravel.

The hens are given rye straw as a scratching material, and are fed soft food of one-half bran and one-half meal, with about ten per cent. in bulk of the best baef scrap added. This is mixed with hot water in cold weather and with cold water in warm weather. They have as a hard food, two-thirds cracked corn and onethird wheat, with an occasional feed of Kaffir corn and buckwheat. Some ground oats are used, but very few whole oats are fed.

The example which Mr. Harris presents is that of a man who begins with a few birds and with little or no experience, and who, by close application to the business, and by the use of brains and energy, has built up one of the biggest egg farms of New England, with a product which meets with the highest cash prices.

\section{ANOTHER NEW ENGLAND EGG FARM.}

\section{That Illustrates What can be Done in This Practical Branch of Poultry Keeping.}

\section{Strictly Fresh Eggs Always and Everywhere in Demand.}

One very strange fact discovered upon looking over the field of opportunity in the various branches of poultry culture, is the neglect which has covered up the importance of the production and marketing of strictly fresh, new-laid eggs. This today is perhaps the best and most profitable end of practical poultry keeping. This field as yet is comparatively unworked and the demand far exceeds the supply, and the few who have been far seeing and quick-witted enough to grapple the opportunity thus offered them are reaping large profits.

There is today, in New England especially, and in all large settlements throughout the whole country, a cash demand for newly laid eggs which it is impossible to supply with the stock at hand. In support of these statements we offer the experience of Mr. Wm. P. Eddy, of Dighton, Mass., who speaks by the book and who has ample knowleckge of this subject, both practical and theoretic.

\section{From Strawberries to Poultry.}

Mr. Eddy is a thorough business man who has traveled extensively for various fertilizer concerns, and who has had the opportunity to discover the best paying part of the poultry business in this section of the country. Mr. Eddy was formerly the largest producer of strawberries in the town of Dighton, but various changes in the methods of growing and shipping berries having caused some uncertainty about this crop, Mr. Eddy decided to try poultry keeping and egg marketing on a larger scale than he had heretofore. 
He expects to winter a stock of twelve hundred hens. He sells the egos to prirate familics, club houses and high class hotels in Boston. Many private families take cases of from fifteen to twenty dozen each, dividing them with their friends and paying Mr. Eddy his own price, which, he says, is never questioned, and which is in excess of the regular retail price. Today, Uctober 13 , he received 38 cents per dozen in these wholesale quantities. He has found it impossible to supply the trade which araits him, and another season will add largely to his plant.

Mr. Eddy keeps the Rhode Island Reds, which he has found quite satisfactory in egg production with this exception, the pullets lay a rather undersized egg. The hens do better in this respect and the eggs are reasonably large. He has this season a flock of White Wyandotte birds which he will give a fair trial, and should they prove to be better layers and a more practical fow than the Rhode Island Reds he will stock his entire plant with Wyandottes. He thinks them unquestionably the best all-round forl, but is not quite sure if in egg production they will prove to be the best. The Rhode Island Reds mature quickly, and he prefers the rose to the single comb.

He is very particular about the laying qualities of the hens from whose eggs the cockerels are hatched, taking special pains to select the eggs from the best laying hens. In breeding to renew the laying stock, yearling hens are mated with cockerels, and well-matured pullets with cock birds. While he has no objection to breeding from well-matured young stock of both sexes he thinks the average results are better when the previous matings are used. In making these matings only the vigorous and prolific birds are used?

\section{TwojThousand Birds and Rations.}

The chickens are fed a soft food, one-half of the best bran and one-half Indian meal, with beef scrap worked gradually up to the proportion of 10 per cent. when the chicks are a few weeks old. They have also oatmeal, boiled rice, cracked corn and a rariety of hard grain foods, and are allowed a grass range. While confined in large yards this range is practically free, as few enough are kept in a pen to allow a constant supply of grass to grow. The young cockerels are killed at the proper broiler and roaster age and are served to the gucsts of the
Eddy House, a summer hotel which is kept by Mr. Eddy. The laying stock is fed a soft food with beef scrap, together with a considerable proportion of wheat and an abundance of clover, cabbage and other green foods. While some regetables like potatocs, tumips, etc., are boiled and fed with the mash, Mr. Eddy has never been able to get satisfactory results on other than the stoutest kind of feeding. He therefore disapproves of too many regetables in the mash, reserving this sort of food for a side dish.

Mr. Eddy raises about two thousand chickens each year and renews his laying stock from the pullets thus obtained. He is very particular in introducing new blood that the birds shall come from the most prolific and best laying flocks which he can find, and no chances of a backward step are taken. He is rery decidedly of the opinion that there is nothing that can be raised on a farm which will compare in value with eggs as an all-year-round crop. To use his own words, "Eggs are as good as gold dollars, and it is one of the most surprising things in the world to me that so little attention is paid to their production by farmers."

-Reliable Poultry Journal.

\section{TWO NEW ENGLAND EGG FARMS.}

\section{An Egg-Farm Poultry House.-Seventeen Hun- dred Laying Hens Under One Roof.}

One of the largest poultry houses of which we have knowledge is the long house (or series of connected houscs) on the poultry farm of G. F. Hosmer, Montvale, Wobum, Mass.; this house being 408 feet long and accommodating serenteen hundred head of laying stock. It is as simple as possible in construction, consisting of roof and walls only, and having only wire netting partitions between the pens. The house is 18 feet wide and divided into 34 pens $12 \times 18$ feet each, and fifty head of Barred Plymouth Rock pullets or hens are housed in each pen. There is no alleyway (or walk), the attendant passing through the gates in the front end of the partitions between the pens from one end of the house to the other. At half a dozen convenient points are doors in the back side of the house, giving admission to the house from the driveway along the rear; for convenience in moring stock in or out, cleaning the droppings from the roost platform, carrying in scratching litter, 


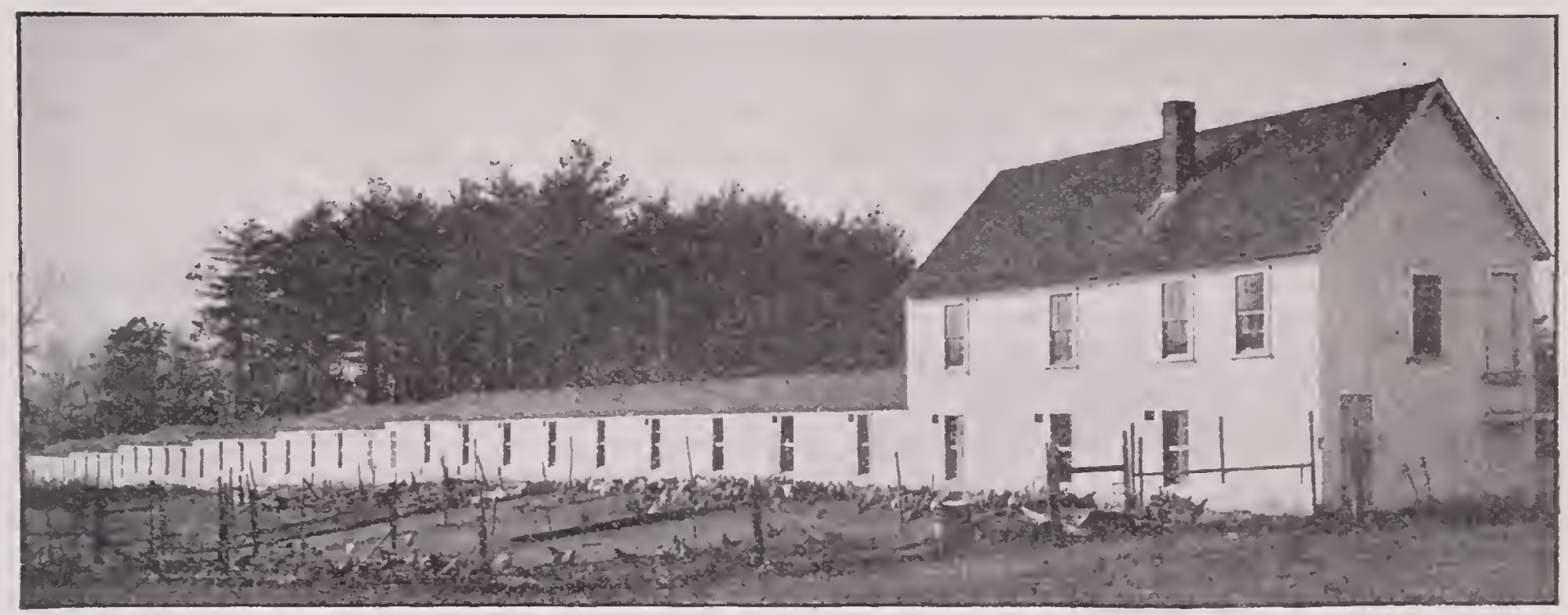

The Long l'oultry Honso on the Farm of G. F. Hoswer, Woburn, Mass.

etc. This long house crowns a low ridge, anċ the ground sloping gently away from it on both sides there is perfect drainage; as there is also a gentle slope to the west the house drops down in successive steps so that the west end is some five or six feet lower than the east end. There being but two solid partitions with dours in this great length of house, there is liability to draughts, and in winter there would be several degrees difference in temperature between the lower and higher pens; such a house should be divided into sections of two (or at most three) pens to aroid draughts and unequal temperature. There are long yards for each pair of pens, extending across the tiny valley into the trees and shrubbery on the adjoining ridge, and a sliding window in front of each pen gives light and air. The second story over the first three pens $i_{\text {s }}$ finished off into sleeping rooms for the farm workmen.

Ir. Hosmer began keeping poultry some rears ago, while engaged in business in Boston. Finding the poultry department of his farm quite profitable he increased his buildings and layingstock, until a year or more ago he found it necessary to give up his Boston conncetion and give his entire time to superintending the poultry work.

He is wintering this rear about thirty-six hundred head of laying stock; the buildings in which the large flocks are housed being located in three different fields, the original plant being elose by the home buildings; two more recent buildings being perhaps a quarter of a mile distant, and about the same distance from each other. The buildings are all upon the closed pen plan, the pens being $18 \times 12$ feet each, and from forty to fifty birds are housed in each pen. In answer to our inquiry he told us the birds were laying less well this year than formerly; but he did not feel that he had any right to complain. He could make his hens pay him a profit of $\$ 1.00$ per head and better, after paying the labor and feed bills, the interest and taxes. In going through the pens we noticed quite a good many birds that evidently were not laying. and such would undoubtedly pull down the average yearly profit.

Mr. Hosmer hatches almost wholly by hens; has gotten out six thousand to seven tholisand chickens a year by that method. Last year he hatched eighty-seven hundred, and this year intends to get out in the vicinity of ten thousand; some two-thirds of these will go to market. Mr. Hosmer has no yards to his pens excepting that an acre or two of land is fenced in for cight or ten pens, all of the birds being allowed access to the enclesure, sorting themselves out as they come back into the house. Mueh of the laying stock is a cross of Light Brahma male on Brown Leghorn females, the pullets being fine bodied birds and great layers.

Noticing a nearly new and quite large manure shed, fitted with platforms on which to spread the manure for drying, we inquired the condition of the manure market, and were informed that it was declining. A few years ago he could sell all the manure he could make to tanners, at good prices; but recently tanners were substituting other material, and tanning by other processes, so that the demand for poultry manure for that purpose is growing 


\section{PROFITABLE EGG FARMING.}

beautifully less. We doubt whether this is to be regretted. The tanners demand that poultry manure shall be wholly free from foreign matter, such as land plaster, fine-sifted coal ashes or loam, and that means that the roost platforms have no absorbent spread on them. As a consequence they become sodden with the urine, and give off a poisonous odor which is certainly injurious. Another point is that poultry manure is such an excellent fertilizer it scems a pity to have it wasted in tanning.

\section{Another Profitable Egg Farm.}

A drive of a few minutes brought us to $\mathrm{Mr}$. Prescott's well-known egg farm. Mr. Prescott keeps about two thousand head of Barred Plymouth Rocks, his houses each have ten pens, $10 \times 28$ feet each on the main floor, and below that they have access to two large basements, $28 \times 100$ feet, opening out into an enclosure of an acre or thereabouts.

Mr. Prescott's house is a capital example of adapting means to encls, as the land is a steepsloping, very rocky hillside, and the house is built around the south and southeast side of the hill, in somewhat the shape of a man's arm with the elbow bent at an angle of about twenty degrees. The house is two stories and an attic on the down-hill side, one story and an attic on the back. The main floor of each wing is divided into ten pens $10 \times 28$ feet each, and yet is not divided, because the pens all open into each other, and all the birds in each wing run together. When they come up from the basement or in from the yards to the roost pens, they fill up the roosting space in one pen, then go on to find quarters in the next, and so on until all are full. Mr. Prescott took a small bucket of grain and led the way to the basement under the west wing, which in a few minutes was fairly swarming with a thousand head of Plymouth Rocks, in one room $28 \times 100$ feet in size. We think that is the largest single flock of fowls we ever saw, and fine Plymouth Rock pullets they are too. A few of them, it is true, had not reached laying maturity, and they, too, would pull down the general average profit of a flock.

Mr. Prescott hatches his chickens wholly by hens, having five hundred sitting nests, in banks of nests arranged in tiers, four hundred of these nests being in the attic space under the double pitch roof, the other one hundred being above the brooder pipes at the back of the brooder house.
The central building of the plant is the cooking and grain house, with the owner's dwelling above. The cooking is by steam in oblong jacket kettles, designed by Mr. Prescott for his special purpose. He is experimenting this year with feeding the cooked ration at night, with good results, quite a part of that cooked ration being whole grain.

For meat food he buys sheep's plucks, and cooks them into a soup which is mixed into the cooked food ration. We cannot do better than quote the description of the steam kettles and cooking from our May 1st, '96, article:

In the cooking room was a Mann bone cutter being run by windmill power, Mr. Prescott telling us he cut up about one hundred and fifty pounds of fresh bone a week. This is not all of the animal food his fowls get, however, as he buys "plucks" and at times, fish, which he cooks in his steam jacket kettles, adding cracked corn and wheat to absorb the moisture and cook in the surplus heat after the "plucks," etc., are cooked and the steam turned off.

Those steam jacket kettles merit a special mention, as they are of Mr. Prescott's own designing, and are really "troughs" about five feet long, eighteen inches wide, and a foot deep. He had them made in this shape the better to cook the contents all through equally. One of those kettles will cook enough for a mash feed for two thousand hens, but Mr. Prescott does not believe in feeding much mash. He said he had found it very easy to overfeed it - " and then look out for roup and other diseases. You get the fowls congested, engorged, and then they are a prey to disease." Mr. Prescott gets one hundred and forty to one hundred and fifty eggs a year from his birds, and hatches about ten thousand chickens; a part of these, however, he sells, when just hatched, there being quite a call for young chicks.

The breeding stock, mostly Barred P. Rocks, we found in the original houses, where the first start was made. He keeps about twenty birds in a pen, and lets three pens, each having a rooster, run together, the gates between being all open, and one large yard in common. We asked him if one male didn't sometimes interfere with another, and he said. "No, not to do any harm; his eggs were then running over ninety per cent. fertile." Mr. Prescott renews about half of his laying stock each year, wintering about half pullets and half year-old hens, and that he can get so goodly an egg vield from 


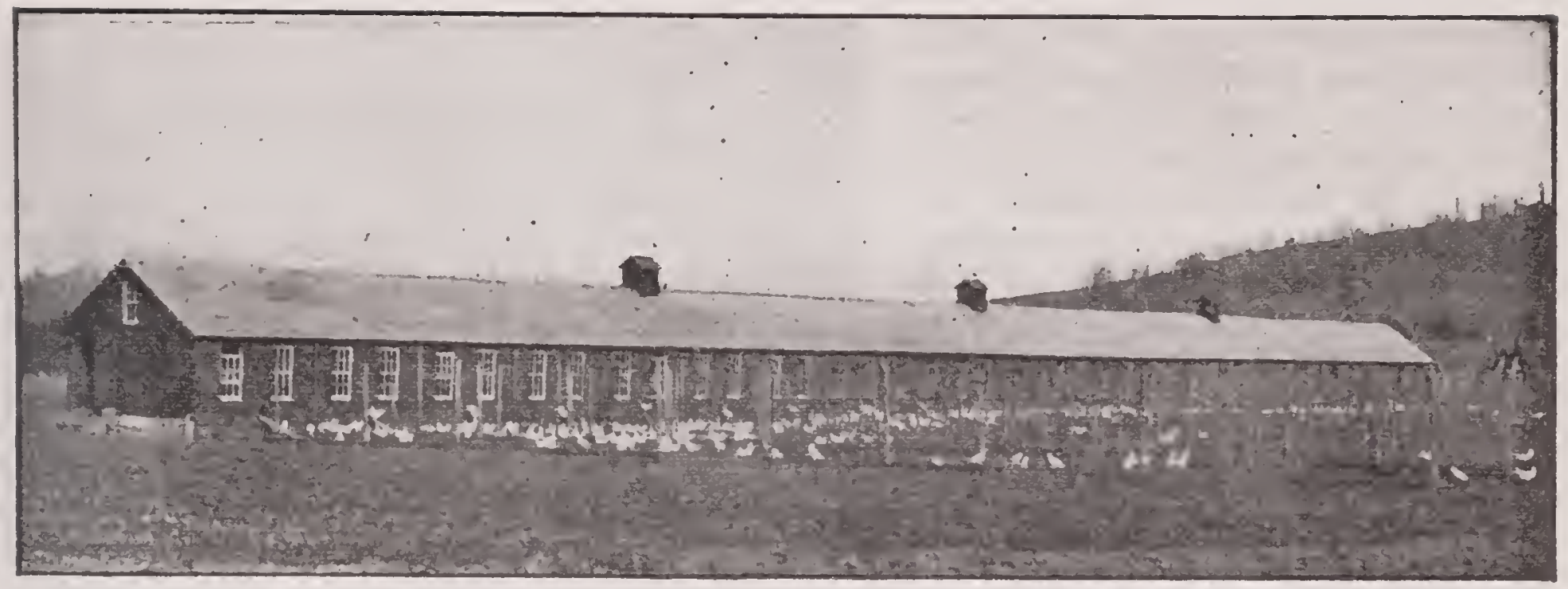

Laying House 250 Feet Iong, White Leghorn Poultry Jaris.

birds ruming together in that fashion. was certainly a surprise. "It isu't according to your teaching," said Mr. Prescott, "and your teaching is right. It takes eternal vigilance to crowd birds as we do and keep them laying, and if you should adrise people to let five hundred or six hundred birds all run together, they'd very soon come to grief. Your teaching of small flocks kept separate is right." We had to laugh at his not practicing what he preached. "That's all right, too," said he. "We have to adapt ourselves to circumstances. and this plant and our methods are the result of our circumstances."

Certainly the success which Mr. Prescott has wrought out there is worthy of emulation; he has proved that there is money for him in the poultry business.

Farm Poultry.

\section{THE WHITE LEGHORN POULTRY YARDS}

\section{One of the Largest and Best Equipped Poultry \\ Farms in the World. The Fancy Side of the Business Given Due Prominence.- A Poultry Plant of 5,000 Head Capacity.}

The great majority of the successful poultry plants today began small and simply grew as circumstances and the experience of the owner warranted, until they attained a capacity of 1,000 or more head of layers annually. Within the last few years, however, poultry farms have been established with the intention of making them great practical-fancy poultry plants. A large farm is bought and buildings planned for with the one purpose of building up a great poultry plant.
One such, the Lakerood Poultry Farm, is described in this chapter, and another which has already attained a notable success and is ranked among the foremost poultry farms in America, is the White Leghorn Poultry Plant, situated at Waterville, N. Y. Here is what may be claimed to be one of the most completely equipped, practical and up-to-clate poultry plants; a poultry plant that in many respects might be considered a model.

The proprietor of the White Leghorn Poultry Plant, Mr. C. J. Brainard, found it desirable, after completing his college course. to take up an occupation which would keep him out of doors a good part of the time, to re-establish his somewhat broken health. Being interested in poultry, he investigated that subject quite thoroughly with a view to satisfying himself whether poultry raising on a large scale could be made a profitable business venture. There have been many failures in the poultry business, perhaps it would be more correct to say, that many have failed of the highest success in the poultry business than to say there have been absolute failures; at any rate, when Mr. Brainard had investigated many causes of failure of success, he decided that they were due to lack of experience and lack of capital; as well as lack of proper business methods, - it could very well be expressed in the homely phrase, "They bit off more than they could chew!"

As Mr. Brainard did not want to personally attend to the details of the business, he employed a practical poultryman, Mr. H. S. Roach, who was formerly engaged in poultry work at the Cornell University Experiment 
Station, and Mr. Roach was instructed to plan for and build a plant for about 2.000 head of layers. with incubator and brooder equipment for chicks to keep up the stock to the required number. This was about four years ago, and instead of stopping at the 2,000 croal the plant has grown until it has reached a capacity of about 5,000 head of layers, and the incubator and brooder department is adequate to the supplying of that number of layers and adclitional breceling stock.

The commercial side of the business was looked upon as the foundation upon which to build, and the furnishing of fancy, "strietly-fresh" cogs for a select trade in Ney lork City was leveloped. The eggs are packed in pasteboard boxes holding one dozen each, and these boxcs of eggs are packed in regular shipping cases, the size of the cases being adapted to the quantity shipped to each customer; these rooden cases are of course returned. A regular trade was established and satisfactory prices agreed upon; the price from Scpt. 1 to Warch 31 (inclusive) being 30 cents per dozcn, and from April 1 to August 31 (inclusive) 20 cents per dozen, this price being net at the station at Waterville, the customer paying charges. The great demand for a choice article of "new laid" eggs was a potent factor in continuing the derelopment of the White Leghorn Poultry Farm. With a practically unlimited demand for these fancy, fresh eggs it was good business policy to increase the supply to meet the remand.

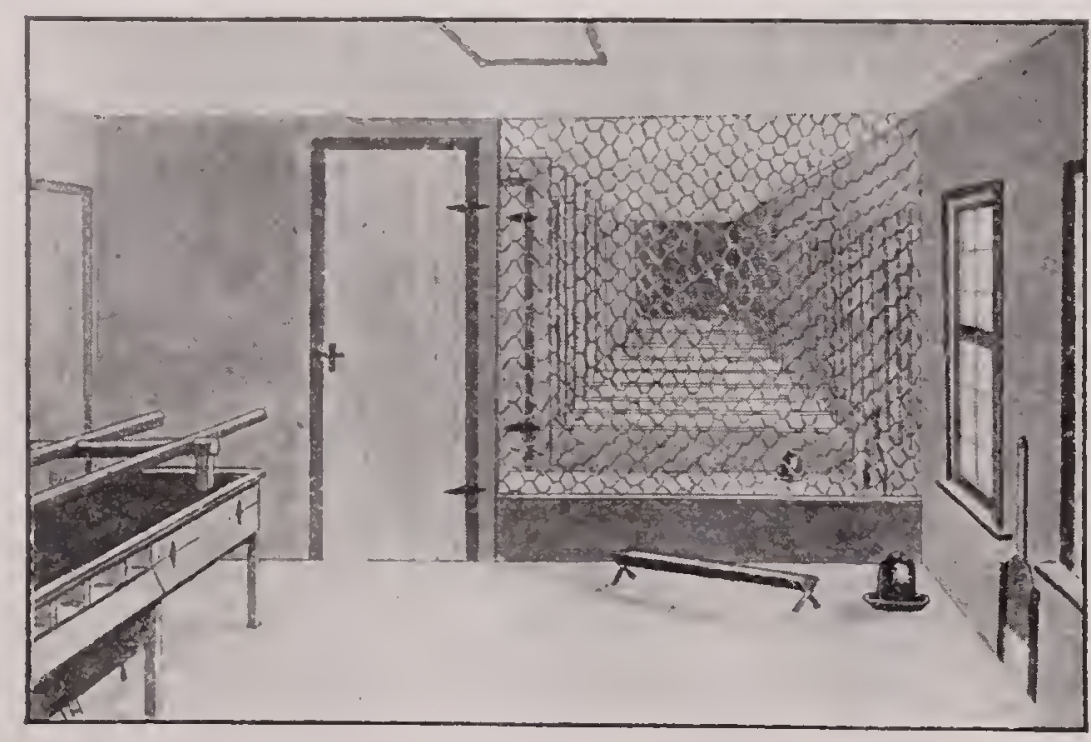

Interior View of Long House, White Leghorn l'oultry Yards.
The development of what is called the fancy sicle of the business has liept equal pace with the growth of the utility side. Starting with the very best stock that could be found, and mating with a view to producing choice exhibition stock, a great success was attained almost inımediately

The goodly pereentage of premiums won at shows and fairs, backed up by judicious adrertising and a perfectly equipped correspondenee department, developed a very great trade in breeding stock and eggs for hatching. This business department of the farm was put in charge of an experieneed business man, who is at the same time a well equipped poultriman, hence fully competent for the rork; and this department employs an office force of clerks and stenographers, varying of course as the increase or decrease of the trade demands. Mr. Brainard firmly beliercs that the business end of such a plant should be conducted just as any other commereial business is. Every letter is attended to on the day it is received and instructions are that every letter must have a courteous reply. no mattcr what the nature of the communication may be. Frery correspondent is given a card-catalogue record, and there is a complete "follow up" system, assuring that every attention is given to every would-be customer.

\section{Artificial Hatching and Brooding.}

All the stock is hached in incubators and brooded by an up-to-clate brooder system. The incubator cellar is $12 \times 30$ feet in size, $7 \mathrm{ft}$. high to the reiling, two-thirds of the wall being 
of brick and the other third wood; the wooden wall and ceiling are covercd with asbestos paper. The floor is of eement; twelve 360-egg Cyphers Incubators are operated.

There are three hot-water-pipe brooder houses, two $125 \mathrm{ft}$. long each and the other 110 $\mathrm{ft}$. long,-these brooder houses are $16 \mathrm{ft}$. wide with a four foot walk at the back, hover pens are $3 \times 12 \mathrm{ft}$. nearest the heater and increase to four feet in width for larger chichs, giving in all 93 brooding pens. With colony and other houses for weaned chicks the plant has a capacity for about 10,000 head of young, but it is not wise to crowd to the limit, and $\tau, 000$ or $\$, 000$ head are as many as it is intended to hatch and raise there. Last year about 6,000 chicks were raised to market size or maturity, and it is interesting to note that a careful record of the hatches and the number of chicks raised has determined that it is safe to estimate to raise 40 chicks for every 100 eggs set. This is better than a good many poultrymen arerage, but we should keep in mind that the stock here is White Leghorn, eggs of which almost always hatch reell, and that the hatching is in the normal breeding season when losses are few.

There are eight laying houses with a total length of about 1,000 ft., and one laying house 250 feet in length. The first houses built were $12 \times 50$ feet, divided into two pens of $12 \times 25$ $\mathrm{ft}$. and in each pen was put a flock of 50 layers. The houses built later were divided into small pens for 25 birds each, - - the plan followed being what is called a house within a house. The outer walls are sheathed, papered and covered with clap-boards. A feed room $10 \times 12 \mathrm{ft}$. is constructed in one end of each house, and a walk $3 \mathrm{ft}$. wide continues the entire length of the building. A tight-board partition separates the pens from the walk, the pens are ceiled orer head and the front wall is ceiled up inside; thus there is an air space entirely surrounding the pens. A rentilating trap opens into the loft from the center of each pen, and in the loft is stored scratching material, etc., for use as needed. Each pen has a door opening into the walk and there is also a door in each partition between the pens. These enclosed pens for housing the laying-breeding stock have been found eminently satisfactory; ther are sufficiently warm to protect White Leghorn combs from freezing. The plan is an excellent one and the health of the birds perfect.
A slightly different plan is adopted for the $250 \mathrm{ft}$. long house; in this there is a feed room in the middle as well as at each end. To provide for getting in scratching litter, etc., in the loft above the pens, doors like dormer windows are built at intervals in the roof.

It is gratifying to know that in breeding, the utility quality of the stock has been kept well to the front, the first object being good size, great laying quality, and great strength and vigor; coupled with these points every attention has been paid to standard requirements as to shape, carriage, etc. Two lincs of breeding stock is kept, one of exhibition matings in which 10 to 12 females are made into a breeding pen with a choice, selected male at the head; and these pens not only contain the cream of their own flock, but choice birds are purchased wherever they can be found when it is thought that such will give strength to the matings. In the ordinary matings about 25 hens or fully matured pullets are put in a pen and two strong, vigorous males provided. One male is giren the run of the pen while the other is resting in a roomy coop provided for the purpose, and the males are alternated, each given a day of duty followed by a day of rest.

It is very gratifying to visit such a great poultry establishment and see a busincss conducted in such a thorough, business-like way. It is such thoroughy up-to-date poultry plants as this that demonstrate what a solid, enduring foundation underlies the poultry businces, and ranks it a truly great industry.

\section{PROFITABIE EGG FARMING.}

\section{A Great Poultry Farm and a Remarkable Suc- cessful Pcultry Business-Story of the Van Dreser Egg Farm, Cobleskill, New York.}

\section{"The Twelve Hundred Hen House"-Interior Construction-Use of the Individual Brooder Houses-Caring for and Feeding the Chicks.}

The story of the growth of a highly successful poultry business, or indeed any grcat businfss. almost always reads like a romance, and has fascinating elements that most powerfully attract the reader. The latest aspirant for popular favor is no exception to this rule, even though poultry was not in this case, as in many others, the lever by which "the mortgage" was lifted. That dread incubus had been suc- 
cessfully disposed of by year's of profitable thoroughbred-stock raising, and when the attention of the farmer was drawn to poultry he had already achieved a national reputation as a breeder and judge of Holstein cattle, and was in demand as a speaker at Farmers' Institutes in many states. The man is Henry Van Dreser and his farm is in Cobleskill, N. Y., where he was born and grew to manhood, his Dutch ancestors being well and favorably known throughout that region. It is a most beautiful country about there. All of that part of New York state lying north of the Catskills and west of the Hudson is an ideal country for a home.

We recognized Mr. Van Dreser on the station platform before the train had come to a stop, and a hearty hand-grasp welcomed us. Driving through the thriving town and out upon the country road, we noted that everyone knew and exchanged salutations with him, and everyone who addressed him called him "Henry." It's a good indication of a man's character to be well known and on intimate terms with a whole townspeople! We drove through some two miles of rural loveliness, up two or three modest hills, then up quite a steep rise (badly washed by recent rains), and there was the farm spread out before us.

"That is our home!" said Mr. Van Dreser, and his voice lingered lovingly upon the word, as we sat in the carriage and looked across the modest valley to the farm buildings and fields spread over the sloping hillside. The buildings were all in sight from that view point, and it was, indeed, fair to look upon that pleasant August morning.

"It isn't possible that you raise hops too?" we said, as we drove past a considerable hop field.

"Yes, those are our hops," Mr. Van D. replied, "and that is our corn just above the hops, and the sunflower's just beyond. This part of our farm lies on the high road on two sides." "Isn't that a fine piece of corn, though!" he exclaimed, "how well that is eared out."

Then the sunflowers came in for comment, and in a few minutes the orchard, across the road from the dwelling house, and fairly overflowing with White Leghorn youngsters, came into view, and we stepped down at the door of the house, to be welcomed by Mr. Green, Mr. Van Dreser's able second, to whose patient, watchful care for the past six years, much of the constant growth and success of the business is due.

\section{Mr. Van Dreser's "Twelve Hundred Hen House."}

The chickens in the orchard first attracted our attention, then the packing house and incubator cellar, and then we crossed the road to the long house, the "twelve hundred hen house" as they call it, which is in the center, indeed the chief object in the plant, and its most distinctive feature. This long house, rumning east from the farm buildings, is situated just upon the edge of the hill slope, and looks off over the valley in which the bulk of the 200-acre farm lies; it is 367 feet long, nine and a half feet high in front, five and a half feet high at the back, and is fifteen feet wide. The single roof slopes north, an excellent thing, relieving the south front, where the fowls congregate, of all drip. The foundation of the house is stone laid up in mortar, and it is filled in to bottom of sills with stones and rubble, then floored with Portland cement; it took nine and a half tons of cement to floor this house. The frame and rafters are of four inch studding and both walls and roof are double boarded, boarded both outside and inside the studs and rafters. The walls are boarded up outside with "siding," and inside with sheathing paper and inch boards, and all the spaces between studs are packed with swale hay and straw. The roof is covered with steel roofing, painted red, is ceiled on the under-side with boards and this four-inch space is likewise packed with swale hay and straw. These (practically) six-inch walls and roof make the house very cool in summer and exclude frost in winter.

\section{Description of Interior of Long House.}

The interior arrangements of the house are very simple. Midway of it is one section carried up two stories, the first floor of which is a tasty and convenient farm office and the second flool is finished off for a sleeping room for a poultryman.

The poultry house itself is divided into twenty-two compartments, fifteen feet square, each three compartments being separated from the next ones by a matched boards partition and wooden door, all the other partitions being of wire netting and gates. Each fiftcen-foot compartment has two windows of twelve lights, $9 \times 12$ glass in the front; a droppings platform 
about three feet wide, with roosts above and a bank of nests below it at the back. A feed trough, water pan, grit and shells box, and (in one corner) a dusting pen comprise the furnishings. The water pan is set on a shelf some eighteen inches from the floor, which puts it up out of the way of the flying litter when the hens are scratching. The shelf

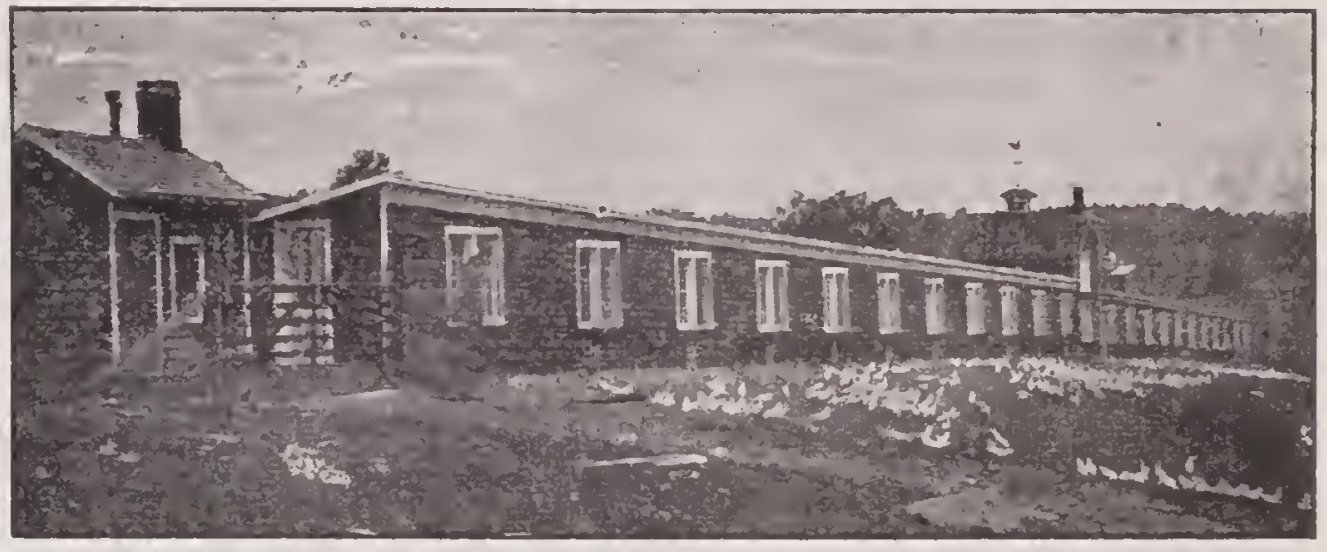

The Long House, Van Dreser Poultry Farm.

is sufficiently broad so that the fowls may stand around the pan to drink, only about two inches of the margin of which is exposed to them. The water dish is a pan, literally; just a common milk pan, set on a broad shelf, with a board fixed just above to corer it all but the edge.

All ventilation is by the windows, one of which in each pen is hinged at the side (just like a door), the windows are covered with wire netting to protect them against any wild plunges the fowls might make if frightened. All doors and gates between pens are in the centers of partitions, and are hung by strong spring-hinges, and they may swing either way; so that the attendant, going from pen to pen to feed or water, can push through from one pen to another without stopping to unlatch and latch doors and gates.

There is straw or some scratching litter (which is frequently renewed) on the floor of these pens at all times. At the time of our visit there were but two or three inches of this, but in winter it is fully a foot in depth, and all the hard grain fed is thrown into the scratching litter and the birds have to scratch it out. Scratching is the forl's normal exercise, and is the best (most natural) exercise for them; fowls that have to scratch and search for their food will be in good health if other conditions are right.

The droppings platform is about eighteen inches above the floor, and the roosts some ten inches abore the platform. These are hinged to the back wall and can be hooked up to the roof to be out of the way when cleaning the platform; a two-inch wide strip is nailed to edge of platform to secure the droppings, and a teninch wide board is hinged below to darken the space occupied by the nest boxes. This effectually prevents egg eating, as the nests are all dark and retired; there is a space at each end of the board which permits entrance to the nests. Of course it adds to the labor of collecting the eggs to have to swing up this board in each pen, but that is a small matter compared to the gain of preventing egg-eating, which is the bane of many a poultry house and effectually dissipates the profits.

The droppings platform is cleaned off but once a week, and then well covered with land plaster (gypsum). That is, this has been the practice, but at the time of my visit, they were about to change to pulverized South Carolina rock, which is rich in phosporic acid, and, combined with the nitrogenous poultry manure, would make a very well balanced fertilizer for Mr. Van Dreser's land, which is already well supplied with potash. When they clean off the droppings platforms a wagon is driven along the front of the house, stopping at the open winclow of each pen in turn, and the droppings are loaded directly into the wagon. There being no pens (or yards) in front of the house, makes this possible. It was a surprise to us that there mere no yards, and Mr. Van Dreser told us he put up fences and made yards when he built the house, but he did not like the looks of them and clic not like to see the birds confined, so he took the fences down, and the $(1,200)$ birds now have absolutely free range to the south, away off into the valley; we could see some of them so far away they looked like mere white specks in the distance. Another surprise to us was that the male birds running free did not fight. We were told they did not and those we saw about had no appearance of having "scrapped"; there was nothing that looked like torn combs or wattles, or their ever having been torn or marred. The explanation of this was that the birds were all brought up together as cockerels, and about three put in each pen together, and so they never fought. If a bird from another farm, a stranger, was in- 
troduced into that peaceable community we opine there would be a different story to tell!

It will be a surprise to many readers that these twelve hundred birds find their way back into the twenty-two compartments at night, after running together outside all day. It is not to be supposed that they all get back to the compartment which they left in the morning. All the compartments are alike, and when the birds are coming in to go to roost the attendant goes through and closes the slide doors (leading out(loors) of such compartments as are full, and the birds then go on to others that are not full. It occurred to us that the swinging doors and gates between the compartments could be left open at roosting time, and the birds finding the roosts of one pen full, would go on to another; this is practically the plan adopted on one large poultry farm of which we have knowledge.

Another point which should not be overlooked. The birds are put into these pens in the autumn, upon the approach of cold weather, and are not allowed out again until spring; they thus have four to five months of confinement in the house, they know no other home and know nothing of the delights of ranging. Under these conditions, being naturally home-loving, they return to their quarters without trouble or bother.

Entrance doors to house are at either end and through the office in the center, which means a considerable walk to reach intermediate pens half way between the office and either end. With no yards in front of the house, it would have been an easy matter to put a "Dutch door" in the front of each pen (the upper part of it being the hinged window), and that would give direct access to every pen. A small building at the west end of this long house (but separated from it by a few feet space) is the cook house, and here all the "mash" and cooked food is prepared.

A high road runs through the farm east and west alnng the hillside; all the farm buildings, including the dwelling house and the long poultry house, are south of this road, and the greater part of the farm also. Across this road and rising up the hillside to the north, is an apple orchard of about twelve acres, in which the brooder houses are placed, and here, 2,500 head of half grown youngsters were ranging at will. A better place for chickens could not be found in ten counties. The strong clay land is well stocked with clover and other grasses, the apple trees furnish abundance of shade and the open spaces between them give access to sunshine if it is desired, while the southern slope of the ground gives sunshine and perfect drainage, making it ideally healthful.

\section{Individual Brooder Houses Described.}

Hore were set three rows of "individual" brooder houses, the rows being sixty feet apart and the houses being fifty apart in the rows. The houses are six feet square, fire feet high in front and three feet high in the back-hare a small window and door (also a small trap door) in front, and covered, roof and walls, with Neponset Red Rope Roofing, and paintcd. The brooder is a common pattern of indoor brooder, the lamp slides into the center of lamp chamber on a cleated board. The little chicks are put into these brooder houses directly from the incubators. They are given the run of inside of house for a day or two, and then let out, on pleasant days, into small, temporary yards which are erected in front of each house. After a week or so, when the chicks have got well on to their feet, the yard fences are taken down and put over to other houses, and these lots giren full range. When the chicks have got large enough so that they no longer need the warmth of the brooder, it is removed to storage room in the packing house loft, and the youngsters continue their life in the brooder house without a brooder, that being their home until they go into permanent quarters.

There are several things about these orchard brooder houses that could be bettered. As it is now with three rows of houses only sixty feet apart, only one-third or loss of the orchard is utilized. It is well known that chicks range more widely as they get older; we would promote that ranging by distributing the houses all over the orchard, setting the row (say) 150 feet apart and the houses (say) 100 feet apart in the rows. This would make more steps for the attendant, it is true, and seemingly umeccssary steps while the chicks are small; but-we are not thinking of the attendant, we are thinking of greater benefit to the growing chicks from that wider and fresher range. It is not wise to economize on the attendant's steps if the ultimate result is (even a slight) falling short of the very best development of the chicks! Another thing we would do differently would be to have a good outdoor brooder that could be used for another family of youngsters after being taken out of the 


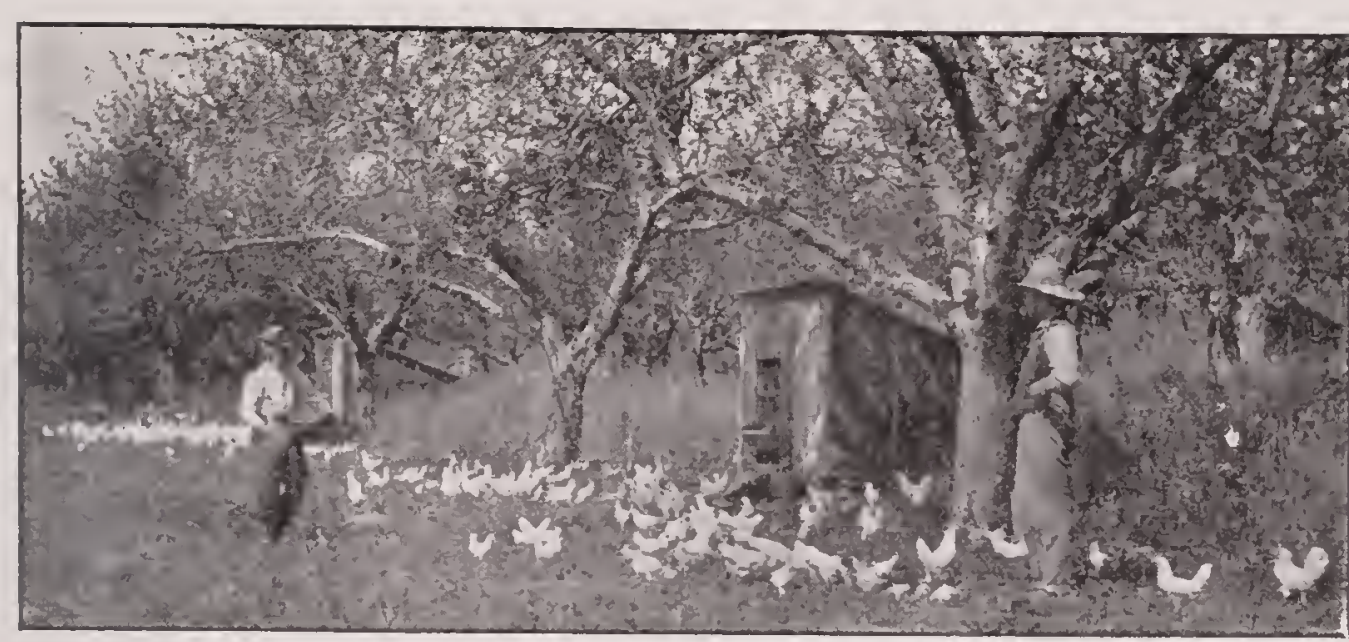

Individual Brooder Iouses in the Orchard, Van Dreser Poultry Farm.

oat flakes are the other daily feeds. Fresh water. grit and charcoal are kept constantly by them.

After the pullets a ${ }^{\circ}$ moved into their winter quarters, they have a mash feed once a day, about ten or eleven o'clock in the winter and about fouro'clock in the afternoon in summer. This mash is made of equal parts of pea meal (made of Canada fresh peas) house; and still another would be to set tl:? houses on rumners so a horse could be hitched to them and hauled to another location; this last we understood Mr. Van Dreser to say he intended to do.

Some families of chicks hatched earlier than it is well to have them rum out of doors, are brooded in the storage room of the building called the packing house; the same "indoor" brooders being used that are later put out in the detached houses in the orchard. With Leghorns, hatched for laring-breeding stock, however, there is really no need of early hatches. May is the best month for hatching Leghorns, and in May, chicks can be put out doors at once in most years in Central New York. If I were conducting such a poultry farm as $\mathrm{Mr}$. VanDreser's. I mould have incubators enough to get out all the chicks desired in two hatehes and have both of these hatches come in May, or possibly one of them in the last week in April, and the other in the middle of May, then have brooders enough to handle "the crop" and have the chichs just about all of an age and size; then I would get eggs galore in November, December and January, when eggs pay the big profits.

\section{Caring for and Feeding the Chicks.}

The chicks get nothing to eat the first day, in fact are best left in the incubator till they are at least twenty-four hours old. On the first day they get bread crumbs soaked in sweet milk and then "Johnny Cake" made of mixed meals and thoroughly baked; this is their food until they are about three weeks old. They are then gradually changed to a mash made of mixed meals, composed of ground oats, wheat and corn meal, with about ten per cent of beef scrap and with a little wheat bran added. This is fed in the morning, and cracked corn, wheat and wheat bran, wheat middlings, and beef scrap, and into this mash is put twenty-five pounds of cut fresh bone for each 1,000 fowls. In winter, as soon as it is light, a grain feed of oats and wheat is thrown into the scratching litter, to set them to work scratching; then the mash, and in the afternoon a feed of corn, either whole or cracked. In the summer a grain feed of wheat and oats at noon and the mash toward night

It is the intention to keep the birds just a little hungry, with the purpose of having them willing to scratch for their grain, and thus get needed exercise. Exercise and an abundance of fresh air from having the house well ventilated (well aired out) are relicd upon to lieep the fowls in good health. And the results justify the reliance! There has never been any sickness and it is almost never that a fowl dies of disease: a year ago last winter, with 2,200 birds put into the quarters, there was a loss of but one from that number in four months; and that is a ronderful record! A factor in this high health is the varying of food ration and the supplying of green food in winter. Mangel beets and cut clover are relied upon chiefly for the latter, and millet, sunflower seed, etc., for the former. Cabbage has been used some in the past, but a few years ago a dealer in New Tork City wanted to contract for a certain number of cases of eggs a week, at a good premium for eggs from hens that were not fed cabbage. and Mr. Van Dreser changed to mangels and cut clover. Said he: "I am perfectly willing to give a man what he wants. provided he will pay for it."

\section{The Business Highly Profitable.}

That this business, as conducted, is highly. profitable is easily seen. Every egg is "clean" when it goes to market, and only the good sized and well-shelled and shaped eggs go into the cases 
for the premium-paying trade; the smaller eggs and those not quite up to "No. 1 " in quality are graded as "seconds" and are sold in market for" what they will fetch.

Mr. Terry, in the Practical Farmer, said the 3,000 hens were last winter turning in an income of $\$ 98.70$ per day for eggs alone, and that stock for breeding carried the income to above $\$ 100.00$ a day. This would be for a limited time only, of course, as the steady lowering of the number of stock layers (by sales) would shrink the egg product. The gross income would not be all profit, there are the food, labor and incidental expenses to come out of it. It makes no difference that about all the food there is raised on the farm; if sold to the hens the hen account should be charged market prices for it. We don't know whether the hens are paid (in the account) for their manure, but it is a very valuable fertilizer and worth many dollars; about three thousand bushels of this rich fertilizer is made there on the farm, and goes back onto the farm every year. And how it makes the crops grow! One year, Mr. Van Dreser put 5.50 pounds of hen manure on a measured acre of wheat and sowed another acre right alongside of it without any fertilizer; the acre with hen manure produced $59 \frac{1}{2}$ bushels of wheat and the other acre but 31 . The hen gives back to the land in the shape of manure, a larger proportion of the fertilizing elements in the food than any other animal. A writer in the Rural New Yorker says that forty to fifty bushels of sunflower seed per acre is an average crop. Mr. Van Dreser raised a measured nine-tenths of an acre of sunflowers last year and the bagged product was 140 bushels of seed. A letter from the thresherman (now before me) says: "My sieves were not designed to clean sunflower seed so that not all was saved, some seed went to waste in the chaff." As the chaff went into the scratching litter in the hen pens, these did not go to waste-the hens got them!

There are ample evidences, there on the Van Dreser Farm, of his being a thorough, up-todate farmer. The best of farm machinery and tools were in use and the best of crops growing or being harvested. A field of twenty-five acres of mixed oats and peas (Canada field peas) was being harvested on the day I was there; there were eighty-four bushels of seed sown on this piece of land, at the rate of two bushels of oats to one of peas. There were raised this season $11 \frac{1}{4}$ acres of buckwheat and ten acres of wheat; two years ago nine hundred bushels of wheat were harvested-and all of this farm work revolves around the poultry; the hens run the farm!

Poultry Plant Holds First Place.

Perhaps the most remarkable feature of this story is that a highly successful stock farm has been turned into a poultry farm, and everything is now subordinated to the poultry. We hear of many farms which, being unsuccessful in general farming, etc., have been turned into poultry farms and thus made successful, but we do not recall another case just like this. Mr. Van Dreser and his brother bought the farm, about forty years ago, and tried hard to make a living and pay the interest on the mortgage by general farming. After several years of this work they were compelled to face the fact that they were not gaining an inch, and then they turned their attention to thoroughbred stock raising, going into Holsteins just on the flood tide. Success crowned their work, reputation and good sales came to them and Mr. Henry Van Dreser was in demand as a judge at shows and fairs, and became a popular speaker at Farmers' Institutes in several states. The house being rather crotided by two growing families, the older brother grasped the opportunity to buy a fine farm near by and sold out his half of the farm to his brother Henry. No particular attention had been given to poultry until Mr. Van Dreser's adopted son, who was educated at Cornell University, came home very enthusiastic about it. Not having much encouragement, he determined to go ahead on his own account and began excavating a basement under the carriage house, working at the job during the noon hour and at odd moments, lest his father should think he was neglecting the regular farm work. Noting the youth's devotion to his idea, Mr. Van Dreser decided that he should start right, and bought him thirty White Leghorns of Mr. Wyckoff, whose stock, bred for laying, had attained an arerage egg vield of 196 eggs in a year; by buying a stock of pedigreed egg layers, the young man secured the advantage of the accumulated momentum of many years' selection and breeding, and success crowned their efforts from the first. The poultry business grew and grew; its greater profitableness being manifest, everything was subordinated to that, and the end is not yet. Mr. Van Dreser intends that the business shall continue to grow.

-Reliable Poultry Journal. 


\section{THE YARD PROBLEM.}

\section{The Poisoning of the Ground. Crops for Fresh- ening the Ground. The North and South Yard Combination.}

In keeping fowls on the semi-confinement plan the yard problem presents not a few difficulties. Where fowls are given the run of even a considerable plot of ground, they annihilate the grass within a year or two (and frequently the first season), then the surface of the ground becomes sodden with the accumulated droppings, and is "sick," or, as some express it, becomcs poisoned. It certainly becomes obnoxious and offensive to the fowls and causes lack of energy and loss of stamina and vigor. The fowls become more or less listless, and seem to have no interest in anything, - in fact, life seems to them not worth living. This condition presents a serious difficulty and one which has caused disaster to many a confiding poultryman. The difficulty of foul yards has caused many poultry writers to antagonize permanent poultry houses and yards; they argue that movable poultry houses, either with or without yards (the yards being movable if supplied), were much more successful. And some have argued in favor of the colony-house plan with the poultry houses themselves being movable and brought together for winter; an example of which we give in one of the illustrations of this chapter.

There is no doubt but that a grass run is of greatest advantage in poultry keeping; if the runs can be kept clean and sweet. Discussing this question Mr. Louis Wright, in the New Book of Poultry says:

"These are the best of all for poultry, giving natural green food at nearly all seasons in England (not in Anerica), and also exercise and more or less insect food. Where space can be given for grass, no single condition will do so much for fowls and owner; but it is no use in attempting grass unless there is adequate space, and a great deal is required. Experience taught us very clearly that in England, one hundred and twenty fowls required an acre of run if kept on it permanently; and the larger breeds should not exceed one hundred per acre. But this is not the very best way of using the land, which will be kept healthier in the long run by over stocking it to the extent of even double, provided each run can be vacated for three months every year. This also brings runs into more compact compass, and so we arrive at a grass rum of about twenty-five feet by fifty feet for a pen of six large Asiatic fowls.

"A run of this reduced size, thus tenanted, will last for several years, even when occupied without cessation, with no apparent detriment. if constantly attended to; but it does gradually become 'sickened,' unless it can be vacated for freshening and purification. Amongst a number of runs this can be managed, either by three months annually, or six months bi-annually. This time need not be wasted wherever grass or hay can be used, as a crop may be taken a week or two before the tenants are returned to it. The runs will also need moving tolerably often, even while occupied; since, although too overcrowded for permanent occupation, this does not mean that the grass is kept down. Near the house it may be, but less so the farther away; and it must be mown whenever it is long, else the fowls may get balls of long, tangled grass in their crops, and may eat blades of it, parts of which are contaminated. Such fouled grass is simply poison. All this is avoided, worms and insects made more accessible, and the droppings more quickly washed into the actual soil, to be absorbed, instead of adhering to the grass, by proper mowing as required. Keeping the grass constantly mown short is the one matter of greatest importance in the management of limited grass runs. Grass cut during full oceupation should be burnt, and the ashes mixed with the other manure.

"Regular cutting is of equal importance to rums meant to be constantly occupied, and which are therefore of larger size. Inch grass will then go to waste, yet the conclusion must not be drawn that so much space is not needed; long experience has shown that it is, if the tenancy is to continue longer than five to six years, up to which time a crowding of considerably more than the hundred per acre may be generally carried on without apparent harm. But somewhere about that time Nemesis comes, and often with no apparent warning."

Mr. Wright says: "Keeping the grass constantly mown short is the one matter of greatest importance in the management of limited grass runs," but how many poultrymen understand the necessity of that, or live up to it if they do understand it? Going over the runs with a lawn mower, say once a week in the growing season, entails a labor charge that would be a serious problem to many poultriymen, and would suggest the question of employing some 


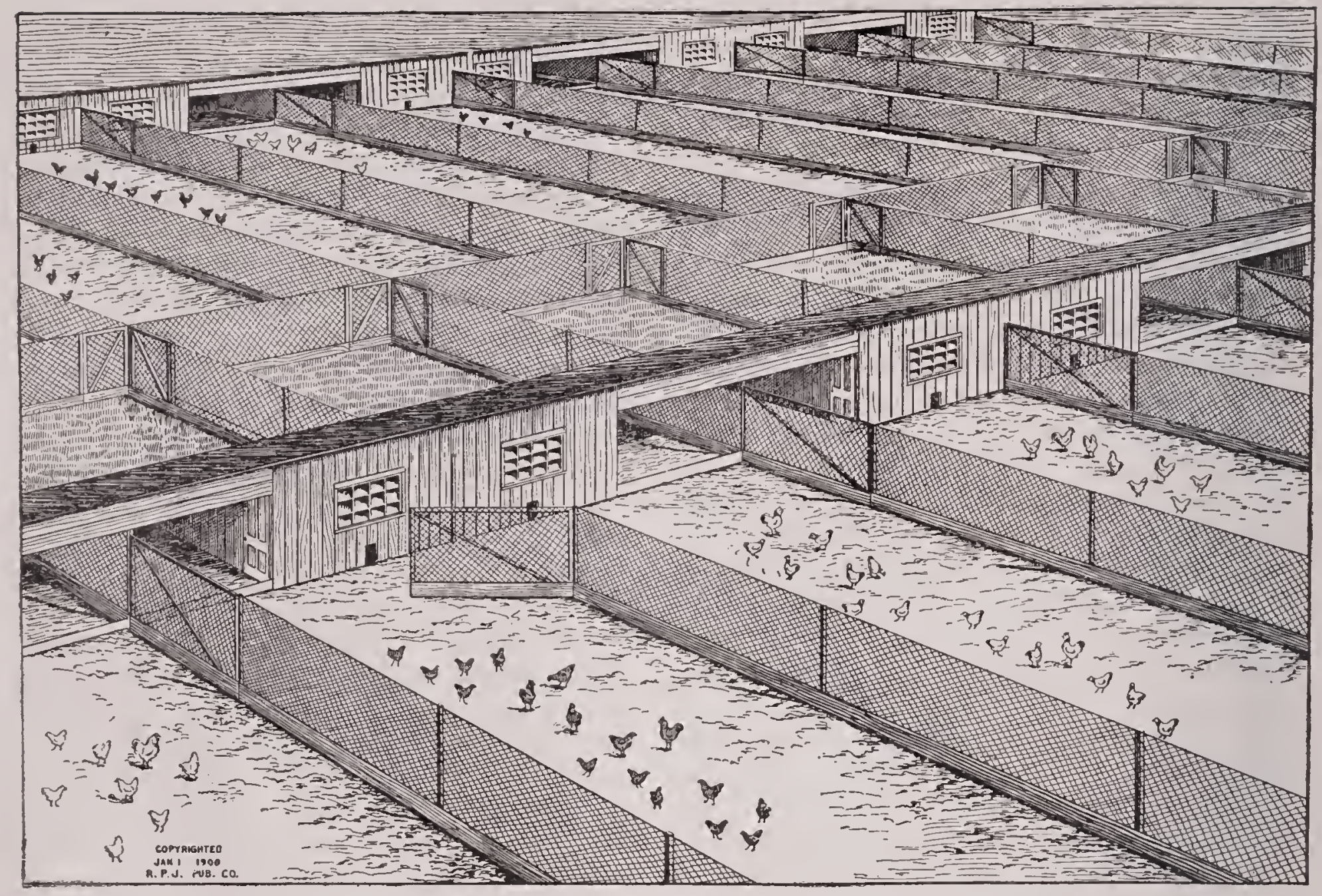

Scratching Shed Houses with North and South lards.

other method, say, for example, that they vacate the yards for two or three months in late summer and freshen with some growing crop, and this may be done in one of several ways. Some broiler raisers freshen their brooder runs in this manner, by spading up the runs and planting some quick growing crop in them, as soon as the chicks are shipped off to market. Duck raisers follow the same plan of plowing the yards and seeding with winter rye or some such crop as early in the fall as it is possible to get to it. The duck growers have the great advantage of only temporary yards, which can be removed at any time, and thus the entire space used for runs is open for plowing. Some system of temporary fencing of permanent poultry runs would not be an insuperable difficulty; it would be possible to attach the fencing to the posts in some manner that it could be easily removed and rolled up out of the way for such time as is needed for plowing and seeding the yards. Some poultrymen have panel-gates next the poultry house, which can be lifted off from the posts, permitting the driving of a team through the yards from end to end of the house for cleaning and renewing the earth floors of the house, and such panel-gates admit a team for plowing when the yards can be plowed and seeded for the desired freshening. In the illustration of the scratching-shed houses with double runs, these panelgates are shown and a short substitute run in rear of each pen, into which the fowls can be turned for such time as the main yards are being plowed up and seeded; this plan of housing and yarding presents many advantages that are well worthy of adoption. It does not require any greater amount of land for houses and runs; instead of giving all of the space between the row of houses to a long run, a fourth of the space is given to the short rums in the rear of the nearer house and the other three-fourths to the permanent runs of house number two,- the subtracted space would be made good by similar runs in rear of pens of house number two.

The soil upon which the poultry plant is located will in a mcasure determine the method employed. For example, at Lakewood Poultry Farm, and in other such sandy-soil locations, it is claimed that the droppings are washed int the sand by every rain, and that, consequently, the surface is always kept fresh and sweet,-is free from poison. Whether this is wholly true 
may well be doubted, certainly the experience of the Hammonton broiler raisers induces them to give the annual freshening to their brooder house runs, and their soil is quite the same sandy loam as that at Lakewood Poultry Farm. Where the soil is a clay-loam there woukd be greater danger of soil-poisoning from the accumulated droppings, than a lighter soil into which the water quickly washes the droppings, and one would need to study the conditions of his ground and govern himself accordingly.

It is very desirable that there shall be shade in the poultry yards, and as a combination of fruit growing and poultry raising is most advantageous. it is adrised that fruit trecs, such as plum. cherry, peach, apple, etc., be set in the rards: and where permanent fences are desired these may be trellises for grape vines and the grape vines furnish the much desired shade. When we speak of shade in the poultry yard, we do not mean complete shade, but that there should be partial shade, so that the forls can choose a shady spot or a sunny spot at will.

It should be borne in mind that the highly nitrogenous character of the poultry droppings induces growth of the trees, hence frequent pruming is necessary to induce fruiting, and many fruit trees need to have the fruit thinned to aroid the danger of orer-bearing. With fruit trees growing in the yards and grape vincs on the permanent fences, the roots absorb a portion of the fertilizing element contributed by the fowls, which will, in a measure, assist in kceping the soil sweet. We use the term, "in a measure" because nothing short of an annual over-turning of the surface and seeding to some quick growing crop will produce complete soil cleansing; and where it is the intention to keep fowls continuously year after year an annual seeding will be found quite essential.

\section{A TYPICAL POULTRYMAN.}

\section{Pluck, Perseverance and Intelligence Win Success.-How a Machinist Became a Successful Poultry Farmer.}

Mr. C. H. Wyckoff, formerly of Groton, N. Y., is a typical poultryman, an excellent example of what a poultryman should be, and ean be. Growing up on a farm, he had a practical knowledge of the advantages and disadvantages of farm life. Being desirous of becoming a machinist he served an apprenticeship at that trade, and worked at it for several ycars, gradually coming to realize the limitations of a mcehanic's life. The freedom and "out-of-doors" of farm life strongly attracted him, but alas, he had no capital,-every dollar of his weekly wagcs being consumed in the family expenses; a condition exactly similar to that of thousands upon thousands of mechanies, clerks, etc., who long to get back to the freedom of farm life. but find themselves confronted with the fact of weekly wages barely meeting the weelly expensos, and no surplus at the end of the year.

About fifteen years ago Mr. Wrekoff found an old man living on an old hill-top farm a mile and a half out of Groton, who was willing to sell his farm for nothing down, accepting as security for the first payment, a note for a thousand dollars with the endorsement of Mr. Wy clioff's father. His father was able to loan him a fow dollars, with which to partially stock the farm, buy a few tools, and get one step ahead. Mr. Wyckoff intended to develop that okl run-down farm into a poultry farm, having kept "a fow hens" at his formel home, and being a firm believer in the profitablencss of producing eggs for market. He bought about twenty-five serub hens, and housed them in one of the old buildings on the place, gradually added to his stock as the eggs produced by the mixed hens warranted it, and had the second year respectable flocks of Plymouth Rocks and Brown Leghorns. From eggs produced by these flocks he sared up $\$ 75$, and the next spring invested it in White Leghorn eggs, and a year later had grorm to a stock of one hundred and eighty good White Leghorns.

Ve want the reader to observe that all of this growth had been paid for by the hens themselves. Mr. Wy ckoff got his "living" out of the old rundown farm and garden, and set aside every dollar of the egg-money to pay for more hens, or for the eggs from which to hatch them. Thercin is the secret of his rapid climb to sticcess. If he had insisted upon using small shices of this egg-money in buying family supplics, or better clothing, or farm tools, or other things which were sorely needed in those first years, he wouldn't have "got there" so quickly.

There were many times when a dollar or two "borrowed" from that egg-money would have eased the pinch of hard times in that household, but Mr. Wyckoff believed that casy timcs were just ahead, that the harder road was the shorter, and had the courage to wait and grow. That third year, when he had one hundred and eighty White Leghorrs, eggs were extremely 


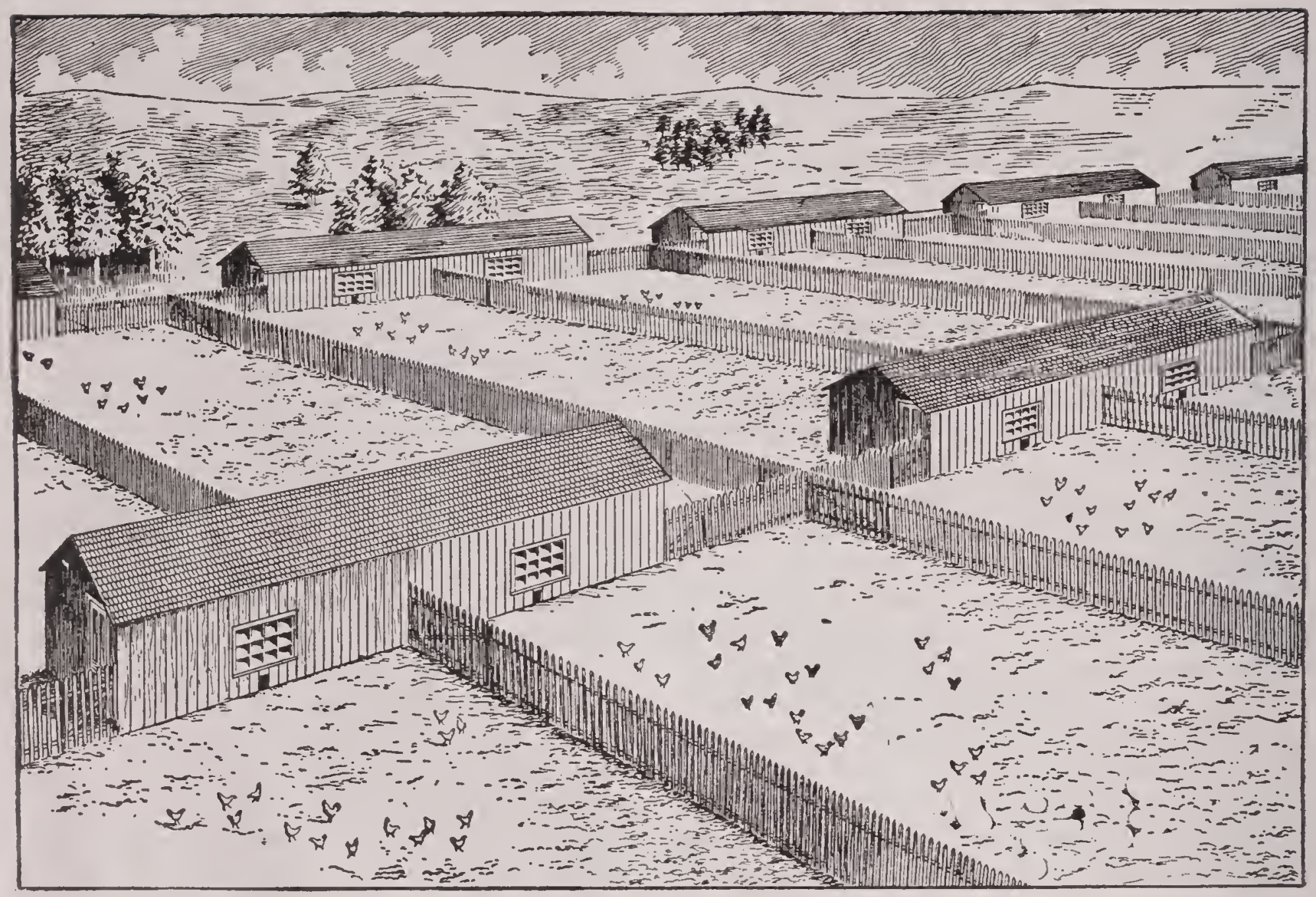

Semi-Detached Houses and lards, Wyckofi Poultry Farm.

scarce and high, and in January alone of that year his flocks gave him $\$ 90$ worth of eggs More chickens were hatched, more buildings and yards built, all paid for out of the egg-money, and for the last ten vears he has been selling $\$ 3,000$ to $\$ 4,000$ worth of products a year from that old farm.

The hens have paid for it all. The total investment was the few dollars paid for the first mixed hens; all the rest is accrued earnings of the hens themselves. Isn't that a cheering example? Are we not right in considering $\mathrm{Mr}$. Wyckoff a typical poultryman? The farm is all paid for-was paid for by the hens. The buildings to house them, the fences built to enclose the yards, the hundreds of young fruit trees set in the yards, together with all the cows, farm tools and machinery for carrying on a sixty-acre farm-have been paid for by those hens; and we know (we didn't ask him-but we know) there's a dollar or two in the bank. Compare that condition with the one of fifteen years ago, when the weekly wages barely paid the family expenses!

Mr. Wyckoff loves the farm, and takes honest pride in his prosperous looking, claen-cultivated fields; but he says his "farm"don't pay any profit.
He keeps six or eight cows and makes butter for market-but says there's no money in it. Indirectly perhaps it pays. because the manure from the cows helps to enrich the fields for the noble crops of corn and wheat he raises for poultry food; then there is the pleasure one gets from well tilled fields; it warms the heart to see the crops grow. We walked back over the farm, and Mr. Wyckoff told us of the hard days' works he had put in there, ditching and draining, and showed us one splendid field of eight or ten acres which he has "made" himself, reclaiming it from wet, rough, stumpy pasture. We suggested that he would be just as well off, perhaps better, if he sold off a part of his farm, and he said that he knew that, and had offered to sell thirty or forty acres off the rear end. As a street runs along the west side of his land, it would be well located for an independent farm, and a better Jocation for a home, and a finer outlook, one wouldn't find in a day's journey. We give him this free ad. for the benefit of anyone wanting to buy land and build his own buildings.

To return to the poultry. Mr. Wyckoff winters about six hundred head of laying stock. As he has built up a large business in cockerels 
and breeding stock, he usually has a thousand head, or even more, at the beginning of winter; but six hundred is his capacity. These he houses in families of about fifty, the pens being $12 x^{2} 0$ fcet in size, each having a yard two rods wide by eight rods long. The houses are built forty feet long by twelve feet wide, and divided into two pens by a solid board partition, haring a door to pass through. The houses have double pitch roofs; roofs are shingled, and walls double boarded, with building paper between the boardings. The windows are noticeably small, two to a pen, of six lights of ten by fourteen glass. These are ample for light, and not large enough to lower the temperature so much as the big windows do, and Mr. Wyckoff, unlike many New York poultrymen, does not have stores in his houses. He has sometimes had a male bird's comb nipped by frost, but never one of his hens.

The houses have board floors, which he litters with straw, and there is an open space of ten or twelve feet between the ends of the houses. With a door in each end and one in the center partition he passes through each house, and from one house to the other, in feeding, collecting eggs, etc. It was a great pleasure to go through the pens at feeding time and look over the flocks of large sized fine White Leghorns. Mr. Wyckoff breeds for business, and calls his stock, "business White Leghorns." He has made a record of one hundred and ninety-four eggs apiece a year from six hundred birds, and has built up his stock by carefully selecting his breeders for large size and great laying qualities; a more vigorous and thrifty looking lot of fowls one couldn't find in a day's journey.

Mr. Wyckoff is a firm believer in green food, and feeds it regularly winter and summer, whether or not the fowls have grass runs. He says he has found, by actual test, that the egg yield increased substantially when he fed green food, and decreased when it was omitted. The chief reliance in summer is kale, but he begins with clover, feeding that until the kale gets a good start, then the latter is gathered and fed daily. Kale (or borecole) is one of the family of plants similar to cabbage, (but which do not boll), which are used for the boiled regetable called "greens," the leaves and stalks having a slightly aromatic taste. When the plants have got a good start the lower (oldest) leares on the stalks are plucked and fed, the plant continuing to grow and produce more leaves. so that with a bed a rod wide by four or five rods long, a con- tinuous crop of green food may be hav vested till the ground is frozen. In Mr. Wyckoff's garden the kale was planted in rows about two feet apart, and the plants stood about a foot apart in the rows.

The eggs are shipped to a retail dealer in New lork city, and bring a premium of from six to fourteen cents a dozen above the highest market quotation of the day of their arrival in New lork. The highest price they have ever netted is fifty-one cents a dozen. He guarantees that the eggs are "strictly fresh" and, shipping them, twice a reek, (Mondays and Thursdays), the oldest eggs in the cases are but three or four days old when shipped. He has no difficulty in selling all he can ship, and during the hatching months (practically April and May) he sells great numbers of eggs for hatching from selected breeders.

This last branch of the business he has recently taken up, but its grom th has been quite rapid. As he never sends birds to shows he has no show record to boast of-only the egg record and the high quality of his stock as "business forls." This is all that is necessary, as nine out of ten buyers want business fowls rather than prize winners; and Mr. Wyclioff can dispose of all he can spare-indeed, could dispose of a great many more, if he had them.

It is curious to note how the gromth of stock selling has interfered with his keeping accurate accounts of egg yield, etc. When he had little call for stock, he filled his pens with layers and recorded their egg yield. Now he puts many more birds in the pens, and is selling them off through the late fall and early winter. This not only interferes somewhat with the egg yield, but the numbers in the pens are frequently changing, and a reliable account of egg production per bird is impossible. In the spring, too, he wants one house for room for brooders and chickens, so the birds in that house are put into the others, crowding them somewhat. Not only does this crowding lower the egg yield, but moving the birds checks the laying. At the time of our visit, a brooder house $60 \times 16$ feet mas being built in the pear orchard, east of the poultry buildings, and that brooder house will not only take the brooders and chicks in the spring, but will house in the fall two or three hundred head of sale stock also; such a house will repay for itself in one year. Mr. Wyckoff told us his sales of eggs for hatching and breeding stock together aggregated $\$ 1, \$ 00$ last year. That is a "business" of itself. 
A soft food is fed in the morning, but it is noticeable that it contains no cooked regetables. He takcs one bushel of corn and two of oats, has them ground up together quite fine, and to each two hundred pounds of this meal he adds one hundred pounds of bran. This mixture is moistened with skimmed milk or sour milk, or buttermilk (with either one or all of them), and five or six pounds of beef scraps added. If he did not have the milk, more beef scraps would be necded. This morning fecd is fed in $V_{\text {-shaped }}$ troughs which are about ten feet long. After ten or fifteen minutes he passes through the houses and gathers up any food that may be left in the troughs, but if any of the forrls seem to be hungry he feeds a little more in that pen; he wants them to have all they will eat up readily.

The noon fecd consists of the green food of the day, which is mangel beets or cabbage in winter, clorer or kale in summer. On the day of our risit he also fed a very light fecd of mixed grain thrown in the litter to make them scratch. This mixed grain, which is the same for the night feed also. consists of two bushels cach of wheat, oats and buckwheat, and one bushel of com ; in winter two bushels of corn, which makcs the mixture then equal parts of the whole grains. Sonctimcs he adds barley, if it is reasonably low in price; and the night fecd is a full onc, all that the fowls will eat up clcan.

This story is too long alrcady, but is so intercsting we hardly know where to stop, and haven't more than half cxhausted our notcs. One or two criticisms we wish to make. We think Mr. Wrckoff makes a mistake in raising his roung stock right there in the old buildings and rards-a mistake which many (almost all) of the Tew Iork poultrymen we risited, also make. The rcason is simply that the old yards and buildings are more or lcss fouled or obnoxious, and the chicks will do better on frcsh ground. On our farm we "colonize" the chicks in families of twenty-five or thirty, out in the grass fields, directly the grass is cut, and find the plan most excellent for chicks, and fields both. No small advantage of this colonizing plan is that the houses and yards are free for the continued use of the laying-breeding stock, and their laying isn't interrupted (as Mr. Wyckoff told us his was), by crowding the hens up to cmpty one or two houscs for the chicks. The grcat adrantage, however, is the free range for the growing chicks. They cat better, because the frcsh air and free range enables them to digest and sssimilate more food, conscquently they grow faster and better. We believe young stock so colonized grows up under the most farorable conditions and comes to the laying pens in October in the best possible condition for winter laying and spring breeding.

We have written to little purpose, if we havcn't shown the reader that Mr. Wyckoff is a most inspiring cxample of the successful poultryman, an example which any man may follow. It is a trite saying that "What one man has done another can do," but-how true it is! Mr. Wyckoff has put pluck and persererance, and intelligence into his opportunity; that is all. It will be conceded that he had no "soft snap." The way was not made easy for him by plenty of capital; he made his own capital as he went along. With his own bare hand, plus pluck and perseverance and intelligence, he has wrought success. - Farm Poultry.

\section{WHITE LEGHORNS FOR UTILITY AND FANCY. \\ Methods Employed at Fairview Farm; Season- able, Sound and Practical Advice.}

BI H. J. BLANCHARD, GROTON, X. I.

We usually begin selccting our breeding stock in December or carly January, so as to have plenty of time to look the birds over very carefully for a few weeks, remove all specimens that may show undesirable traits and replace with finer oncs. Tigor is the first cssential in any fowl, and cspecially brecders. as it is the foundation on which to build the best layer or finest show bird.

Select your brecding hens from the pens having the bcst egg record, and if selling brecding and exhibition stock and eggs for hatching, look well to standard requirements also. In mating hens, use vigorous, active cockerels, well marked, for standard matings; and for pullets use vigorous cocks. Look well to the rigor of the cocks and sce that they are not sluggish or inactive.

Don't push your brecding birds for eggs, but feed a good, balanced ration and let them come to laying naturally. Right here let me say that while I favor feeding liberally a good, balanecd ration, yet $I$ firmly believe it is not so much what we feed as the way we fecd and manage that makcs hens lay best.

Don't try any "forced molting" processrour birds will molt when it is best for them. 


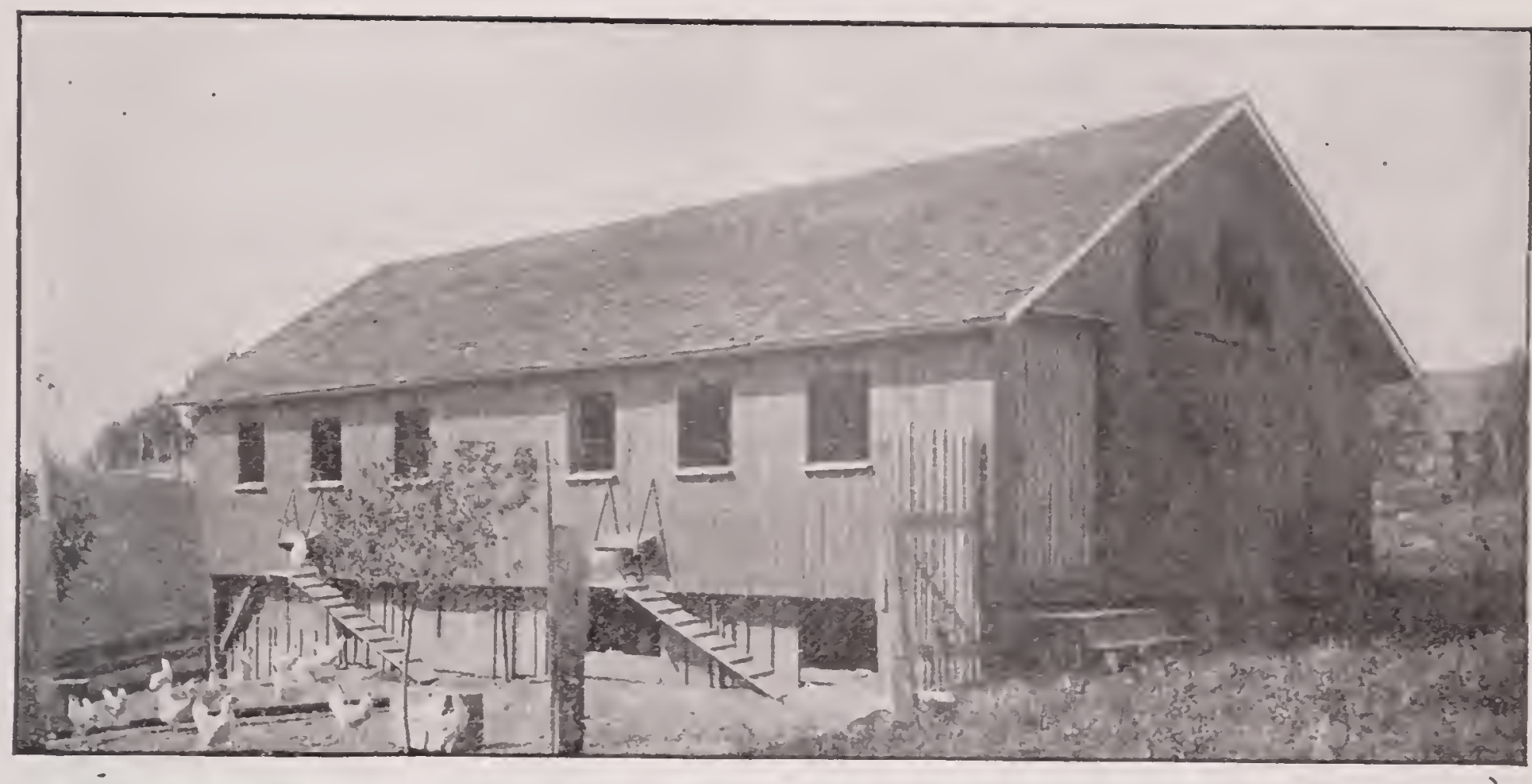

Houscs and lards for Breeding Stock, Fairview Poultry Farm.

However you can assist Nature in the molting process by feeding the birds old-process oil meal, sunflower seed or other foods which will assist in growing feathers as well as nourish the bird. We always feed meat during molting. eren though we get few eggs to pay for it. as it helps the birds to recover and get into condition more quickly.

We read a great deal about feeding for fertility of eggs, as if it were a special process, but it is only good, sensible feeding for general health and eggs, which includes shell, grit, plenty of succulent green food, and a liberal amount of exercise, scratching for grain in litter in a properIy ventilated, dry, clean house.

If White Leghorns are the only variety you keep, and you wish to hatch and raise your chickens by the natural method, you had best get some Plymouth Rocks, Wyandottes or Brahmas, as the White Leghorn is a treacherous sitter even when she is inclined to make a business of it, and only a small percentage of them will sit. Then you have lice to contend with as well as the ragaries of the hen, and if chickens are wanted in any considerable numbers, I would certainly adrise the use of good incubators and brooders.

Our White Leghorns have been hatched and reared in large numbers continuously for many years by the artificial method. and we are satisfied it is by far the best and most profitable way. Some few breeders still maintain that artificially hatched and reared chicks do not make as large, rigorous birds, nor as good layers, but our experience is quite the reverse. Buy the best incubators and brooders you can get, even though the first cost is more-the cheap machines are usually "made to sell" and would be dear as a gift. Run your machines a few days before using, so as to becone familiar with them and able to keep them well under control.

At the end of the 21st day, after the hatch is done, open the incubator and remore the trays with the shells, unhatcher eggs and dead chicks, if any, open wide all ventilators and rum the heat down to $9 S$ or 100 degrees, leaving the chicks in without food or water until the next day. The brooders, well littered with dry sand or finely cut straw in run and hover, should now show 95 to 100 degrees of heat under the hover. The chicks will now be strong, lively and in good condition to transfer to the brooder hover, which should be done without chilling them.

Feed very little the first day and give water with the chill off, using a good chick-fountain. Be sure the chicks have some fine, hard. sharp grit with the first feed and ahways thereafter. What to feed is largely a matter of circumstanees. Te use Cyphers Chick Food exclusively for first three or four weeks, and like it rery much. After this we work in a little whole wheat and cracked corn, gradually learing out the Cyphers Chick Food. 
We use indoor brooders early in the season while yet cold, but later, when mild, use outdoor brooders. As soon as the chicks are strong enough and. Weather suitable, they should be got out doors on the grass, in a little yard at first, but when old enough, they should have free range all summer and until snow comes in fall. When chicks are about eight weeks old, we begin feeding once a day a mash of ground grain in which we mix a very little high-grade beef scrap, gradually increasing the quantity of meat.

Always keep fresh water in sharke where the chicks can help themselves to it all day.

We believe in the colony house plan for both chicks and old fowls, and free range for breeding stock so far as possible. We have colony houses for chicks near our corn fields and one near a half-acre blackberry patch, and find the shade and protection afforded by these crops very raluable to our growing chicks, and the crops and soil are also benefited by the foraging birds.

One line of our breeding birds have houses in a small wooded valley through which flows a brook, making a typical place for the birds to roam at will. From stock kept in such a manner, you will not fail to get strongly fertile eggs and chickens of sturly frame and robust constitution.

The cull pullets and hens can be confined in large yards planted with fruit trees of any kind, or blackberry bushes, of which we find "Snyder" the best all-round variety. TVe amnually gather good crops of blackberries and tree fruits from our poultry yards, while the trees and bushes make the yards seem more like free range and the confined fowls do much better than in the ordinary small, bare yard.

Most of our colony houses for layers as rell as the breeding houses are $16 \mathrm{ft}$. wide by $40 \mathrm{ft}$. long and $7 \frac{1}{2} \mathrm{ft}$. from bottom of sill $(6 \times 6)$ to top of plate $(4 \times 4)$. We set the sills about 30 inches above the ground on a stone wall, cedar posts, or gas pipe; if on the latter we nail boards inside the sill extending to the ground, with windows in south side. Wall double with dead air space. Lower floor of single matched lumber or laid double with plain lumber and Neponset black sheathing paper between. Overhead on the plates are laid $2 \times 6$ joists notched two inches on lower side and spiked to side of each $2 \times 4$ rafter. On these joists is laid a floor of cheap lumber with wide cracks between each board. Over this the third-pitch shingle roof without paper under shingles. In each gable cut a door as large as will swing under roof.

On this loft floor put about twelve inches loose straw. In very cold weather, when house is tightly closed, the rapor thrown off by the fowls will ascend through the cracks in loft floor and be absorbed in the straw above instead of being condensed on walls and roof in the form of frost, thus keeping the house warm and dry. On mild days we open the door in each gable over the straw and let the air draw through and chry out the loft and straw without any draught on the birds below. The straw loft also keeps the natural heat of the birds confined below, which makes the house warm and comfortable. In hot weather these gable door's are left open day and night, and the draught through the loft, together with ventilation from open doors and windows below, keeps the house cool. The basement, being light, is not infested by rats or other vermin, and is greatly enjoyed by the birds during summer as a resting and wallowing place in stormy weather, also when very warm.

Our winter food for layers and breeders is about as follows: First comes water, slightly warmed in coldest weather, next a very light ration of whole mixed grains, wheat, corn, oats and buckwheat about equal parts, scattered in a heavy litter of straw on the floor. After this the birds are given mangel wurzel beets cut in halves and placed on the floor. They are thus kept busy all the morning scratching for grain, running to the water pan, picking at the mangels and are getting very hungry, as the food has been scant and slow to get. About eleven o'clock we feed a warm mash in the troughsall they will clean up in a very short time.

Our mash is ground oats and wheat bran, about equal parts by measure, to which is added corn meal, hominy feed or both, and sometimes wheat or buckwheat middlings. To this we ardd about half an ounce per hen of good meat meal or beef scraps, and one fourth as much old-process oil meal, and mix all thoroughly while dry. To this we sometimes add boiled and mashed potatoes, turnips or other regetables. Clover cut into $\frac{1}{8} \mathrm{in}$. lengths, about two quarts to each 100 hens, is put in pails and boiling water turned on, then pails covered and the clover allowed to steam a half hour. The steamed clover or boiled vegetables are 
then thrown in the mash-box and hot water, in which has been dissolved a little salt, poured on. The whole mass is then thoroughly mixed until all this is moistened but not sloppy. Along in the afternoon we feed more mixed whole grain, scattered in the litter, all we think they can eat, and if any is left over they look for it in the morning. We ventilate the houscs more or los, every day by the windows, except on coldest days.

The best mangel wurzels are the Golden Giant Intermediate, sold by W. Atlee Burpee and Co., Philadelphia, Pa., and we grow them as follows: Select a clean picce of ground and plow under a heary drcssing of stable or hen nranure, harrow very thoroughly and remove all rubbish, broadcast on a good dressing of commercial fertilizer and harrow in. Nark out rows three feet apart, sow seed in drills, about twelve pounds to the acre, and cover about one inch. Soon as the plants are large cnough (about one inch high) thin out to a foot apart in the row, then cultivate, hoe and keep clean. The roots should be gathered before any hard freezing and stored in bins or piles in a cool cellar.

We never store the hen manure as it is a costly job to "fix" the nitrogen and pulverize the inanure. It is drawn directly from the poultry houss to the fields and spread. winter and summer, and gives grand results with all crops except potatocs, which it is liable to scab.

When snow comes our chickens are taken from the colony houses in the fields and put in warmer winter quarters. During fall and carly winter we dispose of a large share of our hens for breeding, laying or exhibition, thus making room for the pullets.

The cockerels are separated from the pullets, about August, and given free range on another part of the farm. They are kept in warm houses in winter that no combs may be frozen. Our best cockerels go in our own breeding pens or are sold for breeding or exhibition, and a great many of our pullets are sold and shipped all over the country. Sales of eggs for hatching also help swell the income. Market eggs was our first object, and our plant was built up largely from the profits of their sale. When producing in large quantitics we went to New York City and after some difficulty succeeded in placing our output at a good margin above regular market prices. Every egg must be new-laid, clean, good size, neatly and securely packed, to hold such trade, and you must have eggs in fall and winter.

Nothing desirable comcs without earnest endeavor, and the poultryman must expect to work hard and have for his motto, "Eternal vigilance is the price of success."

\section{-H. J. Blanchard.}

\section{TWO COLONY-PLAN EGG FARMS.}

\section{Some of the Advantages and Disadvantages of the Colony Plan.}

It was a lovely spring-like day early in $\mathrm{No}-$ vember, that we stepped off the train at Mattapoisett, far down the west side of Buzzard's Bay, on a journey in scarch of poultry farms run upon the colony plan. A drive of a mile or thereabouts brought us to the farm of Mr. James B. Hamblin, which we found being turned into a poultry plant of about two thousand head of laying stock. The buildings are seattered over two large, sandy fields, and are from one hundred and fifty to two hundred feet apart; in one field, being set in rows, so as to drive up and down the roads to the houses to feed, etc., and in the other arranged conveniently for reaching with the horse and wagon. It is the intention to house forty birds in each house, $\mathrm{S} \times 12$ feet in size, and give them free range. The food is loaded upon a wagon, which is driven about from one house to another, the driver jumping down at each house with a scoop (or measure) of food, which is fed in a few seconds, and the driver jumps up behind and drives on to the next. There is a broad step hung on behind the platform of the wagon, similar to that on baker's and milkwagons, for the driver to ride on, and the wagon being on two wheels, (a "gig" practically) it operates easily. The horse soon becomes trained to its route, with the regular stops and starts, and once the horse is well trained the operation of feeding and watering is comparatively simple. Fortythree houses (of the fifty planned for) are completed, the roofs being shingled, walls of rough boards, with the cracks battened, and a small ventilator hole being cut in each gable; but the houses are not all stocked as yet, some of them being still occupied by surplus cockerels which are being fattened for market.

The stock which Mr. Hamblin now has is Light Brahmas and Rhode Island Reds, and crosses of Indian Game males on females of those two varieties; and it is the intention to 


\section{PROFITABLE EGG FARIING.}

run the plant chiefly as an egg-farm, although the incubators and brooders will be occupied in winter with chicks for broilers and roasters.

We spent a few minutes inspecting the old, old dwelling house, built in 1703, still in good, habitable condition, and the old hand-hewn bcams of oak look as though they were good for another two hundred rears. The rooms are furnished with the old time furniture, and anyone enjoring the antique would have much pleasure in a ramble through that old house.

Eating our lunch as we drove along the charming, woodsr roads, we came in due time to the poultry farm of Mr. Geo. E. Howland, of Fairhaven, who keeps about fourteen hundred head of fowls, for eggs only. Here can be seen in perfection the growth of a poultry farm. Mr. Howland bought the farm about ten years ago. and started in business with a few pens of fowls, housed in buildings of various sizes and shapes. The plant has gradually grown, absorbing an adjoining farm on the north; and the buildings, which are scattered all over the two farms, are mostly of the lean-to-shed pattern. Some of these houses are of stone ends and back, the front and roof of wood; but the majority of them are wood, the walls shingled, the roofs of all being covered with tarred felting. Three or four houses, including two that they are just building, are sixty feet long, divided into five pens $11 \times 12$, with yards $12 \times 100$ in front; but all the others are scattered about the rocky fields, being about one hundred and fifty feet apart, but set in such a position as favored easy access by the horse and feed wagon.

The stock here was mostly "common hens," although some first crosses were in evidence, and Leghorn and Minorca blood was casily predominant. The object being eggs, and only eggs. the stock is bred for layers, and only enough chickens raised to reproduce about two-thirds of the laying stock, the best third of the old stock being carried over. Mrr. Howland puts never more than twenty birds in a pen or house. As the latter arerage to be about $11 \times 14$ feet in size it is easy to see that they have (with absolutely free range) plenty of elbow room. We told him of Mr. Hamblin's houses, which we had seen but an hour before, and that Mrr. Hamblin planned to house forty birds in a house $8 \times 12$. "He'll miss it if he docs," said Mr. Howland, "I have proved that I can get more eggs from twenty birds together than from forty in the same house; not only more eggs per hen, but, actually, more eggs per house. I have tried it and proved it." As we fully agreed with him there was no chance for an argument.

Mr. Horland sprays the insides of his houscs twice a rear with petroleum. and the effect is to darken them very much. We cannot but think whitewash would be superior, because it rould be equally cleansing. and would make the houses lighter, more cheerful.

IIr. Howland "pickles" his eggs in spring, when eggs are selling at a low price, and sells them when eggs are scarce. He put down serenty-five hundred dozen last spring, fifty barrels of one hundred and fifty dozen each, and two-thirds of them are already gone to market. He preserves them by the lime-rater process, having an improvement upon that process by which he can keep the eggs about as fresh as when laid, and he warrants them to "beat up into frosting," or stand any other test of freshness. As the dealers are at this season glad to get them, and "rumning after him for more," Mr. Howland thinks there is a good profit in pickling eggs, in spite of the fact that there is quite a bill of labor attached.

Mr. Howland hatches and raises his chickens by the old hen method, there being neither incubator nor brooder on the place; and he also doesn't believe in cut fresh bone, having fed it for three rears and discarded it. He says he can get more eggs from his forls by using "beef scraps" for animal food than he can when feeding cut bone, hence he fecds beef scraps. His ration is a mash consisting of cooked vegetables mixed up with a meal which is five parts shorts and one part beef scraps, and a little condition powder in the morning, and in the afternoon a fecd of corm, oats and wheat, equal parts. He burs three hundred to four hundred bushels of small potatoes each fall for winter feeding; as he docs no farming whatever he has to buy his regetables. Another thing that he does is to buy grain in large quantities when it is low in price. He has just got in about seventeen hundred bushels, as grain is now very low.

We sometimes hear it said that large poultryfarms never have succecded; but here is one that most certainly has. It has grown from small beginnings, an additional farm has been bought, a fine new dwelling house has been built, (the old cottage being moved back about fifty yards and used now as grain-store house), and there are very many evidences of a pros- 


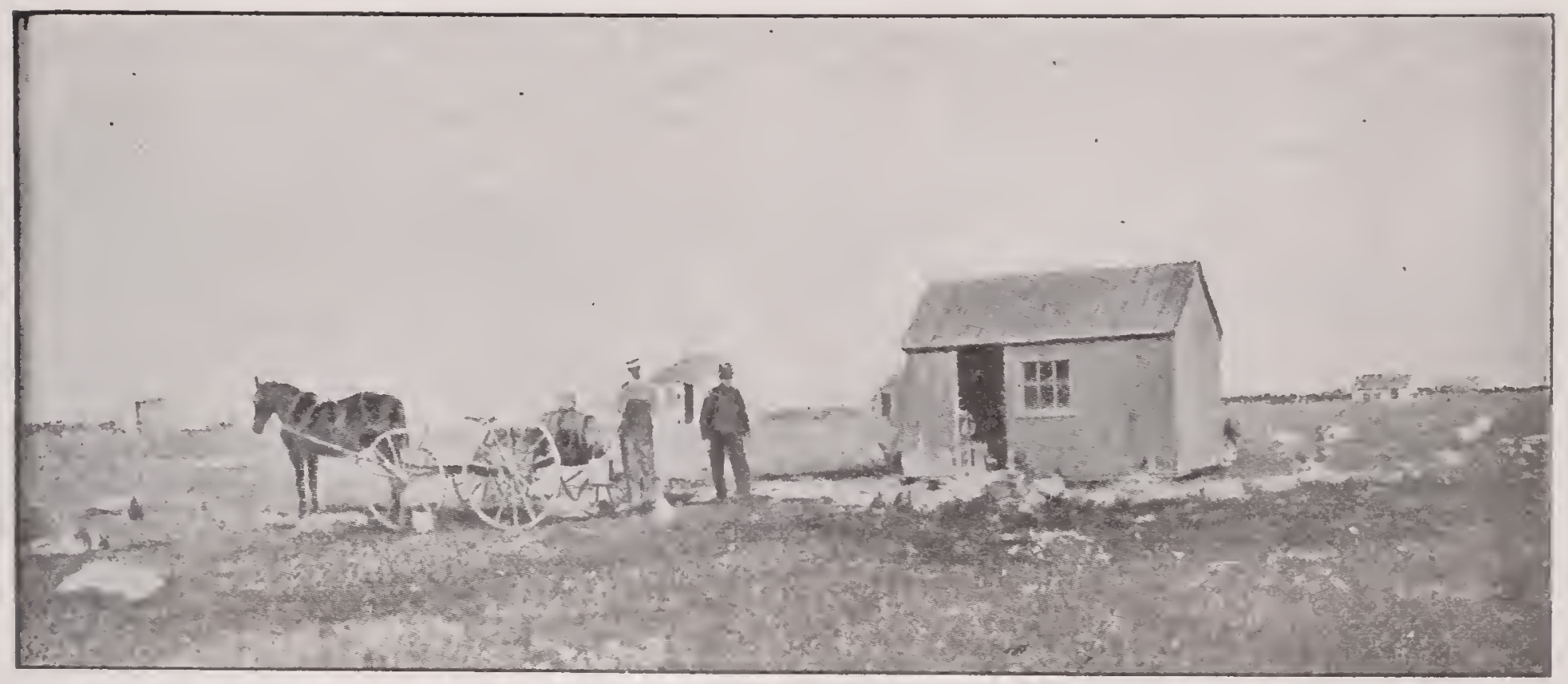

Colony Houses at Little Compton, R. I., Showing the Cart for Food and Water.

perous condition of things. Mr. Howland doesn't adrertise because he has nothing to sell. He manufactures eggs and the market takes all he can produce, and pays him cash for them, and his farm is an egg-farm and nothing else-no side issues. nothing to interfere with the production of eggs.

\section{MR. WILBUR'S GREAT POULTRY FARM.}

\section{The Colony Plan and Rhode Island Reds.}

A poultry farm which carries four thousand head of laring stock may fairly be considered "great." In fact. we behieve it is the greatest we have ever risited or heard of, and as we think we should have heard of it if there had been one larger, we will assume that this is the largest poultry farm in the Lnited States; and is, consequently, the largest in the world. It goes without saying that the United States is a long way ahead of every other country in poultry culture, hence what is greatest in poultry here is the greatest in the world. Isaac Wilbur, Esq., of Little Compton, R. I., is the poultry farmer we have in mind, and his poultry farm and poultry business, the result of thirty or more years of growth, is the subject of our sketch.

Mr. Wilbur did not begin life as the traditional poor boy. nor did he buy his farm with a small payment down and a big mortgage. His farm of two hundred acres has been the home of the Wilburs for many generations, and the men of the family have been prominent citizenshis grandfather, whose name he bears, haring been governor of the state and a leader in public affairs in his day. A man of culture and refinement himself, Irr. Wilbur is a type of the best class of farmer-citizen of America, the "solid men" of our country.

Forty years ago Ur. Wilbur farmed by the old methods, beef for market being his main stay, for which business his excellent naturalgrass land is rell adapted. Every farmer kept a flock of hens in those dars. chiefly for eggs and poultry meat for the table, and some eggs and dressed poultry were each rear sold to market. As Mr. Wilbur is a dozen miles from a railroad and four miles from a steamboat wharf, he saw the adrantage of a concentrated market product, decided to keep two flocks of forrls instead of one, and built a second house for the other flock. There were "croakers" even in those days, and one conservative neighbor remonstrated with him for his foolishness in building a second poultry house. "Why," said he, "you'll glut the market with eggs, you'll knock the bottom all out of the business with orer production!" As Mr. Wilbur's two houses have increased to a hundred, and as, influenced by his example and encouraging words, many of his townsmen are doing likewise, and selling their eggs to him. until MIr. W. handles and ships one hundred and thirty thousand to one hundred and fifty thousand dozen eggs in a year, the croaker woukd seem to have been shortsighted.

Mr. Wilbur keeps the forks on the colony plan, housing about forty head in a house $8 \times 10$ or $\mathrm{S} \times 12$ feet in size, these houses being about one 


\section{PROFITABLE EGG FARMING.}

hundred and fifty feet apart, set out in long rows over gently sloping fields. He has one hundred of these houses, scattered over three or four fields. The food is loaded on to a low wagon, which is driven about to cach house in turn, the attendant feeding as he gocs; at the afternoon feeding the eggs are collected. The fowls are fed twice a day. The morning feed is a mash of cooked regetables and mixed meals; this "mash" is made up in the afternoon of the day before; the afternoon feed is whole corn the year round. It is none of our business, but it seemed a little droll to find western (dent) corn brought to this out-of-the-way corner of the land, teamed four miles from the steamboat landing, and fed to fowls! That may be economy of labor, but we doubt it - which is wholly outside of the question of the unwisdom of feeding so much corn. We could not but think that a more varied food-ration would induce a greater egg-yield per fowl; but as we were unable to get a statement of what the egg yield per fowl is we can only guess at this.

The houses are of the simplest and cheapest, could be built for twenty dollars apiece, probably. Some of them are of the double-pitch roof pattern, others of the sloping (shed) roof pattern; but all are alike in being built of the cheapest unmatched lumber, and all are innocent of shingles or roofing paper on roof and walls. Of course they are thoroughly ventilated, the numerous cracks between the boards admitting fresh air in abundance, and sunshine and rain with absolute impartiality. In that location, close upon the seashore, snow is practically unknown, and the fowls can rum at large every day in the year; and that free range, with unlimited fresh air through the houscs, keeps the fowls in perfect health. Whether fowls so housed and cared for will produce as many eggs in a year as fowls better housed, and fed a more varied food-ration, may well be doubted. We would like much to see a test made there, of shingling (or roof papering) the roofs and walls of one row of houses, putting half the number of birds in each of those houses, and feeding them a balanced ration. We believe the birds in those houses would lay nearly twice the number of eggs in a year, and that three-fourths of that greater egg yield would come in the fall and winter, when eggs pay the creamy profit. This could only be determined by a careful experiment carried through a whole year, the record being kept of the egg yield of each houseful.

Another experiment we hope Mr. Wilbur will try is adding a small (say $6 \times 8$ or $8 \times 8$ ) scratching shed on the west end of some of those houses. The advantages of such a shed would be very great in stormy weather, of which they have quite a little there on the coast. That Mr. Vilbur is not himself wholly satisfied with his houses and the colony plan, we judge from the fact that he is planning to build a long, scratching-shed house on land east of his present plant, and below his son's residence.

While considering the colony house plan we will digress to remark that we have found two or three other cases of a desire to try the longhouse method. Mr. Mapes, for example, of Middletown, N. Y., has (or his son has) just built a house $320 \times 16$ feet, divided into twenty pens $12 \times 16$, and an alleyway four feet wide extending the entire length of the building; and Mr. Howland of Fairhaven is building his later buikdings each sixty feet long, divided into five pens $12 \times 12$, and with $12 \times 100$ feet yards adjoining. From these recent exampls we may infer that the colony plan of housing poultry is not the greatest success; if it were these men would not be trying something else.

To our mind the strongest argument against the colony plan is that too much of the fowls' physical energy is wasted in "ranging," energy which if properly conserved will turn to egg production. We try to plan for house room and yard room enough for good health, and to keep green grass accessible all the growing season-and we believe we get the best egg product by that plan; which, for want of a better name, we call the semi-confinement plan.

The bulk of Mr. Wilbur's stock is the Rhode Island Reds, a variety well known in southern Massachusetts and Rhode Island, and famous for both egg production and dressed poultry. They probably originated in crosses of the old Shanghai fowls with native stock. Of this, however, there is no proof; and the fact that in one section of that country they were known as "Malays," is suggestive of their being an importation originally from an eastern country. That they are a very much mixed stock is shown by their breeding both rose and single combs, and both clean and feathered legs-and it will take time to "establish" them, fix a type. The single combed and clean legged bird seems best suited to meet the popular taste, and that is the 


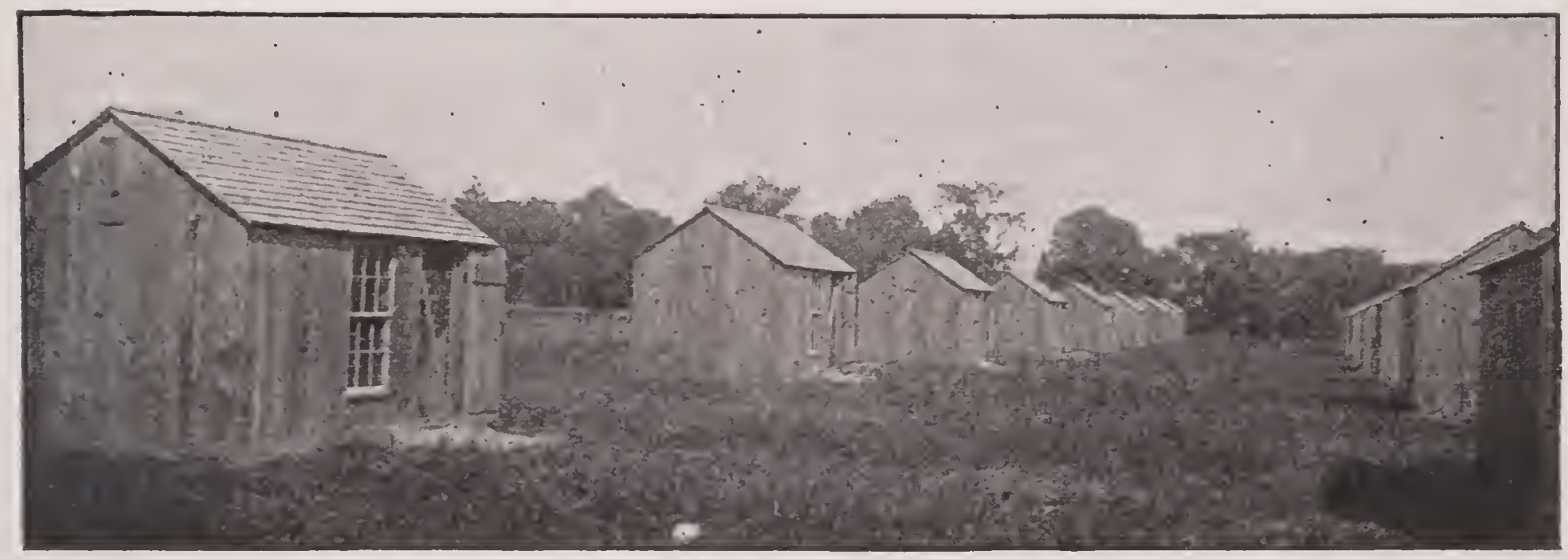

Colonf-Farm Houses Brought Together for Winter, de Wolf Farm, Bristol, R. I.

type of bird Mr. Wilbur is selecting for his breeding stock. The R. I. Reds lay a beautiful brown egg, good proof of their Asiatic ancestry; and their skin is a rich yellow, making them extremely attractive as dressed poultry. They are smaller than both P. Rocks and Wyandottes, hence exactly hit the popular taste in size, the great demand being for chickens and fowls dressing eight to ten pounds the pair.

The trpical males are of a deep, rich buff color, with greenish-black tail and greenishblack stripe in hackle. The females are a lighter buff, many of them (especially after the adult molt) quite light and showing some stripe in hackle and color in tail. Being wonderfully hardy, both as chickens and fowls. and quiet and docile, no wonder the farmers of that region like them as "business fowls."

We greatly enjoyed talking "hens" with Mr. Wilbur, as we walked over the farm, notwithstanding the various matters we have described; but we would fail of our object if we gave our readers the idea that all of his business is poultry and eggs. In addition to his own four thousand hens he buys up the poultry and eggs from a considerable region about there, and ships some one hundred and thirty thousand to one hundred and fifty thousand dozen eggs to market yearly. How many tons of dressed poultry he ships we do not know; but four men were busy dressing fowls, chickens and ducks the day we were there, and one was dressing lambs-as Mr. Wilbur keeps about one hundred sheep, and sonds considerable mutton and lambs to market. He also raises veal, keeping about forty cows for that purpose, buying the calves for fattening from farmers about; on the whole his farming is considerably varied-and he makes it pay.
He told us it was his intention to make a profit out of each line of farm work, so that no part of the farm should be a tax upon another part.

Such an example of profitable farming is the best answer to those that croak- "Farming don't pay nohow!" and what a record such a man as Mr. Wilbur makes in a community. What stability, for instance, is suggested in the fact that one of his men has been in his employ continuously for forty-two years. Indeed, the cook in the kitchen claims to have been in his employ still longer, but Mr. W. smilingly says her record was broken by a not altogether successful matrimonial venture, so that she cannot claim continuous service. Such facts point a moral in these days of rapid transformation in farm help. Isn't it splendid that the stability of character which unites master and servants in a long life-wrork together is one of the aids to making farming pay? -Farm Poultry.

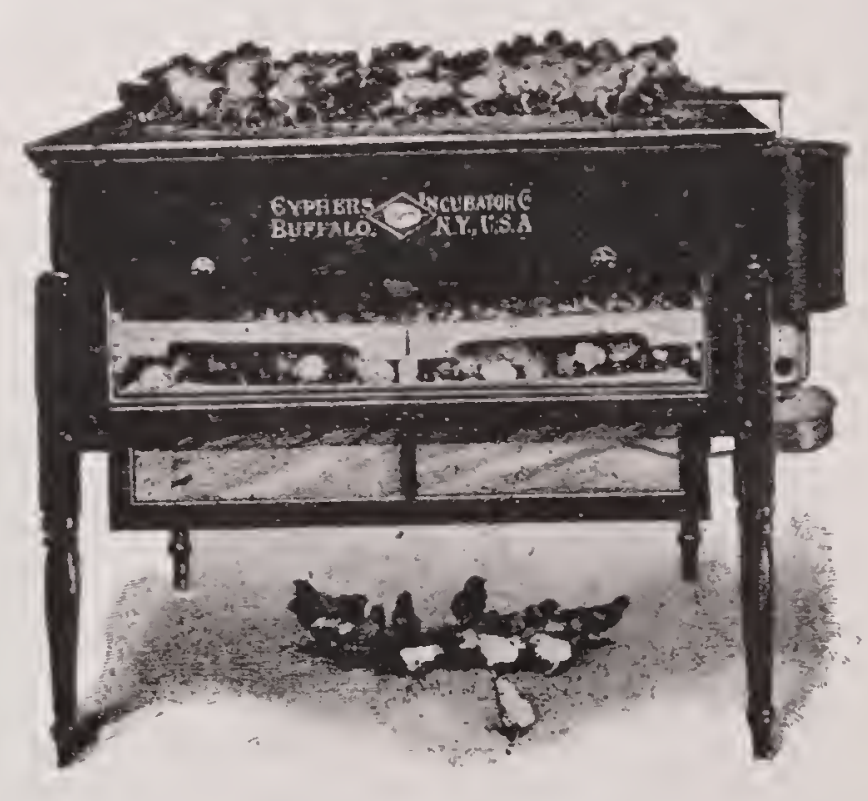




\section{PROFITABLE EGG FARMING.}

\section{Some Advantages and Disadvantages of the Colony Plan.}

It could be stated roughly that the advantages are economy of house construction, complete isolation of each fanily, and free range, but we feel bound to say we believe the lessened cost of construction is more than counterbalanced by the enlanced cost of operation. The greater cost of construction of long houses and yards demands an immediate investment of money, requires more ready capital at the start, while the increased cost of operation is an amnual tax, a year in and year out expenditure of time and muscle. True it is usually the muscle of a hired man and horse, but hired men's wages eat into the income rapidly, and horses have to be fed; hence we feel bound to say frankly that the largest advantages are on the side of the longhouse plan.

We have visited several colony-plan farms, Mr. Hayward's, Hancock, N. H., Mr. Wilbur's, Little Compton, R. I., "Tanglewood," East Greenwich, R. I. (now defunct), and others besicles Mr. Hamblin's and Mr. Howland's.

Mr. Hayward's is farthest north, and being far back from the seashore, is much more effected by snow and cold than the others mentioned, which are close upon tide water and practically free from the invasion of snow, which must mean considerable in the expense of operating. Mr. Hayward's buildings are scattered over half a wile or more of rocky hillside, and the labor of "breaking roads" to them in such a snowy, blowy winter as we had last winter must be a heary handicap. The houses are "A" shaped, eight feet square on the ground, and house a family of twelve birds each. As he has about three hundred of these houses set about one hundred feet apart, and told us they cost about $\$ \$ .00$ apiece, that means an investment of but $\$ 2,400$ of cash to house three thousand six hundred head of fowls. It would be well to note here that Mr. Hayward claimed to clcar only about one dollar apiece on each fowl.

Mr. Hamblin's houscs are $S \times 12$, and intended to house forty birds in each; while Mr. Howland's houses are $11 \times 14$ (average, they vary a trifle), and he houses twenty birds in each. Mr. Wilbur's houses average about $S \times 10$, and he houses twenty-five to thirty head in cach. We feel bound to say (as did Mr. Howland when we were discussing Mr. Hamblin's plans), that we believe the better all-round results and better profit per hen can be obtained from twenty birds in a family than thirty or forty in the same houseroom. Mr. Howland, a veteran of many year's experience, was emphatic in saying that he could get fully as many eggs in a year from twenty birds in a house as he could from forty in the same house. In the one case he had bought the food for twenty birds, and in the other for forty; the egg yield being practically the same the net profit is the greater with twenty birds.

This is a digression, perhaps a justifiable one, and we are prompted to make another to speak of open-front scratching sheds, which coukl be so easily and cheaply added to the Hamblim, Howland and Wilbur type of house. A simple lean-to roof, with a west wall (say) three fcet high, and a north end would cost but very little, and would be of immense adrantage for giving the birds fresh air and exercise in the open air. With such an open-front shed $8 \times 8$ or $8 \times 10$, these houses would easily carry twenty-five or thirty fowls; and we feel certain they would lay enough more eggs every rear to pay for the shed.

We stated at the outset that the apparent advantages of the colony plan were: 1st.-Econony of housing; 2nd.-Complete isolation of each family; 3d.-Free range. The cheaper construction will be conceded without discussion; the cheaply built (not permanent) houses, without yards, cost rery much lcss per head of fowls housed than the substantially built longhouses and yards. But, as we said above, this apparent advantage is fully counterbalanced by the greater labor of feeding and caring for the fowls; the long-house plan requires more capital put into buildings at the outset, but minimizes the expenditure of labor; the colony-plan requires less capital at the outset, but exacts the maximum of labor.

The complete isolation of each family is not so certain as some would think unless the houses are two hundred or more feet apart. A fowl will take a notion to "go visiting," and enters another flock; or she may wander so far in search of insects, etc., that she doesn't know which of the three or four houscs nearcst her (all alike) is hers, and goes to the wrong one. This is of little consequence if all are in good health; if biddy lays in house number one, or' number two, or three, or four, 'tis all the same to the owner.

In case of an outbreak of discase, however, if it can be confined to one house much is gained. Can this be done? Take roup, one of our worst 
scourges, for example. We have been told of a case in Hammonton, N. J., where a broiler-man lost thrce thousand chickens in one season from roup, which he claimed was brought from a neighbor's brooder house, either in the clothing or in the dirt adhering to the shocs of a visitor. With our present hazy knowledge of roup we will not say such a case is not possible; we would rather say that it is barely possible, but highly improbable. If howerer, the contagion was so carried to the Hammonton man's brooder house. it coukd be similarly carried from one house to all the others of a colony farm, provided, as is usually the case, the one attendant went to all in turn. In "Hens by the Acre," in the Rural New Iorker, Mrr. Collingwood tells us about a colony-plan farm in Orange county, New lork, where one thousand hens are kept, and says:- "The reason why we have not heard from the place is that a scourge of roup swept through the flocks last year, and Mr. Mapes has been so busy clearing it out that he has had no time to talk. Now that the discase has been about wiped out, he is going to tell us how he did it." As these fowls were kept in flocks of forty, in colony-plan houses scattered over a rocky pasture, and the "scourge of roup swept through them." it woukd look as though the complete isolation was more apparent than real.

The other advantage we have to consider is free range, - and we have strong doubts about this being an adrantage. Mr. Josiah Quincy tells us in his exccllent little book on "Soiling," that the most profitable method of conducting a nilk-farm is to keep the cows confined in the stable constantly, excepting (say) a couple of hours in micl forenoon and a couple of hours in mid afternoon for healthiul exercise; just sufficient exercise to promote digestion and keep the cors in good health. He tells us that the largest possible milk flow will be promoted by this method, and no food energy wasted in "ranging." Just so with fowls, if kept for profit. Just cnough exercise in the open air to promote digestion and the turning of the food energy into eggs, is the best method; and we firmly believe the semi-confinement plan is that method. By semi-confinement we mean having a roosting-laying room, adjoining it an openfront scratching shed, and, extending south (preferably) from this pen and shed a yard sufficiently large to give cach fowl from seventyfive to one hundred square feet of yard room. $\mathrm{By}$ this plan the energics of the forl are conserved and turned into egg production-i. e. into profit, instead of being clissipatcd in wide ranging. If the object is "long life," "... say unhesitatingly that the free range plan is the betterbut we don't keep forls to see how long we can make them live. On our farm we intend to get the best possible egg yicld for ten or eleven months after the fowls reach laying maturity, and then turn them off to market, to make room for another generation of eager layers. It is well known that pullets are far the best egg producers. It is true year-old hens lay well, but no one denies that pullets lay better; hence, we argue, it is better to get the hens out of the way, cren if they are still laying, and give their places to well matured pullets. Then licep these pullets on the semi-confinement plan, get the best possible egg yield from them till the recm is again wanted for the incoming layers, and so on year after year. We believe there is a much better profit in fowls licpt in this manner than in forls kept by the colony plan. k.

-Farm Poultry.

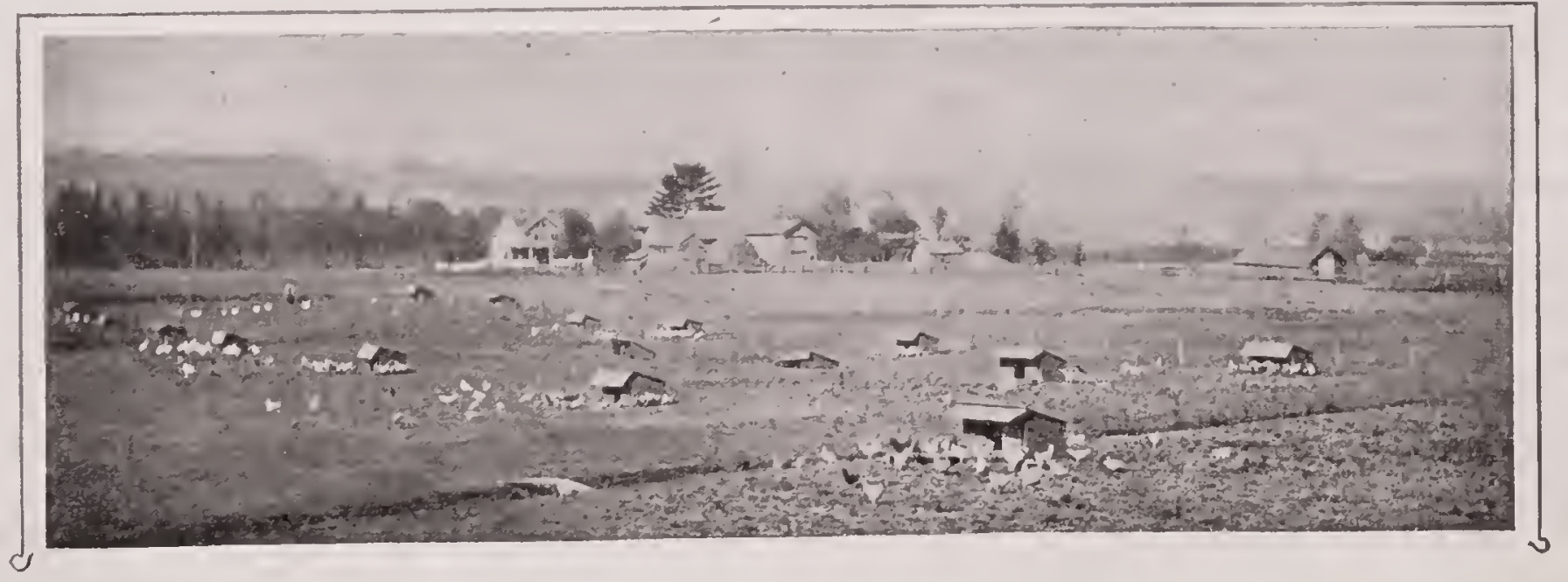




\section{Chapter VI.}

\section{FOODS AND FEEDING. BEST RATION FOR EGG PRODUCTION. SOME}

\section{TESTED EGG RATIONS.}

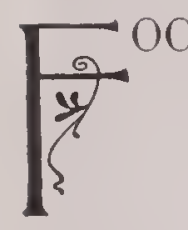

OOD is required to repair bodily waste and maintain the bodily strength. The materials of which the body consists are continually breaking down, being consumed and passed off as waste, and are being replaced by new materials supplied through the blood from the food eaten; to keep the body in a healthy and vigorous condition there must be a constant supply of new material to take the place of the old. If this supply of new material is insufficient hunger manifests itself, and if the supply is cut off for a considerable time death may result. To keep up this supply of new material is the chief function of food, but in addition the food maintains the heat of the body, furnishes the force or energy which enables muscular movement, and also enables the performing of the necessary functions of the body. In young animals growth has to be made, and while that growth is made by supplying new material to take the place of the old, there is also an excess of new material necessary to make the growth, or development. In many matured animals milk or eggs are secreted, and for this purpose a supply of food is required in excess of the normal bodily wants, and to supply food of the right proportion to meet the bodily requirements of the animal without a waste of the food material, constitutes the science of feeding.

There are many different methods of feeding fowls, and not a few habits of feeding which can be characterized as wholly lacking in method; this is unfortunate because method and regularity in feeding are most important for best results. It is hardly the province of this book to enter into the question of the chemical constituents of foods; we shall better serve the interests of our readers by describing several methods of feeding which have been successful in many hands, and the rations here given are those of successful poultrymen.

In the articles selected for this chapter the feeding of a "mash" for breakfast is very generally recommended, hence we desire to call especial attention to the dry-feeding method described by Mr. Park. It is perhaps too early yet to decide that all-dry-food will give as good (or substantially as good) results as the mashfor-breakfast method of feeding; if it should be demonstrated that it induces (substantially) as good an egg yield with the acknowledged better average health of the flocks, then the dry-feeding method is the better. It certainly effects a considerable saving in labor and as there has been, on the part of not a few poultry keepers, an abuse of mash-feeding which has induced liver-disease and other disasters, the dry-feeding method deserves careful study.

The right feeding of fowls is not at all a difficult matter; the prime essentials are a proper. proportion and a sufficient quantity; with a variety of food elements provided in sufficient. quantity, the fowls will properly "balance" the ration. Feed a variety; feed in sufficient quantity, but don't overfeed; feed systematically and regularly - these are the rules for successful poultry feeding.

\section{FEEDING FOWLS FOR EGGS.}

\section{Feed a Variety; Do Not Overfeed. An Excel- lent Food Ration and Feeding Method.}

Constant discussion of the question of "feeding fowls for eggs" has caused many to think it. a very difficult matter, which it is not, if one uses plain, common sense, and feeds only what the fowls will clean up quickly. The two greatest stumbling blocks for the beginner are a lack of a variety of food-elements, and overfeeding. A small flock of fowls, ranging at will through and around the farm buildings, will pick up half their living, and greatly vary the food-elements consumed by eating quantities of insects and worms, grass seeds from the hay mow, ete., and in winter will eat the leaves, etc., off the hay (especially clover); and by these pickings they 
"balance" the orer-supply of starch in the grain that is thrown to them. Fowls ranging at will, however, lay decidedly fewer eggs than those kept in semi-confinement and given only so much range as; promotes reasonably good health. For fowls kept in houses and yards it is necessary that we consider variety in the food given them, and if we want them to lay eggrs we must give them in the food the materials of which to make eggs. It is not at all necessary fol the beginner to bother about the chemical elements of food, or worry over the exact proportions of carbohydrates or nitrogenous matter, if he will see that the fowl get enough to eat without their getting too much, and that they get a rariety of food-elements in different grains, with green food ("roughage") and aninal food in place of the insects, worms, etc., they get when ranging at will.

We give below a feeding methor which was worked out by the writer on a farm on which 300 or 400 forls were kept for eggs, and the materials used were ordinary farm-grains, etc., supplemented by what could easily be obtained at a feed mill in town. This ration was not weighed in ounces and decimals of ounces; the proportions were to be from the grain bins or barrels in scoopfuls, as stated, and this food ration gave excellent results both in egg rick and the healthfulness of the flocks. This feeding method was quoted by Mr. John H. Robinson in his book "Winter Eggs, How to Get Them." and is there recommentied to be "one of the best ever derised; and has probabiy been adopted with gratifying results by more poultry keepers than any other ever published. *** * The method as a whole is a good one, adapted to a wide range of circumstances, and anyone who follows it closely may know that if he does not get eggs it is not the fault of the ration." Another endorsement of this feeding ration came from the Rhode Island Agricultural College. Prof. A. A. Brigham had it compounded and
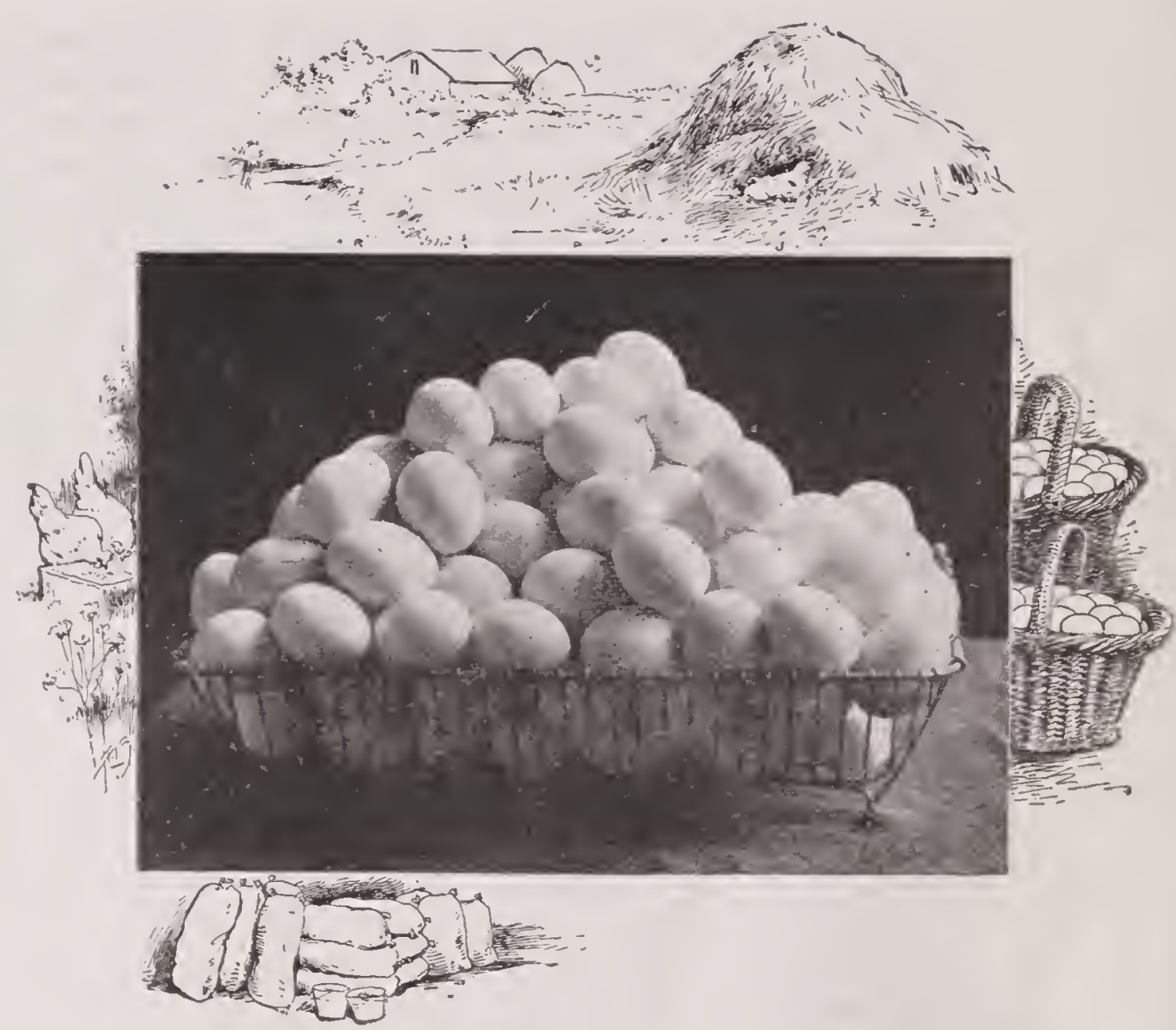

"the lind for which a Good Premium is Paid.
Eggs, Raised by C. C. Pape. Fort Wayne, Ind.

analyzed by the Poultry Class there, and said it was "a very well balanced ration, probably as near perfect as could be made with the materials available on the average farm." This ration, we ought to add, has been given to the public many times from Farmers Institute platforms, and in rarious papers and books.

"Five mornings in the week we feed a mash made up of alout a third cooked regetables mashed fine, or cut clover cooked by being brought to a boiling heat in water, an equal amount of boiling water added, a heaping teaspoonful of salt to a bucketful; a heaping teaspoonful of ginger tro days, then cayenne one day, ginger two days, then powdered charcoal one; and into this is stirred mixed meal until the mash is as stiff as a strong arm can make it.

"This mixed meal consists of one part each of corn meal, fine middlings, bran, ground oats and meat mcal, a scoop or dipper of each being dipped in turn into a bag, and poured from the bag in to the meal barrel, from which it is dipped into a mash. We consider the thorough mixing of these meals a considerable factor in making a good mash. 


\section{PROFITABLE EGG FARMING}

"When we have cut fresh bone in abundance we omit the meat meal from the mixture; ordinarily we have only about half rations of cut bone to go around, so use, regularly, half the amount of meat meal to make up the deficiency.

"The foundation of the mash is the cooked vegetables, which may be refuse potatoes, beets, carrots. turnips, onions (anything in the vegetable line), and into the pot goes the table waste, potato parings. etc., and the potato, squash and apple parings from the kitchen. The potatocs or beets, etc. are washed before putting on to cook. and the mess when boiled is sweet and sarory. If one has a set kettle in which to stir up the mash and there leave it to cook in its own heat and the heat of the brick work, they are fortunate-we haven't, and have to make ours up in common water pails.

"The regetable or clorer liettle is put on before sitting down to dimner, usually, and another kettle of water to be boiling hot when wanted. Then the regetables are cooked, we set nut four buckets in a row, dip out the regetables into the buckets about equally, mash them thoroughly, add the salt—ahrays-and the condiment of the day, add boiling water till the bucket is two-thirds full, then stir in the mixed meal till it is stiff and firm; then corer and set away to cook in its own heat.

"Clorer rowen (second-crop-clover) cut fine makes an excellent foundation for the mash, and two or three days of the week in winter we use that instead of regetables. We fill two kettles with the cut clover and as much cold water as they will conveniently hold, and heat to a boil. The clover is ladled out in to the buckets about equally, the clorer-tea added and boiling hot water as before. then salt and the stimulating condiment and the meal stirred in.

"The morning mash is fed in troughs large enough so that all of the fifteen fowls in a pen can get about it at one time-another important factor, because if the trough is small some of the birds have to stand back and wait for the second table, and when their chance does come there is nothing left for them. With a trough four feet long by six inches wide there is plenty of room, and if a biddy is driven away from one place she runs around and goes to eating at another, and thus all get a share.

"Our fowls hare exercise ground in summer in yards $125 \times 12$ feet, which gives them a grass run (with growing grass always in the growing season), and they will take ample exercise in pleasant weather. 'To keep them out oi doors the noon feed of whole barley (or buckwheat), and night feed (before sunset) of wheat or corn are scattered upon a graveled space immediately in front of the houses. Each family of fifteen has a pen within the house twelve feet square, or one hundred and forty-four square feet of floor space, which gives about ten square feet per fowl. The floor is the carth, covered about six inches deep with screened grarel. On this gravel the grain is scattered in stormy weather in spring, summer and early fall, when we want the birds to stay indoors. When cold weather approaches exercise must be stimulated, and we cover the pen floors three or four inches deep with coarse meadow hay or common straw, into which the grain is scattered and the biddics have to dig it out. Some poultrymen use dry lares for pen litter; chaff from a threshing mill would be most excellent (nothing could be better), and $w^{2}$ have found one or two cases where common cornstalks were used. With us. straw or meadow hay is most casily obtaincd. and we use that. What the scratching material is, is of far less importance than that the scratehing material be there.

Whole wheat is the best grain food for fowls. whole barley is the next bost and buckwheat next. We make barley or buckwheat the norm fecd five days in the week, and wheat the night. feed five or six days in the week. We do not make the mash on Sunday because we want to reduce the work to its lowest terms on that day, doing no more than the regular feedings and waterings, and collecting the eggs.

Monday, we fecd oats (or barley'), wheat, whole corn.

Tucsday, mash, baprley (or buckwheat), wheat.

Wednesday, mash, cut bone, wheat:

Thursday, oats, barley, wheat (cr corn).

Friday, mash, barley, wheat.

Saturday, mash, cut bone, wheat.

Sunday, mash, barkey (or buckwhoat), wheat.

"Two fecds of cut bone each week, one or two of whole oats, and one or two of whole corn (according to the scason), give variety to our ration, and to that are added whole cabbages hung in the pens in cold weather to tempt picking them to get green food; or turnips, or beets, or carrots are split in halves and placed in the pens, to be picked to pieces and caten.

"Ground oyster shells are always accessible, and fresh water, replenished three times a day 
(warm in winter), and the watcr pans are carefully rinsed every day."

\section{Feeding for Eggs: How Much.}

The problem, as every poultryman knows, is not what to feed, but how much. If you do not believe this write the clitor of your favorite poultry paper and ask him how much food you should give a flock of 15 hens, and see what he will say. It takes a great deal of care to steer between over-fecding on the one hand and underfeeding on the other. I believe, however, that there is a scientific principle underlying the matter, and think that after a great dcal of study and experimentation I have discovered the principle.

In order to determine how much to feed we must again interrogate Nature. Before we had begun to dissect the crop of the hen we had killed, suppose we had put it on the scalcs to ascertain its weight. If the hen from which the crop was taken was of an American brecd, if she had been rumning in the fields all day and just before she had been killed had been given all the corn that she would eat, her crop with its contents would weigh not far from six ounces. Allowing that two ounces of food have passed from the crop into the gizzard during the day, and from the gizzard into the intestincs. it will be seen that when a hen is on the rarge. supplied with abundance of food, she will consume about eight ounces of food in the course of 24 hours. It would seem therefore that this is the amount of food a hen necds to supply all the demands of her system and lo ave a margin for egg production. But before we settle down to this conchusion there are some things to be taken into consideration. On the range the hen has had plenty of exercise, and needs more food to supply the tissue lost than when in confinement. On the range food is more bulky and less nutritious than the food the hen receives in her pen. It contains a larger proportion of grass and regetables. It is probable that in the pen, where the hen dors not exercise so freely as she does on the range and where her food is more concentrated, she does not need so much food by one-fourth as she docs when at liberty. Six ounces of food a day ought therefore to be ample to supply all the needs of a hen in confinement.

Suppose we try a little experiment to verify. this conclusion. Let us take a laying hen a year old and shut her up in a pen by herself, feeding her but once a day, but giving her all she will cat at this meal. The food we set before her is a mash containing all the elements for nutrition and egg production. We will find that the hen will continue to thrive and lay eggs on six ounces of food a day. There will be a falling off of egg production, nwing to the close confinement and change in methods of feeding, but the hen will live and lay on six ounees of food a day. We are now confirmed in our conviction, that in the American breeds six ounces of food a day is about the normal amount for a hen in confinement. Whether she needs a little more or a little less must be determined by individual experimentation.

Six ounces of food a day for a hen weighing six pounds seems at first sight an enormous quantity. In the same ratio a man weighing 160 pounds would consume 10 pounds of food every 24 hours. But before we dismiss the matter as absurd, let us consider a moment. The hen's food is not so concentrated as the man's. It contains far less nutriment in proportion to bulk. A considerable proportion of it will be voidcd in the form of excrment. Then the hen has a task to perform such as is imposcel upon few other creatures. She is expected to lay an egg weighing not less than two ounces; and an egg. as everyone knows, is one of the richest of food-products. Deduct from the six ounces of food two ounces for waste and two ounces for egg production, and it will be seen that only two ounces are left to repair the tissucs and maintain the temperature of the body. The laying hen necds a generous dict, ard these doctrinaircs who advocate kfeping her in a state of semi-starvation have no support in roason for their theory.

-From "200 Eggs a Year per Hen: How to Get Them."

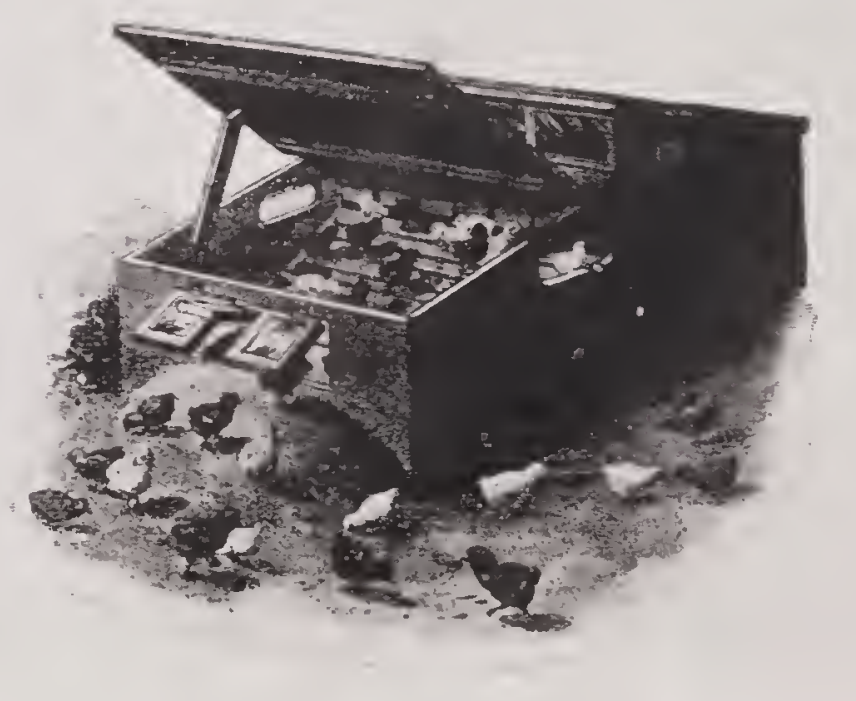


PRODUCING EGGS AT MINIMUM COST.

\section{Digestible Nutrients Which Should Be Fed to Laying Stock to Furnish the Chemical Constituents of the Egg and Main- tain the Hen in Health and Activity-Properties of Protein and Nitrog- enous Materials.}

BY MAIIES R. COVERT.

Of the United States Experiment Stations, Department of Agriculture, Washington, D. C.

As cold weather approaches and the marketability of eggs increases, the problem of how to increase the yield of that toothsome article becomes interesting. The veteran, the amateur, and the good housewife vie with each other in an endeavor to compound a ration which shall produce the maximum yield of eggs at minimum food-cost. The public is awakening to a realization of the food value of the egg. MIore attention is given the subject of feeding, and the agricultural press is devoting more space to articles on poultry. Some of the Experiment Stations are investigating and throwing light in many hitherto dark corners. Their conclusions in many cases closely coincide with the teachings of experience and show conclusively that correct feeding is both a science and an art.

If to the sum total of the chemical constituents in the eggs produced during a given season, we add the materials required to maintain the

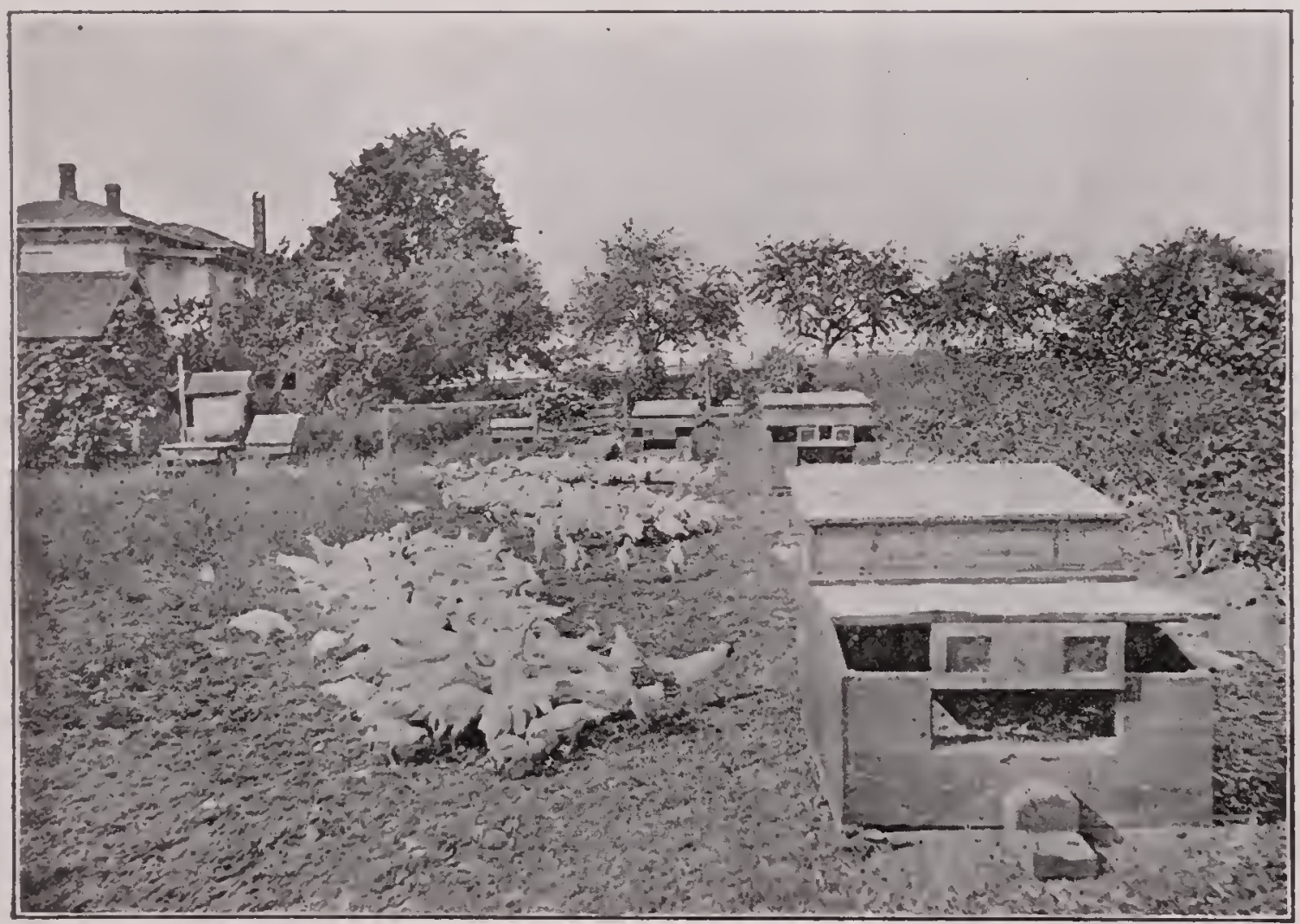

White Leghorn Chicks in Outdoor Brooders, Blanchard's Fairview Farm, Groton, N. I. hen in health and actirity, we have approximately the amount of digestible nutrients which should be present in her food. As we all know, the digestible nutrients in food-articles vary in amount and quality, and some breeds of chickens return a greater profit in cggs for the food consumed than other's. This article, however, is confined to the subject of rations which must be prepared with due regard to the purposes for which the chickens are kept. Thus, if we desire to produce flesh we must feed a ration richer in flesh forming ingredients than, if we were feeding for eggs which require nitrogenous materials. Reports of digestion experiments with forrls are seldom met with, presumably because they are not often undertaken. The public should take an interest in the matter and demand of those expert in the determination of feeding problems the solution of this question.

It is assumed that the nutritive ratio for the laying hen and the milch cow should be approximately the same. Their products closely resemble each other, but their relative actual cost makes milk the much cheaper food-article for man, especially in the larger citics. The German feeding standard for feeding milch cows calls for $15.4 \mathrm{lbs}$. total nutritive substance in the digestible portion of her food, these nutritive substances to be proportioned as follows: Protein, 2.5 lbs.; carbohydrates 12.5 lbs.; and ether extract, or fat, $0.4 \mathrm{lbs}$. This gives a nutritive ratio of $1: 5.4 . \quad$ In other words, to every pound of protein there are 5.4 pounds of nitrogenous materials.

The nutritive ratio may be determined by nultiplying the ether extract by 22, adiling to this product the carbohydratcs, and dividing by the protein. Each pound of fat or ether extract is assumed to have a feeding equivalent of 2.2 pounds calbohydrates. The author has been 
unable to find the reports of any experiments determining the amounts of these materials necessary for fowls. For want of definite information on several points he is unable to do the subject justice, but with many apologies and a few misgivings he will attempt to formulate a ration which shall be practicable for the farmer.

It is usual to feed a ration of soft foods in the morning, with a whole grain ration at night. We will suppose we have our choice of the following feeding stuffs: Bran, corn meal, ground oats. oil cake, cotton-seed meal, beef and blood meal, red clover hay, skim milk, with oats, rye, wheat. and corn for a whole grain ration. The following table gives the digestible nutrients found in 100 pounds of each of these and a few other articles:

Percentage Digestible Matter in American Freeding Stuff:

Feeting stuff.

Red Clover Hay.

Alfalfa Hay....

Cowpea Hay. ......

Potatoes.....

Corn. arerage for all varieties .........

Wheat arerage for all rarieties

Rye.....

Oats. .

Bran

Middlings

Cottonseed Meal.

Linseed Meal.

1)ried Blood.

Meat Scraps......

Skim Milk.

3.1

For convenience we will mix 250 pounds of soft food at a time. selecting as an cxperimental ration 100 pounds bran, 50 pounds corn meal, 50 pounds ground oats. 25 pounds cottonsred meal, 25 pounds beef and blood meal (assuming the latter to be composed of equal parts of blood and meat s(raps). These quantities by reference to the foregoing table are seen to contain the following amounts of digestible nutrients: Protein 45.34 pounds; carbohychates, 101.90 ; ether extract or fat. 11.51 pounds. The nutritive ration we find is $1: 2.8$, while the German standard for milch cows is $1: 5.4$. Therefore to balance the ratio we must. serect some material rich in carbohydrates and fat. In selecting clover hay, we secure a high percentage of carbohydratcs and at the same time by properly preparing and mixing the clover with the morning mash we are able to furnish what closely approximatcs green food. Fifty pounds of red clover hay added to our ration, raises the nutritive ratio to about $1: 3.00$.

When skim milk is at hand a very profitable use can be made of it by mixing the soft food with it. A quart of skim milk weighs about two and a half pounds. By arding in the fecding period an aggregate of one hundred pounds of milk we make it rery palatable but lower the nutritive ratio to $1: 2.76$. This we will accept. for our morning mash, feeding what each fow will clean up quickly. For our whole grain ration, we may select corn, whe at or rye, as they are all relatively rich in nitrogenous materials and will help balance the ration. "We will select. corn to scatter in the litter in the erening. If we use two hundred pounds in connection with the two hundred and fifty pounds soft food. our nutritive ratio will stand $1: 4.3$, somewhat narrower than the standard but rery practicable.

The relative amount of grain and soft food used raries with different individuals, some using more and others less. The nutritive ratio, however, should conform more closely to the stanclard than the average ration does if best results are desired. The experimental ration outlined above is not intended as a criterion, but simply to show how the different factors are obtained. Theoretically it would be better for the growing chick than the laying hon. - Reliable Poultry Jcurnal.

\section{VALUE OF ROOTS FOR HENS.}

\section{Substitute for Fresh Grass and Vegetables to $\mathrm{Be}$ Found in Various Root Crops-An Article of Highly Practical Value.}

Some June day watch a hen in a small flock left to roam and pick at liberty and see what she eats. Just as soon as it is light she is up and hustling around to catch the earth worm. You will find her always busy searching for food; a tip of grass here, then a clover leaf. next a grass-hopper, a strawberry, another grass leaf, or a sharp pebble attracts her attention. A little rest in the shacle, with perhaps a dust bath, is hel only recreation. She $i$; active all day long trying to satisfy her appetite, and at night she comes back to roost with a full crop. These are happy days for biddy and she lays an egg

$$
\text { L. of C. }
$$


nearly every day, besides storing up fat to assist in nourishing her while she is hatching her brood.

To imitate these conditions during the cold, dreary winter months, and induce biddy to lay the daily egg, keeps the poultryman busy from November to March preparing roots and mashes. The scientist has shown the farmer how to make June butter in December. He has told him just how much muscle and fat forming food the cow wants every day. The pig, the sheep and the big stcer have each had their needs studied, but up to this time very little scientific work has been done on the hen. Our hen is not so easily studied as the large animals. We confine a pig, a sheep or a steer, feed it certain food, and determine by analyzing the solid dung (which is undigested food) just what proportion of the constituents in the given food the animal has made use of. The hen voids urine in solid form mixed with the dung. This has proved a stumbling block so high that the scientist has not surmounted it and accurately determined the digestive powers of fowls. In the feeding experiments which have been made it has been assumed that fowls use food the same as higher animals, but some think that fowls use it more economically.

However, poultrymen have found by many different trials rations that produce good results, and these are being fed in ignorance of why. The hen at liberty eats a great deal of fresh grass in its season. This serves a two-fold purpose. It not only furnishes food, for tender growing grass is very nutritious, but it also dilutes other foods, furnishing necessary butk. But when biddy is confined and fed wholly on grains, which are concentrated foods. in order to extend the crop sufficiently to overcome the hungry feeling, she eats miore than she requires. This forms fat and the active fowl is changed to a sluggish hen. When fresh grass and regetables cannot be had, roots furnish a very acceptable succulent food.

The various root crops resemble each other in composition. They all contain a very large percentage of water. On the average.

Potatoes contain.....75 per cent water.

Sugar beets contain . 81.5 per cent. water.

Carrots contain. ... . 85.9 per cent. water.

Rutabagas contain. . .87 per cent. water.

Mangolds contain. . .88 per cent. water.

Parsnips contain. . . .88.3 per cent. water.

Turnips contain ...991.5 per cent. water.
They all contain very little nitrogenous or muscle-making material; they are, however, quite rich in carbonaceous or fat forming nutrients. In the potatoes these are chiefly in the form of starch, and in the others chiefly in the form of sugar and gums. Roots are considered to be wholly digestible by the higher animals. They do, however, decrease the digcstibility of other substances fed with them. As stated before we do not know much about the hen's digcstion. I consider that the chief value of roots for heus lies in theirsucculence, palatability and addition of bulk, rather than in their nutriment. A fresh beet or turnip hung in the sunshine is much relished by fowls. By boiling them to a soft consistency and thickening theni with soft grains and adding a little salt, a very acceptable mash is made. The cooked vegetables give bulk and add to the flavor and variety of the mash. For this use I think no root superior to the small potato.

There is no vegetable that will completely fill the place of cabbage as a winter food for hens. The crisp, tender leaves more closely resemble fresh grass both in composition and mechanical condition. Fowls seem to relish it and will eat a surprising amount if it is kept before them. Just now clover rowen cut into short lengths is largety used by poultrymen. This is an excellent food, very nutritious, cheap and easily preserved and prepared. Unlike ronts, clover is rich in muscle forming materials. If steamed soft and mixed in the mash in the proportion of one part to five or six of the ground grains a very gratifying mash is produced.

To see if clover could be used to replace cabbage entirely the Hatch Experiment Station conducted the following experiment. Forty Plymouth Rock pullets were divided into two equal flocks. The divisions were housed and fed in every way alike, except that to one a cooked mash containing cut clover was given daily, while the other received a mash prepared of the same grains in the same way without the clover. In this house a small cabbage was hung once a week.

The clover in the mash of the first division increased the bulk of the breakfast to such an extent that the fowls were satisfied with loss ground grain than were the others. The actual cost of the entire food consumed during the experiment by each lot of the fowls varied but five cents. At the first of January, the beginning of the test, neither division had laid an egg. 
At the first of May the clover fed forls had laid 468 eggs and the cabbage fed fowls had laid 588. Analysis of the eggs showed that the cabbage fed fowls laid a richer egg. The eggs were given to different cooks who knew nothing of their source to try. The rerdict was that the egas from cabbage fed fowls were strong. The superior richness of the egg apparently made them strong in flavor. One woman said the clover eggs were the finest she (ror ate.

The result of the test indicates that we cannot with profit substitute clover entirely for cabbage or other succulent food. Some have obtained good results by using bright corn silage as a regetable food for hens. If the poultry-keeper has other stock and feeds silage, this would undoubtedly be the cheapest and most convenient green food. It is so difficult to keep silage satisfactorily except where large quantities are used, that a silo for poultry alone is not practical.

-H. M. Thumsos, in Reliable Poultry Journal.

THE DRY FEEDING METHOD.

\section{Practical Pointers by an Expert-Facts from Four Years of Dry Feeding-Results with Chickens and Adult Fowls.}

BY P. R, PARK, READING, MASS.

Since his borhood dars the writer has been deeply interested in the subject of feeding stock, and has marked the similarity of anmals and plants in their manner of assinilating nutriment offered them. Whatever the subject under treatment, it should be fed with some object in view. If plant life, either for foliage, fruit or seeds; if animal life, for whatever feature the grower is aiming to excel in.

The plant has no power to create, it can only assimilate such component parts as come within its reach. Some gather them from the roots largely, others gather quite a little from the air. The combined product makes the result sought. In feeding poultry the same gencral law exist: Birds have no power to create and can only gather such food as conles within their reach, which we regret to say in many cascs is a very pitiful supply. In the state of nature with an unlimited range and inexhaustible variety, they seldom, if ever, have a new disease. In the state of domestication, having an appetite which eats almost anything, it is usually giren the opportunity, and the feeds distributed to poultry would wreck nearly any other organization in the anmal kingdom. We think hogs would have to take lirer pills as a steady regulator if they were asked to eat the composite mess distributed many poultry plants.

The skillful feeder should aim first, at what his market pays best for, and if he has had experience, can then study the fiekd of foods, buying those which are offered at the lowest rates, if the quality is what it should be. There is money enough in the business to buy the best of everything and still show a splendid margin on the the right side of the ledger, with almest any market in the world, if we can get over the mortality of young chicks which is discouraging so many begimners and not a few of the so-called "professionals."

A growing chick has without doubt, as economical digcstion as the steer, sheep) or hog, and a pound of chicken meat can be produced for as small a number of cents as any of these. With poultry still regarded as a luxury in ninety per cent. of the homes of America, it seems that the market is yet very poorly supplied and the field for the producer practically unlimited. We think the poultry papers would serve the public demand even better than they do, if they taught us how to make money with flocks of birds averaging from 120 to 150 eggs per year, rather than trying to teach that we should aim to produce 200 eggs in the same length of time. A 200-egg hen may be nearly

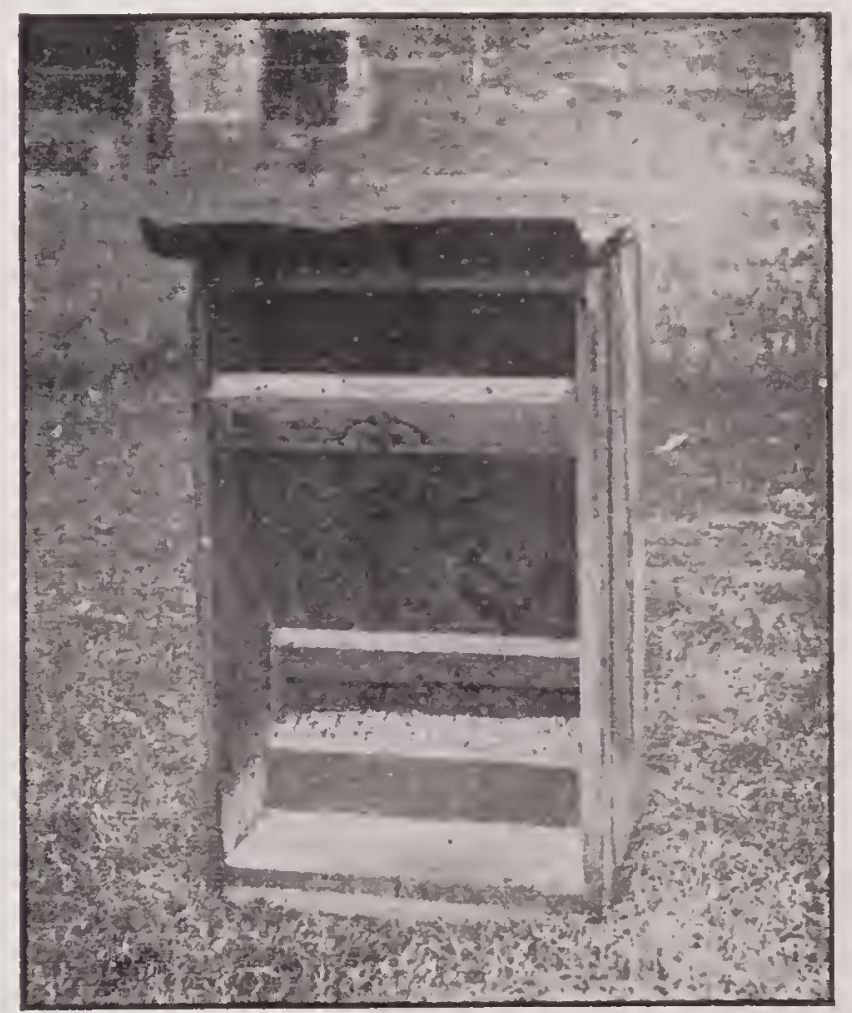

Mr. Park's Dry Foorl Hopper. 
in sight, but we fear when she arrives, she will be like the two-minute horse-useless for any other purpose. Of what avail is it, if we get her henship to the point of laying $200 \mathrm{eggs}$ per ycar and we cannot reproduce her kind in paying numbers or rear those chickens which we do succeed in inducing to come from the shell?

There are many sicles to the poultry business and twehe months in every year, all of which should be figured in looking forward and weighed in looking backward. A hen laying a n average of ten to twelye dozen eggs per year usually throws strong chicks easily reared and consequently showing a splendid profit in the surplus as market poultry, and in the second season with the strong, sturdy pullets ready to do business from the date of their first egr intil the hatchet intervenes later in their lives. We think the striving for the 200-eggs-per-year hen responsible in part for the large mortality in chicks betreen the egg and maturity, but much of it is due to ignorance, or her sister, carelessness.

That the business, taken the country over, pays a good margin of profit on the capital invested in spite of a heary mortality in small chicks, would seem to argue that this is one of the most fruitful fields for scientific thought and research. If we can eliminate fifty per cent. of this mortality, do not we show nearly a corresponding increase in the profits? Certainly it would show twenty-five per cent.

The skillful feeder will be found to possess a keen eye for the appearance of perfect health and will be ever on the lookout for the departure from the sign posted upon every living, healthy beast or bird in the universe. The difference between a bird out of condition and the one in perfect health to the old breeder, is as marked as between brightly burnished metal and the same when suffering from tarnishing and neglect.

\section{Well Bred Chicks Are Naturally Hardy.}

Feeding with some end in riew, breeding along the same lines, there should be steady headway made from year to year, and while there may be an occasional set-back, for we are all human, the average progress should be sure. WeH-born chicks-perhaps we had better say chicks born of strong. hardy parents,-come into this world about as well dereloped and fitted for the stern battle of life as anything we know of. Given half an opportunity, fed within the bounds of common sense, and properly brooded, it seems practically impossible to kill them. They have an ample coat of dorn which protects them from ahmost any lind of weather for short periods. Given a well regulated brooder they will cheerfully march out into zero temperature and apparently be as happy as though the sun stood high in the heavens and the temperature registered 90 degrees in the shade, and they certainly grow much better than when placed under the latter conditions. Fed improperly or kept at suicidal temperature or being unfortunate enough to have weak parents on one or both sides, and the reverse condition seems to be the result; they are about as delicate, puny and unsatisfactory atoms of mortality as the iniverse produces.

By closely studying nature's methods, we would find that the mother hen, learing the nest when the chicks are one or two days of age, does not have a chance to lead the way to a dough dish and fill them with an indigestible mash. On the contrary, she starts out on the hunt. Perhaps she lands in the garden the first shot, and to the owner's constemation, proceeds to tear up the newly made land in her endearors to seek ticl-bits for her charges. If she is undisturbed, she makes a good display by nightfall and unearths quite a little food,succeeding by this time in filling the crops of her numerous family. If we could dissect them, we would not find any carefully prepared mixture of one to four or one to five, or "sixteen to one." or any other startling array of chemical combines, but we would find a bug, a worm, an occasional seed that the owner so carefully planted a few days previously, together with a few of the reed seeds which he did not plant, and plenty of grit. This composite mass has been gathered together in ten or twelve hours' time, with a liberal sprinkling of exercise thrown in, and if the weather conditions are farorable and our mother hen does not pull the youngsters around through the wet grass too much in the morning. she usually comes out at the end of the season with about as many full-sized chickens as she started from the nest with.

The usual methods when the old lady brings off her family, are to shut her off in a coop and bring on all the wet mash she and the chicks ought to eat for a full day's time, and dump it down on a board in front of the coop. Some of this is eaten, most of it forms a door mat for the youngsters, and in one-half hour's time looks much like the dirt surrounding the coop. Lying in the hot sum does not take long to start 


\section{FOODS AND FEEDINC.}

rapid fermentation. and we soon have germs of bowel trouble growing at the rate of forty miles an hour. Books say chicks should be fed five times a clay, and the nervous owner thinks that if five is good six is better, and soon comes around with another dose of the same food and puts on the top of the first "charge," and we have a sandwich of wet dough and dirt. In a few dars time the chichs begin to start for the world where mashes are unknown and the owner say's "Darn the chicken busincss," or else he blames the man from whom he purchased the eggs for haring "iubred stock," and we have another case of "the business don't pay." Perhape his painstaking neighbor improves on this method and bakcs the mash, which is quite an improrement as it removes a large part of the water, but at the same time is quite a little labor. His chicks do better, making phenomenal growth for a few weeks, and he thinks that the solution of the poultryman's trials lies in cooking the food. He invests in an amateur bakery and bakes everything. His chicks continue to thrive apparently, but as the hot weather comes on: he notices some borrel trouble among the half grom birds. These die and he shouts that cholera has struck him, writes to the editor of a poultry paper who tells him that the srmptoms look like cholera. After changing the food and losing half his flock, he gets around to hard grain and pulls them through, or what is left of them, although they are not now as large as the chick raised under the natural method without the assistance of the bake shop.

\section{Feeding the Chicks.}

Uur method. which we have practiced now for four rears with uniformly good sucecss, has been to gire the chicks a mixture of assorted grains and grit ground to about the size of a pin head for their first feed. With a dish of beef scraps standing constantly before them, and the fine ground food fed in litter with plenty of green food (cabbage or green grass), they hare an inducement to scratch from sunrise to sunset, and take the food slowly and naturally. With the beef scrap alwars within reach, they at no time crare more animal food, and their srstems rapidly adapt themselyes to the season of plenty and nature constructs a body planned for a continuation of this same diet, namely: good, thick, strong leg and frame and a chicken that looks ready to eat at any stage of the game, -long-bodied, short-legged, hardy", "born to

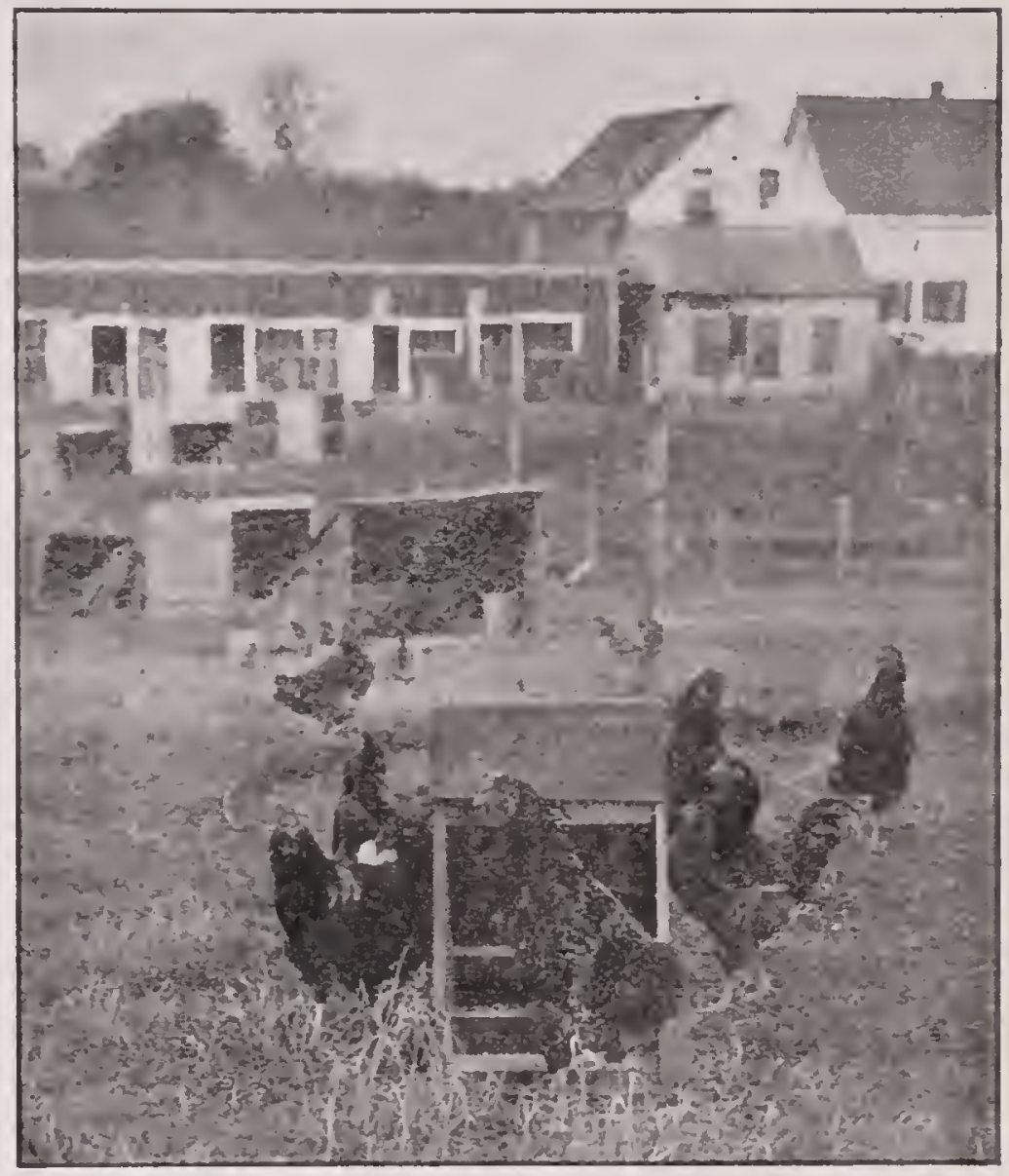

Mr. Park's R. I. Reds at the Food Hopper.

live" looking fellows, free from all the ills and pains of chickendom and fit to wrestle for a liring through thick and thin. good weather and bad, as long as the food holds out.

When they reach a more mature age, say from six to eight weeks. We gradually wean them from the small grains and substitute cracked corn and wheat, place them in colony coops on grass range and soon discontinue the wheat, feeding cracked corn and beef scraps in hoppers, feeding once a week or of tener as the size of the hopper and number of the chichs demand. These hoppers should be made quite high in front,-three inches or more at least, as the birds are always looking for the largest pieces of beef scraps, and with low-front hopper waste quite a little by throwing it out with their bills. Figs. 1 and 2 show the style of hopper we use, made of second hand boxes or other available material. Ther should be covered with waterproof paper to prevent the food's becoming wet if kept outside the roosting coops. This system continues until the sexes are separated, and then we place the males in yards sufficiently large so that the birds never eat them bare of grass. Placing the cull cockerels intended for market by themselves, we compound a mixture of equal weights-corn, wheat, 
oats and barley, ground fine as flour if we can induce the miller to reduce it to that fineness, feed it dry and continue the beef scraps. This mixture has given us fatter chickens than we have ever been able to produce by any other fystem.

A mixed lot of cockerels is about as uncomfortable a set of individuals as is ever gotten together, and this is the only system by which each bird can be fect singly. Here each one goes to the hopper and eats as long as he has plenty of saliva. then moves ariay allowing the weaker brother to come up and take his turn. They must necessarily eat slowly' because they can swallow only a.small amount of this dry mixture at one time, and thus all have an equal opportunity.

\section{Food Is Digested Naturally.}

Here the digestion of the ford begins in the mouth. If the crop of one of these birds is cut open, in place of the sour; partly fermented food that is found in a mash-fed:-chicken, we find the grain as sweet as ever, but smelling as though partly cooked, no fermentation of any kind, and we think the crop now does the work nature intended for it. Your mash-fed chicken gets up in the morning, waits around an hour or two until the pleasure of the feeder brings around a pail of hot or cold mash, which is placed on boards, troughs or other devices, and a wild scramble begins. Each one gulps what he can reach; the weaker get a little, and the stronger the bulk of the food. If the mash is hot it raises the temperature of the bird above normal and sweat is started, which is anything but what it should be, laying the foundation for colds and roup. The food goes through the crop with very little change, except fermentation, direct to the gizzard, and the entire work of the digestive system is thrown upon the gizzard and the intestines; whereas the crop should have done quite a little towards softening and partly digesting it.

With the chickens on range, this hopper of food awaits them immediately they are off the perch in the moming and they then start upon the day's hunt over the fields for the bugs. worms, grasshoppers and grass, which go to make life one sweet dream for poultry. At any time during the day that their appetites dictate, they can call at the coop and get a supply of such grain and ineat food as they desire, and eat it unmolested in a very gentlemanly and lady- like manner. Much more uniform gains result; the younger and weaker chick thrives as well as the larger and stronger, summer chickens grow practically as well as the spring hatched, and bowel trouble is a thing unheard of from the shell to maturity; if the proper heat is maintained in the brooders and the grain and beef scraps used are of the first quality.

The cooking of food, some say, makes it more digestible, which we have no doubt is true, but the question arises as to what particular portion of the food it makes more digestible. Of course the starch is more easily assimilated, but the protein is not, and we think here is where the mischicf arises from cooked food. The simple scalding of a mash makes no chemical change. You might as well mix it with cold water as hot, rhemists tell us. The books say, mix the mash as clry as you can mix it. If it is to be mixed as dry as you can mix it, why not leave the water out entirely, surely it is much easier to mix dry than wet. "But." you say, "fowls won't eat it." This is true. they will not eat it for one or two feeds, if brought up on the wet ration, but brought up properly they eat it freely and it nover stands before them sour; the last spoonful in the hopper is as sweet as the first and each bird gets its proper share.

\section{Getting Strong, Fertile Eggs.}

When the pullets go to the laying houscs, they are fed cracked corn, wheat, oats and barley; fifty per cent. however is corn. A hopper of beef scraps is still kept before them but we now add a hopper of dry bran. The whole grain is fed in litter three times per day. Birds are kept scratching for all their grain, but they have cabbages to eat constantly before them. If cabbages are not plenty we use cut elover, scalded to soften it, fed in deep troughs. We have used with good success a dry mash consisting of twenty-five per cent. corn meal, twenty-five per cent. beef scraps and fifty per cent. bran, fed dry in boxes during the morning, giving what they will eat up by noon, when we give a light feed of whole grain, with another full feeding at night. Hard grain is fed in litter as previously noted, and while this ration is a little cheaper than the other, the dcalers usually put the poorest grade of corn which they purchase into their meal, and results are not always as satisfactory as we could wish for this reason. A good egg yield will result from this ration if the ground grain and beef scraps are of good quality. 
We have no difficulty in getting birds to one. two or three pounds above standard weight upon this systen. We bulieve that ninety per cent. of the chickens raised in the country do not have sufficient food to develop as they should. Orerfeeding. we think, would be much better expressed as improper feeding.

There are very few breeds that would get too fat to lay if properly exercised, and we have yet to find one of our birds in that condition. It is not a fact that the bird which is ignorantly condemned as being over fat and out of laying condition will usually, when killed, show that it was really one of the workers of the flock? The egg is a surplus proluct and unless the bird is well nourished, it cannot produce them. As to fertility, we think no system of feeding can equal this methorl. The egos uniformly test well and the germs live right through and hatch good strong, bound-to-live chicks that are ready to take up with the dry-food method where their ancestor's began. No weaklings result, provided the other conditions surrounding the birds are properly met. one of the most important of which is an abundance of fresh air; and the fowl will stand an almost unlimited amount of this if free from draughts and not subject to the daily sweating orer a hot mash. Each generation of chicks seems hardier than their ancestors, are more cheaply raised, for any increase in the general health of a flock must be reflected in the decrease of the mortality of the youngsters.

\section{Labor and Expense Saved.}

The labor savel is no small item, for the difference between feeding the chicks three times per day dry, hard grain right from the bag, and cooking johnny-cake, et cetera fed five times per day, the heating of water and the stirring of the mash for a large flock of hens, all of which we have demonstrated, to our satisfaction at least, is useless labor. This labor directed toward other cletails, and the poultry business is full of them, will grow the chicks and care for the flock much better, or will allow double the numbers to be kept with the same number of steps taken daily. Perhaps not quite so many eggs would result asby the mashsystem of feeding laying hens the first season, but if any old stock is kept over it will be found to lay nearly as well the second as the first year; the birds lay better through the molt; there is less mortality among the adult birds. and the profits will be found on the right side of the ledger of the dry sistem.

In order to give the thing a proper trial make up your mind to try half the flock, if not the whole, for one year with this scheme, starting with the chicks from the eggs, or at any other time that seems best, and continuing the experiment until the year is through, carefully noting results. Remember that January to January is the test through which poultry must be fed and from which profits should be expected, and it is the books at the end of the year which tell the tale. The general health of the flock is no small item in reckoning up your assets for the coming season, be sure and take account of it.

We think the science of feeding farm animals very little understood in this country, or in any country in fact, and the feeding of poultry is less comprehended than any other branch of it. Doubtless as the importance of the industry is impressed upon managers of the different experiment stations throughout the country, tests will be made, but many of these are misleading as the results themselves are very unsatisfactory, and the careful noting of details is usually left to assistants who have $n$ interest in the matter and who may report correctly or otherwise. The poultry business is hardly in its infancy vet, and we look for ranches that will carry birds in the thousands to be successful in the near future. At present rery few of these exist and we think the cause is largely through improper feeding or the ignorance surrounding the whole subject. From our observation we are very sure that for best results we should feed animal protein and regetable fat in some form. Gluten meal has nearly as good a protein analysis as the best beef scraps, but when fed, birds clo not like it and fail to thrive or produce the results desired. Animal fat tends to disturb the digestive sistem and we do not get the results hoped for, but a feeding composed of fifty per cent. corn in some form with beef scraps constantly before the bird, from the hatch to the hatchet, seems to promote the general health and thrift from start to finish.

Corn has been sadly abused by the poultry press in the past, but we find it one of the safest foods in the list. The birds always like it, and our experience has shown that what they like usually agrees with them. We do not think it possible to over-feed upon any good meat. Given plenty of it, they eat only such as they 
can properly assimilate and pass by the balance. ()f course tainted and partly decayed meat foods should be rejected without question. Boiling and cooking helps them, but does not restore the good that they originally contained.

So much of the poultryman's prosperity depands upon the health of his flock that any step which may bring up the general tone should be eagerly sought and rigidly adhered to, once found. We do not think there is a case of failure in the poultry kingdom where the birds were kept healthy that was not due to causes entirely outside of the business; either the owners were radically unfitted for the business end of it, and would have failed at any undertaking which they might have ventured into, or they were hampered by improper help.

Other animals seem to recorer from a severe fit of sickness and apparently are as vigorous as ever, but we have yet to see a bird of any kind which was thoroughly sick for twenty-four hours or more that fully recovered. Ther may look all right, eat well, and be apparently healthy, but sometimes they are found dead under the roost and we wonder why. A hen in health is about one of the hardiest of farm animals. In the other condition she is anything but that.

In closing we would say that milk, if available, makes one of the best foods, used as a drink, that can be found for growing stock, fed either sour or sweet. We prefer it sour for the reason that you can always get it sour or make it so, and cannot always have it sweet, and the change from sweet to sour or vice versa is rather injurious to young chicks. They seem to adapt themsalves to a constant diet of sour milk or do equally well if it is alwars sweet, but a mixture s?ems to produce ill results.

Try a pen each way, if you have milk at a reasonable price, one pen with water to drink and the others give nothing but milk in connection with our methods, and carefully note results. Some object to it, saving that the birds get all "stuck up." If the dishes are never empty, the birds then do not get over thirsty and erowd around when a new supply is brought on, and if each one has a chance to drink by himself, they do not then become fouled.

\section{Feeding Clover for Eggs.}

Of all the regetables and grasses, clover aud cabbages seem to be the ones that poultry delight most to indulge in; and ret, notwithstan ling so much has been written upon the value of clover as a green food, and finely cut clover hay as a winter green food, few poultrymen realize its value.

It has great value as a "food" pure and simple, it being rich in both nitrogen and lime, two most important food clements. Its nutritive ratio is $1: 6.1$; while that of wheat is but $1: 6.5$; corn $1: 8.9$; barley, $1: 6.1$; potatoes $1: 17.3$. It is easy to see, then, that clover has as high a nutritive ralue as barley, and ahmost as high as wheat, our two most valuable grain foods. Of lime clover contains 1.3 per cent., ranking next below green bone in the food value tables, and contrasting with the commonly used grains as follows: wheat, .2; barley, .1; corn only a trace; in other words, clover has six and one-half as much lime as does wheat, and thirteen times as much as barley.

Clover has even greater value as a bulky food, as extending, diluting the food ration, reducing the too concentrated grain food, and preventing the accumulation of internal fat. Grass or some green food should be fed to extend (dilute) the grain food, increasing its digestibility; and for that purpose there is no better article than clover. When it is understood that clover is the best of all grasses for extending the food ration, and is, itself, a most excellent food, rich in nitrogen and lime, its surpassing merit will be conceded.

One of the great advantages of clover is that it is so casily and conveniently cured and stored in summer for winter use; in fact, once well cured and housed, it will keep indefinitely. We esteem second crop clovel (or "rowen," as many call it), to be the best, and it should be cut when well in blossom; we let it mature until the first blossoms are just beginning to turn slightly brown. At that time the nutriment intended for perfecting and ripening the seeds is all in the stalks and leaves, and the plant is at its best. The goodness in the clover is best preserved if it is crred in the shate; but as that is inconvenient, the usual method is to let itstand in the swath for three or four hours, until the top is considerably wilted; then turn and leave for three or four hours more, then cock it and let it stand for two or three days. until it "sweats." then open the cocks and dry lightly, put in the barn, and stow away. Cured in this manner, the "life" of the plant is not all burned nut of it. and it comes out in the winter as sweet as new-mown hay.

Farm Poultry. 


\section{PRODUCING AN EARIY MOIT. The Van Dreser Method and Some Comments Upon it.}

A couple of years ago the story of Mr. Henry Van Dreser's poultry farm was published in an agricultural weekly paper, and in it an account of how he induced his hens to lay at the time when most hens had retired from busincss and were busy with the molt; the method wis described as follows:

During July and August the wialthy people of the city who eat these fine eggs, are (ff at watering places and pleasure resorts and the eggs are not wanted; Yan Dreser makes his hens molt and get ready for fall business. For two weeks they are kept in a pen and get only one-fourth of their ration; this reduces their flesh. They are then let out into the sunshine, and fed with a rush, with the best possible food; all ther can eat,-peas and oats, wheat and corn and particularly sun-flower sech. This soon loosens up their old feathers so as to leave the hens almost bare. Lnder the heary feed they soon take on new plumage; the combs get red, and just about the time the aristocracy get home and other hens are on strike, Tan Dreser's are in full lay."

There was much discussion of this story in the poultry papers, but there was nothing particularly new in the idea. We were told of similar work done by a farmer in Vermont a dozen years ago. This farmer's method was to select out perhaps 30 or 40 of his (about 150) hens, put them in a pen in a hen house in the rear of the farm buildings, and after keeping them shut in for a few days to wean them from any desire to return to their old quarters, he gave them the run of a pasture-lot, watered by a brook and dotted with trees. This he called "turning them out to grass," and during the month in which they were thus treated they were fed once a day a light feed of some grain. as oats and wheat, and at the end of the period they were substantially reduced in flesh, and had got into good, "hard" condition. They were then fed a good grain-ration, with the usual proportion of corn, etc., and beef scraps. The result of this was the hens molted immediately and in three or four weeks were rell clothed with a new suit of feathers, and laid abundantly. Mr. Foster did this in order to be supplied with eggs in fall and early winter, that he might keep up with his orders for select-

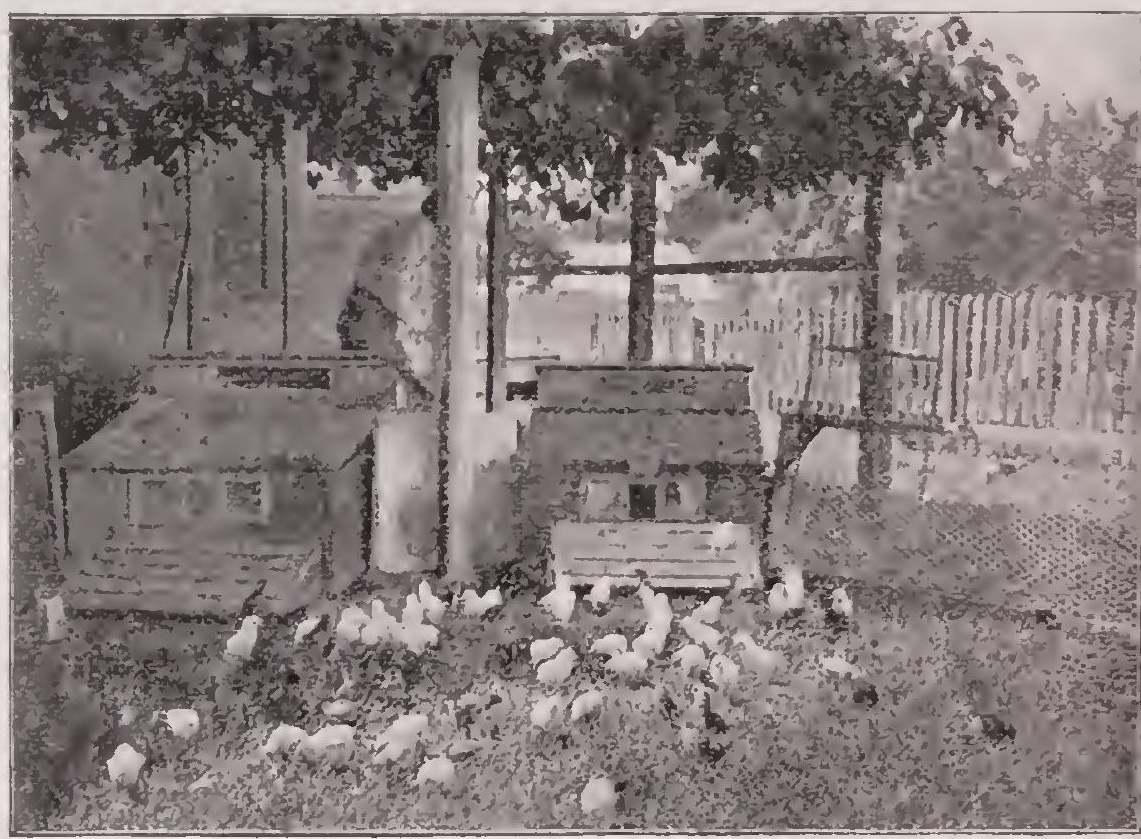

Outdoor Brooders Under Natural Shelter.

ed eggs for New Tork City clients; and he spoke of the method as working exellently well

There is no doubt but an early molt can be produced in this manner. Whether it is profitable to thus force the molt is an altogether different question, and much would depend upon the object in view. If the object is to have hen's eggs in fall and early winter, forcing the lluvit will accomplish it; if, however, the object of keeping over a proportion of the yearold hens to have especially good hatching eggs in the spring, it may well be doubted if an early molt is of any value. It is the opinion of many cbservant poultrymen that we get stronger and better chicks from eggs of yearold hens that have laid very little during the winter, hence come to the breeding season not at all exhausted in strength, and, indeed, in the best possible condition to produce eggss which will turn out the strongest and most, vigorous chicks. Cntil we have further light upon this subject, and perhaps have tested the ability of hens to lay for an entire twelve months following the forced molt, it may be well to suspend judgment.

The following is the report from Bulletin No. S3, September, 1902, of the West Virginia Agricultural Experiment Station:

\section{A Trial of the VanDreser Method of Producing an Early and Uniform Molt.}

When a specialty is made of producing winter eggs it is of much importance to have the hens shed their feathers early in the fall so that the new plumage may be grown before cold weather 
begins. In case molting is much delayed the production of the new coat of feathers in cold weather is such a drain on the vitality of the fowls that few if any egrgs are produced until spring, while if the molt takes place early in the season the fowls begin winter in good condition and with proper housing and feeding inay be made to lay during the entire winter.

A few years ago Mr. Henry VanDreser proposed a way whereby fowls may be caused to molt as early in the fall as is desirable. Briefly, this method consists in withholding food either wholly or in part for a few days, which stops egg production and reduces the weight of the fowls, and then feeding heavily on a ration suitable for the formation of the feathers and the general building up of the system.

The experiment designed to study this method was begun August 5, 1902, with two pens of Rhode Island Reds, and two pens of White Leghorns, about two years old. One pen each of Rhode Istand Reds and White Leghorns received no food for thirteen days except what they could pick up in their runs, which had been sown to oats in the spring. These runs were fifteen feet wide and one hundred feet long and nearly all of the oats had been picked from the heads before the beginning of the experiment. The other two lots of fowls were fect as usual on mash, beef scraps, corn, wheat, and oats. After the expiration of the thirteen days all four lots of fowls were fed liberally. Each lot of fowls contained twenty hens and two cocks.

The following table shows the number of eggs produced during the first thirty days after the beginning of the test:

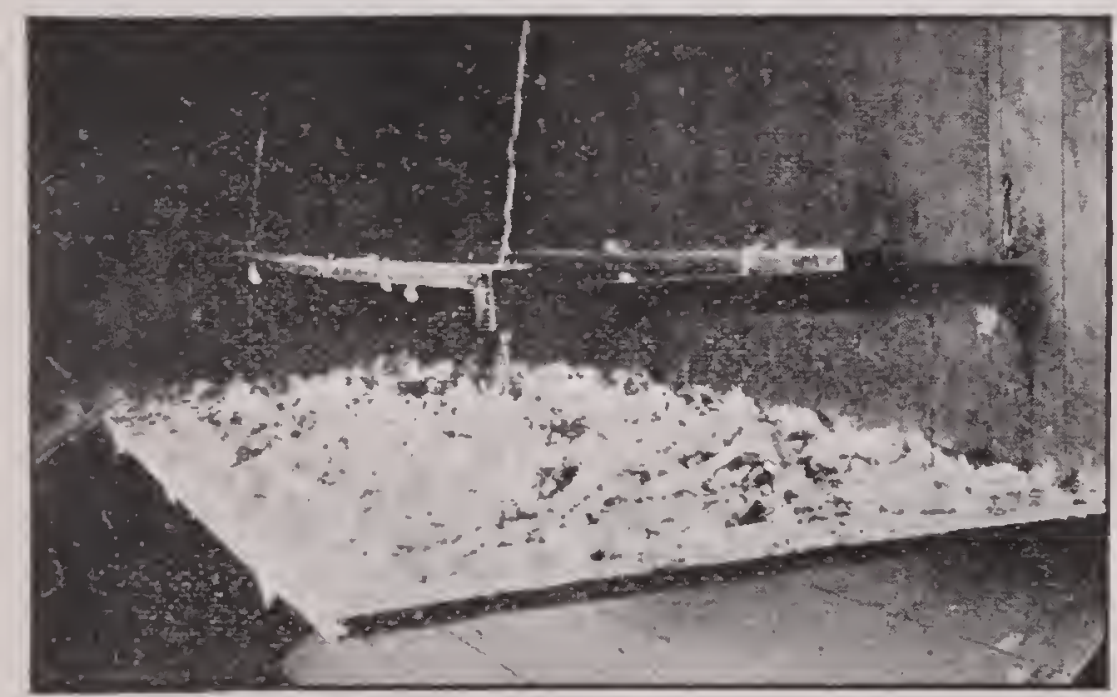

The Droppings Platform, Fowls Fed as U'ual.

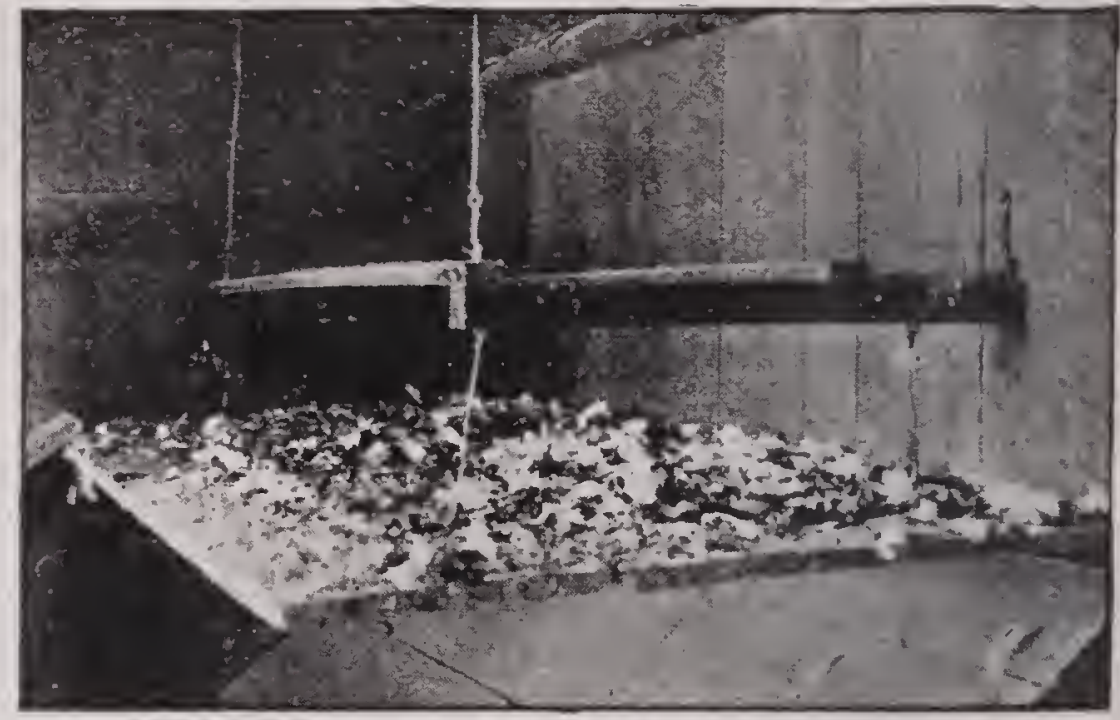

The Droppinge Platform, Fowls Fed to Induce an Early Molt.

1... Rhode Island Reds |Fed continuously 75 \begin{tabular}{|l|l|l}
2 ... Rhode Island Reds & No food & 17
\end{tabular} 3 ... White Leghorns $\quad$ Feck continuously 172 \begin{tabular}{l|l|l|}
4 ... White Leghorns & No food
\end{tabular}

Lots two and fou ceased laying entirely on the seventh day of the test.

'Thirty days after the test began the "no food" pen of Rhode Island Reds had practically a complete coat of new feathers, had begun to lay, and within a week from that time onehalf of the hens were laying regularly, while the other lot of Rhode Island Reds were just begimining to molt, and the egg production had dropped down to two or three eggs per day. Both lots of White Leghorns were a trifle slower in molting than the Rhode Island Reds, but otherwise the treatment (ffected them in a similar way.

For tell days begimning August 19, the droppings boards in the two White Leghorn houses were not cleaned. At the expiration of this time photographs were taken and the plates show the great accumulation of feather's from the "no food" lot of fowls, and the relatively small amount of feathers which had been shed by the other lot.

\section{Summary.}

Nature hens, which are fed very sparingly for about two weeks and then receive a rich nitrogenous ration, molt more rapidly and with more uniformity, and enter the cold weather of winter in better condition than similar fowls fed contimually during the molting period on an egg producing ration. 


\section{FOODS AND FEEDING.}

\section{What to Feed.}

Green boncs are not as extensively fed as they should be, because grain can be obtained with less difficulty and at a low cost; but as egg producing material, the bone is far superior to grain-nor docs the bone enst more than grain in sone sections. The cutting of the bone into available sizes is now rendered an easy matter, as the bone cutter is within the reach of all. Bones fresh from the butcher have more or less meat allhering, and the more of such meat, the better, as it will cost no more per pound than the bone, while the combination of both meat and bone is almost a perfect food from which to produce eggs.

If the famer can get two extra eggs per week from each hen in winter, he will make a large profit. We may add that if the product of each can be increased one egg per week only in winter, that egg will pay for all the food that she can possibly consume, and it therefore pays to feed the substances that will induce the hen to lay. If the hens are consuming food, and are producing no eggs, they will cause a loss to their owner; and this happens every winter on a large number of farms. The hens receive plenty of food, but not the right kind.

A pound of cut green bone is sufficient for sixteen hens one day, which means that one cent will pay for that number of fowls. If one quart of grain be fed at night to sixteen hens, and one pound of bone in the morning it should be ample for each day (and the majority of fanciers do) we find in winter. In summer only the bone need be given. Such a diet provides fat, starch. nitrogen, phosphatcs, lime and all the substances required to enable the hens to lay. As an egg is worth about three cents in winter, it is plain that it is cheaper to feed bone than grain; as the greater number of eggs not only reduces the total cost, but increascs the profit as well.

The bone cutter is as necessary to the poultryman as his feed mill. It enables him to use an excellent and cheap food, and givcs him a profit where he might otherwise be compelled to suffer a loss. It is claimed that the bone cutter pays for itself in egrgs, and really costs nothing. Boncs are now one of the staple articles of food for poultry. and no rations shoukl have them omitted. They are food, grit. and lime, all combined in one, and the hens will leave all the other foods to receive the cut bone. If cut fine, even chijcks and ducklings will relish such excellent food, while turkeys grow rapidly on it. To meet with sucecss requires the use of the best materials, and green bone beats all other substances as food for poultry. There is quite a difference between the green fresh bone, rich in its juices, as it comes from the butcher's and the hard, dry bone which has lost its succulence. The value of all foods depends largely upon their digcstibility, and the more this is provided for the greater the saving of ford, and the more economical the production of eggs. -Poultry Keeper.

\section{The Importance of Green Food.}

There is another most important article of diet, without which it is absolutely impossible to keep fowls in health. We refer to an ample and daily supply of green or frcsh regetable food. It is not perhaps too much to say that the omission of this is the proximate cause of nearly half the deaths where fowls are kept in confinement; whilst with it, our other directions being observed, they may be kept in health for a long time in a pen only a few feet square. It was to provide this that, wherever they are large enough, we recommended the open yards, when possible, to be laid down in grassthe very bcst green food for poultry, and a run of even an hour daily on such a grass plot, supposing the shed to be dry and clean, will keep them in health; but if a shed only be available, fresh regetables of some kind must be given daily. Cabbage leaves may suffice, though they are alsout the worst of green vegetables as regards a tendency to diarrhoea. They or other refuse vegetables may be minced up and mixed pretty freely with soft food; or the whole leaves may be thrown down for the forls to devour: or a few turnips may be minced up daily, and scattered like grain, or simply cut in two and thrown into the run.

Lettuce leaves and most garden refuse are very wholcsome, also dandelion learcs and other ficld salads. For fowls in a shed one of the best things is to cut a whole cabbage head in half and hang it up br a string, which will give the fowls both green food and occupation. Something they must have erery day, othermise their bowels sooner or later become disordercd and their combs lose that bright red colnr which will ahways accompany good health and condition, and testifies pleasantly to abundance of eggs.

$$
\text { Wright's "Practical Poultry Keeper." }
$$




\title{
CHAPTER VII.
}

\section{COLIECTION AND CARE OF EGGS. CATERING TO THE MARKET. GUARANTEED}

\author{
STRICTLY FRESH EGGS.
}

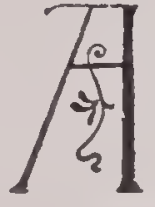

great many poultrymen fail of getting the best price for their' eggs, and it still greater proportion of the farmers fall short of marketing the bcst and getting the best prices. A study of the market quotations shows a remarkably wide range of prices, and one rery soon learns that this range of "price is cletermined by the quality of the eggs marketed. This is almost a truism; it applies to evely line of business and every kind of goods bought and sold. If one has a second, or third, or fourth, or fifth rate article to sell, he has no right to expect the price of a first rate article, and if he fails of getting the price of a first rate article he is a foolish man who does not ask himself, "Why" "-and then set about to reform his methods so that he shall have goods which merit the best price.

Freshness is the quality of the greatest importance, and where there is any question of the quality the eggs are tested for freshness at the outset. If one is located near a city or large town he can get a private family trade, which will pay a fancy price for strictly-fresh new laid eggs; even if at a considerable distance from a city or town one can have such a trade, by an alliance with a dealer in the city or town. The description of the marketing metheds $\mathrm{em}-$ ployed at the White Leghorn Poultry Plant in Chapter $Y$, explains this. The eggs are put up in pasteboard boxes holding one dozen each and shipped daily to a dealer (or dealers), the latter distributes the eggs to the preferred customers. Whether it will pay one to establish an egg route and deliver guaranteed fresh eggs to selected customers, after the mannel of the familiar milk-route of our cities and towns, each poultryman or farmer must determine for himself. Such an egg route takes time; for example, he will start with his eggs in the morning, going ovel his route making deliveries, and it will be noon probably before he gets back to his home; this means two lialf-rlays a week for a man and horse, and as the time of both man and horse are worth a certain amount, it is simply a question of mathematics whcther the increased price receired for the eggs pays a profit over the market price of the eggs plus the cost of delivery.

After all the egg loutes, etc., are taken into account it would have to be acknowledged that 99-100 of the egos produced are marketed through the regular channels, and it is the general market conditions that we should consider. There is rery great room for improving the quality, and thus improve the price. After the question of freshness has been considered, next in importance is the size of the egg and color of the shell. An illustration of improvement in quality came to our knowledge on a visit to the Industrial Fair at Toronto last September. Talking with Professor Graham, of the Ontario Agricultural College, he told us that in one township a dozen or fifteen miles from Guelph, a grain dealer has been interested to induce, his patrons to improve the quality of their poultry; the result being that nearly all the poultry raised in that town is Barred Plymouth Rocks or Plymouth Rock grades; so that the eggs shipped to the Toronto market from that tomn are larger in size and are of a more uniform brown' (or brownish) color than from any other, and retail dealers gladly pay the commission man a cent a dozen premium above the price of other eggs shipped into Toronto. At first thought this does not seem to be of tremendous importance, but if we consider the yearly total of eggs produced in the United States, we see that it would make a very great difference in dollars. Fren if a hen lays but ten dozen eggs in a year it mears 10c increased profit to her owner-if she lays 15 dozen it means $15 \mathrm{c}$ increased profit; it is commonly estimated that a hen will pay her owner one dollar profit in a year, and the in- 
crease of this amount by 10 or 15 c each hen means an immense gain to the farmers of America.

Some markets prefer white eggs, notably New lork City and cities and towns imediately adjacent. Boston notably prefers bromn egres and pays a substantial premium for them, and taking the country over, the preference is for brown eggs by a large majority, where any preference is expressed. The proprietors of Lakewood farm in New Jersey, told us a few weeks ago that even in New lork City and the city of Newark, there were many families who preferred brown eggs, and Lakewood Farm keeps a large number of Thite Wrandottes to furmish those preferred brown eggs. Where there is a preference, and whicherer the preference is. one should keep a variety which lays the eggs of the preferred color. On ega farms where white eggs are the specialty, the Single Comb Thite Leghorn is the rariety most in evidence. If, however. one has customers which will pay a special premium for size of the egg (as well as the white color), Black Minorcas would be the variety preferred; Minorca egcs are of extra large size and of the much desired clean-rhite color.

For brown eges the Asiatic varieties rank first. but the American varieties are a remarkably close second; and some strains of $\mathrm{Ply}_{\mathrm{y}}$ mouth Rocks and Wrandottes lay good-sized, dark brown eggs. which are quite as good in both size and color as the arerage of Asiatics. In this particular selection and careful breeding is of great assistance. If one selects dark brown eggs and eggs of marked good size to hatch his chickens from rear after year, he will soon establish both size and color in his strain, and thereafter the pre-eminence is easily maintained.

Eggs must be clean to command the best price, or to sell to a select family trade; to have the eggs clean it is necessary the nest be clean, and that the eggs be regularly and prompty eollected and sistematically cared for. So little heed is paid to this point. that we see "dirties" regularly quoted in the market reports. This means that hens have been allowed to lay in nests of their own making, perhaps at the base of the manure pile. perhaps under a bush or under the eares of some out-house or building where the dripping rain water soiks and stains them. Whaterer the cause, it is evident that a greater number of these soiled and stained ("dirty") eggs come upon the market, and they have to be sold for what they will fetch. This is unfortunate, for very many reasons which it is unnecessary to give space to here; it is sufficient for our purpose that they appreciably lower the arerage quality. which effects a lowering of the arelage price. We cannot too strongly urge upon our readers the importance of maintaining the qualities of cleanliness, good size and good color if the 5 would produce the article which pays the best profit, and it is our duty to produce the best and market the best-then shall we get the good prices that pay the best.

\section{Building Up a Family Trade.}

A reader in eastern Massachusetts asks us for advice about catering to a family trade; says he is now getting about thirty dozen eggs a week, and rants to get better prices for them than he can get at the store.

We think he is quite right in tuming his attention to this, and think he will find it a profitable business if he will give it proper attention. There are sereral points in that connection, however, which he should carefully consider. It costs something to get family trade, and it costs to keep it-that is, it has got to be taken care of. It pays a considerably better price than the selling of egers to the store, and that consiclerably better price is in itself a good profit, but a careful personal attention is the price paid for that better profit; or, to put it differently, the better price is the reward for the careful personal attention. Generally speaking, a family trade in strictly fresh eggs, delivered say twice a week, pays about ten cents per dozen above the price the store-keeper pays for eggs, and if a hen lays twelre dozen eggs in a year, (and she is not worth keeping if she does not) ten cents per dozen increase in price means $\$ 1.20$ a year increase for each bird. With our friend's one hundred birds that means $\$ 120$ a year; and that $\$ 120$ is his pay for attending to the family trade. There is one point in this connection which he should not orerlook. He cannot estimate the rearly capacity of his flock by the thirty dozen cggs a week which he is getting now. To take good care of family trade he must have eges all the year round, and he must gauge his capacity by the egg vield in October, Norember and December, rather than by the egg rield in April and May. There is another point to be considered here, 
and that is that the lower price of March, April and May, will in many cases, increase the consumption of eggs, and a family which takes but two dozen eggs a week in November and December is likely to take three or four dozen a week at the lower price of April and May.

Another point we would suggest to our correspondent is, that he add poultry to his egg business - that is, that he raise spring, summer and fall chickens, taking orders in advance for a pair or two to be delivered on the next trip, and adding that department to his egg business. We think he will find it decidedly profitable, especially when he gets his business well established, if he produces a superior article of chickens and fowls, an article which would command a fancy price.

The poultry and egg business is almost exactly like the milk business, and every one is familiar with the value of fresh sweet milk, new milk-cow's milk-as compared with milkman's milk. And it requires but a little education for the public to appreciate the fine flavor of freshly laid eggs and nicely fatted chickens, just as they now do of choice milk.

One question which our friend asks is how to builk up such a trade. We woukl ask him in reply how he would build up a milk trade, supposing he had half a dozen cows, and wanted to deliver milk to private customers. Of course he would go to the families he wanted to serve, and introkuce himself and his business to those families. In most instances this can best be done by a personal canvass and here the personality of the individual is an important factor. We knew two men who started in the business as partners-one of them being a hearty, good-natured, genial man, and would make friends anywhere and everywhere. The other was the very antipodes of him-cross, grumpy, suspicious, and would have the grea test difficulty in making friends. Naturally the bluff, hearty one took the business end of the work, and his success was phenomenal.

A man to secure private customers for eggs, poultry, or for milk, must have faith in himself and faith in his goods, and having that commodity he can induce housewives to give him a trial. We would caution the novice in this business not to make too strong a setting forth of his claims to public patronage, nor show samples of eggs better than the average which he can deliver. That is, he should not pick out all big eggs for the sample basket he will take with him when he solicits orders. They should be a fair average lot, just such as he expects to deliver week after week. Furthermore, they should be clean and attractive. If they are put up in neat pasteboard boxes of one dozen each, with partitions between the eggs, so much the better. The housewife does not like to bother to go and get a dish to put her dozen or two dozen eggs in, and if the clealer can take his one or two boxes into the house and set them upon the table without bothering the perhaps busy housewife any more than to bill her a cheery "Good morning," that of itself favors trade. Of course the simple request to return the empty boxes will be readily acceded to, and while now and then one will get lost or smashed, their cost is so insignificant, about one dollar per hundred.

It would be a good plan to have some postal cards printed with your name and adchress on the address side, and on the other:- "Dear Sir:-Please bring me...dozen of eggs each Tuesday and Friday," leaving room below for the name and address of the party writing them. One or two such cards left with the housewife will frequently bring an order where the first or second visit has failed to accomplish that purpose. The housewife has found one or two bad (or undeniably stale) eggs in that last dozen she had from the store, and as she realizes that that means money out of pocket in addition to the annoyance possibly of having spoileck a batch of cake, she declares, "There, I will have Farmer Jones bring me two dozen eggs a week, and see if I can get fresh eggs": and having the postal card at hand, she fills out the request for Farmer Jones to call, and another customer is gained.

A business card is another very good thing. The writer has samples of two of these cards:

\section{From}

THE JONES POULTRY YARDS, Greenfiekds, Mass.

George E. Jones................ Proprietor.

\section{EVER I EGG WARRANTED FRESH.}

The Supplying of Families with Eggs and Poultry a Specialty.

That is a neat and attractive business card, and sets forth the case in a straightforward, business-like manner. Certainly the leaving of such a card with a housewife who is likely to 


\section{CATERING TO THE MARKET.}

want fresh egos and good poultry would be likely to invite custom.

Here is another, considerably more costly, evidently an engraved carl. though at the present time "process" work is so inexpensive that the making of a carl of special lesign is easy.

This card is ormamented with the cut of an attractive Brown Leghorn hen. and below, in the left hand sicle, a nest full of attractive, clean-looking eggs. The card reads:

\section{EGGS LAID WHILE YUU WAIT! Family Trade Solicited.}

\section{THE JONES FARII . Cireenfields, Mass.}

We cannot but think the first one simpler and more attractive, although the humorous element in the last one woukl be rery attractive to some people.

* Having gotten your customers. a punctual delivering on your part is absolutely essential. The eggs must be delivered on regular days. just as you promised-and they should always be clean and attractive, and as a rule. of good. large size. Cenerally speaking, it is unwise to have one or two extremely large ones or extremely small ones in the dozen-that is. extremely large or extremely small ones, which not infrequently turn up in the egg basket, should be kept for home use. or sold outsilke of the regular customers.

It won't be all smooth sailing eren with the best of management; there will be times of the vear when eggs are abundant, and some of vour custoners will incline to going back to store-egos. because they can get them cheaper, or something of that kind. Do not expect to always keep a customer, because you can not do it. Lpon this subject what Mr. Robinson told us of his personal experience, in his comments upon the Utah Experiment Station's poultry bulletin, is interesting. While considering the selling of eggs by weight he says:

"Apropos of the above. my own experience in selling large and small egos will not be untimely. Even selling eggs by the dozen, I found it most profitable to produce large eggs. because people were willing to pay a better price for them. I don't think any poultryman can hold a special trade if he furnishes his customers small eggs. Again and again I had customers quit me because some one else would furnish eggs just as good for less money, only to come back to me inside of a month, with the complaint that the other eggs were too small. As to the relative cost of producing large and small eggs. I can only say that the hens I had which laid small eggs seemed to eat just as much as any of the others.

"Posibly harl all foods been weigher, as in the Ltah Experiment, the records woukl show not so much profit in the large egos as would appear from the salesbook, though quicker sales mean quite a saving in the labor of selling the eggs."

We think that what Mr. Robinson means here by large eggs was eggs which average a gook size, and not abnomally large, and that was what we had in mind in recommending "good sized eggs." and leaving out the very large and rery small. Color, too, is an important matter, and a nice brown (or vellowish brown) ega, generally speaking: is the most attractive to the eye. Whether or not it is richer in color and attractireness is a most important factor when considering a family tracle. In those parts of the country where white eggs are given the preference, of course large, white eggs will command the fancy price. but. as a rule. large brown (or yellowish brown) eggs are coming to be considered the best. and are the ones to rely upon for winning and holding the family trade.

\section{Furm Poultry.}

\section{Quality.}

We shall never be insured a first-class article until the consumer clemands it, and refuses to accept anything else. So long as there is no radical kick against limed or cold storage eggs being delivered as the fresh article, so long will dealers palm off the poorer and cheaper and charge for the richer and dearer. A knowledge of the source and nature of distinct flavors in eges, as well as butter will be of material service in protecting from fraud and insuring a choice, fresh product. To neglect this is unjust to one's self; to protect is one's highest duty. Demand fresh eggs, pay for the same, and then charge back for every one proving faulty. This in itself will bring clealers to terms, and make them more critical, and insure better egg fruit for the table, no matter what the form in which it comes. A stale or impure egg is a positive injury to the person consuming it. Nothing will accomplish more for the man producing and delivering 
straight goods than an active demand and appreciation of such by the public, and refusal to accept anything else. Without this the business is demoralized, and the straightout hemman at a clisadvantage. His goods go in competition with an inferior article, and always to his loss. Buyers and consumers have a responsibility as well as producers, and until this is recognized the distinctions between grades of quality will not be observed by dealers.

Maine Farmer.

\section{Keeping and Marketing Eggs.}

The exgs, whether intended for market or lor hatching, should be kept in clean cases, either the wire spring pattern or pasteboard fillers, and should be kept in a moderately cool room that is clean and well ventilated, and where the temperature rloes not go below 50 or above 60 degrees. This room should not cantain any regetables, oil or other matter having strong odor, as such will taint the eggs. The eggs should be packed in the cases small end downward. Where they are intended for hatching, it will be a wise plan to turn them every day or two. For this purpose a revolving ( gg cabinet will prove a labor-saving essential. These cabinets are a practical invention, levised for the purpose of caring for eggs for hatching, providing means for turning the (ggs with little expenditure of time and no loss through breakage or careless handling. Thes cabinets can be purchased in several sizcs. from 150 to 700 eggs.

In earlier times eggs, if sold at all, were mar- keted near the place where they were produced and many are still sold in local markets, but with improved methods of transporation the market has been extended and large quantities are now shipped to distant points. Special egg cases are required for carrying eggs long distances.

Eggs which are to be shipped, should be perfectly fresh and should never be packed in any material which has a disagreeable or strong odor. All new laid eggs should be graded according to size and color. Nusty straw, cardboard, bran, or other packing material having a disagreeable odor will injure the flavor and keeping qualitics of the egges packed in it. Keeping eggs near a lot of apples, or other goods having a pronounced odor, during transportation, has been known to injure the flavor of the eggs and reduce their market rahue. Micro-organisms may enter the minute pores of the eggs and start fermentation which ruins the eggs for market purposcs. Eggs which have been kept in a warm place, or where the grerm has been started under a broody hen, willalso become rotten, and the presence of a few such eggs in a case will result in a loss of price on the whole shipment. The normal nucilaginous coating of the surface of the egg protects it, and somewhat hinders the entrance of the organisms which start fermentation. This coating is removed or injured by washing the eggs and the keeping qualitics of the eggs thereby diminished. For this reason it is not a good plan to wash eggs which are to be shipped some distance to market or which are not intended for immediate use.

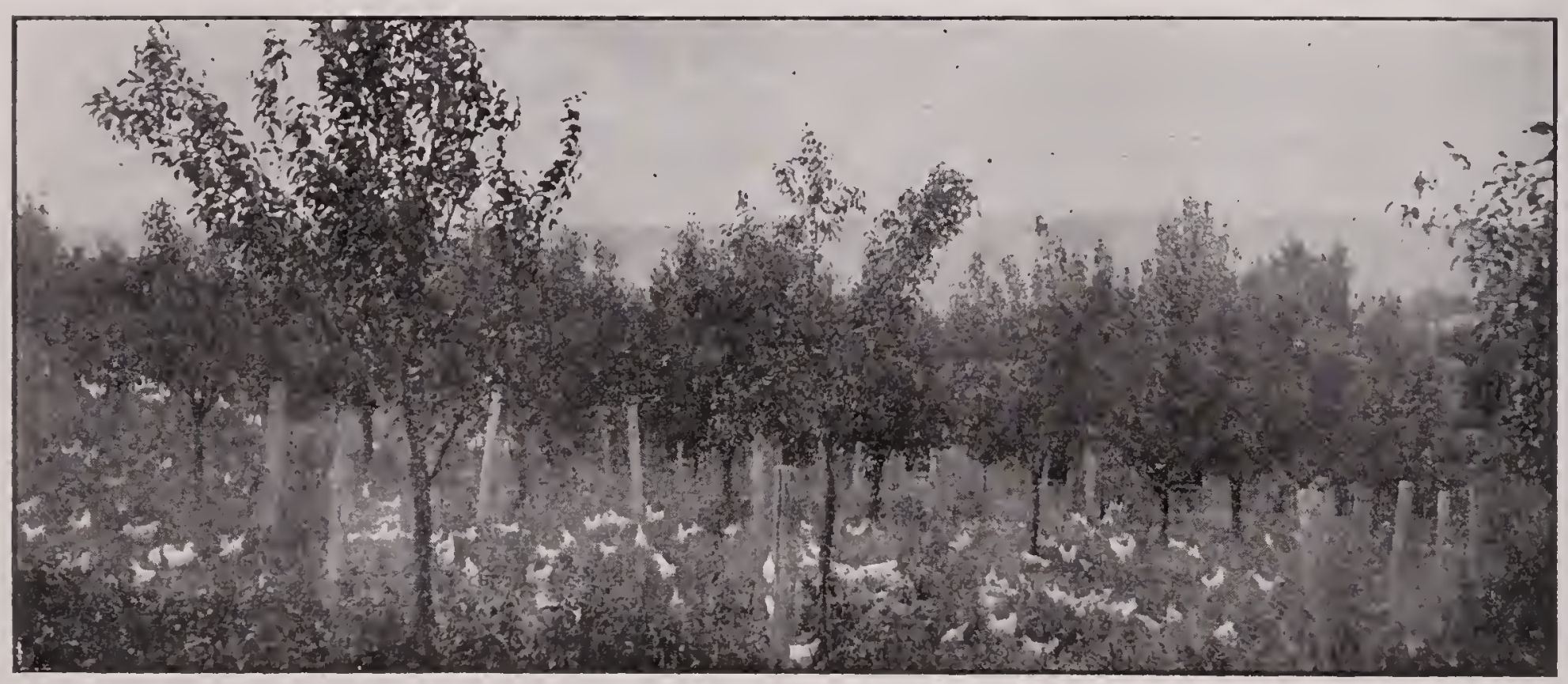

Fruit Trees for Shade, in Poultry Yards of II. J. Starke, Groton, N. I. 


\section{CHAPTER VIII.}

\section{COMBINATION EGG-FARMING. COMBINING EGGS AND POULTRY. EGGS AND FRUIT GROWING. EGGS AND BEEKEEPING. PROFITABLE COMBINATION CROPS.}

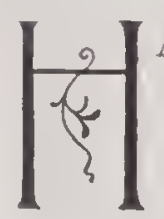

AliNG the incubator and hrooder equipment for hatching the chickens to reproduce his laying stock. what more natural than that the poultryman should start the incubators in season to get off a couple of hatches before he intends to hatch the chicks for layers. With the American varieties April is the best month for hatching for the pullets, hence the first hatch of the future layers will be set about March 10th, to be off by April 1st, thus bringing the second hatch within the desirable month. This would mean the setting of the incubators for the tro hatches of broiler chicks about January 15th and February 12th, which will get them well out of the way of the April chicks hatched for layers. Broilers bring the highest prices in April, and the chicks hatched from the first setting of the incubators will be ten weeks old April 17th or 18th, in season for the high April prices, and the broilers of the second hatch will be marketed before the middle of May; the income from the broiler chicks will come just in time to meet the expense of feeding and raising the breeding stock.

A succession crop and a decidedly profitable one is two or three hatches after the incubators have hatched the chickens for the layingbreeding stock, the cockerels of these last of May and June hatches being caponized and grown to capons for the next February and Iarch markets. A poultry dealer in South Jersey told us in February, 1902, that he had just bought 200 capons of a farmer-neighbor, which averaged to weigh ten pounds apiece and fetched twenty-three cents a pound; these were June hatched chickens, caponized, and had grown by the following February to be worth $\$ 2.30$ each, the farmer receiving $\$+60.00$ for the two hundred of them.

Fruit growing makes an excellent combination with poultry raising, and the fruit branch of the work may be either tree or brush fruits, or both. Poultry in the apple or pear orcharcl is of the greatest adrantage to the trecs, the birds keeping worms and insects in subjection and rollicking in the freshly ploughed or cultivated earth. It will be found, too, that the soil in the orchard will need less frequent ploughing (or cultivating), as the birds keep the grass and weeds in subjection and will likewise scratch up and stir the soil. The great benefit of the poultry droppings to the trees is not so well known as it ought to be. Poultry growers who have apple trees in their $h \in n$ yards have told us that the fruit was doubled in quantity, improved in quality, and that trees which formerly bore but every other year now produce full crops annually; the abundant fruiting being due to the increased fertility of the soil by the poultry droppings. The shade of the trees is of decided benefit to the fowls, and they can, in an orchard, find either shade or sunshine at will. When possible it is well to locate the poultry house or houses in the orchard, and if it seems best to have yards for a part or all of the flocks a part or all of the time, temporary or permanent fences can be erected. Where permanent houses and yards are constructed one can get quick returns from Japan plum or peach trees set in the yards, but in the case of plums it is neccssary to look out to thin the fruit, sometimes as much as half, to prevent the trees overbearing themselves and becoming too exhausted to recover.

Bee keeping makes another most excellent combination with poultry growing, the comparatively little time required for the care of the bees not only not conflicting with the poultry work but being a change of thought and work, hence a recreation. The poultryman's busiest season is the spring of the year, when the incubating of the eggs and care of the growing chicks takes all of his time, and rot 
infrequeditly dimands more- and at that scason becs need little or no attention and the less they are moddlcd with the better, excepting to give them a look-over in the middle of the (lay to spe that all is going well; in the honey storing and swarming season of May, June and July there is call for more attention to the apiary, and the time then can easily be spared to it. There is both plcasure and profit in this combination of bee and poultry intercsts.

Here is an item, clipped from the Reliable Poultry Journal, which emphasizes the great benefit poultry may be to an old orchard: "One part of the land bought and added to Mr. Duston's poultry plant was an old orchard. Writing of this purchase, Mr. Duston says: 'The past fall we must have gathered better than 100 bushels of apples from these old and practically abandoned trees. This productiveness I attribute entirely to the ranging of the hens under the trees. The old apple orchard had not been trimmed or had anything done to it for at lcast 15 years; the few apples the trees did bear were measly little things, but after the birds had rum on the land only one season, we got a fair crop, and the next year still more. A year ago these trees were trimmed up, and this year we had Hubbardstons that would make your mouth water, and many of them would weigh a pound apiece, I shoukl think.'" 'The shade of the trees is of most decided benefit to the forls, protection from the hot sum being cssential to their comfort in summer; in furnishing this much desired shade the trees reciprocate the benefits received from the fowls, which can, in an orchard, find both shade and sunshine at will.

An excellent example of the bent fits of thinning plums was reported by Mr. C. H. Wyckoff. of Groton, N. Y. His plum trecs (which were in the poultry yards) promised a heary crop, and odul half hours were spent in thinning out fully half of it, the result being that the fruit grew to double the size of that on a neighbor's unthinned trees, and ripened to a plumpness and fine flavor that are impossible where the trees overbear so that they haven't the strength to properly mature it. At harrest time the choice fruit from the trees that had been thinned sold quickly (and "more" was wanted) at $\$ 1.50 \mathrm{pcr}$ bushel. While the neighbor"s poorly-matured plums could hardly be sold at 50 cents a bushel. The thimned fruit was fully equal in quantity (in number of pounds or bushels), and was of the juicy plumpncss which captures the palate at the first taste; it was of the much desired "superior" quality of which the market never gets enough and will gladly pay a big price for, while poor-quality fruit goes begging.

A most desirable place for grape rines is along wire fenecs of permanent poultry yards; the foliage of the grape vines giring additional shade and shelter for the hens and the wire netting making satisfactory trellises for the vincs. It is best to train grape vines well up towards the top of the netting; then they furnish desirable shade and the fruit is up above the reach of the birds. If there is danger of the fowls scratching or digging too deeply just about the trunks of grape vines or fruit trees, some small stones the size of one's fist, or a few half bricks scattered about, will sufficiently protect them.

In setting out an apple orchard, one should consider the future growth of the trecs and good authorities adrise setting standard apple trees 35 to 40 feet apart each way, and even with that distance apart in 20 years the trees will probably begin to crowd. It is not at all necessary that the apple trees be given the whole of this land at first, and an excellent plan is to set peach or plum trees between the apple trees each way. The quicker-growing peach and plum trees will develop, bear fruit several years and die of okl age before the apple trees need all of the ground; as they decline in fruitfulness or the apple trees encroach upon them they should be cut out, so that the roots of the apple trecs may have all the room they necd.

Plantations of bush fruits, such as blackberrics, raspberries, currants and gooseberrics, and vineyards also, make superior chicken rums, especially for small and half-grown chicks; and it is an excellent plan to put brooders of chicks out in the small-fruit plantations, as early in the spring as brooders can be set outdoors to adrantage. Small pens of temporary fencing will be needed to inclose the chicks the first few dars. until they get used to running in and out of the brooders, then the fences may be taken away and the chicks be given free range among the rows of bushes. The chicks will not injure the growing fruit, and, indeed, when the fruit is ripe, will only very, very rarely touch it; and then it will be only a berry or two from the lowest stems or branches, and this lowest fruit is of indifferent quality. 


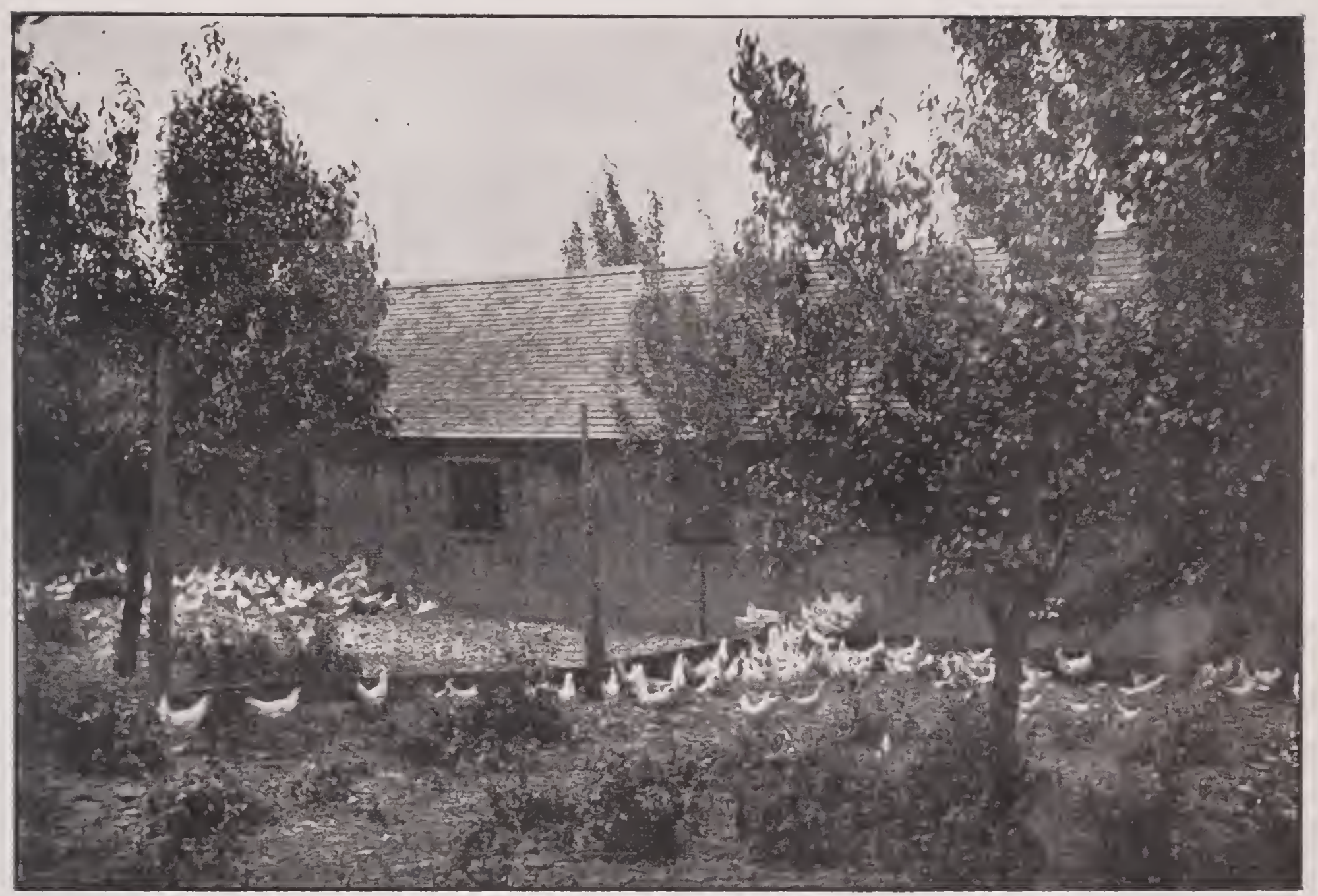

Fruit Trees for Shade in the Poultry Jards and to Prerent Ground Poisoning.

It is impossible to overestimate the advantage gained from having young chicks running and working among the rows of canes or bushes. The innumerable insects and worms they destroy are only a part of the benefit, though no small part by any means. The droppings are stirred into the ground by the scratching and thus incorporated with the soil so that the feeding roots can reach it, and the frequent stirring of the soil gives the roots an opportunity to get the plant food necessary for best growth and to make fruit. It is not intended that the brooders shall remain in the fruit plantations through the entire time of the growth of the chicks; as soon as they have passed the bronder period, the brooders can be removerl elsewhere to be refilled, and small colony houses put in their places. The chicks will adapt themselves quickly to the change of hom?.

No two branches of farm work combine together to better advantage and profit than fruit growing and poultry raising, and we cannot too often nor in too strong terms urge the uniting of the two interests. They can be worked together most admirably, each decidedly benefiting the other, and enabling the growing of two profitable crops on the same ground at the same time. Everyone can well afford to invest some money in fruit trees for the home place, and fow investments pay better. They make the place more attractive and valuable, and the products are a welcome addition to the table delicacies, greatly relished by all the members of the family, and the surplis can be old readily at good prices.

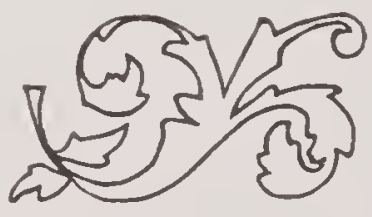




\section{PLUM TREES AND POULTRY.}

\section{They Furnish Necessary Shade and Double Profit on the Same Ground.}

BI W. J. STORKE, GROTON, x. Y.

I find that growing plum trees as an adjunct to the poultry business is very profitable. In each of my hen yards, which are about 150 feet long, I have a row of plum trees running through the center. The hens do not bother the fruit, and on the other hand are a great help. They keep away all the bugs and worms, also the hen manure is the best fertilizer that can be had. The trees in turn furnish the shade which is so necessary, if hens are to do well.

I have trees of the following rarieties: The Green Gauge, Reine Claude, Lombard, Bradshaw, Washington, Quackenbosh, Coes' Golden Drop, Genii. Of these I much prefer the Reine Claude and Bradshaw, as they will bring a good deal more on the market than any of the others. They also bear well and the trees are as hardy as any of them. We get whips or young trees direct from the nurseries in Rochester when they are two or three years old. They will begin to bear so that they will pay a profit in three years after they are set out. We set the trees in rows 15 feet apart.

In the spring after the plums have grown about as large as marbles, we go through the yards and pick half of them, that is, where they hang in clusters. By thus thinning them out, the ones that are left do much better, grow to a much larger size, and so command a much better price in the fall.

We send all our fruit to New York, and it nets us an average of about $\$ 1.75$ a bushel. After once setting out the trees there is practically no expense with it with the exception of thinning in the spring and picking in the fall. The receipts from the sale of the fruit are almost clear gain.

i

In shipping to the New York market or any other market, the plums ought to be picked before they are dead ripe. In fact, they should be picked rather green, when the plum is hard or just before it begins to get soft. They will ripen faster after they are picked. By picking this way and putting them up in eight pound baskets, we get a much better price than by sending the same fruit loose in large baskets.

I would strongly advise any one in the poultry business, if they are in a climate where plums can be grown at all, to setout trees. It will surely prove a very good investment.

\section{Reliable Poultry Journal.}

\section{BEGINNING WITH POUITRY AND FRUIT.}

\section{A Profitable Combination of Fruit Orchard and Poultry Yards.}

BI Wr. L. HOWELI, GENESEO, N. Y.

Four years ago I discovered that our poultry plant was too small, and I decided to buy more land and start anew. I added seven acres, on which I erected a new dwelling, a barn, a shop and four pouttry houses. Knowing by past experience that in fancy poultry of any breed, and especially the Buff breed, the prerequisite to success is good shade; therefore the first thing after my buildings were finished I turned my attention to shade-and the question arose what shade trees can I have, that will at once grow the quickest and produce the best results. My former experience had taught me what to avoid and again what to cultivate. Owing to the rapid growth of the peach tree, I planted plenty of them near the buildings. Desiring a variety of fruit and knowing the profit in it, I literally filled my acreage with apple, pear, plum, cherry and quince trees. Under the peach trees near the house I kept the water fountains, and during the hot summer days changed the water three times a day, each time emptying the warm water around the trees, thus keeping the soil loose and the droppings soaked well into the ground. I have thereby produced the phenomenal growth of from one-half inch in diameter when planted to four inches in diameter in four years. These peach trees stand 10 feet high and measure 10 feet across the boughs.

In setting out the trees in poultry yards I dig holes for them deep enough so that they will set in the ground as deep or just a little deeper than they did in the nursery row; which is usually where the bulb or little bunch shows where the tree was budded. The hole must be broad enough so that every root will lay straight. When the tree is in position I put some of the finest, best soil I have around the roots, working it tightly until the roots are all well covered ( $t$ wo inches) with soil; this I firm down well; then I put two inches thick of well rotted manure on top of this soil, using care that no manure comes in contact with the stem or trumk of the tree, or any of the roots. 
Then I fill the hole nearly full of dirt and pack it as hard as possible with the foot; then put loose soil on top and leave perfectly loose. Peach, pear, apple, plum, cherry and quince trees have done splendidly for me with this treatment, but best of all the peach, and the plum next.

In rich land that is light, sandy and welldrained, there is no other fruit tree that I have tried to cultivate that will make so strong a growth, with the same treatment, as the peach tree. The profit in fruit growing in this way is always greater because of the superior quality, especially of the variety known as the Crawford, which is always large and fine.

Of course it might not seem practicable to treat all fruit trees with such care. At the same time, a fruit tree is like a child, the more carefully it is cared for and nourished the richer and finer is the fruit, (character). All the fruit trees I have named will be greatly benefited by being treated in the foregoing manner. Ther will do much better in chicken rards, as the poultry helps to keep the soil loose around the roots, which is rery essential to the life of the tree. The chickens take all the insects away too. I have nerer heard of a tree being damaged by borers where chickens were allowed to run. It seems needless to add that in a very short space of time the grounds in chicken yards will do double duty and bring double profit in extremely fine products.

\section{Rcliable Poultry Journal.}

\section{Pruning to Improve the Trees.}

Do not be afraid to cut back your trees and vines, for herein lies the secret of success in the fruit business. Plant well and prune well. Cut your trees and vines back hard and let the strength go to the roots, and the third and fourth years they will grow right along and surprise you. When spring comes, what a beautiful sight are your yards full of peach, plum and quince trees in full bloom, with their pink, white, and pink and white blossoms and the air full of their fragrance; the chickens under them full of life, enjoring the first spring weather, the flies, bugs and insects buzzing around. Did you ever notice a place roid of regetation? How still at night, with not a sound. Then go among the trees, the grass and the shrubs, especially on a summer erening. What a constant buzzing! Why the difference? Insects want regetation-so do chickens.
Poultry must have shade, why not fruit trees?

The cuts need no explanation. The idea is to show the fruit trees and vines among the poultry yards. Contrast the trees with the buildings and fences so as to judge their growth in the few years they have been planted. Let me say right here the Japan plum trees are wonderful growers, especially the Abundance. Why not help pay your feed bills and have plenty of fruit to eat? IThy not enjoy the beautiful sight of the trees in blossom? Think of the returns from the fruit, especially in those years when chicks do not do well. Think of the comfort of your forts. Compare a flock of Pekin ducks or White Wrandottes in a yard planted with plum trees, the fences covered with grape vines. with another flock in a yard where there is only artificial shade.

Allow me to leave my subject here and give the beginners in the poultry business a little adrice. Plant fruit trees, rines and bushes. Even if you are on a rented place and have a fair number of years (five to ten) it will pay you to plant grape vines, or eren peach trees.

\section{Retiable Poultry .Journal.}

\section{Poultry and Bees, an Ideal Combination.}

It is quite safe to say that nearly every person has some ideal which he is trying to attain. The question was asked a man in the city of New Iork the other day if he intended to follow up the busy, hustling. traveling city work all his life. "No," said he, "after the children have grown up, or after the mortgage has been paid, I intend to settle down in the country, and keep poultry and bees." Hence this article. Now I wish to suggest right here that you do not wait until the mortgage is paid before you make a start, but begin at once, this very spring, and then from the earnings of your little side issue wipe out the debt which enslares you. That is just what I did. We should try to enjoy life as we go along, and try to keep young in spirit if not in years.

It seems to me that poultry and bees make an ideal combination. The readers of FArirPoultry are no doubt more or less familiar with the life and habits of the hen. so I will devote a little attention to bees, which work for nothing and board themselves, and at the close of the season diride with you their earnings Nearly every one who has a small open space has felt at one time or other a longing for the pleasant occupation of tending bees; but 


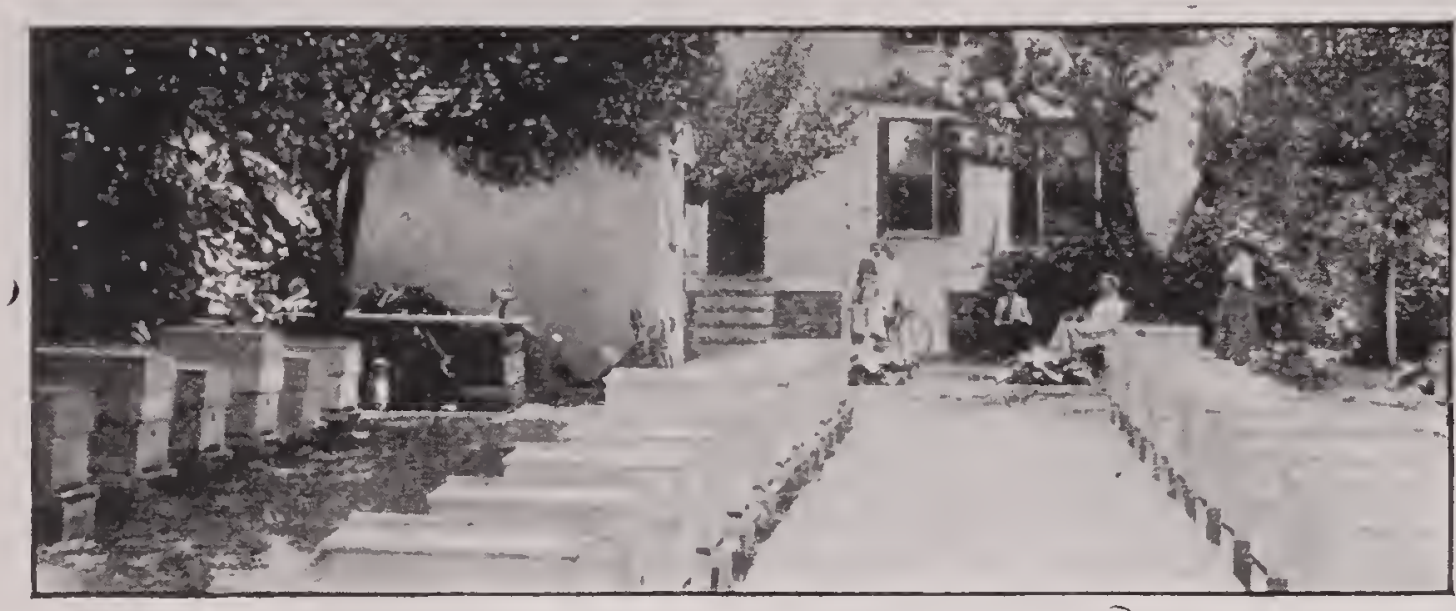

A Bee Farm Six lears from the Start. to whom great honor is due, is the father of American beekeeping; indeed, it was through him that the pursuit has been developed from a game of chance to the great industry that it is today; for it was his invention of the movable-frame hive that has changed the occupation of theapiarist from one of pleasure

most people are frightened away from the undertaking by the difficulties which seem to present themselves. In the first place they are puzzled to know how to make a proper beginning, and what the requirements really are; for it goes without saying that no person wishes to invest very much capital in an uncertainty. A little looking into the question will usually disclose the fact that someone within a radius of five or six miles of you is a bee keeper of some degree. If this is the case it is well to buy your bees close at home, even if they are common bees, and in a box hive. Of course it is best to begin with only one colony, which, in the spring of the year, consists of one queen, a few hundred drones, and from twenty to fifty thousand workers. This will keep you fully occupied at first, and furnish you with experience which would be costly if obtained on a larger scale.

Your colony of common bees in a box hive should not cost you more than from three to five dollars. Afterwards you can transfer them into a movable-frame hive and introduce an Italian queen. As the queen is the mother of all the bees. in the hive, you will soon have a race of thoroughbreds.

It has been my experience and that of bee keepers generally, that there are fewer risks and larger profits in comparison to the amount of capital invested in bee keeping than any other business. Of course, emergencies do arise, but if they are met by ordinary foresight and common sense, they are not likely to result disastroushy. For detailed instructions, such as it is beyond the scope of this article to give, there are numerous bee books to help the novice over the rough places in this delightful branch of agriculture. Rev. I. I. Langstroth, but uncertain profits in to a well-paying business.

The illustration herewith shows a growth of six years' duration, or in other words, an old box hive transformed into a cosy little apiary of sixty colonies. The crop of honey has multiplied from two pounds to two thousand. Who can fortell the possibilities of the busy little bee?

And now as to profits. As I am bat an amateur, and bee culture is still only a side issue with me, possibly you may not consider my own testimony valuable; though my bees bring in a tidy, easily earned, and crer increasing addition to my regular income. It is a conservative estimate of the bee keepers generally, however, that each hive shoukl bring in about five dollars a year; in farorable seasons, considerable more. And as each hive also throws off a swarm annually, it is easy to see how a little capital invested in bees will grow and multiply, besides yielding a very fair percent of profit.

In locating an apiary and arranging the hives much taste can be displayed, but a few general principles should always be observed. It is an advantage to have the hives facing castward or southward in order to have the moming sunshine in the entrances of the hives, which induces the bees to fly forth early in quest of the nectar which collects in the flowers during the night. When the hives are in this position they will also be protected from the north and west winds. A hedge of evergreen or honersuckle will be a further protection and make a splendid enclosure. A few shade trees in the apiary are an advantage, and invariably attract the swarms which nay issue from the hives at swarming time.

$$
\text { F. G. Herman, in Farm Poultry. }
$$




\title{
CHAPTER IX.
}

\section{SELIING STOCK FOR BREEDING PURPOSES AND SELLING EGGS FOR HATCHING.}

\author{
WHEN AND HOW TO ADVERTISE. POULTRY FARM BOOKKEEPING.
}

图

study of the growth of a poultry business is extremely intercsting, and is certainly most instructive to the begimner in poultry work. The accounts which we rearl of highly successful poultrymen contain a valuable lesson for the beginners, because cvery one of the prominent poultrymen of today were the beginners of five, ten, fiftcen, or twenty years ago, and the success to which they have attained has been the result of a simple. natural growth. The selling of stock for brecding purposes and the selling of eggs for hatching is a natural development of the starting in the poultry busincss and having thoroughbred stock themselves. All of the great poultrymen of today began with raising poultry and eggs for market; they realized that thoroughbred stock laid the most eggs and produced the bost market poultry. so equipped themselves with thoroughbred stock. What more natural, then, than that they should offer to sell of their thoroughbred stock, and eggs for hatching, once they had secured it for themselves? (ioing into the sale of stock for breeding purposes and eggs for hatching is but a natural development, and is practically the old, old story of "first the blacle, then the ear, then the full corn in the car."

The giants of the poultry world. Hawkins, Duston, Bright, E. B. Thompson, Wyckoff, Knapp Bros., Fishel, McClave-all began by raising poultry and eggs for market. All the difference between these grcat poultrymen and those who started similarly is, that these great poultrymen of today did not stop with raising poultry and eggs for market; they continued to grow, and by the aid of printer's ink have developed businesses of $\$ 5,000, \$ 10,000$. $\$ 15,000$ or $\$ 20,000$ a ycar, with their consequently splendid profits; and others can do exactly the same if they will but follow in the path where these men have lod. There are just as great (res, grcater!) opportunities today than in the years ago when these men started. The poultry business is growing steadily, and the demand for stock for breeding purposes and eggs for hatching is ten times greater today than it was ten years ago, and in all probability will be ten times greater ten years hence than it is today; those of us who can look back 20 or 30 years fully believe that. The essential thing is that we outfit ourselves with the best of stock of the best variety, and then tell the buying public that we have got that stock for breeding or eggs for hatching; the public, ever anxious to buy the best, will do the rest.

In making a start in the thoroughbred poultry business a most essential thing is that we start with good stock. by getting the very best that our money can buy. Most begimners have little idea how much time is saved (and time is money!) by buring good stock. A most interesting example of this is seen in the egg-farm of Mr. Henry Van Dreser, the story of which farm is told in Chapter $V$. When his step-son convinced him that poultry keeping was a profitable branch of farm work, he went to Mr. Wyckoff and bought 30 birds of his grcat laring stock, and thereby outfitted himself with stock which had in it the accelerated momentum of many years of breeding,-first for a great egg production, and second for standard quality; by making this start Mr. Van Dreser bridged many years of preliminary work at one step, and other begimmers would be wise to follow his example.

Another point, breed but one rariety. A most common mistake of the beginner is to think he will start with several varieties and thus be better prepared to meet the wants of the public. The whole of a lifetime is not too long to get the best out of one variety, and the man who devotes himself to one, makes that one his specialty, and gets out of that one the best that there is in it, - will have achieved a great success. The great successes among poultrymen 
today as a rule, are those who hare made their reputations with one variety; the men who get the largest prices, who do the largest and best business, are those who are deroting themselves to the breeding of one variety and making that a specialty; who are putting into the development of their chesen variety all the energy and ability with which they are endowed.

\section{How and When to Advertise.}

Having made a start with good, thoroughbred stock, the next thing is to let the public know it and solicit orders by advertising. The merchant or storekeeper tells the public who he is and what he offers for sale by signs over his door and on his windows, and by displaying samples of his wares in his windows or beside his door; that is one way of advertising, and such advertisements are likely to be seen by those passing the store. Another method of telling people who one is and what one has for sale is by publishing an announcement in the advertising columns of the local paper; the card in the local paper is another form of the "sign" or the "window display." For the poultryman who has breeding stock or eggs for hatching for sale the poultry and farm papers are "local." Through them he will reach the public that is interested in the goods he offers for sale, and it is in them he will make his arinouncements.

Advertising is simply telling the public something; if you adrertise breeding stock and eggs for hatching you are telling the public that you have such for sale. Without such telling the public, no one outsicle your own immediate neighborhood will know of rou and know. what you have for sale; adrertising is the first step towards making sales to the general public; it is the one road to a successful business with thoroughbred stock and eggs for hatching.

Make rour advertising truthful; tell the public exactly what you have to sell, do not overstate the case nor misrepresent in any way, shape or manner. Make a study of advertising; much depends upon how you tell your story. Some advertisers rely upon an attractive design or telling illustration to catch the eye and hold the attention of the possible customer. At any rate, make your ads. attractive and convincing so that they will both catch the attention and then hold it; that is the may to solicit trade.
When to adrertise is, of course, when you have something to sell. The great bulk of the sales of breeding stock are in the fall and the early winter; the sales of eggs for hatching are almost wholly in the spring. Two-thirds of the poultry advertising is in the fall and spring, but the most successful advertisers are those who keep their ads. rumning all the year round. The beginner is not likely to do that, and as he probably is not equipped with stock with which to fill a large number of orders he will ahmost certainly begin small, and increase his ads. as his ability to handle business increases. That is the way great poultrymen all began, they advertised in a small way at first, and as trade increased they raised more stock and increased the size of their ads. and the number of papers they advertised in.

If one advertises in several papers he needs to keep a record of the calls he gets from each one. A simple memorandum book will serve the purpose. Ascertain by the record of sales which papers pay, and increase the space used in those papers; cutting off those which have not brought paying sales. Put system into the business; don't trust to guess-work. Many customers will tell you in their letters where they saw your ad., and it is an easy matter to write a note to such as omit to mention it and ask them; enclose an addressed return postal card and they will almost certainly tell you. Business is business, and the poultry business is exactly like every other. Make a study of it; make a study of your advertising; make the ads. read right, make them attractive and to the point; then they will draw custom.

\section{Farmers Who Advertise.}

The marketing of the farm produce is a business by itself and demands the most careful consideration.

There is no question but that the aggregate loss to farmers from selling their goods in a poor market is very greot. In a certain $\mathrm{N} \in \mathrm{W}^{\circ}$ England watering place, for instance, I have known eggs, before the advent of the summer visitors, to be almost a drug on the market; while at another city, only thirty miles distant, they were in brisk demand at ten cents more on the dozen. This is a great difference in price and was far more than the extra cost of transportation, which could hardly have exceeded one cent on the dozen. And yet rery $f \in W$ farmers took adrantage of 


\section{WHEN AND HOW TO ADVERTISE.}

the situation, the inertia of long-settled habit keeping most of them in their accustomed channel of trade.

I also recall an instance in $m y$ own farming, when I had a lot of turkeys to dispose of, as I hoped, at a fancy price. I sent one wagon load to a wealthy residence town and another to a manufacturing city, the two men in charge being about equally expert as salesmen. The lot sold in the manufacturing city brought twenty cents a pound (two cents above the price current of best turkers), while the lot sold in the residence torm brought twenty-five cents and sold quicker. The manufacturing city Was the larger place of the $t \pi{ }^{\circ}$. but it had not the class of people who were willing to pay outside prices.

Another instance that comes to $\mathrm{mr}$ mind of allvantagreously seeking a good market, regardless of a considerable distance, is that of a New England farmer whom I know well. He lives in a very fertile reach of country, but his farm is fifteen miles from the nearest railroad station, and from there fifteen more to the city. Most of his neighbors "trade" at the country store, but this farmer goes twice a week to the city, taking with him large quantities of butter, eggs, poultry, fruit and farm produce. In the city he hires two wagons, one to deliver the wholesale orders, and the other for the family trade.

It is needless to say that he pays more for these teams than he would for the same accommodation in his native town, and one of his neighbors reflecting on this "blame inordinate expense," observed that "parin' out what that crazy cuss does in cal fares and for teams in the city, he didn't see how he made his dum'd business pay-and he didn't more'n half b'leeve it did pay, either." And ret the "crazy cuss" is today rated as one of the rrealthiest men of his torn, while his critic. though owning by inheritance a larger and better farm, is comparatively poor. It is right for me to add, however. that the latter is an acknowledged oracle in the country store, an accepted authority on all things. from points of theology to the digging of wells-to say nothing of his neighbors' affairs. It is not given to one man to compass all the heights of greatness, and personally I never knew a thrifty, prosperous farmer who was a countrystore oracle.
How is a good market poorly utilized" By dumping into it cartloads of stuff to be sold by commission houses, thus losing not only the middleman's profit but sharing witl the commission man a large part of the profit that properly belongs to the farmer himself by letting gilt-edged fancy goods go along with the indifferent or poor to fetch what they may chance to bring; and last but not least by sending inferior goods which bring so low a price as hardly to offset the cost of transportation. The competition in farm products of ordinary quality is tremendous, often running the price down to a very low figure. It is the superior goods that pay and that place the farmer on such a footing in the market that he can boldly state what he askis for them, instead of humbly inquiring from some third-class dealer what he will give. Be assured that in every large city there is a class of people who are willing to pay the very best of prices for farm products if they can have the very best of goods.

This brings me to the proper means of reaching this class of customers and introduces another important factor in the marketing of goods, adrertising, a thing as essential to the farmer as to any other business man. It is true that, having once got a foothold and established a reputation for his goods, he may need much less advertising than at the start; but it is doubtful if he can wholly dispense with it at any time. Advertising in various ways, has long been practiced by nne class of farmers-the stock-breeders; indeed we should hardly know how to get along without it. To my mind it is clear that it would very often be of just as much value in other branches; but custom-a strange thing, I have sometimes thought, in the powerful grip that it has on farmers-has long restricted advertising to stock-breeders alone.

"Advertisin' never created a customer!" said a country sage to me once. Perhaps it does not create customers-though I have known cases where this might be questionedbut it brings together the man who wants to sell. and the man who wants to buy.

The whole matter of marketing furm products resolves itself into what is necessary in any well-conducted enterprise: a careful study of the situation and the exercise of common sense. I would say, in conclusion, what I bdre of ten said before when speaking of the possibilities of agriculture, that, as the demand for the 
best farm products is always in excess of the supply, he who has them has a great advantage in the market if only he knows how to profit by the situation. And if he has practiced a proper economy in their production and follows up with sagacity and perseverance the arlvantages that the nurket conditions afford, he need have no fear of the result; his reward will be ample.

\section{Saturday Eveniny Post.}

\section{Common Sense in Poultry Advertising.}

Plain common sense is today the greatest factor of success in any business. It is a rare article-this co-called common sense. As a matter of fact, it is decidedly uncommon.

Another name for it is genius. The man who believes in "luck" does not possess it. The man who conducts his business on the let-'ergo-Gallagher plan does not possess it. Natural ability counts for much; education is a great help; "a liking for the business" is a happy factor; but plain, hard headed, keep-in-themiddle-of-the-road. won't say-die common sense is the real stuff!

Take the matter of poultry advertising. I, a poultryman, have, we will say, some utility fow's to scll. Out there in the world somewhere is a man who wants to buy them. I can reach that man through the poultry or farm paper he reads. That is simple conigh; but what shall I tell him?

The plain facts, the exact truth. It should be as though I met him face to face, and said: "Sir, come and see for yourself. I have for sale ten hens of Barred Plymouth Rocks, nine rearling hens, and a two-year-old cock-fowls of a strain that has been bred systematically for large size, great vigor, rich, yellow skin and increased egg production. If you want fowls for eggrs and meat. mine will suit you. The hens will average scren and one-half pounds each. Two of them weigh nine pounds apiece. The cock is a ten pounder. Not one of them has ever been sick, to my knowledge. They are in perfect health today. Six of the hens are now laying. Their eggs are considerably larger than the average store egg. and brown in color. My price for the pen is \$15."

That's easy, isn't it? It'll clo the business. No use to tell your man that the name of your outfit is the Purling Brook Poultry Farm. comprising eleven acres of land. He does not want to buy the name, nor your farm. Tell him about what he does want to buy! Tell him this, and only this, in the advertising space you buy, and in the letters you write. IJurn in on his mind precisely those facts, those points that he is most interested in. Do not waste a line. not one word.

Know, as a man who is well posted in his business does know, why a prospective customer wants what he wants; then tell him the facts in a plain, straightforward, common-sense way. He will discover quickly enough that you know what is what-and every sensible man much prefers to deal with men who know their business.

So much by the way of selling utility fowls. Now about selling fancy stock. If you have fancy stock for sale, put fancy points into your acl., into your talk as a salesman. Show by the wording of your ad. that you know perfectly rell what is desirable in exhibition poultry, in stock with which to win prizes or breed exhibition specimens. Do not waste a single sentence. Make every word count in the art of winning the confidence of the would-be purchaser by convincing him that you know, as well as he, just what he wants. If you haven't what he wants, it should end there; but if you have, do your plain, common sense, level best to make him realize that fact.

Business is business. The poultry business is business. Do not overlook this fact for one minute. People who are in the market to buy poultry do not want to "play horse." Nine out of ten of them want to make money. They need to make money! Parting with a portion of their capital in hand is, with most of them, a sarious matter. It is business. Leave out, therefore, the fancy rhetoric and big wordsleave out of your ad. everything but the solid facts. Provided what you have for sale is in demand, nothing will have greater weight than facts; nothing will do your business interests more good than the simple truth. This is common sense. Have what the trade demands, tell the truth about it in a convincing way, and the buyers will find you out.

A few thoughts now on the subject of seasonable advertising. Use common sense in that too. How often do we see in the July, August and September issucs of poultry papers ads. offering "eggs for hatching." Men who advertise like this do worse than throw their good money away. They pay the publishers of papers to tell the poultry world what? That here are men 
who neglect their business. who neglect their own interests. who are not really in the poultry business. They may imagine they are, but they are not. They really give precious little attention to the essuntials of the businers.

Is it not logical and reasonable for a woukdbe customel to ask himself this question: "If thesa men thus neglect as inportant a business matter as theil advertising. what about the other part of their busincss?" Loes not such a "sign." hung up on the printed pange for thousands to reach say to the intersted public, "Here is a man who is not in real earnest. Here is a man who is either careless, neglectful or incompetent?" Is it not natural for the thinking man also to conclude. "Such a man is unsafe to do business with. We would be foolish to entrust our orders with him. Men who neglect their own important interests eannot safely be trusted with ours."

Is not this conclusion natural ant reasonable? It is, in the main. There are three months' poultymen and there are twelve months" poultrymen. The latter are "in the business" all the time. It is business with them. They" are the men who "make things go." They are the safe men with whom to deal. An "eggs for hatching" acl., if run out of season because of neglect on the part of the man who pays for the space, is due waming to buyers at this end of the line that the man at the other end of the line is not attending to his business-and the trade goes elsewhere. into safer hands.

Attend to business. those of you who crave success. Put into your work all the brains you have yourself and all that you can hire. Even then some other fellow, a competitor, will crowd you.

\section{(i. M. Curtis in Agricultural Adrertising.}

\section{About Advertising.}

There are a great many people advertising who don't get the returns they should because they don't adrertise what the people wanteven when they have it. They advertise the qualities they prize mostly in their stock, without apparently considering that more people would ralue the stock for qualities to which they attach less importance.

We know of more than one such man who has stock that is both useful and beautiful, but will not in his ads. call attention to the utility value of his strain, because he fears to do so will injure his reputation as a breeder of exhi- bition fowls. We think they are mistaken in this. As long as their fowls can win as they have won now and won in the past, they need have no fears of hurting their reputation as prize winners by advertising their useful yualities. On the other hand, they can by artvertising those qualities attract the attention of that class of buyers who want fowls principutly for eggs and meat, but (lon't want scruh or mongrel stock.

We don't think breedors generally realize how large this class is or how well it would pay them to eater to its wants. These are not the people who want something for nothing. They are willing to pay a fair price for what they want-and what they want is stock not quite good enough for No. i brecding, yet fairly good. Every large breeder has buts of that stock to sell. and we think most of them find it the hardest stock to handle, because the people who buy such birds so often buy them with the expectation of getting a winner or a bird that will breed wimners for $\$ 2.00$. (If course they are disappointed; but if the same bird were from stock bred also for practical qualities, the man who purchased with useful points first in his thought will not be found among the "kickers."

We wish all breeders who have this cliss of stock could see the letters that come to this office asking where just such stock, of one breed or another can be obtained. We print some of them occasionally: but probably not one in a hundred received is printed. We answer then all. The stereotsped replies are "We don't know," or "We cannot say," an d "Consult our advertising columns." The latter we use as often as possible; but too often we know it is useless to refer inquiries to the atvertisements.

There is one encouraging feature, though, and that is, the number of men who advertise the practical qualitics of their stock is constantly increasing, (it is more than five times as harge today as it was five years ago), and in that number are included a few of the best known breechers in the country. We not. too, that these men are among our best advertisers, and we cannot see that they are using any less space in other poultry papers than they used to.

Now there is a better-larger and on the whole more profitable-demand for harly, quick growing, early maturing. prolific laying stock of arerage or medium standard excellence 
than for any thing else. And breeders who have such stock to scll will find that they can sell it to the best adrantage by advertising its practi(al qualitics most, just because an adrertisement that docs not attract attention to those qualities of the class it should reach. If a man adrertises, "Stock mated for best results," or "Winners wherever shown," and trusts to his circulars or to correspondence to make known the excellencies of his fowls, he makes a mistake. His circular and letters go to people incited by his ad. to make further inquiries, and people who don't find what they want mentioned in the acl. don't generally make further inquiry in that direction. And a man must have what he adrertises. He must deal honestly with every one. An advertiser's sins are not long in finding him out. A breeder might advertise his stock as good utility stock when it was not, and for a little while catch trade that way. He would soon be found out, and would find it difficult to sell stock on any representation; if, indeed, he could still find poultry papers willing to take his advertisements.

For the class of stock we have described there is a good demand. We believe that the demand is largely in excess of the supply; even while we are sure that the actual supply is much greater than the visible supply, i. e. the amount of stock for sale by those advertising it. If you have what the people want, tell them so. You cannot do business with them unless they know where to find you. -Farm Poultry.

\section{Rewards of Success.}

The rewards of success in poultry work are most satisfactory and come in the shape of a liberal profit for egges and poultry sold, and a comfortable living. It is "the living" that we are all after, and it is safe to say that there is not one branch of farm work which gives a comfortable living more easily than poultry raising. The market is sure; the great consuming public is calling for more and more choice meat and selected fresh eggs, and is able and willing to pay. The public will do its part if we will but do ours and produce the goods most ranted. The successes chronicled in this volume are only a few of those that could be described; they hare been selected as typical of what can be done by intelligent, persevering cffort, with the thought that the story of the success of others will encourage those just starting in poultry work to push on to the goal.

\section{Conditions of Success.}

The reasons why poultry is still thought nothing of upon many farms are not far to seek; but the curious thing is that they pay the wosrt just on that system of "a few round the homestead" so recommended by certain writers. In days when other branches of farming paid well, a few fowls were kept just to supply the house, and left to the women; thus the farmer never knew anything about them, and never thought of them as having money in them. Any outlay was never thought of, or return for it believed in; the fowls were kept on till very old, left to breed together indiscriminately. Thestock was mostly of bad layers, and half the eggs were stolen by the farm hands. All this must, of course, be changed if profit is to be realized. A paying stock must be sclected and thereafter bred for laying or for table; necessary food and expenses must not be grudged; and eggs especially must be systematically collected and marketed promptly.

As to the stock, it is doubtful if a hen or pullet that lays less than 100 eggs in a year pays at all, while it has been prored.orer and over again that beyond 150 is perfectly attainable; while many farm-hens lay under 60 , and do not account for all of these. All old stock must first be got rid of, and then selection must follow. There are strains now bred and advertised for laying propertics, as distinct from mere "fancy" points, from which a good start can be made in breeding stock; but if any farmer has a prejudice against "pure brecds," there is another course. Let him watch any neighboring market, and get birds or eggs from any neighbor who brings in a good lot of eggs in winter. After that he must select for himself, hatching chickens only from his best layers, and crossing his pullets or hens with cockerels also from the best layers, and so on. It is simple as $A B C$, and in this way the average-that is, "the thing his hens lay on"will be infallibly raised. If he $\mathrm{or}^{\circ}$ his people cannot watch the birds sufficiently to know the best layers, he can still do much by the three simple tests of which lay early in winter or spring; which are down earlicst from the perch; and which lay earliest in the day. Broadly, these tests will at least pick out the better layers, and enable him to discard the really bad ones.

From Wright's Ncw Book of Poultry. 


\section{WHEN AND HOW TO ADVERTISE.}

\section{Poultry-Farm Bookkeeping.}

No one thing is more important than keeping an account of the expenses and receipts of poultry work, and a carefully kept account would most decidedly increase the appreciation of that branch of farm work. One chief cause of the indifferent attention given to poultry on the farm is that the income from it almost always comes in dribblets, and the farmer, having his mind on greater things, - as for example marketing a lot of grain, or a bunch of fat steers. or a drove of hogs,-finds it not casy to realize that "many mickles make a muckle." If one keeps an account of the eggs receired and poultry eaten or sold and puts against it the comparatively small amount expended for food. etc., his appreciation of the profitableness of the poultry would be decidedly increased.

Kerping accounts is not at all the complicated and difficult matter that many farmers imagine. The writer's method was simple and served the purpose admirably. A small and inexpensive blank book was purchased and two pages given to each month's accounts. On the left hand page was entered the debits, that is, the sums paid out, and on the right hand page was entered the credits, or sums received. The number of eggs laid by the hens each day was jotted down on a calendar against each day's date: at the end of the week the total of the eggs laid during the rreck was added up and entered in the book to the credit of the forls. at the arerage market price of the week. Fowls or chicks sold were entered to the credit of the poultry account, and forls or chicks eaten were credited at a fair, arerage value.
Each month's totals were footed up, at the end of the rear two pages following the September account were used for entering the total amounts received and expended each month, which was then footed up and a balance struck.

We found it a decided advantage to begin the poultry year October 1st, because that was the most convenient time for ending the account of the old birds and beginning the account of the new; obviously, however, the poultry account may begin with the first of any month of the year; it is much more important that a systematic account be kept than that it begin at one particular time or another.

In the systematic manner outlined above the poultry accounts can be kept, and at the end of the year the farmer knows exactly what the poultry expenditures and iuceipts have been and how much profit the poultry has paid. Not the least merit of the account keeping is that it induces a verr decided increase in appreciation of poultry profits. We know of many instances where the keeping of so simple an account as we have outlined has proved to the farmer that poultry was tde best paying branch of farm work; with such convineing proof before him the farmer would seem to be foolish if he did not increase that branch of his farm work. This is as it shoukl be. We ought to work along the line of least resistance,-we should push the line of work that pays us best. The opportunitics of profit from poultry are beyond beliof, - we should only need to have it proved to us by clean figures to determine us to multiply our poultry work, and reap the reward in multiplied profits.

A SAMPLE POULTRY ACCOLNT.

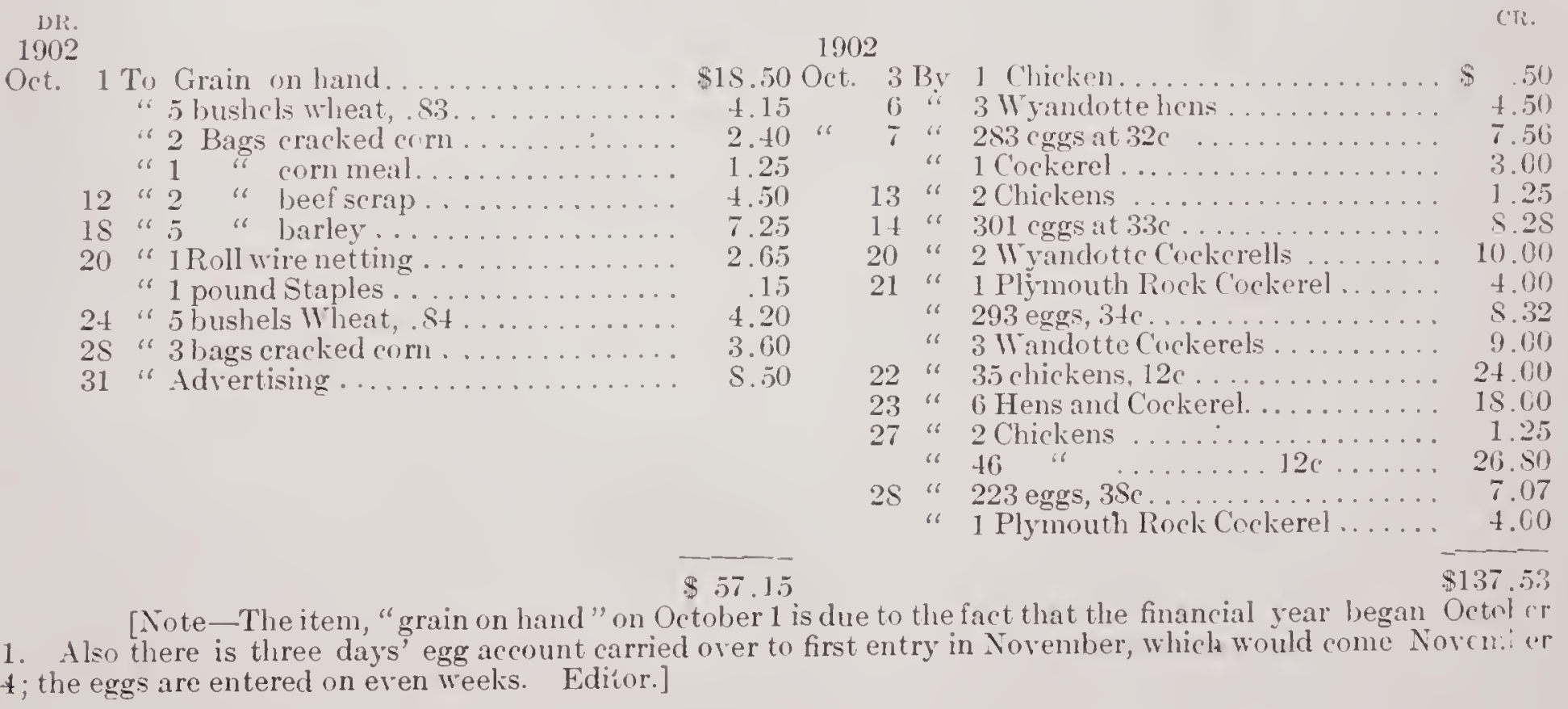




\section{INDEX.}

Advertise, Farmers who

Advertise, How and When to.

Advertising, About.....

Barred Plymouth Rocks.

Bees and Poultry.

Better Lavers and More of Them.

Bookkeeping, Poultry Farm

Brahmas, Licht.

Breeding for Eggs.

Buff Orpingtons

Buff Plymouth Rocks.

Buff Wrinandottes

Chapter I. Natural Habits of the Hen

('Hapter II. Thoroughbred, or Bred to a Purpose

Chapter III. Pedigree Breeding for Egg Production

('hapter IV'. Pullets for Lavers.

Chapter $V$. Practical Egg Farms.

Chapter VI. Foods and Feeding.

Chapter VII. Catering to the Market

C'hapter Vili. Combination Egg Farming

Chapter IX. When and How to Advertise

('hicks. Feoding The.

Colony Plan, Advantages and Disadvantages of

(olony Plan, Egr Farms. Two.

Commonsense in Poultry Adrertising

Composition of Eggs.

December. 4.000 Egrs in

Diet, Place of Eggs in the.

Dry Feeding Method, The.

Egrg Farm, A Great.

Egg Farm, A New England.

Egg Farm, Another New England.

Egg Farm. Another Profitable.

Ege Farnı, Mr. Wilhur's Great

Egg Farm, Mr. VanDreser's

Egr Farms. Practical.

Egrg Farms, Two Colonv-Plan.

Egg Farms. Tro New England. .

Esg Production, Mating For.

Egg Production, Pedigree Breeding For

Eye Records, Nest Boxes for Individual.

Ergg, The

Eggs, Breeding For

Eggs, Description and (omposition of .

Eggs, Feeding Clover For

Egrs, Feeding For, How Much.

Eggs. Feeding Fowls For

Eggs, 4,000 in December

Eggs, Getting Ftrong, Fertile.

Egrs. Increase of.

Eggs In Fall and Winter

Eggs in II inter.

Eggs, Ieeping and Marketing

Eggs, Lay 200.

Eggs, Place of in the Diet

Egrs, Producing at Mininum Cost.

Eggs, storage and Ises of .

Egge, 210 per Hen. Mr. Wood's. . .

Egras, Lises of.

Fair View Poultry Farm

Fall and Winter. Eggs in.

Family Trade, Building up $\mathrm{A}$

Farmers who Advertise

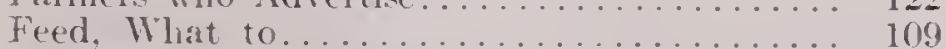

Feeding ("lover for Eggrs

Feeding fowls for Eggs.
122

121-122

125

24
119

36

127

31

43

30

26
Feeding the Chicks................. 103

Future, Probabilities of The ............ 16

Green Food Every Day................... 50

Green Food, Importance of . . . . . . . . . . . . 109

Hen, Natural Habits of The. . . . . . . . . . . . . 11

Increase of Eggs................ 7

Introductory. . $\ldots \ldots \ldots \ldots \ldots \ldots$

Keeping the Records................. 37

Lakewood Poultry Farm................ 61

Large Production.................. 42

Lavers, Better, and More of Them . . . . . . . . 36

Laving, When the Pullets Take to.......... 50

Leading Practical Varieties, The........... 21

Leghorns, single Comb White............ 22

Light Bralmas................... 31

Ilaine Experiment Station Nest Boxes........ 38

Minorcas, Black ................... 23

Molt, Producing an Early.............. 107

Nest Boxes for Individual Records......... 38

Nest Boxes. Maine Experiment Station. . ... . 38

Nests, Trap. . . . . . . . . . . . . . . . . . . 40

()rpingtons .................. 30

Pedigree Breeding for Egg Production........ 42

Place of Eggs in the Dict, The .......... 6

Plum trees and Poultry.................. 11s

Plymouth Rock, The................. 24

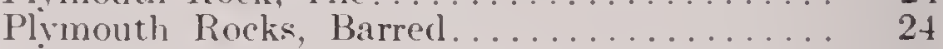

Plymouth Rocks, Buff.................. 26

Plimouth Rocks, White................. 25

Poultry Advertising, Commonsense In ... . . . 124

Poultry and Bees, an Ideal Combination....... . 119

Poultry and Fruit, Beginning With......... 118

Poultri and Plum Trees................ 118

Poultry Farm Bookkeeping.................... 127

Poultriman, A Trpical................ \$1

Practical Varieties. The Leading............... 21

Probabilities of the Future, The.......... 16

Producing an Early Nolt.............. 107

Profitable Egg Farming.............. 73

Profits, a situdy of . . . . . . . . . . . . . . 45

Pruning to Improve the Trees.............. 119

Pullets vs. Hens as Profitable Lavers......... 55

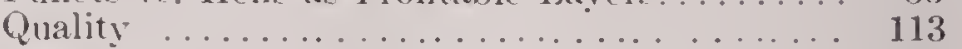

Records, lieeping The. . . . . . . . . 37

Rewards of Success, The. . . . . . . . . . . . 126

Rhode Island Reds, The................... 29

Roots for Hens, Value of ............... 99

Storage and $Y$ ses of Eggs............... s

Success, Conditions of ................ 126

success, Rewards of .................... 126

Trap Nest relection The Best............ 34

Trap Nests. . . . . . . . . . . . . . . . 40

Trap Nests Necessary................. 36

Trees, Pruning to Improve The . . . . . . . . 119

Typical Poultriman, A................ 81

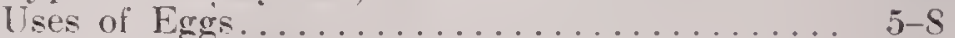

Van Dreser's Egg Farm...............

What Domestication Has Done........ 15

What to Feed........................ 109

White Leghorn Poultry Vards.............. 71

White Leghorns for I"tility and Fancy....... S4

White Plymouth Rocks.................. 25

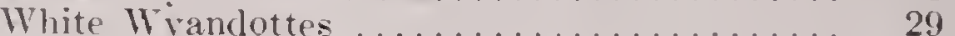

Wilbur's, Mr., Great Poultry Farm . . . . . . . . $\$ . \quad 89$

Winter, Eggs in ................... 57

Wyandottes, Buff ................. 29

Wyandottes, White................... 27

Wyckoff Poultry Farm, The ............. 81

79 



\section{eyphers series oll Practical Poultry keeping}

BOOK 1-P rofitable Poultry Keeping in All Branches BOOK 2-Profitable Care and Management of Poultry BOOK 3-Profítable Poultry Houses and A ppliances BOOK 4-Profitable Egg Farming BOOK 5-Profitable Market Poultry BOOK 6-Capons for Profit 